\title{
Citation:
}

Churchman, G.J.; Lowe, D.J. 2012. Alteration, formation, and occurrence of minerals in soils. In: Huang, P.M.; Li, Y; Sumner, M.E. (editors) "Handbook of Soil Sciences. $2^{\text {nd }}$ edition. Vol. 1: Properties and Processes". CRC Press (Taylor \& Francis), Boca Raton, FL, pp.20.1-20.72.

\section{Alteration, Formation, and Occurrence of Minerals in Soils}

\author{
G.J. Churchman, University of Adelaide, Australia \\ and \\ D.J. Lowe, University of Waikato, New Zealand
}

20.1 Introduction 20-1

20.2 Alteration of Primary Minerals. 20-2

Common Primary Minerals in Soils • Observations of Relative Stabilities of Primary

Minerals in Soils $•$ Thermodynamic and Structural Explanations of Relative

Stabilities • Processes and Products of Alteration of the Main Types of Primary Minerals

by Weathering - Peculiarities of Processes and Products of Alteration by Weathering

in Soils $•$ Processes of Mineral Alteration and Formation by Weathering: Summary

20.3 Occurrence of Clay Minerals in Soils

Occurrence of Kaolinite in Soils $•$ Occurrence of Halloysite in Soils $•$ Occurrence of Illite

in Soils $\bullet$ Occurrence of Vermiculite in Soils $\bullet$ Occurrence of Smectite in Soils •

Occurrence of Palygorskite and Sepiolite in Soils • Occurrence of Iron Oxides in Soils •

Occurrence of Manganese Oxides in Soils • Occurrence of Aluminum Hydroxides,

Oxyhydroxides, and Oxides in Soils • Occurrence of Phosphate, Sulfide, and Sulfate

Minerals in Soils • Occurrence of Pyrophyllite, Talc, and Zeolites in Soils • Occurrence

of Neogenetic Silica in Soils • Occurrence of Titanium and Zirconium Minerals in Soils •

Occurrence of Highly Soluble Minerals in Soils $•$ Occurrence of Secondary Minerals

in Soils: Summary

20.4 Influence of Mode of Formation upon Predictions of Properties of Soils

from Their Clay Mineralogy.

Introduction: The Role of Mineralogy in Soil Science $\bullet$ Contributions of Classical

Clay Mineralogy toward Explanations of Soil Properties • Potential of Classical Clay

Mineralogy for Explaining Soil Properties $\bullet$ Nature of Soil Minerals and Relationship

to Their Mode of Formation

Acknowledgments

References.

Tables are on pp. 159 and following pages

For the definitive version of this article please see the Handbook of Soil Science $2^{\text {nd }}$ ed (citation at top of page) 


\subsection{Introduction}

This chapter, like Churchman (2000), seeks to bring readers up to date with information and understanding about the alteration of minerals and the nature of their products in the context of the formation and development of soils. It complements various articles by Bergaya et al. (2006), and the recent books by Velde and Meunier (2008) and Velde and Barré (2010). This current chapter differs from Churchman (2000) in that it discusses the manner in which minerals, and especially secondary minerals, actually occur in soils, i.e., it deals (in Section 20.3) with the occurrence, as well as the alteration and formation of minerals in soils.

Secondary minerals are the most reactive inorganic materials in soils. Furthermore, they occur commonly in association with the most reactive organic materials in soils. It has often been inferred that knowledge of the properties of these reactive materials should enable close predictions of the useful soil properties, whether for growing plants, for filtering and partitioning water flow, for immobilising contaminants, for supporting human-made structures, or for other purposes. However, most of the information about the formation of secondary minerals through the alteration of primary minerals derives from studies of largely inorganic processes taking place in relatively 'clean' environments. The soil, by contrast, is a heterogeneous milieu that is a dynamic part of the biosphere continually changing in response to climatic variations over all scales of time and space. It is not at all surprising that the minerals in the soil can be quite different in their chemical and physical characteristics from those of the 'type' minerals formed in more 'geological' environments with which they may share a name and ideal crystalline structure (Churchman, 2010). Chadwick and Chorover (2001) made the point that the crisp boundaries in stability diagrams are, in the real world of natural soils, not so clear-cut. However, the effort involved in understanding the real nature of minerals in soils is worthwhile in view of the potential reward of being able to explain and predict properties across different sorts of soils from the nature of their constituents and that of their associations. As is discussed in Section 20.4, soil mineralogy has to some extent been in decline as a sub-discipline of soil science and it may be that this is due, at least in part, to the often unjustified assumption that soil minerals are similar in their properties to those of their well-characterized 'types' formed in nonsoil environments. The implications of this erroneous or only partly true assumption, and new directions for soil clay mineralogy, are also discussed in Section 20.4. 
This chapter deals with minerals, both primary and secondary, with the processes of weathering and associated clay formation, and with soils. We define each of these terms in Table 20.1, which also includes some alternative definitions, and some issues involved in these definitions.

Insert Table 20.1 here (see p. 159)

\subsection{Alteration of primary minerals}

\subsubsection{Common primary minerals in soils}

The most common primary minerals found in soils are listed in Table 20.2 within their chemical (compositional) types and their mineralogical groupings together with the types of (crystal) structures for these groupings. Table 20.2 also lists chemical formulae for the minerals or groups of minerals and summarizes the general sorts of soils in which they occur and often also their relative abundance in these soils. Other properties of the minerals listed are given in Churchman (2006, Table 3.1). In soils, primary minerals, as residuals of physical and chemical weathering processes, most commonly occur in coarser particles (of sand- and silt-size), although the phyllosilicates such as the micas, chlorite, vermiculite, and talc, and some oxides, such as those of titanium and also apatite, and volcanic glass, can also be found in reasonable proportions in the clay-size factions of some soils.

$\underline{\text { (Insert Table 20.2) }}$

\subsubsection{Observations of relative stabilities of primary minerals in soils}

In most cases, weathering involves the reaction of minerals (or mineraloids) with water, or, at least, an aqueous solution. There are exceptions where alteration of primary minerals occurs but where liquid water is either absent or is not the primary agent effecting alteration. This is the case in cold (and polar) and also hot desert zones on Earth (Shoji et al., 2006). It is probably also the case in some extraterrestrial environments, such as the Moon, but not in others, such as Mars, where there is abundant evidence for liquid water, at least in the past 
(Certini and Scalenghe, 2006). In environments where liquid water does not provide the main weathering milieu, the dominant agents of alteration nonetheless involve climatic factors, hence they constitute weathering. These include mainly physical actions such as frost wedging and successive freezing and thawing in cold desert zones on Earth (Shoji et al., 2006), processes such as wind ablation in both hot and cold terrestrial desert zones, and such processes as solar-wind irradiation on Moon (Certini and Scalenghe, 2006), and perhaps also on other dry extraterrestrial bodies and regions. Other agents besides the purely climatic can also alter primary minerals, given enough time. Among these are some resulting from various human activities (Certini and Scalenghe, 2006), including agriculture (Velde and Meunier, 2008), mining (Murakami et al., 1996; Banfield and Murakami, 1998), landfills (Batchelder et al., 1998), industrial pollution (Rampazzo and Blum, 1992; Yaron et al., 2010), and probably also global climate change (Berg and Banwart, 2000; Amundson, 2001; Leifeld, 2006). Most of these agents affect mineral alteration via aqueous solutions, although in some cases, for example, the oxidation of sulfides, particularly iron pyrite, alteration of minerals occurs when water is absent (Dent and Pons, 1995). Nevertheless, alteration by weathering most often occurs in an aqueous environment and the most important determinant of the relative stability of primary minerals to weathering is their relative solubility in water.

All minerals have some solubility in water. Only rarely, however, for example, for simple salts like halite $(\mathrm{NaCl})$ found, for example, in arid and saline soils, do they dissolve congruently in water. Instead, hydrolysis commonly occurs, with the more soluble components being removed selectively from the mineral. This removal may leave a solid residue which differs in composition from the original mineral, or a solid alteration product precipitates out of the solution. The solid precipitate will most likely have a different composition and perhaps also a different crystal structure from that of its antecedent (partly or completely) dissolved mineral. Some texts refer to the synthesis or precipitation of such products as "argillization", meaning the formation of clay; in this case the term "weathering" encompasses only the decompositional phase (Figure 20.1) (e.g., Buol et al., 2003). Another term widely used is neogenesis, effectively the formation or synthesis of new clays and other secondary material from the break-down products of antecedent minerals.

A simple chemical analogy of the hydrolysis undergone by silicates, the most common type of primary mineral, in water, is realised when they are considered as salts of silicic acid $\mathrm{H}_{4} \mathrm{SiO}_{4}$ and bases of the appropriate cation (Carroll, 1970; Chamley, 1989). The hydrolysis of silicates in water results in an acid, namely silicic acid and a base, namely the 
hydroxy-Al-Si, kaolinite (see Box 20.1). Because most aqueous solutions in which weathering takes place are acidic because water is charged with dissolved $\mathrm{CO}_{2}$, giving rise to a continuous supply of carbonic acid $\mathrm{H}_{2} \mathrm{CO}_{3}$ and hence $\mathrm{H}^{+}$ions, hydrogen ions are important weathering agents. Therefore Equation 20.1a represents the natural situation more realistically than Equation 20.1.

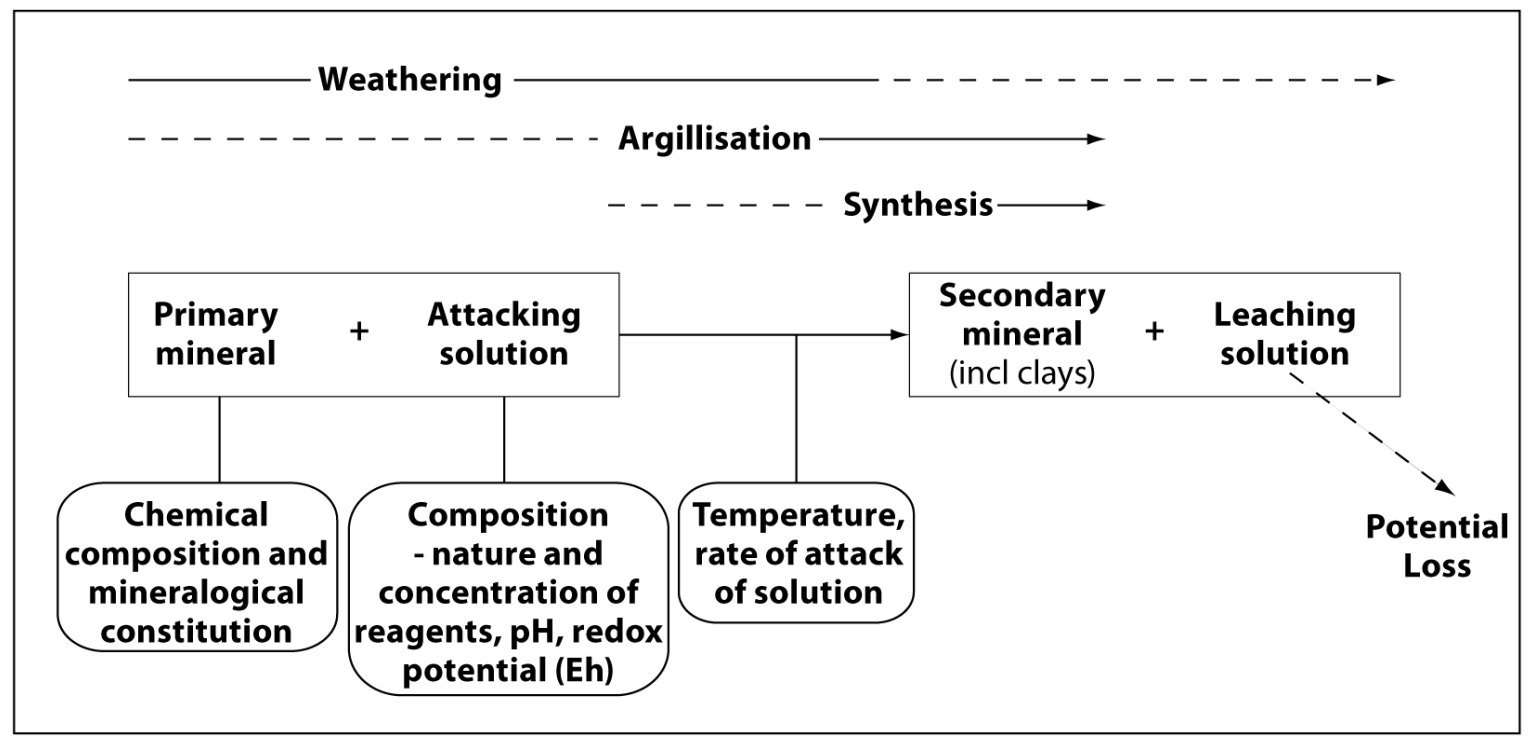

FIGURE 20.1 Weathering (and associated processes of argillization and synthesis) in relation to the factors governing the genesis of secondary minerals including clays in soils. (Modified after Percival, H.J. 1985. Soil solutions, minerals, and equilibria. New Zealand Soil Bureau Scientific Report 69. Department of Scientific and Industrial Research, Lower Hutt, New Zealand. With permission.)

The relative stabilities of the principal primary minerals in soils to alteration have long been studied. More than 70 years ago, Goldich (1938) drew up a stability series for these minerals (Figure 20.2) that has generally stood the test of time and further experimentation, for example, by Franke and Teschner-Steinhardt (1994).

$$
\begin{aligned}
& \text { Silicate minerals } \equiv \text { salt of silicic acid plus base of appropriate cation } \\
& \therefore \quad \text { K-feldspar } \equiv \text { silicic acid }+ \text { hydroxyl-Al }\left(+\mathrm{K}^{+}\right) \\
& \therefore \quad 2 \mathrm{KAlSi}_{3} \mathrm{O}_{8}+11 \mathrm{H}_{2} \mathrm{O} \rightarrow \mathrm{Al}_{2} \mathrm{Si}_{2} \mathrm{O}_{5}(\mathrm{OH})_{4}+4 \mathrm{H}_{4} \mathrm{SiO}_{4}+2 \mathrm{~K}^{+}+2 \mathrm{OH}^{-} \\
& \text {K-feldspar kaolinite silicic acid } \\
& \text { or } \quad 2 \mathrm{KAlSi}_{3} \mathrm{O}_{8}+9 \mathrm{H}_{2} \mathrm{O}+2 \mathrm{H}^{+} \rightarrow \mathrm{Al}_{2} \mathrm{Si}_{2} \mathrm{O}_{5}(\mathrm{OH})_{4}+4 \mathrm{H}_{4} \mathrm{SiO}_{4}+2 \mathrm{~K}^{+}
\end{aligned}
$$

Box 20.1. Hydrolysis of K-feldspar, interpreted as a salt, to form kaolinite 


\subsubsection{Thermodynamic and structural explanations of relative stabilities}

Goldich's series (Figure 20.2) makes thermodynamic sense insofar as the minerals therein are in the identical (but reversed) order to those in Bowen's classic reaction series describing the order in which the minerals crystallized out of a magma on cooling (Bowen, 1922). Goldich (1938) reasoned that the higher the temperature at which a mineral crystallized from magma, the greater the extent to which it was out of equilibrium with the surface temperature of Earth and, therefore, the more susceptible it would be to breakdown by weathering at the Earth's surface.

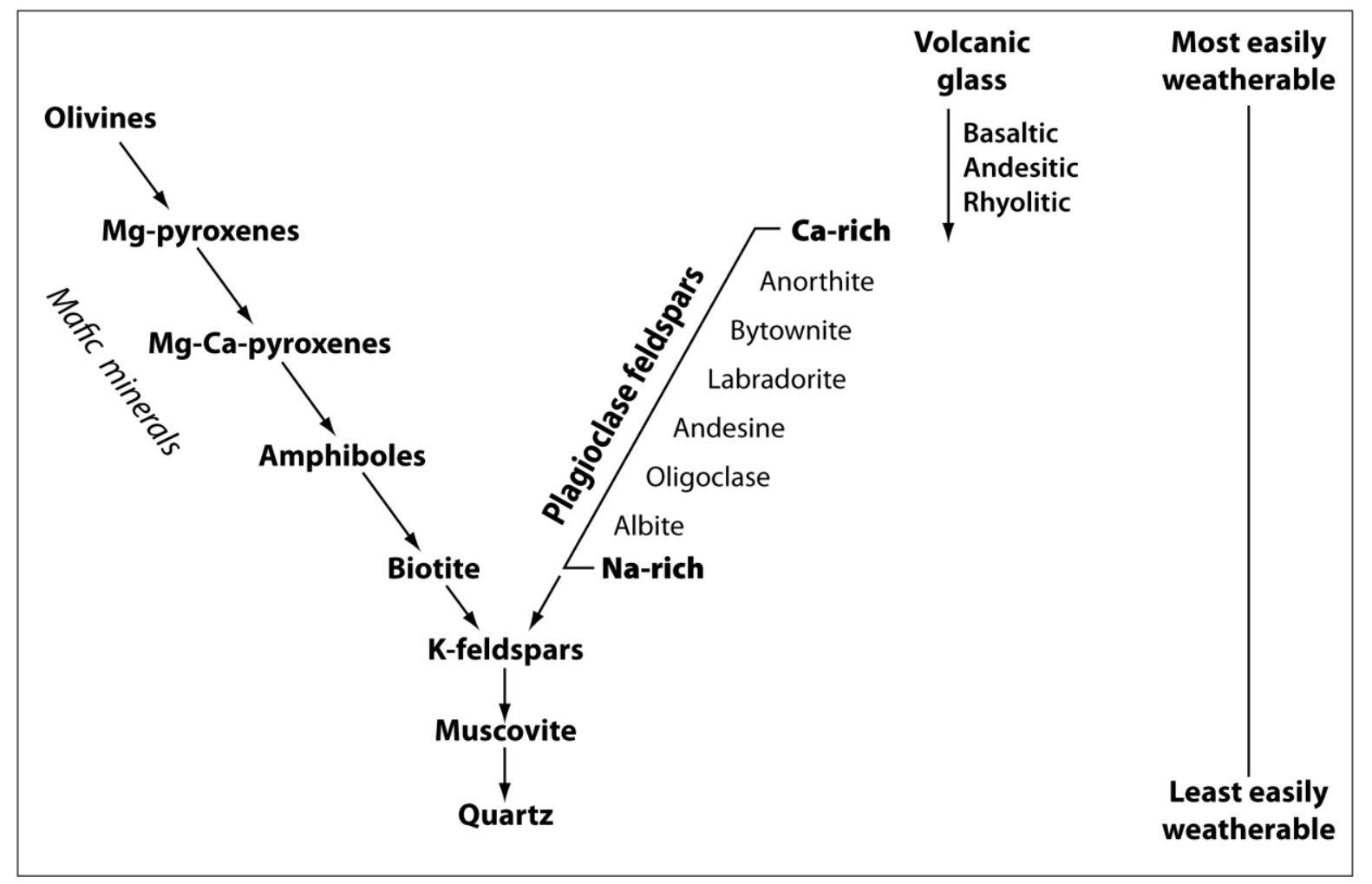

FIGURE 20.2 Stability series for the common primary minerals (after Goldich, S.S. 1938. A study in rock weathering. ). Geol. 46: 17-58.) and also volcanic glass (not part of the Goldich series). Basaltic and other glasses, and olivines, are normally the first phases altered by weathering (WolffBoenisch, D. et al., 2004).

The alteration of a particular mineral or mineraloid begins with the disruption of its weakest bond. Structural explanations of the relative stabilities of minerals have followed this generalization. Bonds in all silicates are based on silica tetrahedra. Their strength depends on he following: (1) the nature of the links between tetrahedra, (2) the extent of substitution of 4valency Si within tetrahedra by 3-valency $\mathrm{Al}$ and hence gain of negative charge (isomorphous substitution), and (3) the extent of incorporation of charge-balancing cations, and their 
location, in the structure. In Table 20.3, we show the nature of bonding in the different structural types of silicates (see Table 20.2 to identify the relevant minerals).

\section{(Insert Table 20.3)}

Sposito (1989) pointed to an apparent correspondence between the ordering of the molar Si: O ratios in the silicate units, namely, olivines < pyroxenes < amphiboles < micas < feldspars $=$ quartz , and that in the Goldich series. Nonetheless, reference to Table 20.3 may lead to oversimplification concerning possible structural control on the relative stability of silicates to weathering, especially when other silicates besides those in the broad groups represented by both types of ordering are considered. Following Loughnan (1969), for example, zircon $\left(\mathrm{ZrSiO}_{4}\right)$ and andalusite $\left(\mathrm{Al}_{2} \mathrm{SiO}_{5}\right)$ are both neosilicates like olivine and have $(\mathrm{Si}: \mathrm{O})_{\text {molar }}$ ratios of 0.25 and 0.2 , respectively, that are equal or less than those of olivine and yet are both very stable (i.e., resistant) to breakdown by weathering, in contrast to olivine, which is notably unstable according to Goldich's (1938) series (Fig. 20.2). Furthermore, the broad classifications shown in Table 20.3 hide the observed differences in the stabilities between individual minerals within structural types. Within the phyllosilicate mica group, biotites are generally much less stable than muscovites, whereas the tectosilicate feldspars include albites and anorthites, each with quite different stabilities.

Another danger of oversimplification arises because weathering (and argillization) is not simply a matter of dissolution of the silicate minerals in water. Instead, weathering often occurs in an acid environment and, commonly in soils, also involves a range of organic compounds, which can complex the ions in the silicate structure and can both enhance their breakdown and also affect its course and the products formed (e.g., Velde and Barré, 2010).

The rate at which hydrolysis affects cations released is related to the strength of the bonds formed by the cations within the minerals, according to Pauling's electrostatic valency principle (Pauling, 1929). The ratio of the valency (the charge on the ion) to the coordination number (the number of ions of opposite charge surrounding an ion) is known as the electrostatic valency. The smaller its value, the greater the ease of hydrolysis (Paton et al., 1995). The hydrolysis, or replacement of a cation in a crystal structure by $\mathrm{H}^{+}$, of $\mathrm{K}$ is relatively easy because it is univalent $\left(\mathrm{K}^{+}\right)$. It is commonly found in feldspars, where its coordination number is 9 , and in micas, where it has a coordination number of 12 . Hence the electrostatic valency of $\mathrm{K}$ in these minerals is $1: 9$ and 1:12, respectively (Paton et al., 1995). 
The hydrolysis of $\mathrm{Al}$ is more difficult because it is trivalent $\left(\mathrm{Al}^{3+}\right)$, with coordination numbers of 6 or 4, so the electrostatic valency of $\mathrm{Al}$ in primary minerals is either 1:2 or 3:4. These differences between cations, and also between the same cations in different minerals, are reflected in the relative responses of the four main groups of silicates to weathering pressures (Paton et al., 1995). The solubility or relative mobility of various ions such as $\mathrm{Ca}$, $\mathrm{K}$, and $\mathrm{Mg}$ relates to ionic potential, which is the ionic charge (valency) divided by the ionic radius (size), so that ions with a low ionic potential such as $\mathrm{Na}^{+}, \mathrm{K}^{+}, \mathrm{Ca}^{2+}, \mathrm{Mn}^{2+}$ are more easily leached (lost) in solution, although temperature and $\mathrm{pH}$ affect solubility as well (Schaetzl and Anderson, 2005).

Some components of the silicate framework can greatly influence the rate and nature of their breakdown. Chief among these is Fe. According to Millot (1970), the most important weathering reactions involve $\mathrm{Fe}$, a component of many of the primary minerals involved in soil formation (Table 20.2). Along with Mn, which is less abundant in the primary soilforming minerals (Table 20.2), Fe generally occurs in its reduced form in primary minerals. Fe occurs as $\mathrm{Fe}(\mathrm{II})$ and $\mathrm{Mn}$ as $\mathrm{Mn}$ (II). These are both easily converted to their oxidized forms - Fe(III) and Mn(IV) - when oxidation occurs, for example, when soils dry. This change in valency sets up a charge imbalance in the appropriate minerals, leading to a loss of other ions from the mineral structures which can destabilize the minerals, enhancing their further breakdown by hydrolysis, which is assisted by the hydrogen ions produced during oxidation. The oxidized forms of $\mathrm{Fe}$ and $\mathrm{Mn}$ occur as oxides and oxyhydroxides and those of $\mathrm{Fe}$, in particular, are almost ubiquitous in soils. Seasonal wetting and drying causes alternate reduction and oxidation of $\mathrm{Mn}(\mathrm{II})$ and $\mathrm{Mn}$ (IV) and lead to the common precipitation of the blue-black mineral pyrolusite $\left(\mathrm{MnO}_{2}\right)$ - as well as other forms of $\mathrm{MnO}_{2}$ such as todorokite (Churchman et al., 2010) - as redox segregations (also known as redox concentrations) in the form of coatings (mangans), nodules, or concretions (Vepraskas, 1992; Birkeland, 1999). Manganese oxides in most conditions form preferably to those of Fe during wetting and drying because of the greater ease of acceptance of electrons by Mn than by Fe. The reduction of $\mathrm{Fe}(\mathrm{III})$ to $\mathrm{Fe}(\mathrm{II})$, commonly by organisms during phases in which a soil is waterlogged, and then its oxidation on drying, leads to Fe oxides being precipitated as mottles, coatings, or concretions. The persistence of reducing conditions causes soil matrix materials to have pale, low-chroma colors (described as redox depletions), and these greyish colors characterize continuously reduced soils which therefore have few or no redox segregations (Birkeland, 1999; Vepraskas et al., 2004; Morgan and Stolt, 2006). Brinkman 
(1970) has characterized the clay decomposition brought about by cyclical alternation of redox conditions by the name of "ferrolysis". Even so, a re-examination of some texturecontrast soils having coarser topsoils than subsoils by Van Ranst and De Coninck (2002) found that such coarsening with depth could be more easily attributed to the translocation of clay than to its destruction.

Weathering and argillisation, together with soil formation, generally occur in a dynamic system that is open to the wider environment. Leaching - the removal or loss of material in solution - commonly occurs. The driving force which provides the chemical potential energy for mineral alteration is the difference in composition between the "attacking" solution and the solid mineral. However, it is the rate of leaching, which governs the rate of removal of solutes, which most influences the rate of mineral alteration and any subsequent precipitation (Figure 20.1). It also influences the course that the alteration takes. Garrels and Mackenzie (1971) stated that, given sufficient leaching, almost all rocks or unconsolidated deposits will leave a residue which is largely composed of the relatively insoluble oxides of $\mathrm{Al}, \mathrm{Fe}$, and $\mathrm{Ti}$.

Hence the origin of primary minerals as given by their temperature of crystallization from magma influences their thermodynamic stability against breakdown by weathering in an aqueous environment, as does their structure and their particular chemical composition (Figure 20.1). However, such environmental factors as the particular composition of the solutions bathing the minerals, the dynamics of the redox conditions, and the rate of throughflow of water past the minerals can play a decisive role in the kinetics, course, and ultimate products of their alteration.

\subsubsection{Processes and products of alteration of the main types of primary minerals by weathering}

Early work exploring either the fate of primary minerals or the origin of secondary minerals on weathering (e.g., Jackson et al., 1948) tended to take the stance that specific primary minerals have led to particular secondary minerals as products. A 1:1 correspondence between altered rock-forming mineral and phyllosilicate product appears justified when one dominant type of primary mineral is altered more than others in the parent material and the overlying soil, saprolite, or regolith more generally is dominated by just one type of 
secondary mineral (clay). Some modern studies have also concluded that each type of primary mineral generally leads to one particular type of secondary mineral. Thus, according to a generalization by Wilson (2006), the weathering of granite rocks leads most commonly to kaolin minerals (kaolinite and halloysite), largely deriving from the alteration of feldspars, and vermiculite minerals from the alteration of micas. Furthermore, many clay minerals appear to be found in close proximity to particular types of altered primary minerals, for example, halloysite tubes on altered feldspar (Figure 20.3). Clay minerals may also have a morphology that appears to mimic that of altering or altered primary minerals. The similarity in shapes between vermicular books of kaolinite and degraded micas, often occurring as some form of vermiculite (Figure 20.4), can be suggestive of a micaceous origin for the particular kaolinite. To examine whether there is always a 1:1 relationship between particular primary minerals and specific secondary minerals, the following sub-sections summarize studies that have concentrated on the fate of individual types of primary minerals to alteration by weathering. In these sub-sections, the generalizations have often been drawn from studies of the weathering of rocks or other geological deposits, the minerals derived from these, and at depth within soil profiles. The influence of particular soil factors on the alterations and products of weathering is discussed in Section 20.2.5.

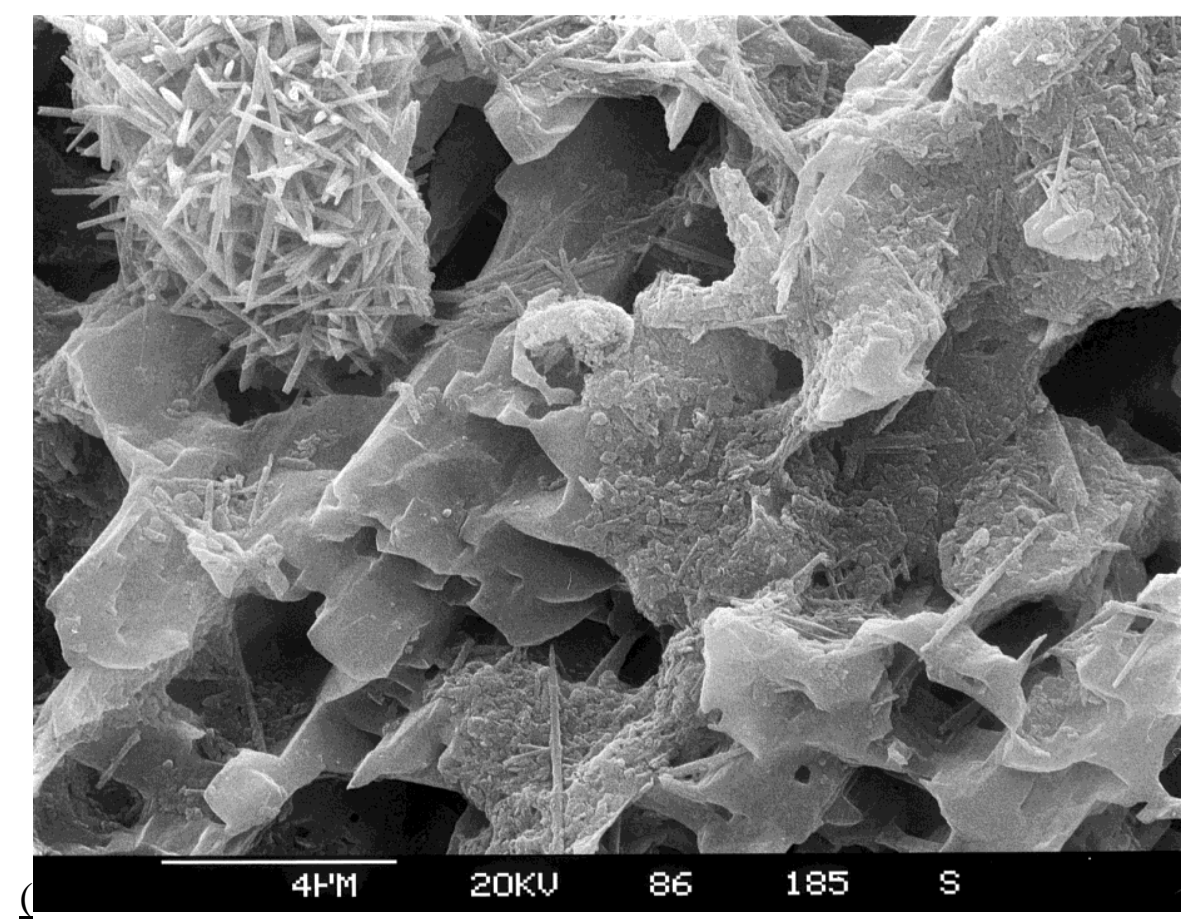

FIGURE 20.3 Scanning electron micrograph of tubular halloysite occurring in close proximity to weathered feldspar in granitic saprolite from Hong Kong. (Photo by Stuart McClure. Reproduced with the permission of the Geotechnical Engineering Office, Civil Engineering Office, Hong Kong.) 


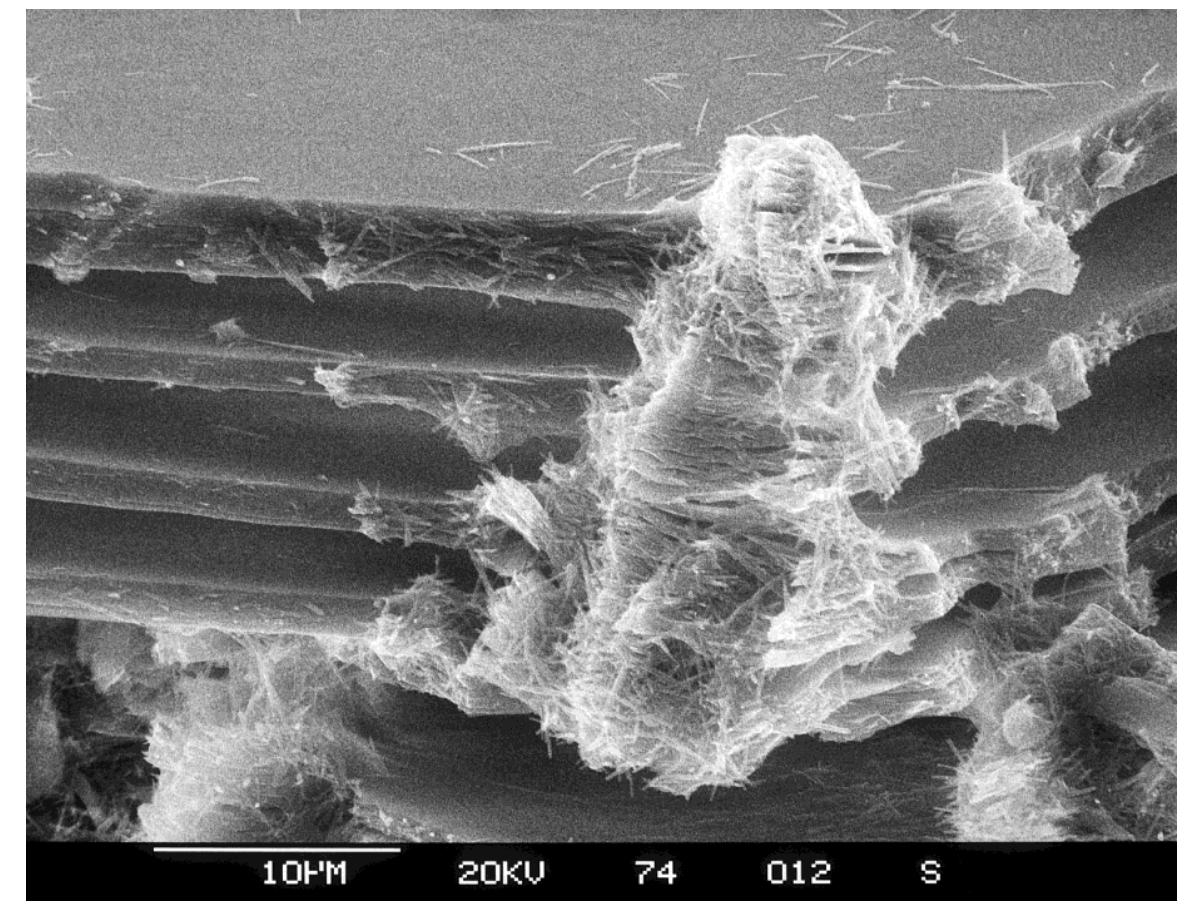

FIGURE 20.4 Scanning electron micrograph of vermicular kaolinite (with some halloysite tubes) occurring in close proximity to weathered mica in granitic saprolite in Hong Kong. (Photo by Stuart McClure. Reproduced with the permission of the Geotechnical Engineering Office, Civil Engineering Office, Hong Kong.)

\subsubsection{Processes and products of alteration of olivines, pyroxenes, and amphiboles by weathering}

In an open environment, generally unstable olivines easily lose $\mathrm{Mg}^{2+}, \mathrm{Fe}^{2+}\left(\right.$ or $\mathrm{Mn}^{2+}$ if manganous) to give, first serpentine, then a smectite (commonly saponite), and also goethite, which together have been characterized as "iddingsite" (Loughnan, 1969; Nahon et al., 1982; Eggleton, 1984). Both optical (Craig and Loughnan, 1964) and electron microscopy (Eggleton, 1984) have enabled identification of iddingsite as a mixture of saponite and goethite. Nahon et al. (1982) made the important observation that an aluminous dioctahedral smectite had formed from the breakdown of the $\mathrm{Mg}$-olivine, forsterite $\left(\mathrm{Mg}_{2} \mathrm{SiO}_{4}\right)$, which contains very little Al. They suggested that Al probably derived from the simultaneous breakdown of a pyroxene, enstatite. Secondary minerals could therefore derive their elemental constituents from the breakdown of more than one primary mineral. Indeed, olivines could give rise to a variety of secondary mineral products, including smectite, kaolinite, halloysite, and also various oxides, hydroxides, and oxyhydroxides of Fe, and, if present, also Mn, upon leaching (Huang, 1989). 
Pyroxenes and amphiboles, although slightly more stable than olivines, tend to break down in a similar fashion to the olivines in the field, with an initial loss of their divalent cations, typically $\mathrm{Mg}, \mathrm{Ca}$ and $\mathrm{Fe}(\mathrm{II})$. Chlorite and/or smectite often result, although talc may also be formed. Calcite can also form as one of the products if $\mathrm{Ca}$ is released in abundance (Loughnan, 1969; Eggleton and Boland, 1982; Huang, 1989). Examination at the fine scale of the mineral grain revealed that amphibole weathering led to a dioctahedral (montmorillonite) and a trioctahedral (saponite) smectite, and also kaolinite-smectite simultaneously at the early stages of alteration, with halloysite developing with time (Proust et al., 2006). The different products were associated with different crystallographic faces of the host amphibole (see Section 20.2.5.1). As with olivines, pyroxenes and amphiboles could give rise to products with simpler structures, such as kaolinite, Fe(III) oxides, and anatase upon strong leaching (see also Wilson, 2004). The common pathway of alteration of this group of minerals by weathering is shown in Box 20.2.

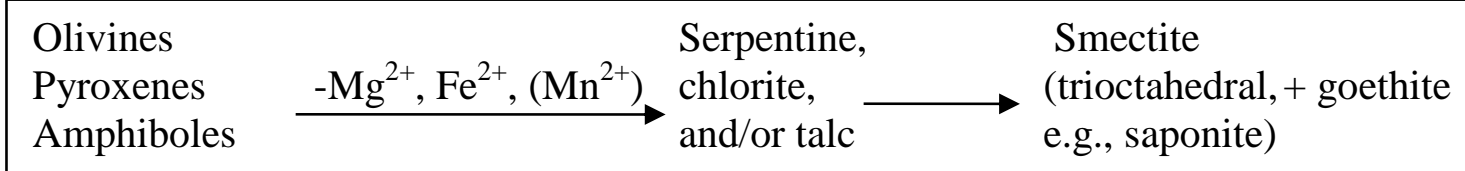

\section{Box 20.2 Initial alteration of olivines, pyroxenes, and amphiboles as commonly reported}

Many laboratory studies have been designed to help understand the initial stages of alteration of these ferromagnesian minerals. At low $\mathrm{pH}$, divalent ions are lost relative to silica, whereas the converse occurs at high $\mathrm{pH}$, with a preferential loss of Si (Schott and Berner, 1985). It has usually been inferred that leached layers, depleted in some of their original constituents, develop as a result on mineral surfaces (Schott and Berner, 1985; Banfield et al., 1995). Experimental studies (e.g., Velbel, 1985) have often indicated weathering rates that far exceed those observed in nature by up to five orders of magnitude (Banfield and Barker, 1994).

However, by following evidence from electron microscopy particularly, weathering of olivines, pyroxenes, and amphiboles has been seen to involve the formation, enlargement and coalescence of etch pits developed on crystal dislocations (Huang, 1989; Hodder et al., 1991; Seyama et al., 1996; Wilson, 2004) rather than through an enleached layer. Velbel and Barker (2008) have acknowledged that surface tension upon air-drying samples for conventional scanning electron microscopy (SEM) may affect surface structure and have 
examined partially weathered pyroxenes using high-presure cryofixation (HPF) and cryofield emission gun SEM, both of which avoid the surface tension effects of air drying. They were thus able to view the products formed in small-scale etch pits on the pyroxenes and have concluded that pyroxene weathers to smectite by a multi-stage process. Velbel and Barker (2008) proposed that the process includes initial dissolution, topotactic reactions, mechanical disruption from wetting and drying cycles, further dissolution and, eventually microbial colonisation of the pores, with weathering finally enhanced by microbial extracellular polymers. As for the alteration of feldspars (see Section 20.2.4.2), the findings from laboratory studies may not reflect the processes occurring in the field because of oversimplification of the factors involved in natural weathering.

Nonetheless, Mogk and Locke (1988), using Auger electron spectroscopy (AES), found that naturally weathered hornblende showed systematic cation depletion to depths of $\sim 120 \mathrm{~nm}$. They considered that the dissolution of minerals generally occurs from both their surfaces and their bulk. Furthermore, Welch and Banfield (2002) were able to produce microstructural channelling effects in the olivine, fayalite, from laboratory dissolution experiments with an initial $\mathrm{pH}$ of 2.0 , that are identical to those seen in the naturally weathered mineral (e.g., Banfield et al., 1991). X-ray photoelectron microscopy (XPS) had shown earlier that surfaces are coated by films of Fe(III) oxides both at low and high $\mathrm{pH}$ (Schott and Berner, 1985; Casey et al., 1993; Seyama et al., 1996), and Welch and Banfield (2002) found that, when either microbes that enzymatically oxidize iron or instead ferric iron was added to the system, the minerals degraded at a greatly reduced rate. They identified the formation of laihunite, a ferric-ferrous olivine-like mineral containing vacant atomic sites, in the region of the mineral surface. This laihunite would protect the mineral against further dissolution.

Generally, alteration of primary minerals to give secondary products involves either transformation within the solid state or neoformation, with either partial or complete dissolution of solutes, then their re-precipitation as new secondary phases. Structural considerations appear to dictate that neither the neosilicate olivines, with independent silica tetrahedra, nor the inosilicate pyroxenes and amphiboles with tetrahedra in chains, can transform directly within the solid state to phyllosilicate clay minerals with flat sheets. Nevertheless, high-resolution transmission electron microscopy (HRTEM) observations of weathering amphiboles led Banfield and Barker (1994) to conclude that a type of transformation of amphiboles to smectites can occur within the solid state. They observed 
these reactions occurring in interstitial spaces within the primary amphiboles, with secondary smectites formed in a topotactic relationship to the altering amphibole. The change was described as a partial depolymerization of the amphibole structure leading to a repolymerization to that of smectite. There is no need for bulk water to bring about this change, with the water of hydration of the smectite product being able to supply the water required for the transformation reaction. Although Banfield and Barker (1994) pointed out that this type of transformation is not representative of all weathering reactions, it enables episodic alteration to take place within rocks or geological deposits, where it is limited by an intermittent supply of water and therefore much slower than that occurring on the surfaces of rocks or rock minerals immersed in aqueous solution. Banfield et al. (1995) found that smectites could form within weathering pyroxenoids (rhodonite and pyroxmangite, both $\mathrm{MnSiO}_{3}$ ), which were studied by a similar type of in situ transformation. Periodic drying, which often occurs in this situation, may promote the repolymerisation of phyllosilicates rather than depolymerised silica (Banfield et al., 1995). The reaction has little significance for soil formation, however, because the smectitic products are "quite ephemeral" and disappear when transported from the altered rock into the more open soil environment (Wilson, 2004).

Not all workers have considered that the primary ferromagnesian minerals are altered directly to phyllosilicates such as smectites. Nahon and Colin (1982) and also Singh and Gilkes (1993) both identified amorphous or non-crystalline intermediates in the alteration of (different) pyroxenes. In comparing this observation with those of Banfield and co-workers, among others, who observed direct formation of phyllosilicates on altering ferromagnesian minerals, Wilson (2004) cautioned that the course of formation of phyllosilicates may have been established by prior hydrothermal or deuteric alteration in the latter cases and alteration by weathering had continued along the predisposed course.

\subsubsection{Processes and products of alteration of feldspars by weathering}

Feldspars have been thought to give rise to many different types of secondary minerals, encompassing the range of structural complexity from smectites through to gibbsite and quartz. Allen and Hajek's (1989) review referred to several studies where smectites have been identified as products of the alteration of feldspars. These authors surmised that the resultant smectites would be beidellitic because the parent feldspars lacked $\mathrm{Mg}$ or $\mathrm{Fe}$, and Nettleton et al. (1970) characterized a smectite seen to form directly from a feldspar crystal as 
a beidellite-montmorillonite. Reports of the alteration of feldspars to gibbsite and quartz, at the lower end of the scale of structural complexity, were given by Allen and Hajek (1989) and Estoule-Choux et al. (1995). Otherwise, feldspars have been considered as the source minerals for micas (Carroll, 1970; Millot, 1970) and very often also for kaolinites and halloysites (Eswaran and Wong, 1978; Calvert et al., 1980; Anand et al., 1985). The micaceous minerals formed from feldspars, both K-feldpars and plagioclases, have often been described as "sericites", with the process of their formation being described as sericitization (Carroll, 1970; Millot, 1970). However, the term sericite has also been used to describe white mica formed from the reaction of biotite with plagioclase during metamorphism (Meunier and Velde, 1976). Furthermore, orthoclase (a K-feldspar) has been considered to hydrolyze to muscovite (Hemley, 1959). On the contrary, Meunier and Velde (1979) found that the micaceous phase, which they considered to be an illite, developed at a boundary between muscovite and orthoclase within weathering granite, and contained more $\mathrm{Fe}$ and $\mathrm{Mg}$ than either the muscovite or orthoclase. Hence, the illite formed (precipitated) out of solution. Using electron microscopy, Eggleton and Busek (1980) detected micaceous phases forming within vacuoles within microcline. They considered these to be either illite or interstratified illite-smectite. Bétard et al. (2009) found that an illite formed within nonalkali feldspar (a plagioclase) by neoformation in Luvisols in northeast Brazil, and, more generally, they considered this particular weathering reaction to be typical of semi-arid tropical and subtropical climates.

Studies of the artificial weathering of feldspars in controlled conditions in the laboratory have largely focussed on the possibility of the formation of a leached layer on feldspar surfaces during their alteration. On the one hand, different types of surface sensitive analyses - including secondary ion mass spectrometry, SIMS (also known as ion microprobe) (Muir and Nesbitt, 1997); elastic recoil detection, ERD, and Rutherford backscattering, RBS (Casey et al., 1988, 1989); and XPS (Muir et al., 1989, 1990; Hellmann et al., 1990) indicated the formation of a dealkalized leached layer of up to $1 \mu \mathrm{m}$ deep, especially at low $\mathrm{pH}$. The leached product from an albite was identified as an amorphous phase with some of the characteristics of nanocrystalline allophane which later became detached (Kawano and Tomita, 1994). The fate of the leached layer was found to be dependent upon the Si:Al ratio in the parent feldspar (Oelkers and Schott, 1995). Where this ratio was 1, as in plagioclases (anorthite was studied), the removal of Al led to completely detached silica tetrahedra, but where it was 3, as in alkali feldspars, Si tetrahedra that were still partially linked remained. 
On the other hand, some measurements by XPS (Berner and Holdren, 1979) showed no leached layer forming, and when the artificial alteration was carried out at near-neutral $\mathrm{pH}$ values (between 5 and 8), rather than at low $\mathrm{pH}$, the layer formed was only thin (Blum and Stillings, 1995). Huang (1989) concluded that, in any case, leached layers are not thick enough to inhibit transport and also that there were no continuous layers of secondary precipitates on weathered feldspars. As in the case of olivines, pyroxenes, and amphiboles, dissolution of feldspars probably occurred at sites of excess energy such as dislocations (Huang, 1989).

HRTEM studies have shown that unweathered feldspars are often turbid as a result of minute vesicles being filled with fluid (Hochella and Banfield, 1995), consistent with the observation that they can have a high microporosity (Worden et al., 1990). HRTEM has also shown that their alteration often occurs preferentially at crystal defects (Wilson and McHardy, 1980; Holdren and Speyer, 1987) and that secondary minerals form throughout the primary mineral, not just at grain boundaries (Banfield and Eggleton, 1989; Banfield et al., 1991). Application of SEM and associated energy dispersive X-ray (EDX) analyses showed etch pits and secondary coatings (of a kaolin mineral) developing as the weathering alteration of feldspars progressed (Inskeep et al., 1993). These authors saw the formation of secondary coatings on feldspars as an integral part of their alteration. These were not observed in artificial weathering studies. Essential features of weathering in the field include those of seasonal wetting and drying, a generally high solid: solution ratio, and long residence times for water (Inskeep et al., 1993). The net effect is a weathering rate, determined for plagioclases, that is several orders of magnitude slower than the experimental dissolution rate (White et al., 1996, 2005; White and Brantley, 2003). Maher et al. (2009) have shown that other factors besides mineral dissolution rate and the rate of aqueous transport of solutes, notably the rate of secondary mineral precipitation, ensure a much slower rate of weathering of minerals, including feldspars, in the field than in the laboratory. Furthermore, fungi have been shown to contribute to the breakdown of feldspars on weathering, partly, at least, through their tunnelling by organic anions exuded at the tips of the hyphae of (presumably ectomycorrhizal) fungae (Smits et al., 2005; see also Section 20.2.5.3 on podzolization). Failure to reproduce these features in necessarily hastened artificial weathering studies under closely controlled conditions almost certainly means that their results cannot be applied readily to the understanding of natural weathering. 


\subsubsection{Processes and products of alteration of micas by weathering}

Changes from any of the neosilicate olivines, with independent silica tetrahedra, the inosilicate pyroxenes and amphiboles with tetrahedra in chains, and the tectosilicate feldspars with continuous frameworks of silica and alumina tetrahedral, to yield phyllosilicate clay minerals with flat sheets, all involve some dissolution and recystallization. These processes usually occur within the solution phase, when they can confidently be labelled as neogenesis, although, as we have seen from Banfield and co-workers' descriptions (see Section 20.2.4.1), neogenesis can also take place by a type of transformation within the solid phase that involves successive depolymerization and repolymerization. By contrast, phyllosilicate micas can transform easily to phyllosilicate clay minerals in the solid state.

The main changes that occur in these transformations are exchange of the interlayer cations and reduction in the charge of the layers. Potassium ions occupy the interlayer regions of the common micas, biotite and muscovite. The replacement of $\mathrm{K}^{+}$by hydrated cations such as $\mathrm{Mg}$ or $\mathrm{Ca}$ leads to a loss of strength of binding between adjacent layers. The interlayers expand, so that, with complete replacement by hydrated divalent cations, the basal spacing increases from $1.0 \mathrm{~nm}$ to $1.4 \mathrm{~nm}$ and vermiculite is formed. The concomitant reduction in layer charge has been supposed to occur by a wide variety of mechanisms. These include incorporation of protons into the layers (Raman and Jackson, 1966; Leonard and Weed, 1967), exchange of Si for Al in the tetrahedral sheet (Jackson, 1964; Sridhar and Jackson, 1974; Vicente et al., 1977), loss of hydroxyls (Stucki and Roth, 1977), and the deprotonation of hydroxyl groups and the loss of octahedral Fe, both occurring together (Farmer et al., 1971; Douglas, 1989; Fanning et al., 1989).

In soils particularly, micas rarely transform completely to vermiculite. In soil science, the term "illite" is most commonly used to describe clay-sized micaceous minerals. According to Grim et al.'s (1937) original definition of illite, it was "a general term for the mica-like clay minerals occurring in argillaceous sediments" which also "showed substantially no expanding-lattice characteristics". It tends to be used more widely in practice. Illites commonly show a deficit of $\mathrm{K}$ and an excess of water in comparison with muscovite or biotite. This deficit reflects the greater ease of loss of $\mathrm{K}$ from micas that are fine-grained rather than coarse, together with a paradoxical especially strong retention of some $\mathrm{K}$ in the fine-grained micas against replacement, both in nature and the laboratory (Fanning et al., 1989). 
Fine-grained micaceous minerals that include some expanding layers are sometimes also called illite (Grim, 1968; Wentworth, 1970; Norrish and Pickering, 1983; Weaver, 1989; Laird and Nater, 1993). Strictly speaking, however, these are interstratified illite (or mica)vermiculites (or smectites). The interstratification may be either random or regular. If they are regular, with close to a 1:1 mix of the two constituent layer types, these two types alternate and the basal spacing is a sum of the spacings of the unaltered mica layers $(1.0 \mathrm{~nm})$ and the hydrous vermiculite layers $(1.4 \mathrm{~nm})$, giving a resultant spacing of $2.4 \mathrm{~nm}$.

Alternating layer types in regular 1:1 interstratifications are explained by the replacement of the $\mathrm{K}$ ions in one interlayer by hydrated divalent ions, leading to expansion of this interlayer, causing, in turn, a strengthening of the bond between $\mathrm{K}^{+}$and the aluminosilicate layers in the two adjacent interlayers (Bassett, 1959). These bonds probably strengthen because of a shift of structural hydroxyl groups towards the opened interlayer (Norrish, 1973). Regular interstratifications of micas with vermiculite (and also with smectites, as products of further transformation of micas) tend to occur in soils in colder climates, such as the upland regions of the former Yugoslavia (Gjems, 1970), Scotland (Wilson, 1970), Scandinavia (Kapoor, 1973), and the South Island of New Zealand (Churchman, 1980). In these cold climates the displacement of interlayer $\mathrm{K}^{+}$occurs more slowly and in more discrete steps, that is, via alternate interlayer regions, than in warmer climates, where the transformation occurs more rapidly and in a relatively haphazard fashion to give irregular layer stacking. The release of $\mathrm{K}^{+}$from micas is considered to occur by either layer weathering, as proposed by Jackson et al. (1952), or edge weathering as proposed by Mortland (1958), or both. In the former, most, if not all of the $\mathrm{K}^{+}$in a particular interlayer is released virtually simultaneously. This release commonly occurs in the alteration of claysized micas. In edge weathering, $\mathrm{K}$ ions are released by diffusion from edges and fractures. This loss by diffusion commonly occurs in the alteration of larger mica flakes and has been observed as fraying in artificially altered micas, but it can also take place alongside layer weathering in clay-size micas (Fanning et al., 1989).

Trioctahedral micas, among them biotite and phlogopite, weather more readily than dioctahedral micas, including muscovite and most illites. Plants can bring about the transformation of biotite to vermiculite through their extraction of $\mathrm{K}$ from the mineral (Section 20.2.5.3). Among vermiculites in soils, the dioctahedral forms are more common than their trioctahedral counterparts (Jackson, 1959). Not only are the dioctahedral vermiculites more stable, but also they can form from biotites at the expense of the 
trioctahedral varieties as a result of a structural rearrangement whereby some octahedral cations are lost from the structure only to be replaced by some $\mathrm{Al}$ cations that are lost from tetrahedral sites (Douglas, 1989).

Transformation of micas in soils to expandable phases often occurs under acidic conditions. When pHs are relatively low (ca. $5 \pm 0.5$ ) and organic matter contents are low, $\mathrm{Al}$ is mobile in the aqueous phase as hydroxyl-cations, and, where wetting and drying frequently occur, the conditions favor the deposition of Al-hydroxy species in the interlayers of vermiculites (and also smectites; Rich, 1968). The products, which are nonexpandable or only poorly expandable, are known by a variety of names including dioctahedral chlorite, pedogenic chlorite, 2:1-2:2 intergrade, chloritized vermiculite, and hydroxyl interlayered vermiculite (HIV), and also their smectitic counterparts, such as hydroxyl-interlayered smectite (HIS) (Barnhisel and Bertsch, 1989).

Aluminous interlayers can protect vermiculites from further breakdown (Douglas, 1989) but can be destroyed by chemicals which dissolve Al hydroxyl species, including citrates. Citrates were once used routinely prior to X-ray diffraction (XRD) analyses (Mehra and Jackson, 1960) but their use can lead to the loss of potentially useful genetic information from the occurrence of the aluminous interlayers (Churchman and Bruce, 1988).

Vermiculitization of micas/illites has been found to occur by the expansion of the interlayer region into a wedge shape, known as the "frayed edge site" (Sawnhey, 1972; Nakao et al., 2009). Through the use of a measurement known as "radiocaesium interception potential" (RIP), which gives the amount of these frayed edge sites, Nakao et al. (2009) have compared minerals in soils that have formed from parent materials containing micas in various parts of Asia for their vermiculitic character in relation to the moisture regimes in which they have formed. RIP measures the selectivity of the frayed edge sites for $\mathrm{Cs}^{+}$in comparison with hydrated ions. A high RIP value, indicating a high selectivity for Cs, indicates a high concentration of vermiculite per se, whereas a low value can indicate either that little transformation of illite/mica has occurred or else that hydroxyl-Al interlayering has blocked the frayed edge sites that develop with vermiculitization. Nakao et al. (2009) discovered that, in subtropical Thailand, with an ustic moisture regime in which there is a distinct dry season, illites showed little alteration and, consequently, RIP was low. However, in a strongly leaching udic moisture regime and hypothermic temperature regime in Indonesia, an advanced degree of vermiculitization was indicated by a high RIP. By contrast, 
an udic and mesic moisture/temperate regime in temperate Japan, while also producing a high degree of vermiculitization, nonetheless gave a low RIP value. This result arose because hydroxyl-Al interlayers blocked frayed edges. Nakao et al. (2009) noted that an index of weathering that is based on the degree of vermiculitization showed no relationship with one based on the oxidation status of Fe, which implied that the Thai soil was highly weathered despite its mica/illite showing little or no alteration. The factors which affect the development of $\mathrm{Fe}$ oxides in soils and those which affect loss of $\mathrm{K}^{+}$from the interlayers of micas and illites need bear no relation to one another. In particular, Nakao et al.'s (2009) results showed that the balance between the time spent by a soil in a dry season and the extent of leaching that occurs plays an important role in determining the extent of vermiculitization of its constituent micaceous phases.

Under low $\mathrm{pH}$ conditions, commonly where organic matter contents are high, as they often are under forests, micas may transform to smectites in soils as a result of acid leaching. These conditions typify podzolization and smectites often form through the transformation of micas in the eluviated horizons of podzols. The resulting smectites are generally Al-rich and hence beidellitic (Ross and Mortland, 1966; Churchman, 1980; Borchardt, 1989), but may also be montmorillonitic (Aragoneses and García-González, 1991). Strong weathering without podzolization can also transform micas to smectites (Stoch and Sikora, 1976; Egashira and Tsuda, 1983; Senkayi et al., 1983; Singh and Gilkes, 1991; van Wesemael et al., 1995), even in Antarctic soils, where smectites were among the transformation products of micas (Boyer, 1975). Smectites formed this way have generally been identified as beidellites. Their genesis contrast strongly with those of most smectites, which form at high $\mathrm{pH}$ under poor drainage (see also Section 20.3.5).

Under cool climates, and, with sufficient rainfall, vermiculitic layers that are interstratified with mica layers can themselves be further transformed while the adjacent mica layers remain essentially unaltered. Thus stepwise transformations of (muscovite) mica, first to regularly interstratified mica-vermiculite, then to regularly interstratified mica-beidellite, have occurred over a climosequence on increasing rainfall on mica-chlorite schist in South Island, New Zealand (Churchman 1978, 1980). These changes to alternate layers have occured under a current grassland vegetation, rather than under forest. Indeed, soils within the area that have formed under forest, but with the same precipitation regime as one of the wetter sites in the climosequence under grassland, showed advanced transformation of the mica to a discrete beidellite phase. It appears that the often more acidic exudates from trees 
(e.g., Courchesne, 2006), impose a stronger weathering regime than that under grassland, so that the driving force exceeds that leading to transformation of alternate layers alone.

An advantage of many cool-climate studies is that not all primary minerals alter at the same rate, and the origin of secondary minerals can therefore be traced to the few, if not single, primary minerals that have altered. In the bulk of Churchman's $(1978,1980)$ studies, feldspars were fresh and only mica and chlorite showed signs of alteration. In warmer climates and, with sufficient throughflow of water and passage of time, micas break down further to form 1:1 minerals, both kaolinite and halloysite. Although the direct formation of kaolin minerals from micas alone cannot be concluded when other primary minerals have also altered, many workers have established that micas have altered to form kaolins mainly because of the appearance of the secondary minerals as pseudomorphs after the micas. This apparent pseudomorphic replacement applies for kaolinites formed in tropical Nigeria (Ojanunga, 1973), from Tertiary weathering in Europe (Stoch and Sikora, 1976), in ferralitic (lateritic) soils in Western Australia (Gilkes and Suddhiprakarn, 1979), and in deeply weathered soils in the continental United States (Rebertus et al., 1986), and also for both halloysite and kaolinite formed alongside each other in close association with biotite in tropical Malaysia (Eswaran and Yeow, 1976).

Mainly with the help of electron microscopy, some workers have even found that kaolin minerals can form from micas early in the weathering process including from both biotite (Ahn and Peacor, 1987; Banfield and Eggleton, 1988) and muscovite (Robertson and Eggleton, 1991). Ahn and Peacor (1987) showed that kaolinite can even form as (irregularly) intercalated layers between biotite layers, presumably by a dissolution/crystallization process whereby one biotite layer gives rise to two kaolinite layers. This change takes place within “plasmic microsystems" (Velde and Meunier, 2008) involving small differences in chemical potentials, which arise because of connections with a major passageway for water outside a rock or geological deposit. Such an occurrence - the kaolinization of biotite - may have occurred in weathered tephra beds aged ca. 350,000 years in northern New Zealand and which contain biotite in the unweathered parent tephra (Rangitawa tephra). The kaolinized mineral occurs as a sand-sized golden platy mineral. It comprises (using SEM) nearly nine primary (6-8 $\mu \mathrm{m}$-thick), four secondary (1-1.5 $\mu \mathrm{m})$, and 5-7five to seven tertiary $(0.7 \mu \mathrm{m})$ lamellae units, and is characterized via XRD as a K-depleted, partially random interstratified micaceous kaolinite intergrade containing $<50 \%$ of $1 \mathrm{M}$ trioctahedral mica and $>50 \%$ of partially disordered dioctahedral kaolinite (Shepherd, 1984; Lowe and Percival, 1993). 
Conversely, some (Esawaran and Yeow, 1976; Gilkes and Suddhiprakarn, 1979) have found that vermiculite - often considered to be an unstable intermediate phase (Kittrick, 1973) - nonetheless occurred alongside kaolin minerals in soils formed under strong leaching. One of the likely reasons for the appearance of apparently early weathering products such as vermiculite alongside apparently late stage products such as kaolin minerals is that iron oxyhydroxides are very common products of the weathering of micas. The secondary iron phases coat other minerals such as vermiculites and preserve them against further breakdown. They include goethite (Sousa and Eswaran, 1975; Eswaran and Yeow, 1976; Gilkes and Suddhiprakarn, 1979; Banfield and Eggleton, 1988) as well as hematite (Gilkes and Suddhiprakarn, 1979). Several studies of the products of natural weathering of micas (Rice and Williams, 1969; Aldridge and Churchman, 1991; Aodjit et al., 1996; Seyama et al., 1996), using variously Mössbauer and XPS spectroscopy, as well as the laboratory study of Farmer et al. (1971), have shown that total Fe and Fe(II) were depleted from micas on weathering while Fe (III), Fe gels, and Fe oxyhydroxides built up outside the micas. Oxides and hydroxides of other metals, including Al, as gibbsite (Gilkes and Suddhiprakarn, 1979), and also titanium dioxide (Milnes and Fitzpatrick, 1989), may also have formed, at least partially, from micas.

\subsubsection{Processes and products of alteration of chlorites by weathering}

Chlorites occur most commonly as trioctahedral minerals in parent materials for soils. They originate mainly from low grade metamorphic rocks and as products of the early alteration of $\mathrm{Fe}$ - and $\mathrm{Mg}$ - containing primary minerals such as augite, hornblende, biotite, and serpentines (see Section 20.2.4.5). They are not common in soils mainly because of their low stability with regard to weathering. The initial stages of their alteration are similar to those of micas and involve the loss of their interlayer species, most often hydroxides of $\mathrm{Mg}$ (i.e., brucite structures), but also those of Fe and other cations. Products of the earliest stages of weathering of chlorites have been identified variously as a randomly interstratified hydrous phase (Churchman, 1980), swelling chlorite, which is a type of chlorite depleted of some of its interlayer hydroxides (Stephen and MacEwan, 1951; Bain and Russell, 1981), and sometimes also regular interstratifications of chlorite and swelling chlorite (Churchman, 1980), as well as a chlorite/vermiculite intergrade (Murakami et al., 1996). There is also a strong tendency to form 1:1 regular, or "semi-regular", chlorite-vermiculite interstratifications at the next early stage of weathering. This mineral type has been observed 
in weathering by Johnson (1964), Herbillon and Makumbi (1975), Churchman (1980), Banfield and Murakami (1998), and Aspandiar and Eggleton (2002a, 2002b) among others. A study with atomic-resolution transmission electron microscopy (TEM) led Banfield and Murakami (1998) to propose that there was a tendency towards regular 1:1 interstratification because interlayer $\mathrm{Mg}$ and $\mathrm{Fe}$ hydroxides are removed from every second interlayer on account of a layer shift (of $\sim \mathrm{a} / 3$ ) occurring after the removal of one interlayer hydroxide that thereby stabilises the adjacent interlayer hydroxide. The stabilisation means that the hydroxide in the next interlayer is more labile to replacement. However, Wilson (2004) warned that observations of regular chlorite-vermiculite interstratifications should be treated with caution as products of weathering alone because some, at least, of the parent rocks may have undergone prior hydrothermal alteration. Interstratified chlorites and also vermiculitelike phases have been found to occur in some metamorphosed rocks. Nonetheless, not all sequences of alteration of chlorites are the same, with several authors (e.g., McKeague and Brydon, 1970; Bain, 1977; Churchman, 1980; Ross et al., 1982; Righi et al.,1993; Carnicelli et al., 1997) finding that the chlorite component, often of chlorite-mica schists, disappeared as a result of acid weathering in a podzolised soil, or Spodosol. Chlorite dissolved, typically leaving a solid residue of iron oxides and oxyhydroxides, for example, goethite (Bain, 1977; Ross et al., 1982). Frequently, however, there is further development of the interstratifications of chlorite with vermiculite to discrete vermiculite (Loveland and Bullock, 1975; Murakami et al., 1996). Often also, smectites are considered to form from chlorite (Herbillon and Makumbi, 1975; Carnicelli et al., 1997). Although the primary chlorites are trioctahedral, the resulting vermiculites and smectites are mostly dioctahedral (Wilson, 2004). Ultimately, kaolin minerals, both kaolinite (Herbillon and Makumbi, 1975; Murakami et al., 1996) and also halloysite (Cho and Mermut, 1992), can result from the strong weathering of chlorites.

\subsubsection{Processes and products of alteration of serpentines by weathering}

Serpentinite rocks, which are dominated by serpentines (mainly chrysotile, antigorite, and minor lizardite), together with iron oxides and such minerals as amphiboles, pyroxenes, and talc (e.g., Bonifacio et al., 1997), are generally unstable in soils. In central California, this rock type gave rise to virtually pure Fe-rich smectite in the fine clay $(<0.2 \mu \mathrm{m})$ fraction (Wildman et al., 1968). These authors attributed the mineralogical change to the loss of the 
more mobile elements $\mathrm{Mg}$ and $\mathrm{Si}$ and relative enrichment of $\mathrm{Fe}$ and $\mathrm{Al}$. In the Massif Central in France, alteration of serpentinite in a poorly drained B horizon led to a trioctahedral chlorite, which is normally regarded as a primary mineral, and also to its alteration products: a regularly interstratified chlorite-vermiculite and a nontronitic smectite (Ducloux et al., 1976). This change, while involving some loss of $\mathrm{Mg}$ and $\mathrm{Si}-$ as expected in an open soil system - is more typical of a closed system (Ducloux et al., 1976). The weathering products of a serpentinite in northwest Italy were found to depend strongly on drainage conditions (Bonifacio et al., 1997). Low-charge vermiculite sometimes formed but either dissolved or was transformed to smectite if drainage was poor. An aluminous chlorite could result from either the preformed vermiculite or smectite as a result of interlayering by hydroxy-Al. Lee et al. (2003) in California and Caillaud et al. (2004) in France also found that vermiculite and smectite were formed in the course of weathering of serpentinites. In general, the smectites formed from serpentinites per se are complex and heterogeneous according to Caillaud et al. (2004). Caillaud et al. (2004) focussed on a microsystem in the serpentinite weathering system. The types of vermiculite and/or smectite formed varied, with both trioctahedral and dioctahedral structural types covering a range of layer charges, depending upon their originating primary minerals. For instance, a thin lizardite bastite gave rise to Al-poor trioctahedral saponite, whereas a dioctahedral Fe-rich montmorillonite appeared to derive directly from chrysotile. Using a toposequence in Taiwan on serpentinite containing chrysotile, antigorite, and lizardite, and also chlorite and talc, Hseu et al. (2007) were able to identify the products of weathering as, firstly, smectite that was dominantly trioctahedral, then interstratified chlorite-vermiculite, and, finally, kaolinite and quartz.

\subsubsection{Processes and products of alteration of volcanic parent materials by weathering}

One outstanding feature of volcanic materials as parent materials for clay-size minerals is that they usually contain glass, which is a fast-weathering source of Si and $\mathrm{Al}$ (and other elements) for mineral neogenesis. They can also contain other weatherable minerals, depending on their origin, nature, and composition. Broadly, volcanic materials may originate from effusive eruptions, forming lavas, or explosive eruptions that generate fragmental, unconsolidated deposits called pyroclastic materials, or tephra, that may be distributed widely by the wind. Among the latter, there are three main types, based on composition. These are (1) basaltic, which are rich in Fe and $\mathrm{Mg}$, reflecting usually high 
contents of ferromagnesian, or mafic, minerals, namely, olivines, amphiboles, and pyroxenes, as well as feldspars and brownish-colored basaltic glass low in $\mathrm{Si}$ and relatively high in $\mathrm{Al}$; (2) rhyolitic, which have abundant Si-rich glass comparatively low in Al, and which may contain minor amounts of mafic minerals including biotite, and also feldspars; and (3) andesitic or dacitic, which are intermediate in composition between basaltic and rhyolitic eruptives (see Chapter 33.3 [McDaniel et al., 2012], for more details on their composition, occurrences, and properties).

\subsection{Glass}

The alteration of glass is a special case. Glass is an amorphous solid with a poorly ordered internal structure comprising loosely linked $\mathrm{SiO}_{4}$ tetrahedra with considerable intermolecular space (in which cations such as sodium occur) (Fisher and Schminke, 1984). The hydration and breakdown of glass results in fluxes of some elements from the glass into interstitial pore waters, and the very rapid precipitation of secondary minerals from such solutions as well as replacement of glass shards by new minerals (e.g., Daux et al., 1994). Dissolution of basaltic glass, and probably also other glass types, as determined by Oelkers and Gislason (2001) and Gislason and Oelkers (2003), proceeds in effectively three steps: (1) relatively rapid and largely complete removal of univalent and divalent cations from the near-surface glass structure via the breaking of metal-oxygen bonds and their replacement with proton-oxygen bonds; (2) Al-releasing exchange reactions between three aqueous $\mathrm{H}^{+}$ions and $\mathrm{Al}$ in the glass structure; and (3) relatively slow detachment of partially liberated silica. The tetrahedrallycoordinated Si-O bonds are the most stable bonds in the glass framework. Si tetrahedra on the glass surface may be connected to the glass framework via one to three bridging oxygens, and the rate of release of any $\mathrm{Si}$ atom at the surface decreases markedly as the number of bridging oxygen bonds increases (Gislason and Oelkers, 2003). The breaking of Al-O bonds does not destroy the glass framework but instead only partially liberates the silica tetrahedral chains by removing adjoining $\mathrm{Al}$ atoms (Gislason and Oelkers, 2003). Glass dissolution rates demonstrably increase with decreasing Si content (Wolff-Boenisch et al., 2004), and hence basaltic glass (low in $\mathrm{Si}$ ) usually dissolves faster than andesitic glass (intermediate Si content) or rhyolitic glass (high in $\mathrm{Si}$ ) under similar environmental conditions (Neall, 1977; Hodder et al., 1990; Shoji et al., 1993a; De Vleeschower et al., 2008; Sigfusson et al., 2008; Figure 20.2). In all cases, fragmental and vesicular glass components, such as those which occur in tephra deposits, have high surface areas and are very porous and so break down very quickly, 
and at rates closely proportional to geometric surface areas (e.g., Dahlgren et al., 2004; Wolff-Boenisch e al., 2004). The initial alteration of basaltic glass, described widely as “palagonitization", is described below as a special case in Section 20.2.4.6.3.

\subsection{The formation of allophane and halloysite from volcanic parent materials}

Allophane and halloysite are the most common secondary minerals that are formed in soils developed from loose volcanic material or tephra, which may be ash, pumice, and cinders (the last also referred to as scoria).

Using ${ }^{27} \mathrm{Al}$ and ${ }^{29} \mathrm{Si}$ NMR, Hiradate and Wada (2005) have deduced a mechanism for the formation of allophane from glass as another step in the weathering-synthesis process (Figure 20.5). This mechanism involves (1) dissolution of Al mainly from volcanic glass (via Al-releasing exchange reactions with protons) and its concomitant transformation from its tetrahedral to octahedral state, ${ }^{\mathrm{IV}} \mathrm{Al}$ to ${ }^{\mathrm{VI}} \mathrm{Al}$; (2) hydrolysis of the $\mathrm{Al}$ released into solution, to give a gibbsite-like sheet; (3) dissolution (via breaking of Si-O bonds) of Si from volcanic glass, where it occurs as a silica gel-like polymer, to give monosilicic acid in solution; and (4) reaction between the gibbsite-like sheet and monosilicic acid to generate allophane.

This process is consistent with modern understanding about the crystal structure of allophane. Its structure is regarded as being based on that of imogolite, another aluminosilicate which is sometimes found (typically in small amounts) in soils derived from tephra and in some other soils including podzols. Imogolite has an ideal chemical formula of $\mathrm{SiO}_{2} \cdot \mathrm{Al}_{2} \mathrm{O}_{3} \cdot 2 \mathrm{H}_{2} \mathrm{O}$ and therefore an $\mathrm{Al}: \mathrm{Si}$ ratio of $2: 1$. The imogolite structure, established by Cradwick et al. (1972), consists of a defect gibbsitic Al-octahedral sheet framework. Si in each silica tetrahedron is attached to this framework by sharing three of its $\mathrm{O}$ atoms (hence the Q3 notation shown in Figure 20.5) with an octahedrally co-ordinated Al on the gibbsitic sheet while the remaining $\mathrm{O}$ atom on the tetrahedrally co-ordinated $\mathrm{Si}$ acquires an $\mathrm{H}$ atom to form a Si-OH bond pointing away from the gibbsitic sheet. Although imogolite, which comprises long, thin hollow nanotubes, always in bundles, has a definite XRD pattern (Yoshinaga and Aomine, 1962), and, hence, some long-range order, allophane gives extremely broad, low intensity humps in XRD and is regarded as a mineral with short-range order (SRO), or a poorly ordered aluminosilicate, as well as a "structured nanomineral" (Hochella, 2008; Theng and Yuan, 2008; McDaniel et al., 2012, Chapter 33.3). 


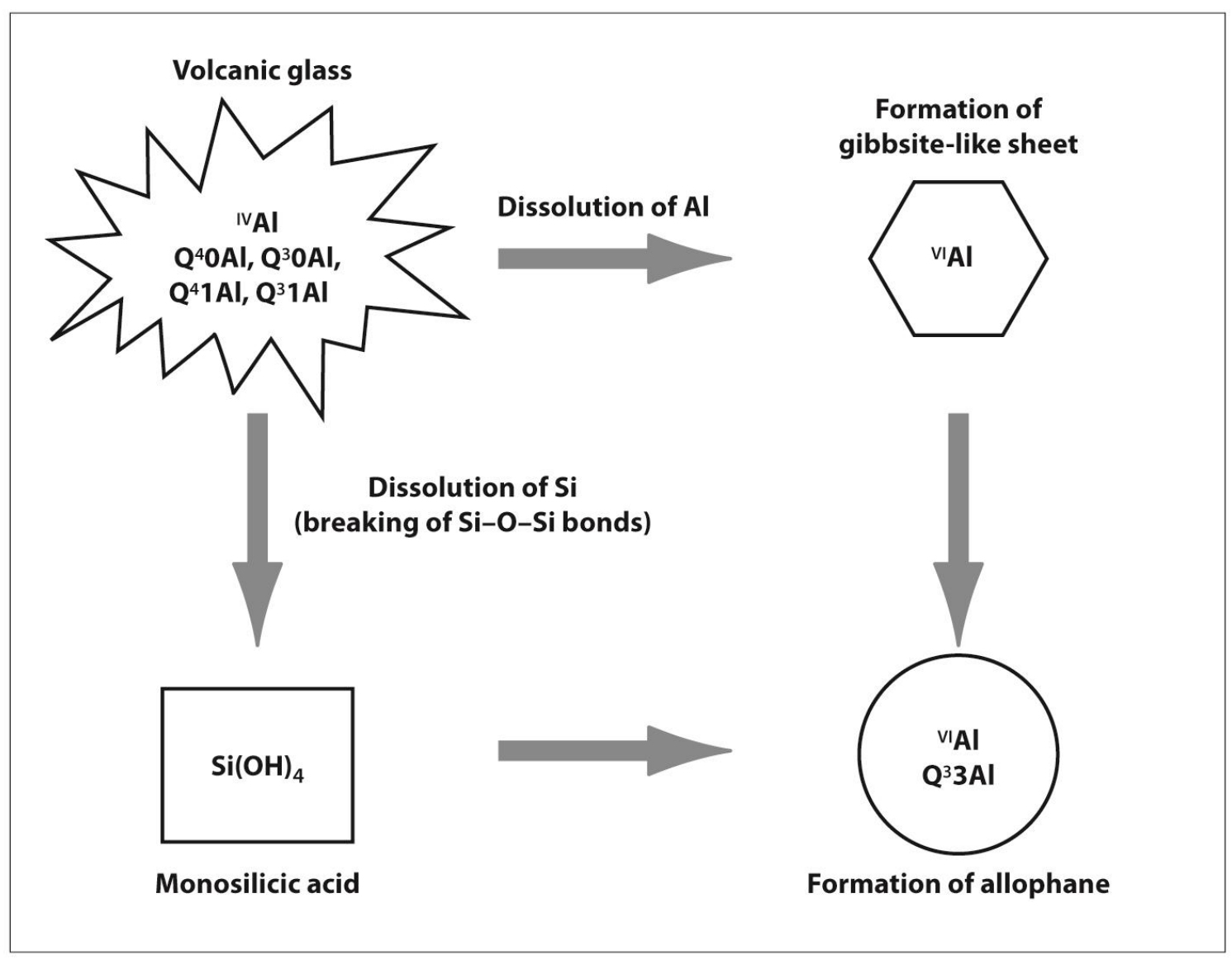

FIGURE 20.5 Model depicting the formation of allophane. $Q$ notation describes the connectivity of a $\mathrm{Q}$ unit-that is, an Si atom su rrounded by four oxygen atoms-to other Si atoms (Wright and Sommerdijk, 2001): Q4 indicates that the Q unit is fully interconnected with silicate groups, and Q3 indicates that the $\mathrm{Q}$ unit is linked in three places (referred to as branching points). (Redrawn from Hiradate, S., and S.-1. Wada. 2005. Weathering processes of volcanic glass to allophane determined by $27 \mathrm{AI}$ and 29Si solid -state NMR. Clays Clay Miner. 53:40 1-408, Fig. 4. With permission of The Clay Minerals Society.)

The best term for it is "nanocrystalline", meaning structured at the nanometre scale, that is, 1-100 nm. (Another nanocrystalline mineral that occurs commonly but usually in relatively small amounts in weathered tephras and other materials, and which is analogous to allophane, is ferrihydrite, described later herein.) Allophane composition varies over a much greater range than that of imogolite, although morphologically all unit particles comprise tiny hollow spherules or "nanoballs" (Parfitt, 2009). In soils, there are two main types: (1) Al-rich, with $\mathrm{Al}: \mathrm{Si} \sim 2: 1$ - these are imogolite-like, or proto-imogolite allophanes; and (2) Si-rich, with $\mathrm{Al}: \mathrm{Si} \sim 1: 1$ - these are halloysite-like allophanes. The imogolite-like nanocrystalline structure applies only to Al-rich allophane, which is the most common type (Parfitt, 2009). Generally, it has an XRD pattern that is often indefinite, even if distinct peaks appear for 
some samples (Parfitt, 1990), but the pattern is likely to be indistinct when allophane is associated with long-range-ordered crystalline minerals. Therefore a number of other sophisticated instrumental methods have been proposed for its identification. Earlier, these included infrared spectroscopy, differential thermal analysis, and TEM (Fieldes, 1955). More recently, electron diffraction (Wada and Yoshinaga, 1969), small-angle neutron scattering (Hall et al., 1985), ${ }^{27} \mathrm{Al}$ and ${ }^{29} \mathrm{Si}$ NMR (Goodman et al., 1985; Hiradate and Wada, 2005; Hiradate et al., 2006), and XPS (He et al., 2008) have also been used. Yet it is a chemical method, for the extraction of $\mathrm{Al}$ and $\mathrm{Si}$, among other metals, using acidified ammonium oxalate and developed long ago by Tamm (1922), which has become the standard (and critically important) procedure for both identifying and quantifying allophane (Parfitt and Henmi, 1980; Parfitt and Wilson, 1985; Wada, 1987, 1989).

Halloysite often also forms by the weathering of tephra. Although halloysite, as a 1:1 $\mathrm{Si}$ Al mineral with the same aluminosilicate composition as kaolinite, has often been identified by a peculiar shape in electron micrographs (see Section 203.2), it is only the occurrence, or else evidence for prior occurrence, of interlayer water that distinguishes halloysites unequivocally from kaolinites (Churchman and Carr, 1975; Churchman, 2000). With the knowledge that allophane is a fast-forming SRO (nanocrystalline) product from the dissolution mainly of glass whereas halloysites, being crystalline with long-range order, generally give distinct peaks in XRD, there has been much debate over the question of whether allophane alters to halloysite and, if so, how this change occurs. There have been two main schools of thought regarding this question. One of these, proposed by Fieldes (1955) and which was the predominant idea until around the 1980s, held that allophane altered to halloysite with the passage of time. This mineralogical change was considered to occur by a solid-phase transformation involving dehydration and "crystallization" from an "amorphous" material.

According to the alternative view, which was formulated in Parfitt et al. (1983) and subsequent papers (e.g., Parfitt et al., 1984; Parfitt, 1990, 2009), it is the concentration of Si in soil solutions [ $\mathrm{Si}$ ], and availability of $\mathrm{Al}$, which largely determine the nature of the aluminosilicate secondary minerals that form from volcanic parent materials by weathering. In particular, allophane is favored by a lower [Si], whereas halloysite tends to result when [Si] is relatively high. This theory was based on mineralogical and soil-solution data from a rainfall sequence of soils formed on tephra-derived deposits in northern New Zealand. It was 
supported by Singleton et al. (1989) who measured in detail modern solution [Si] in soils forming a drainage sequence on tephric materials of similar composition and age.

Parfitt's theory helped to explain some anomalies concerning the application of Fieldes' (1955) hitherto pervasive theory that allophane seemed to inevitably alter or "transform" to halloysite with time. Fieldes' theory was based on the world-wide recognition that halloysite tended to occur at depth in many tephra-derived soil sequences whereas allophane predominated in surface horizons. Because such sequences become stratigraphically older with increasing depth, the assumption was made that allophane formed first and then, after ca. 10,000 to 15,000 years, it apparently transformed to halloysite (see review by Lowe, 1986). However, in northern New Zealand, McIntosh (1979) showed that authigenic halloysite (both spheroidal and tubular) had formed by recent processes in tephra deposits only $\sim 1800$ years old. He demonstrated that such halloysite formation was a consequence of resilication from a Si-rich soil solution - the resilication was indicated by Si:Al ratios of $\sim 2$ at depths of $2 \mathrm{~m}$ or more, in contrast to values of $\leq 1$ in surface horizons , and by modern lysimeter leachate compositions (McIntosh, 1980). Other reports had previously demonstrated the seemingly "anomalous" occurrence of halloysite in young soils (Hay, 1960; Bates, 1962; Bleeker and Parfitt, 1974), and electron micrographs showed a close association of halloysite with the surfaces of parent minerals/mineraloids, both glass (Dixon and McKee, 1974) and feldspars (Tazaki, 1979) (see Lowe, 1986, and also Figure 20.3 herein). Similarly, Ogura et al. (2008) showed in recent, proximal scoriaceous tephras (deposited since 800 AD) near Mt Fuji, Japan, that the coarse particle sizes and large pores facilitated rapid drying, aiding the concentration of $\mathrm{Si}$ and hence neoformation of tiny spherical halloysite particles. Thus, it became clear that halloysite, rather than allophane, was able to form directly from tephra materials in young soils under certain conditions where [Si] was relatively high. In reality, [Si] may vary seasonally, and kinetic considerations can lead to the formation of halloysite if the periods of high [Si] greatly exceed those when [Si] is low. The use of oxygen isotopes to trace the temperature of formation of minerals, among other techniques, led Ziegler et al. (2003) to conclude that halloysite has formed continuously from the early stages of formation from basalt in an arid zone in Hawaii as the result of prolonged extremely dry seasons following short periods of intense rainfall. The release of $\mathrm{Al}$ in the latter had been followed by a prolonged build-up of $\mathrm{Si}$, and hence halloysite formation. In addition, it had long been known that allophane was present in some very old weathered tephra sequences (Ward, 1967; Tonkin, 1970), which had always been a puzzle in view of the 
Fieldes' model (although the amounts of allophane were not well quantified at that time). A key study was that by Stevens and Vucetich (1985) who used ammonium oxalate dissolution methods to quantify allophane content in a 10-m high tephra weathering sequence in northern New Zealand dating back ca. 350,000 years (the basal tephra being re-identified more recently as the Rangitawa tephra: Lowe et al., 2001). They demonstrated unequivocally that abundant allophane was present in many beds in the sequence. Moreover, through tephrochronology, Stevens and Vucetich (1985) were able to show that allophane (as well as subordinate gibbsite) was predominant during warm, wet interglacial periods but that halloysite predominated during cool, dry glacial periods, implying that changing environmental conditions had led to changing [Si] and hence different clays. A similar finding was recorded by Bakker et al. (1996). Thus the weathering of tephra followed separate pathways leading to the formation either of allophane or halloysite, rather than following a single pathway governed by time (Lowe, 1986).

The idea that a high [Si] favored halloysite also made sense of reports of the formation of halloysite instead of allophane when there was a thick overburden (Meija et al., 1968; Aomine and Mizota, 1973; Wada, 1987; Cronin et al., 1996), and also where drainage was impeded or poor (Aomina and Wada, 1962; Dudas and Harward, 1975; Stevens and Vucetich, 1985; Cronin et al., 1996). Both these situations would give rise to a build-up of Si which, it was then thought, would react with pre-formed allophane to form halloysite (Aomine and Wada, 1962; Dudas and Harward, 1975; Saigusa et al., 1978).

Zehetner et al. (2003), in Andean Ecuador, Rasmussen et al. (2007) in the Sierra Nevada in California, and Chadwick et al. (2003), on Kohala Mountain in Hawaii, have studied the mineralogy of soils formed at different altitudes but from a common volcanic source (andesitic/dacitic ash, andesitic lahar, and basaltic lava, respectively). In each case, it was found that allophane (with imogolite and ferrihydrite in Hawaii) was dominant in soils at higher altitudes and halloysite in soils at lower altitudes, confirming the trends discovered by Nizeyimana et al. (1997) in a similar study on volcanic materials in Rwanda. At higher altitudes the precipitation is greater, hence leaching is stronger, solution [Si] is lower and allophane prevails in the soils formed there. Conversely, precipitation and degree of leaching are lower, and [Si] in solution is higher, at lower altitudes and so halloysite dominates in these soils. Chadwick et al. (2003) emphasised in their Hawaiian study, however, that as moisture increased along the sampling transect, different sets of secondary minerals were favored in response to conditions controlled by arid conditions, by rapid and intense cycles of 
wetting and drying, or by essentially continuously wet conditions. They developed a leaching index as the ratio of water balance to the integrated porosity of the top meter of soil on an annual basis. The index reached 1 (total filling of the pore space each year) where the mean annual precipitation (MAP) was $\sim 1400 \mathrm{~mm}$. Index values $>1$ indicated intense leaching conditions because of pore water replacement; leaching losses of soluble base cations and $\mathrm{Si}$ were nearly complete at such index values, whereas only $60 \%$ of $\mathrm{Al}$ had been lost. Where index values were $<1$, leaching losses were progressively lower with the lowest rainfall sites having lost $10-20 \%$ of the original base cations and $\mathrm{Si}$, but none of the $\mathrm{Al}$.

Rasmussen et al. (2007) found further that soils in intermediate zones of altitude contained both allophane and halloysite and also that soils at extremely high altitudes had neither allophane nor halloysite but instead were dominated by interlayered 2:1 Si:Al layer silicates, which they considered to be inherited from the parent material. These authors considered that climate controlled the clay minerals formed from the volcanic materials. Rainfall explained the secondary phases formed except at the higher, colder sites, where temperature inhibited mineral alteration and the formation of new mineral phases. These altitudinal (hence rainfall) studies have further demonstrated the validity of Parfitt et al.'s (1983) model for the effect of [Si] in controlling the formation of secondary minerals from the weathering of volcanic parent materials (where $\mathrm{Al}$ availability effectively is unlimited). Further evidence for the validity of this model was demonstrated in a succession of buried soil horizons formed on rhyolitic tephras dating back $\sim 25,000$ years near Rotorua in New Zealand (Figure 20.6; Newnham et al., 1999). Cold and dry conditions and grassland vegetation before $\sim 13,000$ years ago resulted in halloysite (with minor Si-rich allophane) being formed because of limited Si leaching under lowered rainfall. Al-rich allophane was formed after $\sim 13,000$ years ago when Si loss increased through stronger leaching as rainfall and temperatures increased and forest replaced the grassland. In addition, halloysite formation was likely enhanced through enrichment by $\mathrm{SiO}_{2}$ in leachates carried down the section as the tephras accumulated above, and by a concomitant reduction in permeability in the halloysitic horizons which have a greater bulk density (Parfitt et al., 1983; Bakker et al., 1996). The paleoenvironmental interpretation was established by analyses of phytoliths (siliceous plant cell remains) at the same site together with palynological and other evidence from sites elsewhere in the region (Sase et al., 1988; Kondo et al., 1994; Newnham et al., 1999). A similar conclusion was reached in a parallel study in Mexico (Sedov et al., 2003). 


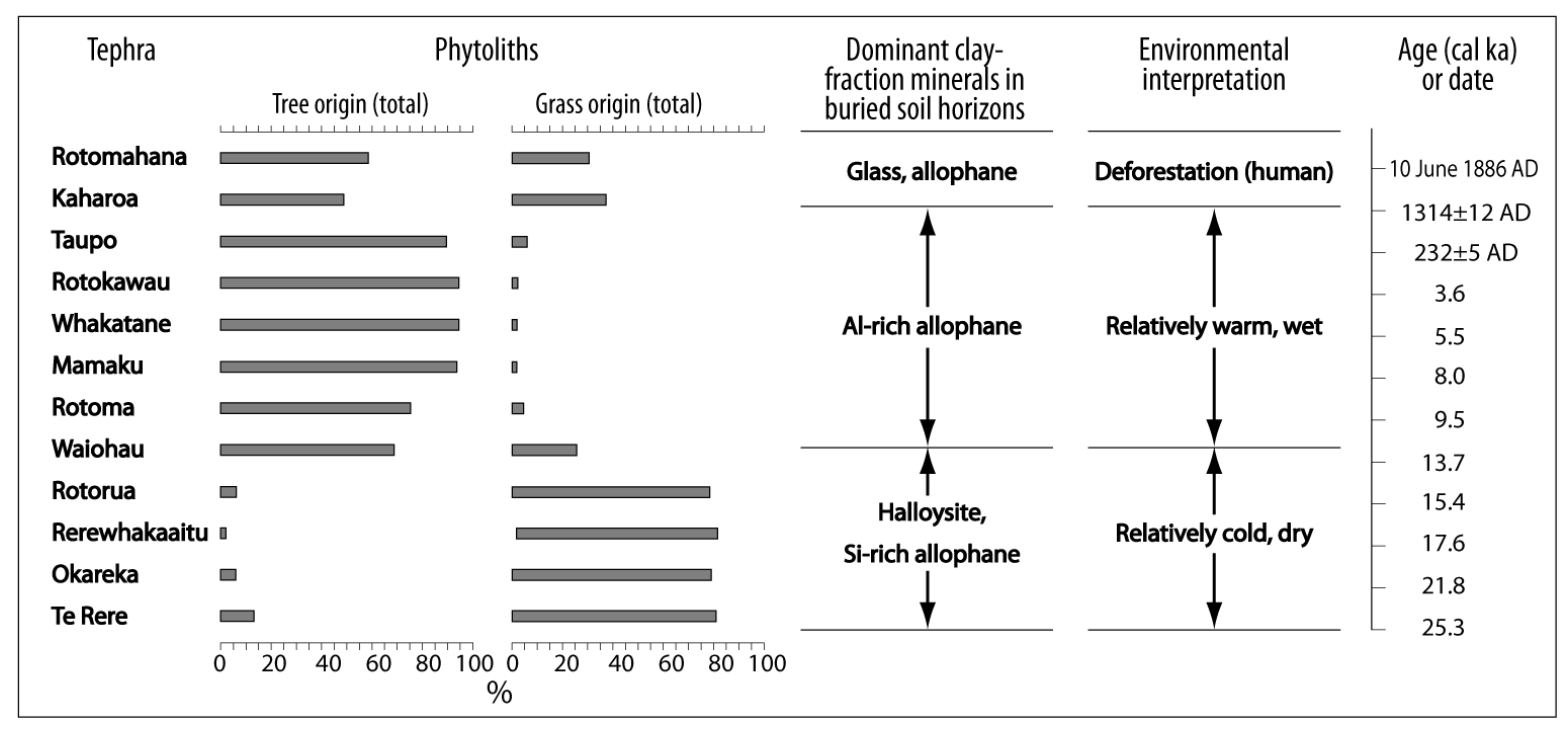

FIGURE 20.6 Dominant day minerals and phytoliths identified in buried soil horizons in a sequence of 11 rhyolitic tephras and one basaltic tephra (Rotokawau) deposited near Rotorua, New Zealand, since $\sim 25,000$ calendar (cal) years ago showing the relationship between the clay mineral assemblages and environment (based on Green, 1987; Sase et al., 1988; Lowe and Percival, 1993; Kondo et al., 1994). ka, thousands of years before present. Dates for Kaharoa and Taupo eruptions are from Hogg eta!. (2003, 2011); other ages are from Lowe et aJ. (2008). (Modified after Newnham, R.M., D.). Lowe, and P.W. Williams. 1999. Quaternary environmental change in New Zealand: A review. Prog. Phys. Geog. 23:567-610. With permission of SAGE Publi cations.)

The model was further supported by a study of seven pedons within the caldera of a volcano in Italy which showed that the secondary minerals reflected the hydraulic properties, namely drainage, of the parent materials (Vacca et al., 2003). In this case, allophane had formed in soils developed in younger, porous, permeable ash deposits, while soils formed in older, less porous and less permeable scoria and consolidated tuffs contained crystalline minerals, especially halloysite, but no allophane.

Other aluminosilicate minerals can also form from volcanic parent materials by weathering. Possible products include 2:1 Si:Al aluminosilicates, which are most likely to occur where biotite is present as a product of the transformation of this mineral through the replacement of interlayer potassium ions, most probably by hydrated divalent cations (see Section 20.2.4.3). Various workers in the past (reviewed by Lowe, 1986) have proposed that a wide variety of 2:1 Si:Al aluminosilicates have formed in soils from volcanic parent materials, including volcanic glass, but several recent publications (e.g., Nieuwenhuyse et al., 2000; Kautz and Ryan, 2003; Mirabella et al., 2005; Rasmussen et al., 2007) have confirmed that these types of phyllosilicates, including illite, smectite, vermiculite, chlorite, kaolinite and their interstratifications with one another may be inherited, either from the parent pyroclastic material, where they may have formed by hydrothermal processes prior to weathering or else as a contaminant of other, non-volcanic origin such as aeolian dust. 
Nonetheless, some aluminosilicate, and also more aluminous minerals, do form from volcanic parent materials either alongside, or instead of, allophane and halloysite (Theng et al., 1982). Parfitt et al. (1983) noted that gibbsite was recognised in a 1968 report as a product of the weathering of volcanic ash that was deposited in root channels in soils from Japan while it has also been found to occur in the weathering products of volcaniclastic materials in northern California that have rhyolitic, andesitic, and basaltic inputs (Takahashi et al., 1993). In these latter soils, gibbsite occurs alongside imogolite (or imogolite-like 2:1 $\mathrm{Al}: \mathrm{Si}$ allophane) and also halloysite. This concurrence suggests that gibbsite formation may occur during the wet season (winter and early spring) of the Mediterranean (or xeric) climate in this region, while, as soils dry out in the approach to summer (the dry season), first imogolite/allophane, and then halloysite, is formed. In humid tropical conditions in Cameroon, the occurrence of minor gibbsite in a soil developed on hydrothermally-altered nephenelitic materials (Si-poor, alkali-rich lavas) was attributed to the development of a strongly-developed microporosity that facilitated the elimination of silica through leaching (Etame et al., 2009).

There appears to be an annual cycle among the secondary minerals resulting from the continually dissolving volcanic parent materials, particularly glass. Fieldes (1968) had proposed that halloysite formation occurred from allophane pre-cursors as a result of seasonal drying (a process invoked also by Chadwick et al., 2003, whereby rapid wetting and drying cycles in arid zones were said to destabilize allophane, forcing it to "dewater and transform into halloysite"). Lilienfein et al. (2003) studied a chronosequence of quite young soils on andesitic mud flows in northern California nearby those in Takahashi et al.'s (1993) study, and found that the amount of allophane increased linearly and quite rapidly in soils up to 600 years of age, although the oldest of these soils had less than half as much allophane as those studied by Takahashi et al. (1993) and hence were probably less well developed than the latter soils. Lilienfein et al. (2003) did not record any gibbsite in their soils.

By contrast, Nieuwenhuyse et al. (2000), who also studied a chronosequence on andesitic parent materials (lava, in this case) but in a humid tropical climate in Costa Rica, found all of allophane, kaolin minerals - kaolinite and halloysite - and gibbsite (as well as Al- and Fe-humus complexes and ferrihydrite) in soils from all ages of the parent lavas, ranging from 2,000 to 450,000 years. Currently, mean monthly precipitation exceeds potential evaporation every month of the year in the present climate for these soils, so there is no dry season to explain the possible formation of relatively Si-rich kaolin minerals along with Si-free gibbsite and Si-poor (i.e., Al-rich) allophane. To explain the simultaneous 
appearance of these different minerals, Nieuwenhuyse et al. (2000), like Newnham et al. (1999), pointed to palynological evidence of a past drier climate, which evidently occurred in this region around the last glacial maximum. This drier climate, as at Rotorua in New Zealand (Figure 20.6), would have enabled Si-rich halloysite to form at that time and some of it, at least, has persisted into the current strong leaching regime, with an average annual precipitation of $4500 \mathrm{~mm} \mathrm{year}^{-1}$. Nieuwenhuyse et al. (2000) proposed that gibbsite is formed in the soils as a result of the disintegration of the kaolin minerals under strong leaching. This mechanism explains the dominance of gibbsite among secondary minerals after 450,000 years of soil formation. By way of contrast, Certini et al. (2006) found that soils formed from 200,000 year-old trachyandesite pyroclastic materials in Italy showed only well-formed gibbsite and an "embryonic" halloysite in their clay fractions. These authors considered that both are products of the early stages of weathering of volcanic glass. In a hot, wet (perudic) climate in Guadeloupe similar to those studied by Nieuwenhuyse et al. (2000), Ndayiragije and Delvaux (2003) found that gibbsite, allophane, kaolinite and hydroxyl-Al interlayered smectite/vermiculite co-existed in a soil from andesitic-dacitic ash, but there was no halloysite in this soil. This soil appears to be similar mineralogically to those studied by Nieuwenhuyse et al. (2000), which occurs in a similar climate, except for the hydroxy-Al 2:1 Si:Al aluminosilicate. This last mineral was seen by Ndayiragije and Delvaux (2003) as an inheritance from the parent tephra and its aluminous interlayers were regarded as performing an antigibbsite (Jackson, 1963) or analogous antiallophane effect by preferentially sequestering $\mathrm{Al}$, at least until the available interlayers became saturated.

Although activity of $\mathrm{Si}$ is clearly critically important in governing the formation of halloysite, allophane, or gibbsite in soils from volcanic parent materials (especially tephra) (see, e.g., a stability diagram for these minerals in Churchman, 2000, Figure 1.11), there may also be competitors for $\mathrm{Al}$, such as hydroxyl-Al interlayered smectite/vermiculite, as discussed by Ndayiragije and Delvaux (2003) (see also Kleber et al., 2007). Quite often competition for $\mathrm{Al}$ also arises from organic matter (especially large quantities are derived from, e.g., pampas grass Miscanthus sinensis in Japan), which gives rise to fast-forming, resistant Al-humus complexes in soils with pHs < 5 (Shoji et al., 1993a; Dalhgren et al., 2004; Hiradate et al., 2004; Parfitt, 2009). Carboxyl groups of humic materials and the 2:1 layer silicates effectively compete for dissolved Al, leaving little Al available for coprecipitation with Si to form allophane or imogolite (Dahlgren et al., 2004; Theng and Yuan, 2008). The preferential incorporation of Al into Al-humus complexes, as with hydroxyl-Al interlayers of 2:1 layer silicates as noted above, is another example of the "antiallophane" 
effect (McDaniel et al., 2012, Chapter 33.3). Thus preformed allophane disintegrated and was replaced by Al-humus after only 30 years under bracken fern, consistent with a fall in $\mathrm{pH}$ from 5.2 to 4.6 (Johnson-Maynard et al., 1997). Furthermore, weathering of tephra from the 1980 eruption of Mt St Helens led to Al-humus and also hydroxy-Al interlayers in 2:1 Si:Al aluminosilicates rather than to any of allophane, imogolite, or opaline silica (Dahlgren et al., 1997). However, opaline silica can form alongside Al-humus complexes, and Fe may also become incorporated into complexes with humus (Wada, 1989). Recent studies in Ecuador (Poulenard et al., 2003) and Japan (Yagasaki et al., 2006) have shown, respectively, that Alhumus complexes form rather than allophane when the content of organic $\mathrm{C}$ is particularly high or that allophane is dissolved in favor of Al-humus complexes when organic C content increases. As well, Al-humus complexing predominates at sites more distal to volcanoes because such sites infrequently receive a "top up" of Al through the deposition of weatherable tephras in comparison with sites closer to volcanic sources that are more regularly dusted with tephra.

A variety of secondary minerals could be found in soils developed in the erupted material from the basaltic volcanoes at Mts. Gambier and Schank in southeast South Australia which are only $10 \mathrm{~km}$ apart and both about 5,000 years old (Lowe et al., 1996; Lowe and Palmer, 2005; Takesako et al., 2010). The main types of clay minerals formed in a xeric moisture regime with a relatively low average annual precipitation of $700 \mathrm{~mm}$ are shown for each location in Figure 20.7. They are compared with the categories of primary minerals in the parent materials, which comprise both volcanic and nonvolcanic "exotic" minerals incorporated into the eruptives from underlying calcareous sands and limestone. There is a contrast between the clays found at or near Mt. Gambier, on the one hand, and Mt. Schank, on the other. The former are dominated by layer silicate minerals, including interstratifications of kaolinite and smectite, illite, and some discrete smectite. The secondary minerals in soils in the vicinity of Mt. Schank show less variety. They tend to contain more allophane and ferrihydrite than those from the Mt. Gambier area. For the soils from both sites, while both kaolinite-smectite and illite occur in many Australian soils (Norrish and Pickering, 1983; Churchman et al., 1994) and probably do not originate from the recent volcanic material, the discrete smectite found in poorly-drained subsoils is probably formed by neogenesis from elements from the dissolution of the basaltic tephra (Lowe et al., 1996; Lowe and Palmer, 2005). Notably, there was no halloysite formed in any of the soils at either Mt. Gambier or Mt. Schank. Allophane showed a range of composition within profiles; its $\mathrm{Al}: \mathrm{Si}$ ratio determined using acid oxalate-extractable $\mathrm{Al}$ (minus organically-associated 
pyrophosphate-extractable-Al) as a ratio to acid oxalate-extractable $\mathrm{Si}$ was $\mathrm{Al}: \mathrm{Si} \sim 2$ in upper parts of the soil profiles but dropped to $\mathrm{Al}: \mathrm{Si} \sim 1$ lower in the same profiles (Lowe et al., 1996; Lowe and Palmer, 2005). Lowe et al. (1996) suggested that there had been seasonal leaching during winter and early spring, leading to the formation of Al-rich allophane towards the surface, but weaker leaching (or even slight accumulation of Si) at depth, leaving Si-rich allophane rather than halloysite.

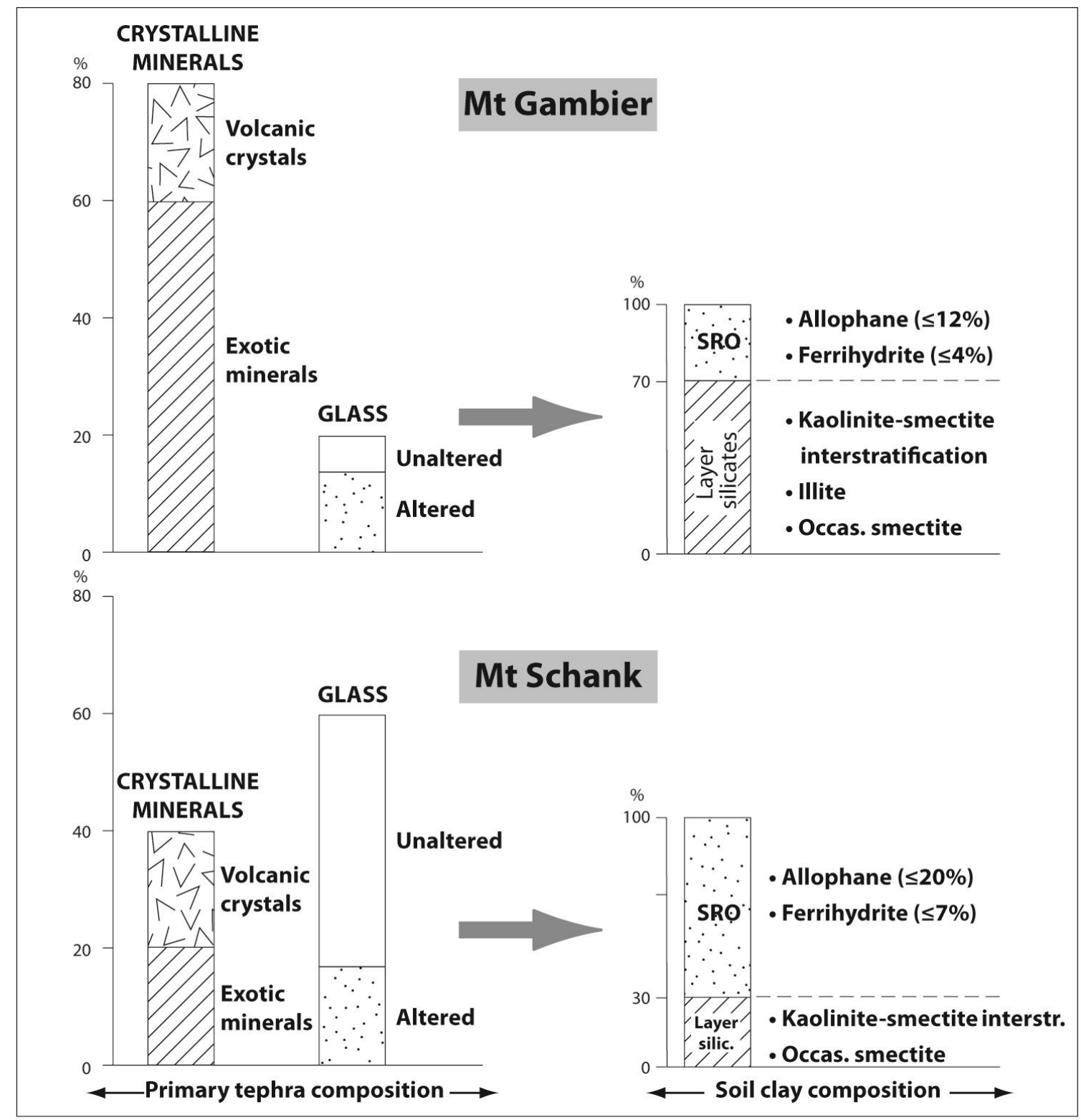

FIGURE 20.7 Contrasts in sand mineral assemblages of soils on mid-Holocene basaltic tephra erupted from Mt. Gambier and nearby Mt. Schank in South Australia have led to markedly different soil clay compositions under a xeric moisture regime. SRO, short-range order (i.e., nanocrystalline); interstr., interstratification; occas., occasional. (Modified after Lowe, D.)., and D.J. Palmer. 2005. Andisols of New Zealand and Australia. J. Integr. Field Sci. 2:39-65. With permission of Tohoku University.) 
The volume of water draining through the upper part of the profile each year has been measured as ca. $280 \mathrm{~mm}$, which just exceeds the threshold of ca. $250 \mathrm{~mm}$ for Al-rich allophane to form according to models derived from New Zealand data (Parfitt et al., 1984; Lowe, 1995). Jongmans et al. (1994) also found both Al-rich and Si-rich forms of allophane, respectively in the B and C horizons, in the same profiles in soils in Guadeloupe. Alloway et al. (1992) similarly found differences in Al: Si ratios (and 15-bar water retention) in upbuilding Andisols in the Taranaki region of North Island, New Zealand, which they attributed to changing climatic conditions from late glacial to postglacial periods: increasing rainfall and fewer prolonged dry periods resulted in higher Al: Si ratios because of increasing desilication.

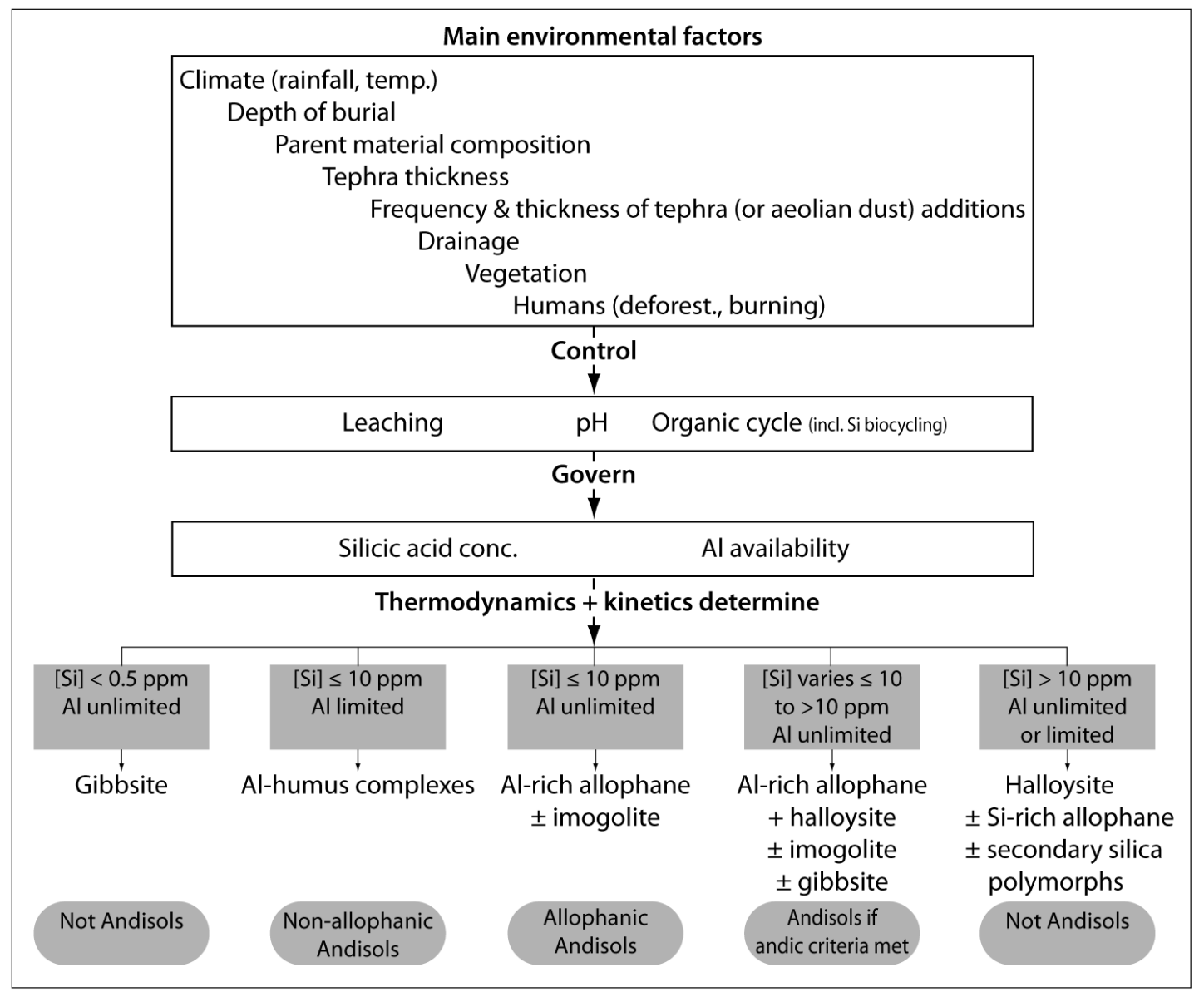

FIGURE 20.8 Environmental influences and controls that govern the critical conditions leading to the formation of different clays from the weathering of tephras, and the likely occurrence or not of Andisols as a result. \pm indicates that the clay mentioned may also be present. (Modified after Lowe, D.J. 1986. Controls on the rates of weathering and clay mineral genesis in air fall tephras: A review and New Zealand case study, p. 265- 330. In S.M. Colman and D.P. Dethier (eds.) Rates of chemical weathering of rocks and minerals. Academic Press, Orlando, FL; Lowe, D.J. 1995. Teaching clays: From ashes to allophane, p. 19-23. In G.J. Churchman, R.W. Fitzpatrick, and R.A. Eggleton (eds.) Clays: Controlling the environment. Proc. 10th lnt. Clay Con f., 18-23 July 1993, Adelaide, Australia. CSIRO Publishing, Melbourne, Australia.) 
Lowe (1986; 1995) and Lowe and Percival (1993) summarized data on the critical conditions for the formation of each of the main products of the weathering of volcanic ash. These are given in Figure 20.8, which also shows if Andisols are likely to formed, and if they are of the allophanic or Al-humus (nonallophanic) type (McDaniel et al., 2012, this volume, Chapter 33.3).

A consideration of rates of chemical processes brings in the question of kinetics. Examples of kinetic studies dealing with the dissolution of glass in tephras and associated soils include those of Hodder et al. $(1990,1996)$ for rhyolitic tephras, Ruxton (1988) and Neall (1977) for dacitic and andesitic tephras, respectively, and Gislason and Oeklers (2003), Ziegler et al. (2003), Wolff-Boenisch et al. (2004), Shikazono et al. (2005), and Sigfusson et al. (2008) for basaltic tephras or lavas. Generally, basaltic and intermediate (andesitic, dacitic) tephras, with lower Si contents, tend to weather more readily than rhyolitic tephras, but in all cases glasses weather very quickly as noted earlier (Kirkman and McHardy, 1980; Wolff-Boenisch et al., 2004). Compared with hard rock, the fragmental tephra components, especially vesicular glass and pumice, have a much greater surface area and high porosity and permeability, and so break down to constituent compounds very readily (Wolff-Boenish et al., 2004).

Ziegler et al. (2003) suggested that kinetics controlled the formation of allophane and halloysite in arid soils on the basis of their work on a chronosequence of Hawaiian soils on basaltic lavas (with ash overlying lava in one case) in arid conditions (MAP 180-225 mm). Thermodynamics do not control the composition of soils unless soil solutions remain in contact with the mineral surfaces until equilibrium is reached. Where this does not occur, such as under arid conditions, kinetic factors control the soil system (Ziegler et al., 2003). Clay mineral synthesis in the Hawaiian arid-zone chronosequence was thus shown by Ziegler et al. (2003) to be controlled by the kinetics of soil drying, rather than thermodynamics, so that halloysite was the favored aluminosilicate end product with the formation of smectite inhibited by kinetic factors (and a lack of micas to "fuel" the dominant pathway for smectite formation; Chadwick et al., 2003). In Cameroon, the depth distributions of 0.7 and $1 \mathrm{~nm}$ halloysite in soils developed on weathered nephenilite lavas were able to be related to both kinetic and thermodynamic factors by Etame et al. (2009). That Si concentrations increased with depth in the profiles while $\mathrm{Al}$ remained relatively constant, and $1 \mathrm{~nm}$ halloysite occurred exclusively in lower horizons whereas both $0.7 \mathrm{~nm}$ and $1 \mathrm{~nm}$ halloysite were present in upper horizons, led Etame et al. (2009) to two suggestions. First, the $1 \mathrm{~nm}$ halloysite formation was 
controlled by direct precipitation from $\mathrm{Si}$-Al-rich solutions (released from the weathering of primary minerals) and, therefore, the availability of Si was the only factor that controlled its formation at the base of the profile. Second, the presence of both forms of halloysite in the upper parts of the profiles implied that kinetics, hence time, controlled the evolution of halloysite through wet-dry seasonality, aided by the thermodynamically favorable factor of the availability of Si (Etame et al., 2009). In tropical Costa Rica, the predominance of $1.0 \mathrm{~nm}$ over $0.7 \mathrm{~nm}$ halloysite in the wetter, lower subsoil horizons of profiles studied by Kleber et al. (2007) was attributed to Si enrichment by percolating waters (i.e., mainly for kinetic reasons).

Returning to the question of whether it is time (Fieldes, 1955) or solution concentration/activity, particularly of Si (Parfitt et al., 1983, 1984), that governs whether or not allophane or halloysite persists in soils from volcanic parent materials (leaving aside Alhumus complexing), it may be said that, while the evidence is very strongly in favor of solution conditions determining the nature of the minerals formed, the passage of time also appears to enhance halloysite formation at the expense of allophane via the so-called Ostwald ripening process (e.g., Chadwick and Chorover, 2001; Dahlgren et al., 2004; Rasmussen et al., 2007). This direction of change is consistent with the thermodynamic stabilities of the two mineral types (see, e.g., Figure 1.11 in Churchman, 2000). Structural considerations, however, mean that an Al-rich allophane, with isolated tetrahedra on the inside of a spherule of coiled gibbsite-like sheets cannot transform in the solid state into halloysite, where sheets of linked silica tetrahedra are generally coiled around alumina octahedra, and hence are in the opposite conformation one to each other as in the allophane spherule. Therefore dissolution and recrystallization must be involved in the change from allophane to halloysite.

Nonetheless, it is likely that the passage of time effects other changes which affect the environment in which mineral alteration and formation take place, so that conditions that favor the formation of allophane early in the weathering process change to those favoring halloysite formation. Most often in upbuilding terrains this comes about through an increase in [Si], which may result from a build-up of overburden through ongoing tephra deposition, or the development of impediments to efficient drainage (e.g., Cronin et al., 1996). Another possible change may be towards a drier climate, so that there is less throughflow of water and hence a buildup of $\mathrm{Si}$ in solution. An alternative situation is that reported by Chadwick and Chorover (2001) for a Hawaiian chronosequence on basaltic lavas and ash deposits not subject to ongoing burial by later eruptives. There, the ongoing depletion of [Si] and increase 
in $\left[\mathrm{H}^{+}\right]$under high rainfall after ca. 400,000 years eventually led to the formation of more stable kaolin (halloysite and kaolinite) and gibbsite. Previously, conditions had apparently favored the formation of allophane. Chadwick and Chorover (2001) noted that [Al] in solution also declined over time, a result that follows from increasing crystallinity and decreasing solubility of gibbsite and kaolin in the soil. Inconsistencies between observed soil mineral composition and stability-field plots of solution chemistry data are evidence of kinetic limitations to mineral transformations according to Chadwick and Chorover (2001), who also noted that such discrepancies can be resolved through consideration of mineral transformation rates and Ostwald ripening processes but that the requisite kinetic data are often lacking.

In considering longer time scales of glacial and interglacial cycles in temperate volcanic landscapes not directly glacierised, the marine oxygen isotope records show that cooler and drier conditions associated with glaciations persisted $\sim 80-90 \%$ of the time whereas warmer and wetter conditions associated with interglaciations occurred for $\sim 10-20 \%$ of the time. In these landscapes where long sequences are well preserved, therefore, it might be expected that soils developed from accumulations of weathered tephras of similar composition dating back several hundreds of thousands of years to one or two millions of years should be dominated by halloysite rather than allophane (e.g., as evident in the socalled Kauroa and Hamilton ash tephra sequences in northern New Zealand that date back to ca. 2.3 Ma; Lowe and Percival, 1993; Lowe et al., 2001).

Overall, the relationship between the minerals formed from volcanic parent materials (especially tephra) and solution [Si], as it is affected by the throughflow of water and given appropriate kinetic circumstances, can be expressed by Box 20.3:

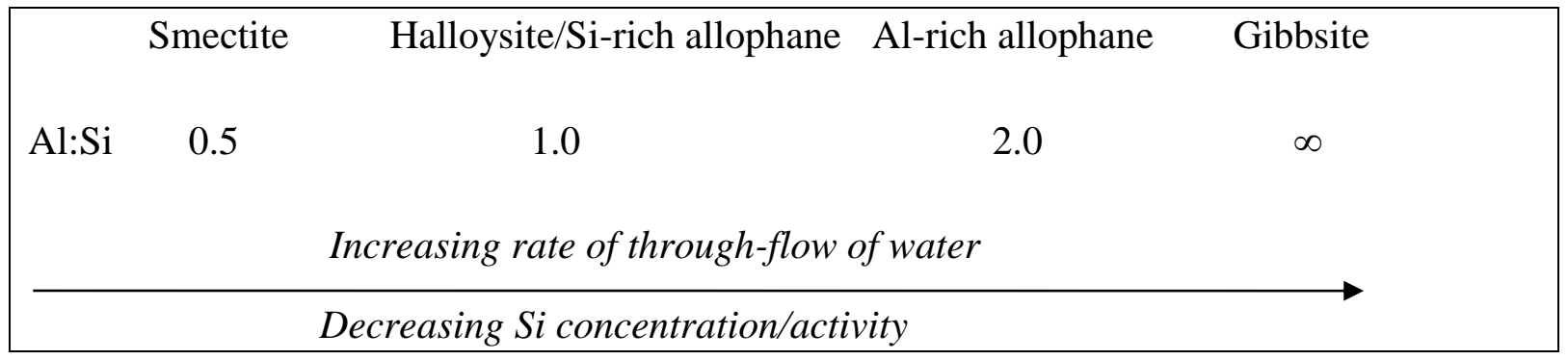

Box 20.3 Relationship between throughflow of water, Si concentration, and types of clays formed from volcanic parent materials 
We note in addition that allophane can be formed in a range of non-volcanic materials through strong leaching and acid conditions, as occur, for example, in loess in upland areas of southern New Zealand (e.g., Eger and Hewitt, 2008), and as a result of podzolization (see Section 20.2.5.3).

Parallel to the alteration of aluminosilicate minerals and the formation of allophane, halloysite and perhaps also gibbsite or smectites, iron is also lost from parent Fe-bearing minerals and incorporated into secondary solid phases. Ferrihydrite forms early in the process of weathering of volcanic parent materials from the precipitation and oxidation to $\mathrm{Fe}(\mathrm{III})$ of soluble $\mathrm{Fe}(\mathrm{II})$ that had been released into solution from volcanic glass and also feldspars and mafic minerals (e.g., McDaniel et al., 2012, Chapter 33.3). It is the presence of other species in solution such as silicate and phosphate ions and soluble organic compounds that inhibit the formation of the more crystalline forms of iron, such as goethite and hematite (e.g., Childs, 1992; Bigham et al., 2002). However, the type of iron oxide that is formed is a function of the same environmental conditions that also affect which particular aluminosilicates are formed in volcanogenic soils. Hence, in young soils on andesitic mudflows, the build-up of ferrihydrite with time paralleled that of allophane, albeit that the amount of allophane formed was $\sim 10$ times or more than that of ferrihydrite (Lilienfein et al., 2003). In a chronosequence of soils in the humid tropics, Niewenhuyse et al. (2000) found that Fe occurred mainly as Fehumus in the two younger soils, especially in their A horizons, but also as ferrihydrite, especially at depth, whereas it occurred mainly as goethite throughout the oldest soil in the sequence. Further, the iron oxides in soils in a xeric moisture regime that contain all of gibbsite, imogolite and/or Al-rich allophane and halloysite as aluminosilicates, were dominantly highly crystalline - they were mainly goethite, reflecting strong seasonal drying (Takahasi et al., 1993). Soils in a toposequence on andesitic lahar deposits covering a range of climatic zones generally showed a similar pattern to that for the aluminosilicates, with poorly crystalline forms giving a high oxalate-Fe analysis dominant in soils at higher altititudes and more crystalline forms giving a high dithionite-Fe analyisis in soils at lower altitudes (Rasmsussen et al., 2007). There was a further subtlety with Fe analyses, however, insofar as the proportion of oxalate-Fe to dithionite-Fe rose again at the lowest altitude, where the MAP was also lowest. In this drier zone, less leaching probably led to higher retention of $\mathrm{Si}$ in soil solution, which would inhibit Fe oxide crystallization (Rasmussen et al., 2007). 


\subsection{The special case of "palagonite"}

In the volcanic and geochemical literature especially, the term "palagonite" is widely used to describe the first stable product of basaltic volcanic glass alteration (e.g., Fisher and Schminke, 1984; Cas and Wright, 1987; Daux et al., 1994). Palagonite has also been described in the clay science literature but uncommonly (e.g., Singer and Banin, 1990; Drief and Schiffman, 2004) and it thus deserves some attention here. As reviewed by Stroncik and Schminke (2002), palagonite (named after the location Palagonia in Sicily) is a heterogeneous substance, usually with highly variable optical and structural properties ranging from a clear, transparent, isotropic, smooth and often concentrically banded material, commonly called "gel-palagonite", to a translucent, anisotropic, slightly to strongly birefringent material of fibrous, lath-like or granular structure, commonly called "fibropalagonite". It ranges in color from yellowish to shades of brown. Since it was first defined in 1845 as a new mineral, palagonite has been interpreted in numerous studies to be a heterogenous material composed variously of different aluminosilicate clays, zeolites, and oxides, or mixtures of these. Based on XRD, HRTEM, atomic-force microscopy (AFM), and electron microprobe analyses, palagonite is now interpreted by most to be composed of a variety of smectites and very minor amounts, if any, of zeolites and oxides (Stroncik and Schminke, 2002). At more advanced stages of alteration, other secondary phases are known to form following Ostwald "ripening" processes.

Palagonite evidently comprises spherical structures 20 to $60 \mathrm{~nm}$ in diameter which have been interpreted as "microcrystallite precursors of smectite" (Stroncik and Schminke, $2002)$ - that is, palagonite would seem to be a nanocrystalline variety of smectite(s). Drief and Schiffman (2004) identified an Fe-rich montmorillonite-like composition in their study on Hawaiian basaltic deposits. The atomic structure of palagonite and, especially, its structural evolution, are not yet fully understood, but both are important to glass-alteration rates and to the evolution of the whole water-rock-soil system (Stroncik and Schminke, 2001). Because kinetic and thermodynamic modeling and mass-balance calculations necessitate exact differentiation of all the secondary products developing during alteration, the term "palagonite" should be used only for the hydrous nanocrystalline alteration product ("gel-palagonite"), not for the long-range-ordered crystalline material evolving from the palagonite itself (Stroncik and Schmincke, 2001, 2002).

So-called "palagonitization" of basaltic volcanic glass is a continuous process of glass dissolution and palagonite formation and evolution, which, according to Stroncik and Schminke (2001), can be subdivided into two different reaction stages with changing element 
mobilities. Stage 1 is the congruent hydration and dissolution of thermodynamically unstable glass and contemporaneous precipitation of "fresh," gel-like, amorphous (or nanocrystalline), optically isotropic, mainly yellowish palagonite. This stage, kinetically controlled and consistent with the models of Hodder et al. (1990, 1993), is accompanied by the loss of $\mathrm{Si}$, $\mathrm{Al}, \mathrm{Mg}, \mathrm{Ca}, \mathrm{Na}$, and $\mathrm{K}$, active enrichment (gain) of $\mathrm{H}_{2} \mathrm{O}$, and the passive enrichment ("default" accumulation relative to other elements) of Ti and Fe. Stage 2 is an aging process during which the thermodynamically unstable palagonite reacts with the surrounding fluid and crystallizes to smectite. This stage is accompanied by uptake of $\mathrm{Si}, \mathrm{Al}, \mathrm{Mg}$, and $\mathrm{K}$ from solution and the loss of $\mathrm{Ti}$ and $\mathrm{H}_{2} \mathrm{O}$. $\mathrm{Ca}$ and $\mathrm{Na}$ are still showing losses, whereas Fe reacts less consistently, remaining either unchanged or showing losses (Stroncik and Schminke, 2001, 2002).

\subsubsection{Peculiarities of processes and products of alteration by weathering in soils}

Much - although not all - of the information on the processes and products of alteration of primary minerals by weathering that is summarized in the preceding Section 20.2.4 comes from observations of rocks or geological deposits, minerals associated with these materials, and saprolites deep within soil profiles. However, soil profiles can encompass a range of conditions, from fragmented, almost abiotic, rock through to organic-rich material containing a great variety of microbial, faunal, and also plant life. The different parts of soil profiles represent different regimes for water, from abundant and mobile to scarce and largely immobile, so studies of some nonsoil situations where each of these prevail are relevant to weathering in some parts of soils but not to others. Most soils have a significant biological input, at least in their surface layers, and, therefore, the biological factor in mineral alteration and formation tends to play a larger role in the genesis of soil minerals than in those from rocks subject to largely abiotic weathering. Furthermore, some processes, notably podzolization, occur within permeable soils but not in impermeable rocks under certain environmental conditions and deserve particular attention. In addition, soils can be further developed even following the depletion of easily weatherable rock-derived minerals. Secondary minerals can themselves be altered and new phases formed. Each of these particular aspects of mineral development in soils will be discussed in the following sections. 


\subsubsection{The effect of position within soil profiles on hard rock}

In a recent review, Wilson (2004) showed that position in the weathering profile on indurated rock has a crucial influence on the nature of the environment for weathering and hence on the processes involved and products formed, as well as the rates at which changes occur. Note that modified models are required for soils formed on unconsolidated materials or, especially, those developed through upbuilding pedogenesis. Following Delvigne (1998), a fully developed weathering profile comprises a soil, which is delineated (in a straightforward case) into A and B horizons (solum) and usually C or CR horizons comprising saprolite/alterite, which consists of completely disaggregated rock grading to the rock base, with fabric and texture changing with depth. At the base of the whole profile is the (partly) weathered rock ( $\mathrm{R}$ horizon), which may be hard and coherent but also incorporates fractures and fissures. Among other features, an increase in surface area characterizes the upward change from the rock to the solum (Hochella and Banfield, 1995).

There is also be a trend of decreasing porosity and permeability from soil down to rock, so that water can flow quite freely within the soil, but can be either stagnant or held in capillaries in the rock. Hence there is a much greater chance of an equilibrium being established between the minerals and the largely immobile solution within the rock, than between the minerals and the highly dynamic water in the soils zone.

Following Velde and Meunier (2008), we note that alteration within the rock proceeds in microsystems. Meunier and Velde (1979) followed the alteration of granites by weathering through developments occurring at the scale of microsites. The system is highly heterogeneous at this fine scale; grains of the primary minerals, muscovite, orthoclase, and biotite each give rise to multiphase assemblages upon alteration. Alteration of the whole mineral assemblage appears to take place in three stages. In the first stage, alkalis are lost but the $\mathrm{Si}: \mathrm{Al}$ ratio is preserved as illitic mica, beidellite, and vermiculite are variously formed. The second stage involves a loss of both alkalis and silica, with kaolinite and oxides resulting. The authors surmised that there is a third stage where quartz is dissolved, leaving only oxides, but not silica. This last stage is seen in tropical weathering. The processes of in situ alteration of ferromagnesian minerals to smectites and of feldspars to illite that were studied by Eggleton and co-workers and Banfield and co-workers, among others, and cited in Section 20.2.4 herein, also occur within microsites where the physical constraints as well as the chemical availability of reagents limit the reactions that can take place. In a particularly 
close study of microsites within one mineral type (amphibole) on weathering, Proust et al. (2006) found that montmorillonite formed on the (001) amphibole face, and saponite on the (110) face, while the sawtooth (001) face fracture surface hosted a kaolinite-smectite and, with time, also halloysite and montmorillonite. The establishment of local equilibria may occur at different sites, within both a single crystal, as in the amphibole studied by Proust et al. (2006), and also within different fractures and fissures in a rock (see the diagrammatic representation for granite in Figure 4.19 of Velde and Meunier, 2008). Within microsites where secondary products remain in close proximity to host primary minerals, reactions may even occur between product and host minerals (Velde and Meunier, 2008). As a result, vermiculite may form by recystallization in a microsite from the dissolution products of the adjacent secondary minerals, saponite or Fe-beidellite and their primary pre-cursor, amphibole for one example (Velde and Meunier, 2008). For another example (Velde and Meunier, 2008), product smectite and host K-feldspar may react together to give rise to illite and kaolinite.

The solid: solution ratio is very high in hard rocks that remain coherent yet contain small fractures and fissures. By great contrast, the solid: solution ratio in the solum or unconsolidated geological deposits within the weathering profile is likely to be both very low and quite variable on both a daily and seasonal basis, except in special circumstances, e.g., in a desert or frozen soil. The dynamic nature of soils alone ensures that the possibility of predicting the course of weathering via stability diagrams for the component clay minerals (e.g., Kittrick, 1967) cannot be realised. Minerals awash in the dynamic water phase in soils almost certainly remain well out of equilibrium with those solutions (Chadwick and Chorover, 2001; Wilson, 2004). However, those formed in microsites within weathering rocks deeper in the weathering profile may not appear in bulk analyses of soils above the weathering rock. In particular, trioctahedral smectites formed during early stages of alteration are rarely reported in soils. Either they are unstable in the soil environment (Wilson, 2004) or they are present in only vanishingly small concentrations (Proust et al., 2006), or both.

\subsubsection{Weathering in the absence or shortfalls of water}

Generally on Earth, weathering occurs because there is sufficient - and usually an excess - of water to effect alteration of primary minerals and either transformation to related secondary 
phases or neogenesis of new (secondary) minerals. However, mineral alteration and formation are also observed to occur where there is little, or no, water. Studies in the normally frozen Antarctic have shown clear evidence for chemical weathering occurring there. As well as salts such as gypsum and sodium sulfate formed by recrystallization from elements leached from rocks by occasional (liquid) water, abundant iron oxides also occur (Claridge, 1965). Furthermore, clay minerals occur - most commonly transformation products of micas such as vermiculites, but also montmorillonite. This last mineral was thought to form in the arid and highly alkaline environment by similar processes to those seen in other terrestrial environments, but occurring at a much slower rate (Claridge, 1965). Some, but not all, clay minerals in Antarctic soils could be inherited from other land masses to the north (e.g., dust blown from southern South America: Delmonte et al., 2004). Boyer (1975) collected weathering products such as rinds on rocks from part of Antarctica and identified various 2:1 minerals, including chlorite-vermiculite and also identified montmorillonite. These products all indicated that chemical weathering had taken place. In the arid Sahel in west Africa, Ducloux et al. (2002) identified beidellite, kaolinite, and mica in soils. They concluded that these minerals formed by a process called "xerolysis", whereby dessication in a hot climate leads to protons from dissociated water reacting with crystalline minerals to produce secondary products.

The new frontier for clay mineralogy is outer space, and especially other planets in our solar system, and there has been a particular focus on Mars from a clay mineralogical viewpoint quite recently. Earlier exploration of Mars involved fly-bys, with spectra being used to identify materials on the Martian surface by remote sensing. These data could have been interpreted to indicate the presence of some phyllosilicates (Hamilton et al., 2003), but the evidence was equivocal. The collection of samples by Exploration Rover from the planet's surface showed that the ferric sulphate, jarosite, which is commonly associated with acid-sulfate soils on Earth (see next Section 20. 2.5.34.), and also possible relicts of gypsum at the Meridian Planum landing site (Madden et al., 2004). Other work on samples from a number of different locations on the planet has confirmed the widespread occurrence of secondary sulfates and also iron oxides (Hurowitz and McLennan, 2007). Hurowitz and McLennan (2007) considered that they originated from altered olivines in Martian rocks. These various localised occurrences of sulfates and iron oxides were compared with the results of a general survey of most of the surface of Mars that was carried out by an image spectrometer during an aerial survey of the planet (Poulet et al., 2005). The survey had 
earlier identified sulfates in localities in addition to those reported by Madden et al. (2004) and Hurowitz and McLennan (2007), but Poulet et al. (2005) also identified phyllosilicates in several localities, albeit that their distribution was quite heterogeneous. They included Fe/Mg smectites in some areas and montmorillonite in others. These occurrences suggested that there had been water in some localities on Mars, in order to alter basaltic and similar rocks to give phyllosilicates, although the sulfates derive from a different, more acidic, environment. More recent work (e.g., Bishop et al., 2008; Mustard et al., 2008; Ehlmann et al., 2009) has identified phyllosilicates in a number of localties on the surface of Mars. The discovery of phyllosilicates has aided our understanding of the climatic history of Mars (Newsom, 2005; Poulet et al., 2005). On Earth, meteorites considered to have come from Mars have been studied for their mineralogy, and iddingsite, comprising a mixture of smectites, iron oxides, and silica, has been identified on the altered surfaces and in the veins of the meteorites (Wentworth et al., 2005). These authors drew an analogy between mineral alteration and formation that has taken place on Mars with that which has occurred - and is occurring - in the Dry Valleys of Antarctica. Examined at the submicroscopic scale, the patterns of alteration of primary silicates, e.g., amphiboles and pyroxenes, were similar in an Antarctic Dry Valley (Wright Valley) and in the Mars meteorites (Wentworth et al., 2005). In addition, soils in the Dry Valleys contain evaporated salts at their surfaces, as have been seen in soils on Mars. In both of these arid situations, alteration processes and their products are distributed heterogeneously, indicating an uneven distribution of water available for the alteration and subsequent formation of minerals, both in space (in the Antarctic Dry Valleys) and time (in the Martian past).

\subsubsection{Biota as important agents in mineral alteration and formation}

It has long been recognised, including by the pioneers in pedology, e.g., V.V. Dokuchaev and Hans Jenny, that biota play an important, sometimes dominant, role as one of the agents in the development of soils from rocks and other geological materials. Plants, animals and microbes share an equivalent status to parent materials, climate, topography, and time as soilforming factors. Therefore it comes as no surprise to find that biota in their different forms have been found to play a major role in the alteration of primary minerals and the formation of secondary clay minerals. 
Even so, it is arguable that the role of biota in the formation of clay minerals has been relatively neglected in comparison with those of other soil forming factors, such as parent materials and climate. Churchman (2000) noted that studies of the alteration and formation of minerals had largely concentrated on processes involving inorganic agents, while observing that there had been an upsurge in studies of the role played by biological and biochemical agents in the previous decade. The effect of these agents on weathering changes is now one of the more active areas of research on mineral alteration and formation in relation to soils (e.g., Dong et al., 2009).

\subsection{Plants as weathering agents}

Plants have been shown to be important weathering agents. Mortland et al. (1956), Hinsinger et al. (1992; 1993), and Hinsinger and Jaillard (1993) showed that trioctahedral micas in soils lost potassium from their interlayers as a result of the growth of plants in the soils. In general, this process is that of vermiculitization (or the formation of beidellitic smectites) (Section 20.2.4.3). However, it generally occurs via mixed-layer randomly interstratified species. In soils, illite-smectites are the most common form of these (Velde and Meunier, 2008). Indeed, since this type of clay mineral is not found in buried sediments or rocks, it is peculiar to the soil environment, according to these authors. Furthermore, it is found particularly in the A and B horizons of soils (the solum), confirming its origin in surface alteration processes (ibid.). Although plants, in general, are the main agents of alteration of trioctahedral micas to produce illite-smectites, Velde and Meunier (2008) summarized observations in the literature to conclude that prairie soils (Mollisols) dominated by grasses contain illite-smectite together with varying amounts of illite under different climate conditions. Even though vermiculites are rare in prairie soils, they can occur in significant amounts in young mountain soils according to Velde and Meunier (2008). Expanded (to vermiculite or smectite), and partially expanded (to mixed layer illite-smectite) products occur, and these often acquire Al-hydroxy interlayers (see Section 20.2.4.3) under forest (Velde and Meunier, 2008). It was the development of a method of XRD peak decomposition by Lanson (1997) that enabled the detection of some of these mineral changes attributable to plants, which can be subtle.

Acidification can be an important effect of plant growth and consequently can play an important role in alteration by weathering. Protons are released into soil solutions to balance 
the overall charge when roots take up more cations than anions (e.g., Hinsinger et al., 2001; Courchesne, 2006; Calvaruso et al., 2009). For some tree species, it is the uptake of $\mathrm{NH}_{4}{ }^{+}$in preference to $\mathrm{NO}_{3}{ }^{-}$by roots that ensures acidification, specifically in the rhizosphere (Calvaruso et al., 2009). Roots (and fungal hyphae tips as noted above) also exude organic acids into soils (Courchesne, 2006). More $\mathrm{Ca}, \mathrm{Na}, \mathrm{Mg}, \mathrm{Si}$, and especially Fe were released from leached basalt when plants were grown in the fresh rock than when there were no plants (Hinsinger et al., 2001). When soils within the rhizosphere of a Norway spruce and an oak were compared with the bulk soil, it was found that $\mathrm{Fe}$ and $\mathrm{Al}$, and therefore their "amorphous" (i.e. nanocrystalline) mineral phases, as well as Al-hydroxy interlayers in 2:1 Si:Al aluminosilicates, were dissolved as a result of acidification by the plant roots (Calvaruso et al., 2009). Forest soils in Taiwan showed a lack of hydroxyl-interlayering of 2:1 Si:Al aluminosilicates in the surface $\mathrm{O}, \mathrm{A}$, and $\mathrm{E}$ horizons but there was interlayering, which was shown to involve both $\mathrm{Al}$ and $\mathrm{Fe}$, in deeper horizons (Pai et al., 2004). It was thought that a low $\mathrm{pH}$ and possible chelation of $\mathrm{Al}$ and $\mathrm{Fe}$ by organic material, which was abundant in and on the surfaces of the soils, led to the clean interlayers in the expandable aluminosilicates near the surface, whereas the higher $\mathrm{pH}$ and lower organic contents in lower horizons were conducive to their formation in the clay minerals there (Pai et al., 2004). In a later study, Pai et al. (2007) found that acidification at the surface of forest soil elsewhere in Taiwan decreased the charge of the K-depleted aluminosilicate layers, which they characterized as vermiculite, occurring either as the discrete phase or in mixed-layers with vermiculite. In the North Island of New Zealand, Jongkind and Buurman (2006) found that weathering under kauri (Agathis australis) trees, which produce especially low pHs (4.0 \pm 0.2), left vermiculites depleted of hydroxyl interlayering and even brought about some conversion of vermiculite to smectite, as Churchman (1980) had found to occur in soils under another native beech tree species (Nothofagus sp.) in the South Island of New Zealand. By matching the rare-earth compositions of the silica particles found within the roots of ferns with those of aluminosilicate minerals in the soil surrounding the roots, Fu et al. (2002) have found strong evidence for the dissolution of clay minerals to leave deposits of silica following their incorporation into plant roots.

Plants can bring about very rapid changes in soil minerals (Turpault et al., 2008). A seasonal study by these authors showed that, in the rhizosphere close to tree roots, mineral dissolution, with loss of citrate-extractable $\mathrm{Al}$ and $\mathrm{Si}$, occurred in surface layers in spring because of enhanced biological activity. That some of the Al came from interlayers was shown in XRD by an increased ease of collapse of these upon K-saturation, and also an 
increase in cation exchange capacity (CEC). There was a corresponding migration of $\mathrm{Al}$ and Si to lower layers. Perceptible changes in the XRD patterns occurred within only three months.

\subsection{The special case of podzolization}

Organic compounds from the activities and decomposition of biota have long been thought responsible for extracting and transporting $\mathrm{Fe}$ and $\mathrm{Al}$ ions and incidentally producing new minerals from them in the process of podzolization (e.g., Russell, 1973), even if equally valid inorganic mechanisms have also been put forward for this process (e.g., Farmer et al., 1980; Wang et al., 1986), as will be discussed further.

Podzolization usually involves the intense leaching of parent materials and soils with acidic solutions. In podzolization, $\mathrm{Al}, \mathrm{Fe}, \mathrm{Mg}$, and $\mathrm{Si}$ are mobilised (e.g., Farmer, 1982; Farmer and Fraser, 1982; Farmer et al., 1983; Taylor, 1988; Churchman, 2000; Giesler et al., 2000). Podzolization can be contrasted with the processes, sometimes collectively referred to as "andosolization", involved in forming allophane and other andic soil materials mainly in tephra-derived soils (Section 20.2.4.6). Normally, allophane and other nanocrystalline clays are formed in situ during andosolization (even though the process typically requires desilication via leaching) whereas podzolization always involves the translocation of mobile constituents as organic or inorganic complexes, or both, from very acid horizons in the upper profile and subsequent immobilisation in lower horizons through an increase in $\mathrm{pH}$, via microbial action, or by adsorption, precipitation,etc. That such movement takes place has been confirmed by micromorphological studies (e.g., Farmer et al., 1980, 1983, 1985; Farmer and Lumsdon, 2001). Broadly speaking, the processes involved in podzolization are: (1) enhanced mineral weathering in upper A and E ("eluvial") horizons; (2) transport of Al, Fe, and $\mathrm{Si}$ and probably also organic matter from upper horizons to lower B horizons - either in metal-organic complexes (chelates) or as independent inorganic complexes including "protoimogolite sols", and as independent organic complexes; and (3) deposition of the $\mathrm{Al}$ and Fe as oxides, together usually with allophane, from (according to Farmer et al., 1985) a mixed $\mathrm{Al}_{2} \mathrm{O}_{3}-\mathrm{Fe}_{2} \mathrm{O}_{3}-\mathrm{SiO}_{2}-\mathrm{H}_{2} \mathrm{O}$ sol, in so-called illuvial Bs horizons.

There have been a number of theories put forward to explain the changes that take place in soils as a result of podzolization (see Churchman, 2000, for proponents and arguments involved in earlier discussions, and elsewhere in this handbook). Briefly, these 
can be grouped into two main hypotheses, both of which may apply to some degree depending on site-specific soil environments (e.g., Wang et al., 1986; Lundström et al., 2000): (1) the organic or "fulvate" hypothesis and (2) the inorganic or "proto-imogolite" hypothesis. A third is the so-called rock-eating fungi hypothesis, which is associated with mycorrhizal fungi found in many soils under pines and heaths commonly in parts of Europe and Scandinavia and elsewhere (Jongmans et al., 1997; van Breemen et al., 2000b). The fungal hyphal tips, which produce organic acids (e.g., citric or oxalic), "drill” directly into mineral grains, including feldspars, thereby bypassing the external acid soil solution, and hence the E horizon is regarded as the fungal "eaten" part of the soil.

An eccentric view is that of Do Nascimento et al. (2004, p.536) who have described podzolization as a deferralitization process whereby the chemical elements that had accumulated during ferralitization are "progressively exported towards the drainage network under the combined effects of waterlogging, organic matter accumulation and lateral subsurface and surface water flows”. In a somewhat related study, Lucas (2001) compared the dynamics operating in podzols with those in ferralsols (Oxisols) regarding the rates of $\mathrm{Si}$ recycling (including storage as phytoliths) by plants and the rates of loss, by leaching, of Si and organometallic complexes involving $\mathrm{Al}, \mathrm{Fe}$, and organic matter. This author concluded that the main constituents of the "weathering mantle" ultimately depended on the balance between (1) the stability of the clay minerals, sustained by the plant Si cycling, and (2) the leaching of plant-induced organo-Al compounds. These findings were evident in equatorial areas where old soils are markedly affected by biological activity, and they were also seen in temperate areas (Lucas, 2001).

After reviewing the literature, Lundström et al. (2000) concluded that organic complexes were important in both the weathering and deposition (or immobilization) processes and Jansen et al. (2005) also decided, on experimental grounds, that organic matter played an important role in the transport of $\mathrm{Al}$ and $\mathrm{Fe}$ down profiles to create illuvial horizons, at least in podzols in The Netherlands and similar climatic zones, while conceding that podzols may form by slightly different mechanisms in both cooler and warmer climatic zones. Contrary views are evident in, for example, Farmer and Lumsdon (2001) who argued that "fulvic acid plays no active role in podzolization, but only recycles $\mathrm{Al}$ and $\mathrm{Fe}$, that has been transferred by biological processes to the O horizon, back to the Bh horizon" (p. 177). Buurman and Jongmans (2005) proposed that podzolization in boreal zones, on nutrient-rich parent materials at high latitudes and high altitudes, hence cold climates, occurred with organic matter (OM) dynamics that led to little accumulation of OM (so-called "fast" OM 
dynamics), and. Hence, illuvial B horizons were dominantly inorganic. These authors proposed an alternative route for podzolization in hydromorphic situations on nutrient-poor parent materials, including in warmer climates, where OM dynamics were "slow", by their nomenclature, and would lead to organic-rich illuvial horizons.

Regardless of mechanism, podzolization leads to essentially two compartments of the soils according to their weathering status and the nature of the secondary phases (Ugolini et al., 1991). These are (1) the upper horizons, and especially the distinct eluvial (or "fungal eaten") E horizon, and (2) the taxonomically diagnostic lower illuvial horizons, and especially the equally distinct Bh and Bs horizons. (Both or only one of the Bh or Bs may be present in podzol soils.) Considerable recent effort has been expended into studying the early stages of podzolization, largely in soils in the boreal zone, namely, under forests, in northern and/or alpine Europe, from a mineralogical viewpoint (Melkerud et al., 2000; Mossin et al., 2002; Mokma et al., 2004). Mokma et al. (2004), tracing the earliest stages of podzolization in sandy soils in Finland, found visual evidence for translocation of $\mathrm{C}, \mathrm{Al}$, and $\mathrm{Fe}$ after 230 years of soil formation while there was evidence of allophane in a Bs horizon after 900 years. There were few differences between the crystalline minerals in the soils of different ages (up to 11,300 years). Buried podzol profiles in northern New Zealand exhibit thin E, Bh, and Bs horizons (about 20, 2, and $5 \mathrm{~cm}$ in thickness, respectively) formed on a pumiceous rhyolitic tephra layer deposited in ca. 232 AD. The Bs horizons contain allophane. The developing podzols were subsequently buried in ca. $1314 \mathrm{AD}$ by deposition of another rhyolitic tephra (Lowe, 2008). The profiles thus reflect about 1082 years of podzolization under $\sim 1500 \mathrm{~mm}$ annual rainfall in a mesic temperature regime under broadleaf-podocarp forest.

In three soils on Quaternary deposits in Fennoscandia, Melkerud et al. (2000) found that the most easily weatherable primary minerals, biotite, chlorite, and hornblende, were depleted from the eluvial horizon, which had the highest concentration of quartz. Vermiculite dominated the clay mineralogy of the E horizons and was also present, but with incorporated Al-hydroxy interlayers, in the B horizon, where poorly-ordered or nanocrystalline imogolite-type materials (i.e., allophane) also occurred. Mossin et al. (2002) specifically searched for imogolite in three Danish podzols. Some proto-imogolite allophane rather than imogolite per se was found, but in smaller amounts than had been found in podzols further north in Scandinavia and not at all under spruce, which was responsible for the lowest $\mathrm{pH}$ for the soils. They ascribed the generally relatively lower contents of allophane to a lower $\mathrm{pH}$, an increase in organic matter, and a parent material with a low 
content of easily weatherable minerals. The $\mathrm{pH}$ conditions and other factors such as aluminum extractability and solubility are important in explaining the differences in composition in different parts of the podzol profile (e.g., Zysset et al., 1999; Lundström et al., 2000; Farmer and Lumsdon, 2001).

Recently, several other authors have particularly examined the effect that the podzolization, namely acid leaching, process has had upon micaceous clay minerals. The results of some earlier studies of this kind are discussed in Section 20.2.4.3 and also earlier in this section herein and in Churchman (2000). While the general consensus from earlier studies was that beidellitic smectites are often identified as a stable phase, if not an end product, of the alterations of micaceous minerals that take place in podzol E horizons as a result of eluviation, Righi et al. (1999), Gillot et al. (2001), Mirabella and Egli (2003), and also Egli et al. (2004) have all found that the smectites that form in this way can be quite complex. They constitute a mixture of several populations with various layer charges (Gillot et al., 2001). A chronosequence of soils in Finland enabled these last authors to find that the products of mica transformation included both a relatively high-charge ferromagnesian smectite and also a vermiculite with higher charge in younger soils. They thought that the Fe-Mg smectite arose from the transformation of the ferromagnesian primary mineral biotite, and from Fe-Mg-bearing chlorite present in the rocks, whereas the vermiculite, which was aluminous, was a transformation product of dioctahedral micas (muscovite and phengite). In older soils, smectites with a lower charge resulted from both the dissolution of the higher charged trioctahedral smectites and also a progressive decrease in the charge of the dioctahedral expanded phases (Gillot et al., 2001). Righi et al. (1999) found the nature of the aluminosilicate products of podzolization in the eluvial A and $\mathrm{E}$ horizons differed from those in the B horizons within a different chronosequence of soils. The A and E (eluvial) horizons contained a mixed layer mica-smectite, and, given time, also discrete smectite, from the transformation of dioctahedral mica. The B (illuvial) horizons, by contrast, contained mixed layered mica-vermiculite and smectite. These last clays were the products of the alteration by transformation of trioctahedral minerals, notably biotite and chlorite (Righi et al., 1999). These authors explained the differences between the transformational products by a difference in the nature of the acids involved as weathering agents in the two different parts (or compartments) of the soil profile. In the upper, eluvial compartment, organic acids are responsible for the mineralogical changes and these are more aggressive than the carbonic acid in the lower compartment, which includes the illuvial horizons (Righi et al., 1999). It is 
only in the upper compartment that dioctahedral minerals become altered and the organic acids responsible for the alteration there dissolve the products of weathering of the trioctahedral minerals. Their dissolution leads to phases that are translocated to the illuvial $\mathrm{Bh}$ and Bs horizons where they accumulate as "amorphous" (i.e., probably nanocrystalline) Fe and Al oxides and as re-crystallized gibbsite in these particular soils (Righi et al., 1999). Studying an altitudinal sequence of five podzolized soils in Italian alpine regions, Mirabella and Egli (2003) also found that the smectites formed in either eluvial or illuvial horizons were highly heterogeneous, mostly comprising mixtures of montmorillonite with interstratified beidellite-montmorillonite, but never consisting of beidellite alone. Some were interlayered with hydroxy-Al species, which needed to be removed by citrate treatment before the underlying phases could be distinguished, but their removal showed that the specific expandable micaceous phases with their variety of layer charges had been formed prior to interlayering (Mirabella and Egli, 2003). The most intense weathering, leading to the lowest charged smectites, occurred in podzols below the tree line but closest to it. Clearly in many of these studies, certain trees are a major factor in the intensification of the podzolization process, if not in its occurrence, in some environments. Churchman (1980) also found that, although podzolization could occur under grasslands provided the rainfall was sufficiently high, the mineralogical changes to micaceous phases were more advanced in soils which were just a few metres away, but which were below the tree line. In the podzols under grassland on both mica-chlorite schist and greywacke lithologies, regularly intertstratified mica-beidellite dominated the clay fractions and there was no discrete beidellite present, but discrete beidellite occurred in substantial amounts in podzols under native Nothofagus beech forest in New Zealand (Churchman, 1980).

Although beidellitic smectites appear to constitute a stable phase in podzols formed in boreal zones, there can be a sequence of products formed at different stages during the podzolization process, as discussed by, for example, Churchman (2000), and also by Righi et al. (1999). Studying seven podzol profiles in the Tatra Mountains in Poland, Skiba (2007) has concentrated on the alteration processes of dioctahedral micas within all parts of these soils. This author found a variety of transformational products of dioctahedral micas that varied in the regularity of ordering of their interstratifications with (at first) vermiculites, in the expandability of the vermiculites formed, both as interstratified layers and also as discrete phases, and in the degree of interlayering of vermiculites with smectite, leading ultimately to a discrete smectite phase. Many of these also exhibited interlayering with hydroxy-Al 
species when $\mathrm{pH}$ was $\geq 4$.4. Skiba (2007) also claimed that kaolinite formed neogenetically in these podzols from $\mathrm{Al}$ and $\mathrm{Si}$ released by weathering.

Three podzols forming in tropical and sub-tropical climatic zones have been studied in Taiwan by Lin et al. (2002), among others. There was a very similar mineralogical pattern to those seen in podzols in the cooler boreal zone. Illite was altered to vermiculite, or sometimes to interstratified illite-vermiculite in eluvial horizons. There was no interlayering with hydroxy-Al species in the eluvial horizons, which exhibited very low $\mathrm{pHs}$ under forest but some occurred in B horizons at higher pHs, and Lin et al. (2002) also considered that translocated Fe, Al, and organic acids coated the Al-interlayered vermiculitic phases with organo-metallic compounds and thus stabilised them against breakdown. As in many other podzols, the system was characterized by the eluviation, translocation, and deposition of mainly $\mathrm{Al}$ and $\mathrm{Fe}$ by organic acids.

The general mineralogical pattern in podzols in summarized in Box 20.4. It is given for podzols on micaceous parent materials, which are common for many podzolised soils, although podzols can form on many parent materials or lithologies.

\begin{tabular}{|c|c|c|c|c|c|c|}
\hline \multirow{3}{*}{ 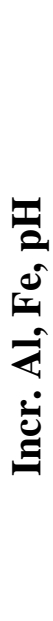 } & & Horizons & Type & Alteration & Phyllosilicates & $\begin{array}{l}\text { Nanocrystalline } \\
\text { (SRO) minerals }\end{array}$ \\
\hline & & $\mathrm{A}, \mathrm{E}$ & Eluvial & $\begin{array}{c}\text { Accelerated loss of } \\
\text { cations } \\
\text { including } \mathrm{Al}, \mathrm{Fe}, \\
\mathrm{K}, \mathrm{Si}\end{array}$ & $\begin{array}{c}\text { Beidellite or } \\
\text { vermiculite; } \\
\text { interstratified with } \\
\text { illite, or discrete }\end{array}$ & 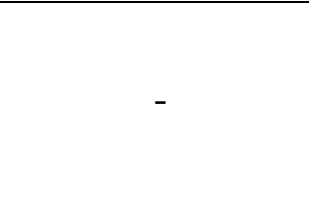 \\
\hline & $\downarrow$ & $\mathrm{Bs}, \mathrm{Bh}$ & Illuvial & $\begin{array}{l}\text { Normal extent of } \\
\text { alteration, for } \\
\text { example, for } \\
\text { climate }\end{array}$ & $\begin{array}{l}\text { Vermiculitic, not } \\
\text { smectitic, } \\
\text { interstratified or } \\
\text { discrete, } \\
\text { possibly Al- } \\
\text { interlayered }\end{array}$ & $\begin{array}{l}\text { Allophane and/or } \\
\text { imogolite, Fe } \\
\text { oxides, especially } \\
\text { ferrihydrite }\end{array}$ \\
\hline
\end{tabular}

Box 20.4 Mineralogical pattern in podzols developed on micaceous parent materials 


\subsection{Apparent counteraction of weathering by plants}

Some work has indicated that plants, as well as acting as potential weathering agents, may also act to counter the course of mineral development that might otherwise be expected from the operation of the other main weathering agents such as climate. Thus, in a chronosequence on basalt in the tropics, both the early formation of an illite and also a lower content of gibbsite in A horizons than in $\mathrm{C}$ horizons across much of the sequence, were attributed by $\mathrm{He}$ et al. (2008) to the transport by plants of nutrients $(\mathrm{K}$, and also $\mathrm{Si}$, as siliceous phytoliths) to the surface of soils. Together the increases in these nutrients has led to the formation and retention of illite and 2:1 aluminosilicates more generally, at least until they are finally weathered out in the oldest soils. Both April and Keller (1990) and also Calvaruso et al. (2009) found that there was a build-up of the discrete mica phase (respectively muscovite and illite in the two reports) relative to its degraded counterpart in the rhizospheres of trees in comparison to the bulk soils. Barré et al. (2009) have concluded from a review of the literature that this effect of plants retarding weathering changes, which is known as "nutrient uplift", "element translocation", or "biological pumping", is widespread and that "the clay mineralogy observed in surface soils is probably largely plant-mediated." The uptake and biocycling of Si by plants has also been studied by Drees et al. (1989), Lucas et al. (1993), Derry et al. (2005), Farmer (2005), and Henriet et al. (2008). The concentration of Si by "nutrient uplift" has probably contributed, at least, to the preservation of kaolinite and halloysite, respectively, in the surfaces of forest soils in Brazil (Furian et al., 2002) and Costa Rica (Kleber et al., 2007), while strong tropical weathering has led to gibbsite dominating the mineralogy of the saprolite in the Brazilian case and the subsoil in the Costa Rican one. An examination of published data on Si concentrations in Bs horizons in several European forest soils, as well as experimental data for some of these, led Farmer et al. (2005) to postulate that plant phytoliths provide a sink, hence short-term nutrient uplift, for Si from soil solutions during the growing season that is released back to solutions during winter and spring. Such a viewpoint is supported by data derived from studies of plant-related movement in soils of $\mathrm{Al}$ and $\mathrm{Fe}$ as well as that of $\mathrm{Si}$ in both temperate and tropical soils that were reviewed by Lucas (2001), although differences are evident for different environments (see Figure 6 in Lucas, 2001). Nonetheless, Lucas (2001) concluded that in most places (tropical as well as temperate), the weathering mantle can be regarded as being in a "dynamic equilibrium sustained by plants". Derry et al. (2005) found that most of the silica released to 
Hawaiian stream water had passed through the biogenic silica pool rather than originating directly from mineral-water reactions in soils in this basaltic environment.

\subsection{Humans and other fauna as weathering agents}

The human being is one biological agent with a potential to affect soil mineralogy which cannot always be ignored. Apart from such effects on soil mineralogy as those from enhanced erosion - leading to, for example, truncation of profiles and transportation of soil minerals over distances from a few metres to the diameter of an entire hemisphere (e.g., Syers et al., 1969) by water or wind, people's activities can also either enhance or retard the influence of other organisms on mineral weathering, whether through the effects of agriculture, pollution, construction, and engineering activities and/or effects on climate and hydrology at either local or global scales (e.g., see Yaron et al., 2010). In the particular case of acid sulfate soils, which are increasing in area globally because of human activities, and which are of increasing concern as a form of both soil and environmental degradation (Dent and Pons, 1995; Ritsema et al., 2000), large-scale changes wrought by humans have led to mineralogical changes which contribute to the properties of these soils, which have been labelled "the nastiest soils in the world" by Dent and Pons (1995). Classed often as Sulfaquents, acid sulfate soils, which are most commonly coastal, but may also occur in nontidal seepage and marsh areas affected by dryland salinity (Fitzpatrick et al., 1996), originate from the oxidation of sulfides, most commonly of $\mathrm{Fe}$ and most often pyrite $\mathrm{FeS}_{2}$, but sometimes also Fe monosulfides such as mackinawite (tetragonal FeS), pyrrhotite (hexagonal $\mathrm{FeS}$ ), and greigite $\left(\mathrm{Fe}_{3} \mathrm{~S}_{4}\right)$ (Burton et al., 2009). These Fe sulfides are themselves products of earlier bacteria-mediated reduction of sulfate ions (Dent and Pons, 1995; Fitzpatrick et al., 1996). Sulfuric acid results from the oxidation of the sulfides (such as occurs after draining the soils), which occurs only slowly in an abiotic environment, but which is greatly accelerated in the presence of Fe-oxidizing bacteria (Ritsema et al., 2000). The sulfuric acid thus produced reacts with soil minerals generally to give a range of compounds. Of these, jarosite $\left(\mathrm{KFe}_{3}(\mathrm{OH})_{6}\left(\mathrm{SO}_{4}\right)\right.$, also known as "cat clay" because of its yellow, faecal-like color, is most widely recognised as a component of acid sulfate soils (Dent and Pons, 1995; Fitzpatrick et al., 1996) and schwertmannite $\left(\mathrm{Fe}_{8} \mathrm{O}_{8}(\mathrm{OH})_{8-2 \mathrm{x}}\left(\mathrm{SO}_{4}\right)_{\mathrm{x}}\right.$, has been recognised in some under very acid conditions (Fitzpatrick et al., 1996; Burton et al., 2006; 2008). The Fe oxidic phases, ferrihydrite $\mathrm{Fe}_{5} \mathrm{HO}_{8} .4 \mathrm{H}_{2} \mathrm{O}$ and goethite, can also form (op. cit.), but many other minerals have been found to form as a result of the processes contributing to the 
evolution of these soils. These minerals include hydrated sulfates of $\mathrm{Na}$ and $\mathrm{Fe}$ (sideronatrile and natrojarosite), $\mathrm{Na}$ and $\mathrm{Al}$ (tamarugite), $\mathrm{Mg}$ and $\mathrm{Fe}$ (copiapite), and $\mathrm{Pb}$ and $\mathrm{Fe}$ (plumbojarosite), as well as gypsum, halite, the Fe oxyhydroxide, akaganéite, and a poorly ordered Al oxyhdroxide (R.W. Fitzpatrick and M.S. Skwarnecki, unpublished results), as well as elemental sulfur (Burton et al., 2009). In the case of acid-sulfate soils, the effects of human intervention in certain environments have been to promote mineralogical changes that are mediated by microbes.

Agriculture brings about disequilibrium in soils (Velde and Meunier, 2008). The effect of cropping on clay mineralogy was assessed through analyses of samples taken from the long-term Morrow experimental plots at the University of Illinois for $>80$ years cropping of different types and with different management regimes (Velde and Peck, 2002).

Continuous cropping with corn has led to a marked loss of illite in favor of illite-smectite phases. In contrast, rotation cropping over the same period has had little effect on clay mineralogy. However, 80 years of growing rice in flood-irrigated soils in China showed strong effects on clay minerals in the soils (Li et al., 2003). Micaceous phases, including interstratified phases have largely been lost, as have Fe oxides, but a Si-poor ferro-magnesian chlorite has formed. Pastures can also influence clay mineralogical development. Poldered sediments in France with up to $~ 850$ years of development under prairie enabled Velde et al. (2003) to show that the dominantly illite-smectite clay minerals in topsoils, which were influenced the most by grass growth, hardly changed with time from those in the sediment. On the other hand, the same type of clay minerals in the subsoils became more smectitic over the same time period. The subsoils had a higher $\mathrm{pH}$ than the topsoils, which were more-orless neutral in $\mathrm{pH}$. The grasses appeared to stabilize the particular mixed-layer composition of the original clay minerals.

The common agricultural practice of adding fertilisers to soils can also have effects on the mineralogy of soils. Thus, Simonsson et al. (2009) found that the long-term use of K fertilizers had contents of illite, both as a discrete phase and also within mixed-layers, which reflected the rate of addition of the fertilizers - illite was more concentrated where fertilizer additions had been higher. K release from the soil minerals appeared to be reversible except where hydroxyaluminum interlayers occurred, presumably blocking $\mathrm{K}^{+}$from entering or leaving the interlayers (Simonsson et al., 2009). Velde and Peck (2002) also found that additions of NPK fertilizer after $>40$ years of continuous cropping with corn restored the clay minerals to their original state whereas, as already noted, illite was sufficiently depleted of $\mathrm{K}$ 
over >80 years of this treatment without fertilizer additions to register a significant change to illite-smectite (I-S). These authors suggested that I-S plays the role of a $\mathrm{K}$ buffer that releases $\mathrm{K}$ when plants cannot access other sources of this essential nutrient and stores it when there is an excess of K. Pernes-Debuyser et al. (2003) found that the content of nonexpandable illite increased at the expense of expandable I-S in long-term K-addition treatments of soil without plants with either $\mathrm{KCl}$ or manure at Versailles in France. Fertilization with ammonium-based N-fertilizers has also been shown to affect clay mineralogy through an increase in the contents of nanocrystalline aluminosilicates and also hydroxyl-Al interlayers in 2:1 minerals (McGahan et al., 2003). On the contrary, Tye et al. (2009) noticed that the greatest mineralogical changes in the long-term plots at Rothamsted in the United Kingdom occurred when fertilisation with ammonium sulfate led to $\mathrm{pHs}$ falling below 3.7, when hydroxyl-Al interlayers in 2:1 minerals became solubilised, allowing entry of the interlayers to $\mathrm{K}^{+}$and $\mathrm{NH}_{4}{ }^{+}$.

Fauna can also aid weathering processes by moving soil materials, especially by bringing less-weathered or unweathered subsurface materials to the soil and land surface as occurs by termites for example in building mounds, and worm ingestion and excretion (e.g., Paton et al., 1995; Johnson, 2002; Meysman et al., 2006). In maritime Antartica, which receives more liquid water than the Antarctic continent, ornithogenic soils formed on basaltic and andesite rocks in abandoned penguin rookeries and which are organic-rich due to penguin guano, show considerable development of secondary minerals, mainly as noncrystalline or nanocrystalline phases, including 1:1 (Al:Si) allophane (Simas et al., 2006).

\subsection{Microorganisms as weathering agents}

It is well-recognised that microbes act as reducing agents and thereby contribute to the reassignment of $\mathrm{Fe}$ and $\mathrm{Mn}$ from primary minerals or secondary oxides, oxyhydroxides, and hydroxides into solution and ultimately into new oxidic phases upon drying, sometimes with the solubilization and release of trace metals such as Co and Ni (e.g., Quantin et al., 2001). Microbes also act commonly as oxidising agents (such as in the formation of ferrihydrite in seepages). Their activity, when simulated by a series of oxidation-reduction cycles, transformed the short-range ordered iron oxide "nano-goethite" to micro-crystalline goethite and micro-crystalline hematite (Thompson et al., 2006). They may also bring about mineral alteration through root exudates, as in the tunnelling action of fungal hypae on feldspars and 
other mineral grains (van Breemen et al., 2000b; Smits et al., 2005, see Section 20.2.4.2). Müller (2009) has shown that the weathering effect of bacteria can vary greatly between different genetic derivatives of a single strain. Organic acids resulting from the life and death of organisms have also been recognised as important agents in mineral alteration (e.g., Huang and Schnitzer, 1986; Robert and Chenu, 1992). In particular, dicarboxylic acids have been identified in soils (Hue et al., 1986) where they greatly enhance rates of dissolution (Amrhein and Suarez, 1988) through ring compounds as ligands for sequestering metals on mineral surfaces (Casey, 1995). One of the main effects of organic acids on weathering may come through their supply of protons (Ugolini and Sletten, 1991; Nesbitt, 1997). It has also been shown in nature and in experiments that both aluminosilicate minerals and oxides of Fe and Mn can form by nucleation on bacteria (Urrutia and Beveridge, 1994; Ferris, 1997; Tazaki, 1997, 2005; Chan et al., 2009). Magnetite formed partly by bacteria in soils has been described, for example, by Maher and Taylor (1988) and Geiss and Zanner (2006). Observations made by Ueshima and Tazaki (2001) in both deep-sea sediments and laboratory experiments showed that aluminosilicates (nontronite in this case) could be formed on extracellular polysaccharides from microbes. The role of microorganisms in the weathering of glass or volcanic materials has been described, amongst others, by Thorseth et al. (1995), Kawano and Tomita (2001, 2002), and Stroncik and Schminke (2002). According to the last authors, bacteria and microorganisms create a local microenvironment as a result of the fluids of their metabolic products. These fluids are either acidic or basic in $\mathrm{pH}$, depending on the type of bacteria: an acidic $\mathrm{pH}$ essentially results in incongruent glass dissolution, whereas a basic $\mathrm{pH}$ results in congruent glass dissolution, leaving large pits on the glass surface (Stroncik and Schminke, 2002). Microbial activity thus enhances the rate of dissolution of volcanic glass and microbial alteration also results in the formation of authigenic phases and is accompanied by redistribution of elements.

Hence microorganisms may play a number of roles in mineral weathering. As summarized by Barker et al. (1997), these include the following: (1) physical disintegration of rocks; (2) production of acids and chelating ligands to accelerate chemical alteration; (3) stabilization of soils to increase their time of exposure to chemical agents; (4) production of extracellular polymers to moderate water potential, maintain diffusion channels, and themselves act as ligands for chelation and also as nuclei for mineral neoformation; and (5) absorption of nutrients, to lower solution concentrations and increase the chemical potential for weathering. All of these roles may also be performed by plants, including grasses, crops, and trees (e.g., Courchesne, 2006). In addition, they may be carried out by other biological 
agents, including lichens (Adamo and Violante, 2000; Chen et al., 2000), fungus-growing termites (Jouquet et al., 2002), and mycorrhizal fungae (Jongmans et al., 1997; van Breemen et al., 2000a, 2000b; Certini et al., 2003). With regard to mycorrhizal fungae, the cited authors concluded that the fungal hyphae dissolved and extracted nutrients directly from mineral grains, such as feldspar and hornblende, through their intrusion into fractures and fissures in the geological deposits and by "drilling" directly into minerals, thereby bypassing the external solution phase. However, in studying the microbiological colonization of primary mineral weathering in volcanic soils in Italy, Wilson et al. (2008) found in this case that microbial activity, particularly fungal activity, was not an effective agent of mineral weathering, that the association with clay minerals was indirect, and that fungal weathering of primary minerals was probably less important than previously claimed as a source of plant nutrients. These authors concluded that pre-formed cleavages and microporous features in primary minerals enable the penetration of fungi for them to bring about mineral alterations and noted that these features were generally absent in the soils they studied.

\subsection{The ecology of biota and soil minerals}

Bennett et al. (2001), in noting that microbes bring about the alteration of minerals through their selective extraction of essential nutrients from the minerals, posed the question of whether the suite of microorganisms is partly, at least, controlled by the mineralogy and by the ability of particular microorganisms to use the nutrients contained within the minerals present. Soil minerals, both primary and secondary, may thus be viewed in the ecological context that is characterized by Young and Crawford (2004) as "the soil-microbe complex". Building on the concept of plants as ecosystem engineers, and on published information on the effects of particular plant species on soils, van Breemen and Finzi (1998) reviewed the evidence that such effects can provide a positive feedback to such plants. They concluded that there was strong evidence for plant-soil feedbacks in a variety of ecosystems, and they argued that these feedbacks could have played a role in the evolution of the plant species in question. Earlier, van Breeman (1992) had asked the question: "have soils merely been influenced by biota or have biota created soils as natural bodies with properties favorable for terrestrial life?" Coleman and Crossley (2003) argued for the latter by reference to the storage in soils of the life-limiting element, phosphorus. They contended that: (1) the interaction of biota with primary minerals produces soluble Fe (and other cations) by weathering; (2) Fe in particular is brought into the solid phase as oxides (including oxyhydroxides) by oxidation aided by (iron oxidizing) bacteria; and (3) the Fe oxides are kept in a largely amorphous or 
nanocrystalline form, from which $\mathrm{P}$ can be extracted by plants more efficiently than from crystalline oxides, through their interaction with (biota-derived) humic substances. Recent experimental work has shown both that (1) bacteria can effect the production of polymeric molecules within the structures of (smectitic) clay minerals hence probably improving the environment for the survival of the bacteria (Alimova et al., 2009), and (2) the structure of bacterial communities in soil is influenced by the (primary) minerals in their microhabitat (Carson et al., 2009). Chickens and eggs come to mind in assessing whether biota or minerals are the limiting factors in the ecology of the soil, but it is clear that, while both are important, it is their interactions that are of overriding and vital importance to the sustainable functioning of soil and the life it supports.

\subsubsection{Processes of mineral alteration and formation by weathering: summary}

Secondary minerals are formed as a result of the alteration of primary minerals or mineraloids by either (1) transformation in the solid state, or (2) hydrolysis, dissolution, and recrystallization out of solution, namely neogenesis. Fig. 20.9 summarizes these two possible mechanisms.

\subsection{Occurrence of clay minerals in soils}

This section concentrates on the particular forms in which clay minerals occur within soils, rather than the general groups of soils in which they occur, or even their distribution in particular environments or globally. These aspects are dealt with elsewhere in this handbook. Instead, our focus is on the sizes and shapes of mineral particles and peculiarities of their chemical compositions and crystal structures, largely in relation to those of "type" occurrences of minerals with the same names in more or less pure "geological" deposits, including those often used as standard specimens of each type. In this section, we also explore the associations of minerals within soils in relation both to other types of minerals and also to organic materials. In particular, we examine the possibility that there is a relationship between the mode of formation (and alteration) of clay minerals, on the one hand and, on the other, the forms they adopt and also their associations within soils. 


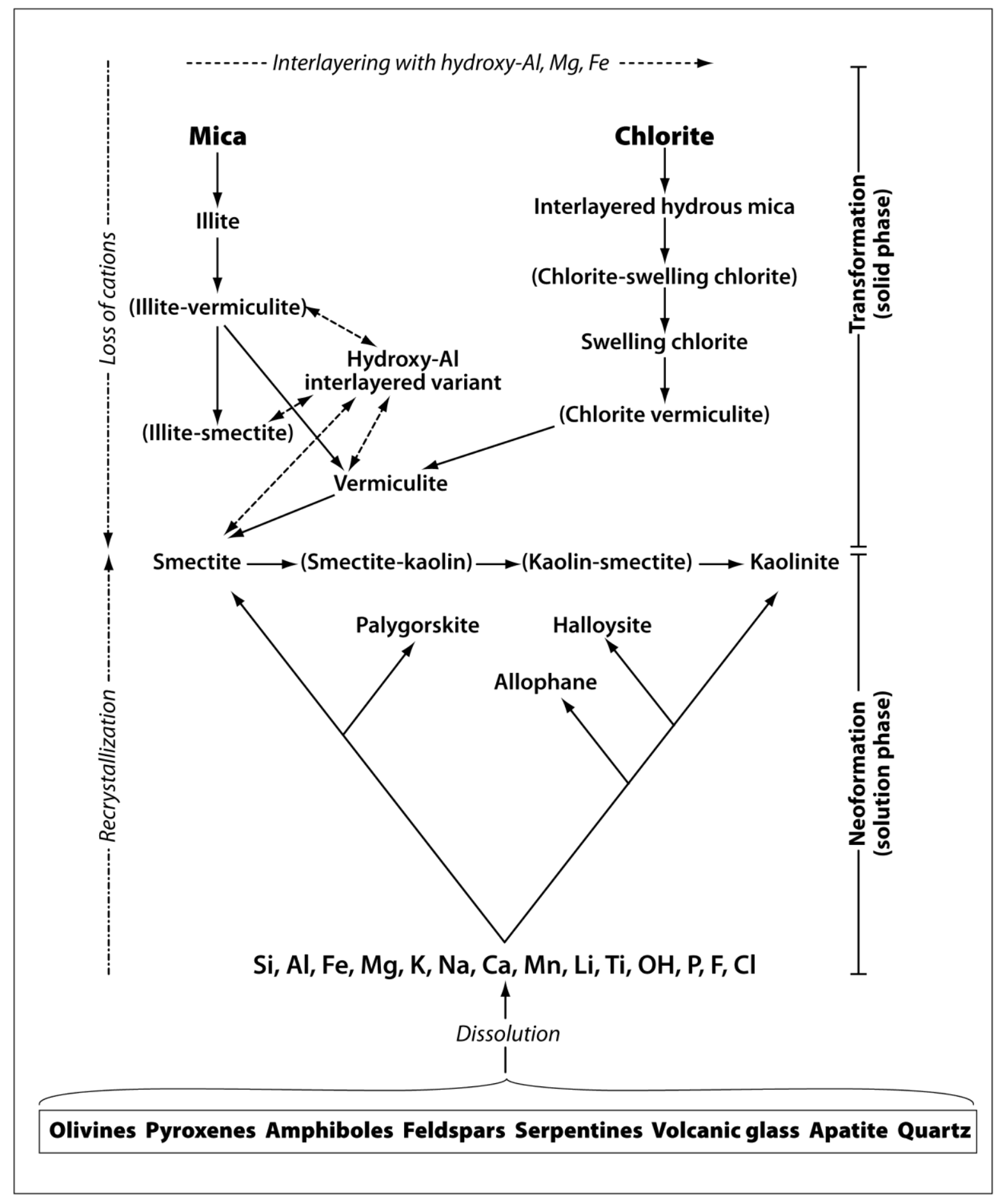

FIGURE 20.9 Main pathways for mineral alteration and formation in soils via either neoformation (lower part of figure) or transformation (upper part). (After Churchman, G.J. 1978. Studies on a climosequence of soils in tussock grasslands. 21. Mineralogy. N.Z. J. Sci. 21:467-480; Wilson, M.J. 2004. Weathering of the primary rock-forming minerals: Processes, products and rates. Clay Miner. 39:233-266.) 


\subsubsection{Occurrence of kaolinite in soils}

Kaolinite is the most ubiquitous phyllosilicate in soils (White and Dixon, 2002).

Nonetheless, kaolinites are most abundant in highly weathered soils, which are formed in warm humid climates, although a high rainfall can result in their formation within soils in temperate climates (Weaver, 1989; White and Dixon, 2002). They can also be found in soils in colder climates that were nevertheless formed under an earlier, warmer climate, e.g., by pre-glacial weathering in Scotland (Wilson et al., 1984). Generally, kaolinites in soils are highly disordered and many of the peaks in their XRD patterns are poorly resolved. As a result, the common index for assessing the degree of crystalline order by $\mathrm{XRD}$, namely, the Hinckley index, is impossible to measure and an alternative, empirical index was devised by Hughes and Brown (1979), which remains in use for soil kaolins (including halloysite). In developing this index, Hughes and Brown (1979) noted that kaolinite in the set of 26 soils they mainly studied, which were from Nigeria, invariably occurred along with other minerals in their clay fractions, as well as containing weatherable minerals in the coarser fractions. These authors suggested that the weatherable minerals present hindered the crystallization of well-ordered kaolins. Millot (1970) had come to a similar conclusion, suggesting more specifically that alkaline-earth cations had caused the inhibition of crystallization. Iron is a common impurity in the kaolinite structure, and there appears to be a relationship between structural Fe and crystalline order (Herbillon et al., 1976; Mestdagh et al., 1980). As Fe increases in amount, displacing the smaller $\mathrm{Al}$ atoms from the structure, crystal strain may increase, thereby limiting crystal growth, so that particle size as well as structural order is likely to be diminished by a high Fe content. Lim et al. (1980) had found that non-soil kaolinites could also be poorly-crystallized. Compared with their well-crystallized counterparts, seven examples of these poorly-ordered kaolinites, from Georgia in the United States of America, showed not only much higher values for specific surface area particularly (between 78 and $114 \mathrm{~m}^{2} \mathrm{~g}^{-1}$, cf. $10-15 \mathrm{~m}^{2} \mathrm{~g}^{-1}$ for the well-crystallized kaolinites), but also some relatively high values for CEC. All were shown to comprise some montmorillonite and vermiculite as impurities, while six of them also contained mica. Kaolinites often occur in vermiform books, suggesting a micaceous precursor. White and Dixon (2002) suggested, rather, that micas, or, more commonly, their expanded transformation products with the same crystal form, e.g., vermiculite or beidellitic smectite, provide nucleation sites on their 001 surfaces for authigenic kaolinite formation, as shown in Figure 20.4. 
A number of papers (Singh and Gilkes, 1992a; Melo et al., 2001; Hart et al., 2002; Kanket et al., 2005) have compiled data describing crystal form, measures of crystal order, and related properties such as Fe contents for kaolinites extracted from highly weathered soils in (Western) Australia, Brazil, Thailand, and Indonesia, although the last also included some halloysite or "tubular kaolins" (Churchman and Gilkes, 1989), so the total set is better described as kaolins. Together with information from Hughes and Brown (1979) for Nigerian soils, these properties are able to be compared in Table 20.4 (from Kanket et al., 2005, with data for the reference kaolinites from Hart et al., 2002). The various kaolins had many properties in common. Alhough there was a range for each value within each set of soil kaolins, their specific surface areas (overall range 34-88 $\mathrm{m}^{2} \mathrm{~g}^{-1}$ ) all exceeded those of any of the reference samples (all $\leq 25 \mathrm{~m}^{2} \mathrm{~g}^{-1}$ ) and their particle sizes, given by coherent scattering domains (CSDs), were generally less than half those of the reference kaolinites. Surface area and particle sizes are expected to be inversely related to each other. Their Hughes and Brown (HB) index values were always less than those of the reference kaolinites, and, although some of the soil kaolins had quite high CECs, some were comparable to those of several, at least, of the reference kaolinites. Regardless of their other characteristics, however, all of the soil kaolins on which Fe was measured (those from Thailand, Western Australia, and Indonesia) had much higher contents of Fe than the reference kaolinites. With the most clear-cut differences between soils and reference kaolinites being in their surface areas, the HB measure of structural order, and their Fe contents, these results bear out the proposition from Herbillon et al. (1976) and Mestdagh et al. (1980) that a high Fe content leads to a low degree of structural order and small particles. Their small size, particularly, is illustrated by transmission electron micrographs showing comparisons between some soil kaolinites from Western Australia from Singh and Gilkes (1992a) and a reference kaolinite (from Georgia) (Figure 20.10). Furthermore, Singh and Gilkes (1992a) found that the kaolinites contained both $\mathrm{K}$ and $\mathrm{Mg}$, which are largely absent from pure, well-crystallized kaolinites. Brazilian soil kaolinites were also found to contain considerable $\mathrm{K}$ and Mg (Melo et al., 2001). These authors suggested that there are residual micaceous layers incorporated in the kaolinites. This finding is consistent with the results of Lim et al. (1980) and also with the common observation that kaolinites appear in vermicular books by crystallization on the surfaces of micas and their transformation products (Figure 20.4). The crystal growth of the kaolinites may have been constrained by interleaved micaceous layers as well as by Fe incorporated into the kaolinite layers. 

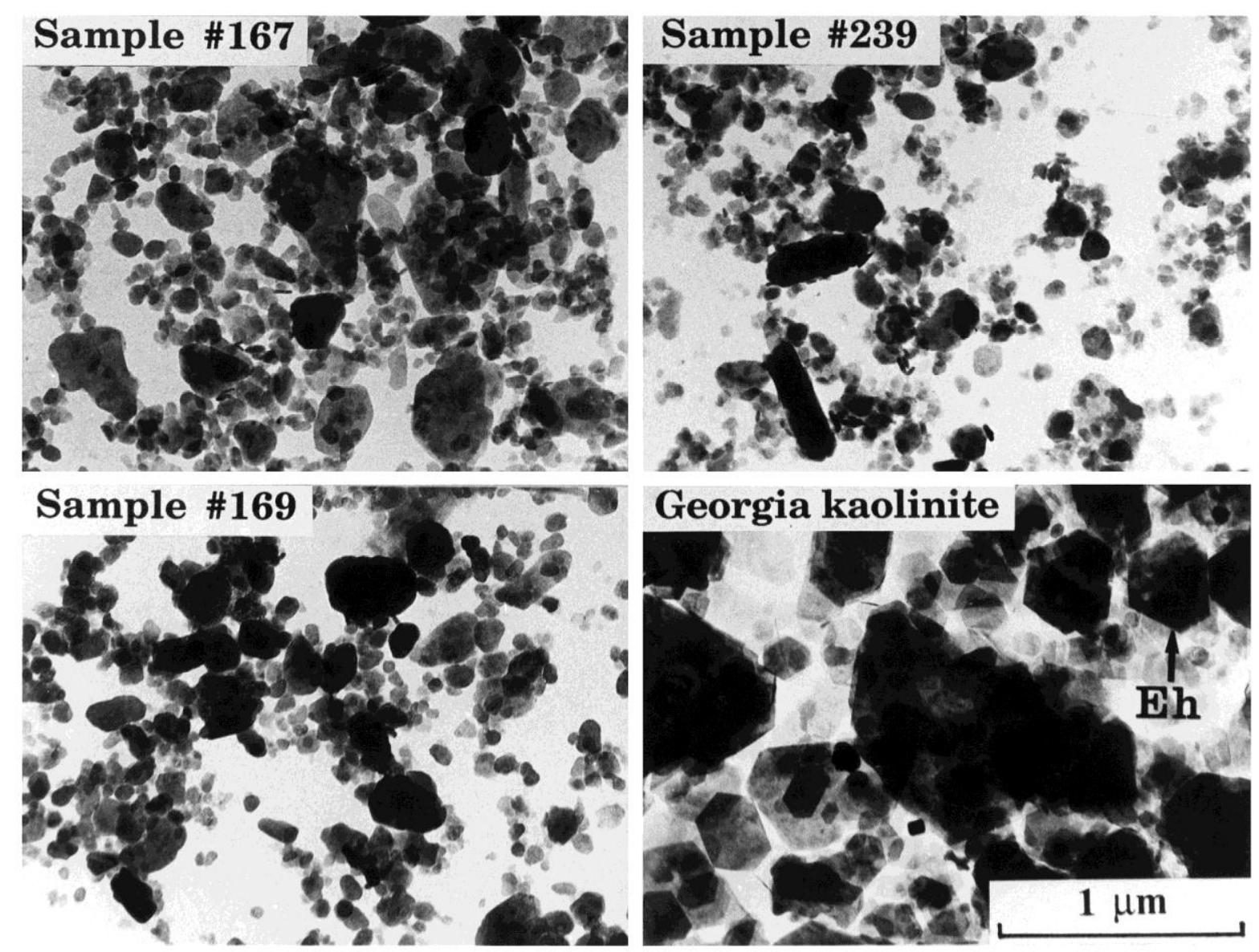

FIGURE 20.10 Transmission electron micrographs showing comparisons between some soil kaolinites from Western Australia and a reference kaolinite (from Georgia). Eh indicates a euhedral hexagonal shape for particles in the reference sample. (Micrographs copied from Singh, B., and R.F. Gilkes. 1992a. Properties of soil kaolinites from south-western Australia.). Soil Sci. 43:645-667. Reproduced with permission of Wiley-Blackwell.)

\section{Insert Table 20.4 here}

Kaolinite (and also, we shall see, halloysite) quite often occur in interstratifications with a smectite. Kaolinite-smectite interstratified phases have been found to occur worldwide, including in Scotland, Canada, throughout Africa, Australia, Central America, India, Japan, China, and the United States (see Churchman, 2000, for citations), and a more recent report (Vingiani et al., 2004) described their occurrence in Italy (Sardinia). Norrish and Pickering (1988) speculated that kaolin-smectite interstratified phases (or "kaolin-smectites") are likely to be a very common component of Australian soils. In Australia, and elsewhere, they have probably been often overlooked in identifications using X-ray diffraction patterns. This "omission" is because the main effect of the mixed layering is to broaden and weaken XRD peaks, so that basal peaks may become invisible even though nonbasal peaks appear 
(Norrish and Pickering, 1983). In part, this effect is a consequence of the inherent variability of clay minerals in soils, so that the properties of the two (and sometimes more) components and their degree of order can vary from particle to particle (ibid.). Most kaolinite-smectites described in the literature are more kaolinitic than smectitic (Churchman et al., 1994), although Bühmann and Grubb (1991), Churchman et al. (1994), and also Ryan and Huertas (2009) each found examples where the proportion of smectite layers was $>60 \%$. In the same way that many interstatified specimens with high concentrations of kaolinite have been identified incorrectly as kaolinites (Norrish and Pickering, 1983; Churchman et al., 1994), so also some with high contents of smectite have been mis-identified as smectites (Cuadros et al., 1994). Some with a high kaolinite content were probably misidentified as halloysites that have a platy morphology (Carson and Kunze, 1970; Wada et al., 1987), but each of these was later interpreted as a kaolin-smectite by Sakharov and Drits (1973) and Parfitt and Churchman (1988), respectively. The identification of phases as kaolin-smectites rather than as either of their components is important in order to fully describe the effect of clay mineralogy on soil properties such as CEC (e.g., Seybold et al., 2005) because they give rise to higher values than can be expected from kaolinites and lower values than from smectites.

Kaolinite-smectites have been found in intermediate zones in toposequences spanning smectitic black soils at their base and kaolinitic red soils near their summits and on their steep slopes (Herbillon et al., 1981; Bühmann and Grubb, 1991; Delvaux and Herbillon, 1995; Vingiani et al., 2004). They have also been recognised within single soil profiles on basalt (Churchman et al., 1994; Vingiani et al., 2004). From the base of the profile to near its surface, their composition changed from highly smectite to highly kaolinitic, but nonetheless with both phases being interstratified kaolinite-smectites (Churchman et al, 1994), or else more subtly, from $\sim 35$ to 40 to $\sim 40$ to $45 \%$ kaolinitic within the interstratifications (Vingiani et al., 2004). Ryan and Huertas (2009) have also located kaolinite-smectites in a set of soils within a chronosequence on mostly basaltic and andesitic parent materials. As it was within the residual soil profiles on rock (Churchman et al., 1994; Vingiani et al., 2004), the progression from youngest (found at the base of the profiles) to the oldest (at the surface in the case of the profiles), was from more smectitic (or pure smectite, in the chronosequence) to more kaolinitic. Kaolinite also occurred as a discrete phase alongside its interstratifications with smectite in the most developed (i.e. oldest) soil in the chronosequence of Ryan and Huertas (2009) and also in the soil profiles of Churchman et al. (1994) and Vingiani et al. (2004). A variety of techniques, including XRD, together with modelling of 
the effect of interstratifications and sometimes also peak decomposition, FTIR, HRTEM, differential thermal analysis (DTA), and permanent and variable charge analysis, have enabled various authors to seek an understanding of the origin of the process of interstratification of the 2:1 and 1:1 layers. Ryan and Huertas (2009) concluded that a layerby-layer transformation occurs as smectite is progressively altered to kaolinite via an interstratification of the two end-member phases with each other. The transformation proceeds by localised dissolution of the 2:1 layers with initial loss of $\mathrm{Fe}$ and $\mathrm{Mg}$ from octahedral layers and of $\mathrm{Al}$ from tetrahedral layers followed by a loss of $\mathrm{Si}$ from tetrahedral layers ("subtraction') and/or a deposition of hydroxyl-Al species in interlayers, leaving 1:1 layers (“addition") (Ryan and Huertas, 2009). These two alternative types of mechanism for the alteration had been proposed earlier by Wada and Kakuto (1983, 1989), who favored a subtraction mechanism, and by Altschuler et al. (1963) and Poncelot and Brindley (1967), who favored an addition mechanism. Albeit through studying a clay deposit rather than a soil, Watanabe et al. (1992) found support for a subtraction mechanism as a result of their discovery that opal C-T, or microcrystalline opal comprising clusters of stacking of cristobalite and tridymite over very short length scales, forms during the early stages of formation of kaolinite from smectite. Vingiani et al. (2004) discovered that the smectite in the sequence they studied consisted of a mixture of a more ferric and a more aluminous type. In the course of mineralogical evolution, there was a decrease in the proportion of the ferrous smectite layers relative to their aluminous counterparts. These authors proposed that the (subtraction) mechanism operated through a preferential loss, by either transformation or dissolution of the ferrous smectite layers, to give kaolinite layers, with the excess Fe forming either Fe oxides (or oxyhydroxides) or becoming incorporated in kaolinite layers, or both.

Kaolinites can also form interstratifications with other types of layers besides smectites, for example, vermiculite (Jaynes et al., 1989), and can also participate in interstratified phases involving several different types of layers. The elevated CECs and also high $\mathrm{K}_{2} \mathrm{O}$ contents of some of the soil kaolins studied by Singh and Gilkes (1992a), Melo et al. (2001), and Kanket et al. (2005), in particular, are at least partly ascribed to their interstratifications by micas and/or vermiculites. Ma and Eggleton (1999) found that some soil kaolinites in Queensland, Australia, had quite high CECs $\left(16-34 \mathrm{cmol}_{+} \mathrm{kg}^{-1}\right)$ and HRTEM had shown that their crystals commonly comprised stacks of many kaolinite layers which terminated in smectite layers, possibly as single layers. These stack-end smectite layers affected CEC but were usually not detectable by XRD (Ma and Eggleton, 1999). 


\subsubsection{Occurrence of halloysite in soils}

As already noted (Section 20.2.4.5), halloysite is a common component of soils formed from volcanic parent materials, particularly tephra including finer components referred to as volcanic ash (e.g., Kirkman, 1981; Lowe, 1986). It has also been identified as a weathering product of a wide range of rock types including nephenilite, granite, gneissic granite and granitic gneiss, gneiss, dolorite, schist, greywacke, greenstone, granodiorite, gabbro, shale, and amphibolites (see Churchman, 2000, and also Joussein et al., 2005, for citations). Halloysite can occur in a variety of particle morphologies including tubes and microtubules, spheroids and microspheres, crumpled lamellae, crinkly films, needle-like or fibre-like forms, and prismatic forms (ibid.; see also Hong and Mi, 2006; Etame et al., 2009). Its morphology appears to relate to the content of impurity iron, with substitution of the larger Fe (III) for $\mathrm{Al}$ in the octahedral sheet, which, without substitutions, is smaller than the tetrahedral sheet. This situation leads to partial or full correction of the misfit between the octahedral and tetrahedral sheets that therefore causes curling (as in tubes) in halloysites with little or no Fe. The impurity $\mathrm{Fe}$ also constrains crystal growth and leads to smaller particles being formed. Recently, Singer et al. (2004) have found halloysites with high contents (up to 6.5\%) of Ti in their aluminosilicate structure that were plate-like, probably from the same cause: larger $\mathrm{Ti}$ atoms replace some $\mathrm{Al}$ in the octahedral sheets, hence also correcting at least some of the mismatch with the tetrahedral sheet. Even so, whereas a peculiar shape was once regarded as the distinguishing feature of halloysite in comparison with kaolinite, it is rather the occurrence, or else evidence for prior occurrence, of interlayer water that demarcates halloysites from kaolinites (see Section 20.2.4.6.2 earlier herein)). Interlayer water is lost irreversibly from halloysites on drying.

However, some shapes, particularly spheriodal, appear to reflect a particular mode of formation for halloysite (Churchman, 2000). Spheroidal forms of halloysite appear often in weathering products of volcanic glass, which has a fast dissolution rate, and recrystallization from the resulting supersaturated solution appears to favor this particular shape (review by Bailey, 1990; Adamo et al, 2001; Singer et al., 2004), possibly when physically constrained, for example, within pumice cavities (Adamo et al., 2001). Nonetheless, Churchman and Theng (1984) and Singer et al. (2004) both found that spheriodal particles had higher Fe contents than even short tubes, suggesting a structural control on shape for spheroids as well as for tubes. By contrast, Johnson et al. (1990) found a spheriodal halloysite with virtually no Fe whereas Noro (1986) and also Adamo et al. (2001) found few, or only minor, differences 
in composition between spheroidal and tubular forms of the mineral. In any case, Soma et al. (1992), using XPS, found that Fe content varied between different layers in a halloysite, whether spheriodal or tubular. Furthermore, spheriodal and tubular shaped particles occur together in halloysites (Saigusa et al., 1978; Churchman and Theng, 1984) and one may alter to another in situ (Sudo and Yatsumato, 1977), suggesting there may be no clear-cut distinction between the conditions that lead to the different particle shapes for halloysite. On the other hand, a very detailed microtextural and microanalytical study of samples taken at various depths in a weathering profile on gneiss in Greece led Papoulis et al. (2004) to deduce a sequence of mineral alteration that encompasses different morphologies for halloysite and includes two forms of kaolinite while simultaneously indicating a correlation between structural Fe and the various products in the alteration sequence. Papoulis et al. (2004) divided the alteration sequence into four successive stages. In the earliest stage, halloysite formed in very small spheres ( $\sim 0.1$ to $0.3 \mu \mathrm{m}$ in diameter) that were located on the surfaces of plagioclase in this case. These small spheres then apparently coalesced to form tubes while new tubes also formed in the second stage. These tubes were generally quite short ( $<1 \mu \mathrm{m}$ in length), although they could develop with time to form longer tubes with tapered ends, which, together with a relatively loose packing and sub-parallel orientation, suggest crystallization from solution (a conclusion supported by studies on halloysite with tapered ends by Hong and Mi, 2006). In the third stage, platy halloysite formed, apparently by interconnection of the pre-formed tubes. This form even occurred in crude booklets, which are commonly regarded as more typical of kaolinites, albeit interleaved with a low proportion of kaolinite plates, according to Papoulis et al. (2004). These authors considered that the platy halloysite was unstable and led to the formation of plates of a poorly-ordered kaolinite, with dimensions of $\sim 1 \mu \mathrm{m}$ in length and $\sim 0.1$ to $0.2 \mu \mathrm{m}$ in thickness. The change from halloysite plates to kaolinite was considered to occur within the single (third) stage by Papoulis et al. (2004). The fourth stage was one of kaolinization, with a disordered kaolinite forming first but with a well-formed book-type kaolinite as the ultimate product.

Concomitant with these changes in morphology, increasing Fe in EDAX/EDS analyses of the products through the first three stages led these authors to allocate increasing proportions of Fe in octahedral sheets at the expense of Al, so that spheriodal halloysite had less substitution of $\mathrm{Al}$ by $\mathrm{Fe}$ than tubular halloysite, whereas the platy form had the most structural Fe among the halloysites. The poorly-ordered kaolinite that developed from halloysite in the third stage had a comparable degree of substitution of octahedral Al by Fe as its supposed platy 
halloysite pre-cursor, and the disordered kaolinite formed first in the fourth stage had even more substitution of Fe for Al. However, the book-type kaolinite had a vanishingly small content of structural Fe. It was almost pure aluminosilicate. Overall, Papoulis et al. (2004) attributed the changes in the sequence from small spheriodal particles of halloysite through tubular and play halloysite to poorly-ordered platy, then well-ordered book-type kaolinite, largely to a changing chemistry of the ambient solutions, with a successively decreasing availability of $\mathrm{Fe}$ for incorporation in the aluminosilicate layers, although they conceded some role to microenvironmental conditions (e.g., time, and space available) in affecting particle morphology.

Bailey (1990) concluded that the structural difference between halloysite and kaolinite is substantial enough to make it impossible for one to give rise to the other without dissolution and recrystallization. Nonetheless, there have been many studies showing an apparent genetic relationship between halloysite and kaolinite in weathering profiles including soils and deeper regolith. There is a general trend from halloysite at depth towards kaolinite at the surface of profiles on residual rock materials (e.g., Eswaran and Wong, 1978; Calvert et al., 1980; Churchman and Gilkes, 1989; Churchman, 1990; Takahashi et al., 2001; Singer et al., 2004; Jongkind and Buurman, 2006). These studies together have covered a range of parent rock types and also climates, including tropical (Eswaran and Wong, 1978, and part of Churchman, 1990), temperate (Calvert et al., 1980; part of Churchman, 1990; Jongkind and Buurman, 2006), and Mediterranean, or xeric (Churchman and Gilkes, 1989; Takahashi et al, 2001; Singer et al., 2004). According to Papoulis et al. (2004), these trends with depth were explained in the context of their morphological and compositional development sequence of halloysite and kaolinites. They pointed out that a depth sequence in a residual weathering profile on rock is inter alia also a time sequence, with the earliest stages concentrated at depth and the latest (oldest) stages to be found near the surface (unlike we note the situation in upbuilding profiles where the opposite is true). Like Churchman and Gilkes (1989), these authors considered that the products of the different stages could also exist simultaneously with one another. Singer et al.'s (2004) examination of the weathering of basaltic scoria at a fine scale showed that, whereas $1.0 \mathrm{~nm}$ halloysite was found in vesicles in the scoria, where it was protected from dehydration, $0.7 \mathrm{~nm}$ halloysite and also kaolinite were found in the less scoriaceous basalt, where minerals had been exposed to seasonal drying. $1.0 \mathrm{~nm}$ halloysite was also found in a buried paleosol in the same region. Its burial in the paleosol had protected it from drying. In New Zealand, Lowe (1986) found that $0.7 \mathrm{~nm}$ 
halloysite predominated in the surface horizons of a soil developed on weathered tephra subject to reasonably frequent seasonal drought, whereas $1.0 \mathrm{~nm}$ halloysite occurred in deeper horizons that were less affected by drying. An intermediate zone of variably dehydrated hallosyite with XRD peaks between 1.0 and $0.7 \mathrm{~nm}$ occurred between upper and lower subsoil horizons.

These findings were corroborated by Churchman et al. (2010), who found that alteration of granite and volcanic tuff in Hong Kong had led to halloysite only in veins within the rocks where there was no evidence of drying, namely, no Fe or Mn oxides were present. By the same token, this study showed that kaolinite formed in these veins, either alone or in association with halloysite, where the appearance of $\mathrm{Fe}$ and Mn oxides indicated that drying had occurred. A weathering sequence on trachy-basaltic parent materials in Sicily was found to produce imogolite-like allophane (i.e., Al-rich allophane) in the early stages of alteration of volcanic glass and kaolinite, but no halloysite in later stages (Egli et al., 2008). This absence is probably because of the xeric moisture regime in the area. Similarly, basaltic parent materials in a xeric moisture regime in South Australia were found to produce allophane, but not halloysite (Lowe et al., 1996; Lowe and Palmer, 2005; Takesako et al., 2010; also Section 20.2.4.6). Kaolinite per se was not formed in this case, and, although kaolinite-smectite was often present in the soils, it could have been derived ultimately from limestones and calcareous dune sands underlying the basalt that were incorporated into the soil parent material during the basalt emplacement, with 1:1 Al:Si allophane the likely result of further development of initially formed 2:1 Al:Si allophane by resilication. Albeit that a drier regime tends to favor halloysite over allophane in soils from volcanic ash (see Section 20.2.4.6.2), these various observations suggest that the presence of water is a necessary condition for the formation and preservation of halloysite rather than kaolinite under similar conditions of, for example, parent material, temperature, and time.

Even so, a trend from halloysite at depth towards kaolinite at the surface in residual soil profiles does not necessarily imply that halloysite transforms to kaolinite as weathering intensifies with time. Churchman and Gilkes (1989) found rather that hydrated, tubular halloysite, which dominated the clay fraction of the saprolite deep in a lateritic profile in dolerite in Western Australia, became progressively more dehydrated and progressively more difficult to intercalate with the polar liquids - formamide, hydrazine, and a concentrated potassium acetate solution - with closer approach to the surface. As weathering intensified up the profile, kaolinite began to appear as hexagonal particles but by a different pathway from 
that for halloysite. As has been found elsewhere in the old, strongly leached landscapes of much of Australia (Janik and Keeling, 1993), Churchman and Gilkes (1989) observed that tubular particles with a kaolin layer structure and composition appeared even in the uppermost duricrust of the weathering profile, but they were dehydrated and completely resistant to intercalation by polar liquids.

In seeming contradiction to this trend and also to Bailey's (1990) contention that halloysite and kaolinite cannot transform from one to the other in the solid phase, both Robertson and Eggleton (1991) and also Singh and Gilkes (1992b) showed electron micrographs from within weathering profiles in Australia in which tubular particles, suggesting halloysite, are seen to apparently form on the surface of kaolinite platy particles. Dissolution of kaolinite and recrystallization of halloysite could have occurred in both situations.

Like kaolinites, halloysites have been found to form interstratified phases with smectites. However, halloysite-smectites form under conditions different from those that result in kaolinite-smectites (Delvaux and Herbillon, 1995). Delvaux and Herbillon (1995, and earlier papers cited therein) have generally found interstratified halloysite-smectites in soils formed from volcanic ash. They form under similar (usually alkaline) conditions which give rise to smectites but where the drainage is less restricted (i.e., more leaching occurs) than for smectite formation (Glassmann and Simonson, 1985; Smith et al., 1987).

There do not appear to be any studies of the form of halloysites and their associations in soils that are similarly detailed to those of soil kaolinites by Singh, Gilkes and co-authors (Section 20.3.1). However, many electron micrographs including those of the highly halloysitic Naike and Hamilton soils in New Zealand (formed from strongly weathered tephra) that are shown in Fieldes (1968) and Churchman and Theng (1984), respectively, display mainly tubular particles that are practically all $<0.2 \mu \mathrm{m}$. Lowe (1986) also found tubes, some split, between $\sim 0.07$ and $\sim 0.3 \mu \mathrm{m}$ in length in similar materials. Furthermore, high values for surface areas of halloysites in soils or halloysite-rich soils from around the world have been recorded by several workers (Quantin et al., 1984; Theng, 1995; Takahashi et al., 2001; Singer et al., 2004). Specific surface areas $>100 \mathrm{~m}^{2} \mathrm{~g}^{-1}$ were measured for soil halloysites or halloysitic soils in all of the studies cited. These area measurements point to the likelihood that halloysites, like kaolinites, commonly occur as quite small particles in soils. The fineness of their particles very likely reflects compositional or structural features 
that have limited crystal growth. In the case of the high surface area halloysites studied by Singer et al. (2004), it is likely that the high degree of substitution of $\mathrm{Al}$ by $\mathrm{Fe}$ and/or Ti introduced strains into the layer structure that limited the size of particles. The clay fractions of two halloysitic soils studied by Takahashi et al. (2001) were found to have high CECs and a high selectivity for $\mathrm{K}^{+}$in addition to high surface areas, and ${ }^{27} \mathrm{Al}-\mathrm{NMR}$ showed that their constituent halloysites had 2\% tetrahedral $\mathrm{Al}$, and probably also some $\mathrm{Al}$ vacancies and impurity Fe in their octahedral sheets. They contained some Fe as oxides, which could have been present as surface coatings, and some 2:1 Si:Al minerals could also have been present in the clay fraction, even if not detected there, because of their obvious appearance in coarser fractions. While these authors could not reach unequivocal conclusions about the extent to which halloysite per se contributed to the unusual properties of these soils, the dilemma they encountered was the result of the complex mineral assemblages that could involve halloysites in soils, and emphasises how halloysites, like kaolinites, can be bound into multi-phase associations in soils.

Halloysites often occur in close associations with iron oxides and oxyhydroxides in soils (Churchman and Theng, 1984; Bakker et al., 1996; Takahashi et al., 2001; Pochet et al., 2007; Etame et al., 2009). Pochet et al. (2007) showed that they can form stable microaggregates with Fe oxides, and especially ferrihydrite that probably preserve the halloysites in spite of nearby soils being at an advanced state of weathering which would normally drive the change towards kaolinite in a humid tropical environment.

In a study of soils formed from nephenilite (alkali- and rare-earth-rich lava) in tropical Cameroon, Etame et al. (2009) demonstrated a chemical dependence of the halloysites upon parent minerals: Ce-rich halloysite characterized alteromorphs formed from the mineral phillipsite, Fe-rich halloysite characterized alteromorphs on clinopyroxene, Ca-rich halloysite characterized alteromorphs on hauyne, and K-rich halloysite characterized alteromorphs on leucite. A Ce-rich halloysite $\left(\mathrm{Ce}_{2} \mathrm{O} 0.1 \%\right)$ was also identified in saprolite derived from hydrothermally-altered nephenilite (Etame e al., 2009).

\subsubsection{Occurrence of illite in soils}

Illites can form in soils by weathering as a result of transformation, in the solid phase, from micas (Section 20.2.4.3, and also, via biota, Section 20.2.5.3) and, like most of the other secondary minerals, they can also precipitate by neogenesis out of solution. There is little 
doubt that they most commonly form by transformation from primary micas. The degree of transformation they have undergone differs greatly, so that, in younger and less weathered soils, especially those in arid environments (Section 20.2.5.2), the clay-sized micaceous phases may be mainly a product of comminution of primary micas by physical weathering processes (e.g., Fanning et al., 1989). In this case, the secondary phase may be better described as clay-sized mica rather than as illite. However, the term illite is used quite widely to describe mica-like clay-size minerals in soils, as already noted (Section 20.2.4.3). In all but the youngest or little-weathered soils, the micaceous phase in their clay fraction, hereafter referred to as illite, or illitic, contains some expanded layers; hence some degree of interstratification of the K-rich illite layers with vermiculite or smectite layers that have become depleted in $\mathrm{K}$ through its displacement by hydrated cations. Hence they are expandable.

Micas, especially muscovite and biotite, are particularly abundant in mica schists and some other metamorphic rocks (Fanning et al., 1989). Mica schists are especially abundant because they originate from the metamorphosis of argillaceous sediments such as shales and slates (ibid.). According to Fairbridge and Bourgeois (1978), shales comprise $~ 40-60 \%$ of all sedimentary rocks by volume and $\sim 80 \%$ of crustal weathering products. As relatively soft minerals, micas in the schists are readily broken down during transport and sedimentation. Thence, they become important components of shales and slates, the types of sedimentary rocks from which they originated. Hence, illite may originate by inheritance from micas in underlying or nearby sedimentary shales or slates that may ultimately be recycled by metamorphosis into new mica schists (e.g., Garrels and Mackenzie, 1971). Illite in soils formed from these widespread sedimentary rocks is most abundant in the coarse clay $(0.2-2$ $\mu \mathrm{m})$ size fraction (Fanning et al., 1989).

On the other hand, illite that has undergone considerable transformation to include expansible 2:1 layers of vermiculite and/or smectite is more likely to occur in the fine clay $(<0.2 \mu \mathrm{m})$ size fraction (Fanning et al., 1989; Laird et al., 1991; Robert et al., 1991). Studying soil clays derived from the major sedimentary rocks, Robert et al. (1991) found that illite-smectite interstratified phases (I-S) are "the most widespread and representative soil clays", a conclusion that was echoed by Velde and Meunier (2008; see also Section 20.2.5.3). Generally, they are randomly interstratified (Thompson and Ukrainczyk, 2002). Robert et al. (1991) distinguished two types of I-S. One, which they termed "micromicas", may occur as large crystals and have layers with $1 \mathrm{~nm}$ periodicity that are separated by "swelling spaces" 
(Robert et al., 1991). It is a "structural" type of interstratification. The other type consist of random superpositions of elementary particles, "like monolayers", to quote Robert et al. (1991). These authors characterized it as a "textural" type of interstratification which is the same type as that identified by Nadeau et al. (1984) in the context of diagenetic clay minerals in sandstones.

One of the main conclusions to be drawn from Robert et al.'s (1991) work is that I-S, as common soil clays, differ significantly from reference clays. Among their defining characteristics, they are always multiphase, their smectitic phase is dominantly dioctahedral, and Al-rich, hence beidellitic (Robert et al., 1991), their particles have a very small lateral extension (often 30-50 nm) and a very small number of layers. Furthermore, their smectite component includes partially collapsed layers and the clays have a high external surface area, particularly relative to their internal surface area (Robert et al., 1991). Laird et al. (1991) studied an I-S mineral that fully occupied fine clay fractions of a soil and found that the smectitic layers comprised a high-charge Fe-rich montmorillonite. This finding is at odds with several reports of soil smectites being more beidellitic, albeit Fe-rich (see Section 20.3.5). Laird et al. (1991) also found that the illitic layers had a low, largely tetrahedral charge, and were dioctahedral. Their layer charge was more typical of a beidellite than an illite. These authors speculated that the illitic layers in the I-S could themselves constitute a break-down product of illite in the coarse clay fraction or else they could have formed by the collapse of pre-formed beidellite layers, but the evidence available to Laird et al. (1991) favored neither mechanism. Examination of a fine clay $(0.02-0.06 \mu \mathrm{m})$ fraction by HRTEM in a later study (Laird and Nater, 1993) revealed that this was composed of (1) two-layer elementary illite particles, which were most abundant, (2) one-layer elementary smectite particles, and (3) rare discrete multilayer illite particles. The elementary illite particles could be separated from the smectitic component and were shown to comprise a rectorite-like phase with alternate swelling and non-swelling layers except that, in this case, the swelling and nonswelling layers each had a similar low charge of $\sim 0.47$ per formula unit in contrast to rectorite, with $\sim 0.35$ for the swelling and $\sim 0.85$ for the non-swelling layers (Laird and Nater, 1993). Like Robert et al. (1991), Laird and coauthors identified this I-S mineral phase as being characteristic of soils. Whereas it was identified as a component of an interstratification with smectite by Laird et al. (1991), the ease of its separation, together with the lack of a $1 \mathrm{~nm}(10 \AA)$ peak for illite in XRD analysis, indicated that the I-S phase in this 
fine clay fraction is a "textural" type of interstratification, similar to those identified by Nadeau et al. (1984), and, in soils, by Robert et al. (1991).

Illite can also form by neogenesis. Such illites include some that have formed in close proximity of feldspars, most probably out of solutions bathing the feldspars (Section 20.2.4.2). In many soils in Australia (Norrish and Pickering, 1983), and also in Iran (Mahjoory, 1975) and in some semiarid soils in North America (Nettleton et al., 1970), there is a concentration of illite towards the surface of soils, contrary to the trend in soils where micas are subject to transformation, which leads to increasing vermiculite and smectite at the expense of illite towards soil surfaces. The trend towards more illite in surface soils than at depth suggests that illite may have formed by neogenesis in these soils. Norrish and Pickering (1983) characterized a Fe-rich illite from a deposit ('Muloorina') near a seasonally wet and dry central lake in Australia (Lake Eyre) as a product of neogenesis in the lacustrine environment (although it may not be pedogenic) (Wilson, 1999). Its neogenetic origin was suggested by the very uniform shape and size of its particles, which are almost all $\sim 0.07 \mu \mathrm{m}$ in diameter (see Churchman, 2000, Figure 1.8a). Similarly sized and shaped particles of illite are also found in a number of soils in various parts of Australia (e.g., Willalooka - see Norrish and Pickering, 1983). The size, shape and uniformity of these illites are in complete contrast to those originating from micas in rocks. They are more similar in their size and shape to the lacustrine illite from Muloorina (Norrish and Pickering, 1983) than to clay-size break-down products of rock-derived micas. Bergkaut et al. (1994) found a mineral alongside halloysite in soils formed from pyroclastic layers in a semiarid climate in Israel that comprised very thin crystallites of a randomly interstratified illite-smectite with $70 \%$ illite layers and which they considered had formed authigenically. An authigenic origin for illite/mica in soils in Hawaii that was proposed by Swindale and Uehara (1966) was later discredited when oxygen isotope ratios for the fine quartz found alongside the mica in the soils indicated its origin as tropospheric continental dust (Rex et al., 1969) and it was concluded by Syers et al. (1969) that the mica had arrived in the soils in aerosolic dust along with the quartz. Similar findings have been made in other countries such as Japan and New Zealand (e.g., Mizota and Takahashi, 1982; Stewart et al., 1984; Inoue and Sase, 1996; Nagashima et al., 2007; Marx et al., 2009). 


\subsubsection{Occurrence of vermiculite in soils}

Most vermiculites in soils have formed by the transformation of micas by weathering (Wilson, 1999), although some form by the analogous transformation of chlorites (Wilson, 1999; Velde and Meunier, 2008) (see also Sections 20.2.4.3 and 20.2.4.4). Dioctahedral vermiculite is much more common in soil clays than its trioctahedral counterpart (Wilson, 1999). This is because, although the first transformation products of trioctahedral biotite (and phlogopite) and also chlorite on weathering may well be trioctahedral, for example, the regularly interstratified phases, hydrobiotite and chlorite-vermiculite, a variety of structural and composition changes occur within the aluminosilicate layers alongside the loss of $\mathrm{K}^{+}$ during vermiculitization (see Section 20.2.4.3). The net result of these changes is the loss of $\mathrm{Al}$ from the tetrahedral sheet and its gain in the octahedral sheet at the expense of $\mathrm{Fe}^{2+}$ and Mg. As a consequence, the layer structure becomes more dioctahedral (Wilson, 2004). Nonetheless, in the North Island of New Zealand, the occurrence of trioctahedral vermiculite in a soil derived from a composite of weathered tephras was attributed to the presence of biotite which was known to occur in some of the parent tephras because such tephras had been preserved unweathered in layers within sediments in lakes adjacent to the soil (Lowe, 1986).

Although dioctahedral micas are much more stable in the weathering environment than trioctahedral micas, their alteration can also lead eventually to vermiculites, sometimes via regularly interstratified mica-vermiculites, as found in soils formed on mica schists in the South Island of New Zealand (Churchman, 1980). However, where pHs are moderately acid, that is, between ca. 4.6 and 5.8, organic matter contents are relatively low and there is frequent wetting and drying - all conditions that are conducive to the vermiculitization of micas - Al-hydroxy species are deposited, usually as polymeric cations, in the interlayers of vermiculites (and also some smectites). As a result, vermiculites in soils most often occur with incorporated hydroxyl-Al interlayers (see Churchman, 2000; Wilson, 2004).

Only few reports have considered the possibility of a neogenetic origin for vermiculite. These include those of Smith (1962), who observed that vermiculite replaced feldspars in some Scottish soils of igneous rock origin, and also Barshad and Kishk (1969), who found dioctahedral micas in soils derived from rocks containing no mica. Ildefonse et al. (1979) found that a vermiculite formed as large (up to $150 \mu \mathrm{m}$ ) crystals by crystallisation from solution, hence by neogenesis, within a weathered metagabbro containing plagioclase 
and amphiboles, hence no micaceous pre-cursor. However, this trioctahedral vermiculite proved to be unstable within the soil above the weathered rock, where it was replaced by a Fe-rich smectite.

\subsubsection{Occurrence of smectite in soils}

Smectites occur in soils either because they are inherited from parent materials, have been formed by neogenesis by crystallization from solutions of the constituents of rocks, or else they are the products of the strong, or long-term, transformation of micas and chlorites. They share the possibility of an inherited origin with most other types of clay minerals. Either (1) pre-formation in, or prior to, the development of parent materials, for example, sedimentary rocks; (2) a detrital origin from other eroded soils or soft sediments; and, arguably also (3) pre-formation in the soil profile but under previous conditions that differ from those currently prevailing (Buol, 1965), have been responsible for the occurrence of at least a large part of the smectites found in skeletal soils and soils in arid zones and also in some soils found in strongly leaching climatic regimes (Wilson, 1999). Hence inheritance may be the main, or a major source of smectites in Entisols, Aridisols, and Ultisols, and could also have contributed to soils classified into almost all of the other orders of Soil Taxonomy (Wilson, 1999).

The possible origin of smectites by the transformation of micas and chlorites by acid leaching, and particularly, podzolization, processes was discussed in Sections 20.2.4.3, 20.2.4.4, and 20.2.5.3 (and particularly Section 20.2.5.3.2). The smectites formed in this way, and hence those found in the eluvial horizons of podzols, that is, Spodosols, are beidellitic (Ross and Mortland, 1966; Churchman, 1980; Carnicelli et al., 1997; Wilson, 1999; April et al., 2004), consistent with the effect of acid leaching in selectively removing structural Mg, especially, from 2:1 Si:Al aluminosilicates which thereby become more aluminous. As the products of changes in the solid-state they may also be expected to occur, like most illites (Section 20.3.3), mainly within the coarse clay fractions of soils.

Most typically, however, smectites have been formed in soils by neogenesis from alkaline solutions that have developed under poor drainage. Their formation requires high concentrations of $\mathrm{Si}$ and basic cations and is therefore favored typically from basic parent materials. Concentrations of smectites comprising bentonite deposits form under similar conditions, most commonly from large bodies of water, for example, lakes or marine lagoons 
or shallow marine embayments into which tephra has fallen or been deposited fluvially (e.g. Millot, 1970; Chamley, 1989; Naish et al., 1993; Velde, 1995; Gardam et al., 2008). Work in New Zealand on detrital glass deposits in shallow marine Holocene muds showed that the early diagenetic transformation of glass to smectite occurred as a two-stage process initially with diffusion-controlled hydration and dissolution of glass followed by first-order precipitation of smectite (Hodder et al., 1993). Interstitial marine waters of slightly reduced salinity (lower $\mathrm{Ca}^{2+}, \mathrm{Na}^{+}$) and higher concentrations of dissolved silica relative to those in ocean water played a key role in the smectite formation. Rate constants for both the dissolution of glass and the precipitation of smectite were two orders of magnitude greater than those determined for the formation of clay minerals on similar tephra-derived glassy materials in soils (Hodder et al., 1993).

Some of the knowledge of the conditions for the formation of smectites by neogenesis has come from studies of the conditions for their formation in the laboratory (e.g., Harder, 1972; 1977; Siffert, 1978; Farmer, 1997). The requirements for a successful synthesis of a smectite included $\mathrm{pH}>7.5$ and some $\mathrm{Mg}$ and/or Fe in solution. In nature, smectites are often found in calcareous environments, which provide a high $\mathrm{pH}$, and often also where leaching is infrequent or minimal, or where there is an impediment to drainage (e.g., Fieldes and Swindale, 1954; Lowe et al., 1996). However, smectites can form from many types of rocks or geological deposits and minerals, provided that they can provide a sustained supply of the necessary cations and silica (Churchman, 2000).

The origin of smectites occurring in soils is not always clear-cut. While smectites formed by transformation may occur in relatively large particles, as already noted, smectites most often are especially fine-grained materials, a feature more consistent with a neogenetic origin. Somewhat confusingly, Boettinger and Southard (1995) found an aluminous dioctahedral smectite occurring in each of the sand, silt, and clay fractions of an arid zone soil. Although the soils also contained biotite, a trioctahedral vermiculite, and a hydroxylinterlayered 2:1 Si:Al aluminosilicate, Boettinger and Southard (1995) considered that the smectite in all size fractions was neogenetic, with the coarser particles comprising aggregates of smectite cemented by opaline silica. A geomorphic and salinity gradient transect in another arid environment contained smectite in both its beidellitic and montmorillonitic varieties (Reid et al., 1996). These authors considered that there were multiple origins for the smectite in the soils. The beidellites probably originated from shales by transformation processes, and, while some montmorillonite was inherited, the groundwater chemistry was 
suitable for some having been neoformed. Studying a toposequence of soils surrounding an alkaline-saline lake in Brazil, Furquim et al. (2008) found smectites in both an upper zone that is largely higher than lake level and also in a lower zone that is submerged seasonally by the lake. However, the smectites in the two zones were different structurally and compositionally, pointing to different origins for each of them. In the upper zone, a dioctahedral Fe- and Al-rich ferribeidellite had formed as a result of the transformation of micas whereas in the lower zone, trioctahedral Mg-rich smectites that were characterized as saponitic or stevensitic had formed, apparently by chemical precipitation from the lake, i.e., by neogenesis (Furquim et al., 2008).

Most smectites in soils are dioctahedral, including the products of the alteration of Mg-rich serpentinite, where saponite might be expected to form (Wildman et al., 1968). Saponite often does form as a weathering product - for example, within the crystals of altered rocks containing ferromagnesian minerals (Section 20.2.4.1) - but it gives way to dioctahedral smectites in the upper parts of soil profiles (Section 20.2.5.1). Of these, the beidellitic and montmorillonic varieties of smectites are most common in soils, although nontronites have been found there (Sawhney and Jackson, 1958). Even so, nontronite is thought to be particularly susceptible to attack by complexing agents from roots (Farmer, 1997). Generally, soil smectites have more tetrahedral Al and more octahedral Fe than the type of montmorillonite associated with most bentonites (Wilson, 1987; Weaver, 1989). There appears to be a tendency towards a ferri-beidellite composition for smectites in soils, albeit that a given soil smectite is most probably heterogeneous in composition. Petit et al. (1992) found that the smectite in a lateritic profile in Brazil could be described as a true solid solution between nontronite and beidellite end members.

Smectites themselves can be subject to alteration and change within soils. As already discussed (Section 20.3.1), smectites can incorporate kaolinite layers to become interstratified kaolinite-smectites (K-S), most probably following the prior adsorption of hydroxyl-Al species into their interlayers (e.g., Ryan and Huertas, 2009). Kaolinite appears to be the ultimate product of this process (Section 20.3.1). Nevertheless, Fisher and Ryan (2006), studying a chronosequence of soils on fluvial fill terraces in tropical Costa Rica, found that there was a transition with age from smectite-rich to kaolinite-rich soils without any K-S intermediates being formed along the way. The smectite was a beidellite and the kaolinite was disordered. These authors generalised their results and those of others who had studied this transition by suggesting that K-S forms as an intermediate phase in the transition from $\mathrm{S}$ 
to $\mathrm{K}$ where the MAP is between $\sim 500$ and $\sim 2000 \mathrm{~mm}$, whereas the transition occurs without a $\mathrm{K}-\mathrm{S}$ intermediate when MAP is more than $\sim 3000 \mathrm{~mm}$. The changes may be more subtle, however, resulting in a change within the composition and structure of the smectite. Thus a low-charge beidellite inherited from the parent pelitic sediment was converted to a highchange beidellite during the formation of a Vertisol (Righi et al., 1995).

\subsubsection{Occurrence of palygorskite and sepiolite in soils}

The fibrous 2:1 Si:Mg clay minerals, palygorskite and sepiolite - the so-called hormite minerals - undoubtedly occur in the sedimentary parent materials of many soils containing these minerals; and, until relatively recently, their inheritance from these parent materials was considered to be their source in soils (Singer, 2002). However, both have since been found to form in soils in many countries, including Israel, Syria, Egypt, Morocco, Iraq, Iran, Turkey, Spain, Portugal, China, the United States, Mexico, Australia, South Africa, and Argentina (see summaries in Zelazny and Calhoun, 1977; Singer, 1989, 2002; Churchman, 2000; and reports by Owliaie et al., 2006; Bouza et al., 2007; Kadir and Eren, 2008). Even so, they almost invariably form in calcareous environments (Singer, 2002) and often in calcretes, in particular. Verrechia and Le Coustumer (1996) have listed many reports of their occurrence in calcretes and there are also later similar reports (e.g., Kadir and Eren, 2008). The main conditions under which they form have been summarized as (1) a fluctuating saline or alkaline groundwater, (2) strong and continuous evaporation, and (3) a sharp textural transition (Singer and Norrish, 1974; Singer, 1989, 2002). A strong textural transition means that water is likely to accumulate at the transitional boundary, hence maintaining a saturated solution from which the hormite minerals can precipitate, under even arid conditions. Calcretes (or caliches) provide such a transition and, hence, these minerals are often found in or below these secondary carbonate concretions. Albeit that palygorskite is most commonly associated with calcareous soils, gypsiferous soils appeared to contain more palygorskite than calcareous soils within the same region in Iran (Khormali and Abtahi, 2003; Owliaie et al., 2006). It appears that an increase in the concentration of $\mathrm{Mg}$ that occurred upon the precipitation of gypsum was particularly conducive to the neogenesis of palygorskite (Owliaie et al., 2006). 
Chemically, the neogenetic formation of both palygorskite and sepiolite requires considerable magnesium and silicon in a high $\mathrm{pH}$ solution. Palygorskite would also require some $\mathrm{Al}$ and $\mathrm{Fe}$ (Singer, 1989). Although there had been no reproducible synthesis of palygorskite, at least up until Singer (2002), sepiolite has been synthesised many times from alkaline solutions with high activities of Mg, and Si (see, e.g., Churchman, 2000), confirming the conditions for their formation in nature. In nature, the required $\mathrm{Mg}$ may originate in dolomite or $\mathrm{Mg}$-containing calcite. The conversion of high- $\mathrm{Mg}$ calcite into low-Mg calcite has been observed to accompany palygorskite formation (Singer, 1989, 2002). The required Si may derive from the dissolution of any silicate mineral, including illite and chlorite (Gálan et al., 1975; Gálan and Castillo, 1984; Dias et al., 1997; Owliaie et al., 2006), smectites (see Singer, 1989; Bouza et al., 2007; Kadir and Eren, 2008), and even quartz (Singer, 1989, 2002). It is not surprising that smectites may give rise to palygorskite and/or sepiolite because the chemical conditions of high $[\mathrm{Mg}]$, high [Si], and a high $\mathrm{pH}$ are shared between these three mineral types. Bouza et al. (2007) suggested that, as Mg concentration increased with time in calcic and calcic-gypsic horizons in a weathering profile in Argentina, smectite gave way to palygorskite. Nor, therefore, is it surprising that palygorskites and sepiolites often occur together with smectites in soils and may disappear in their favor, as observed by Paquet and Millot (1972), Khormali and Abtahi (2003), Owliaie et al. (2006), and Bouza et al. (2007), for example. Paquet and Millot (1972) suggested that this dissolution and reformation occurs when rainfall rises to a MAP of merely $300 \mathrm{~mm}$. Khormali and Abtahi (2003) found an inverse relationship between the occurrences of palygorskite and smectite with regard to soil available water, measured by the ratio of precipitation to plant transpiration. Smectite was favored over palygorskite at higher values of soil available water. On the other hand, in soils in an irrigated cropping area in India, smectite predominated in the rain-fed soils, but irrigation, which exacerbates salinity and sodicity (and attendant waterlogging), had led to the formation of palygorskite in just 40-50 years (Hillier and Pharande, 2008). It appears that evaporative concentration of the irrigation waters has led to solution conditions more favorable to the formation of palygorskite than smectite. It has also been observed that the highly siliceous environment in which palygorskite and sepiolite form may give rise to an excess of $\mathrm{Si}$ in solution, which results in deposits of secondary silica upon their formation (Singer, 1989; Verrecchia and Le Coustumer, 1996). Experiments with nonsoil palygorskite and sepiolite showed that they were unstable, giving rise to kaolinite, within the rhizospheres of common agricultural crops (Khademi and Arocena, 2008). In this situation 
the high acidity of the rhizospheres and the extraction of $\mathrm{Mg}$ from the minerals by the crops had destabilised them (see also Section 20.2.5.3).

Palygorskite is much more common than sepiolite in soils (Singer 1989, 2002). However, Bouza et al. (2007) found that sepiolite formed chronologically after palygorskite within a mature calcrete.

\subsubsection{Occurrence of iron oxides in soils}

Iron oxides and oxyhydroxides (generically known as "iron oxides") occur in almost all soils (Allen and Hajek, 1989). They are usually the product of the oxidation of Fe(II) occurring either within the structure of primary minerals or upon their breakdown by weathering, whereupon the newly formed Fe(III) hydrolyzes (e.g., Churchman, 2000). The resulting iron oxides are essentially insoluble at the $\mathrm{pH}$ values encountered in soils and are mainly remobilized by reduction. As we have seen for soils from volcanic materials particularly (Section 20.2.4.6), the specific Fe oxides which occur in a soil depend largely on the environmental conditions under which they were formed.

Following Schwertmann and Taylor (1989), Cornell and Schwertmann (1996), Churchman, (2000), Bigham et al. (2002), and Schwertmann (2008), in the main, we can make some generalisations regarding the conditions under which goethite or hematite are formed. Goethite, which is yellow to yellowish-brown in color depending partly on particle size, is found in soils almost everywhere. But it is most common in cool and temperate climates and where there are high contents of organic matter. Hematite, by contrast, is most common in aerated soils in generally warmer temperatures, in the tropics and subtropics and also in arid and semiarid regions, as well as in xeric (or Mediterranean) climate zones. Hematite is characteristically red in color. High organic matter content favors the formation of goethite over hematite and it is not uncommon to find soils with yellowish goethitic topsoil over red hematitic subsoil. Goethite also tends to be favored at low $\mathrm{pH}$, hematite at higher pHs. Laboratory syntheses have shown that, from ferrihydrite as a starting material, the most goethite was formed at a $\mathrm{pH}$ near 4 , while the maximum yield of hematite occurred at $\mathrm{pHs}$ between 7 and 8 . Synthetic work has also shown that hematite is favored over goethite by a high rate of release of Fe into solution. This finding is consistent with the observed occurrence of hematite in a soil on basalt but not in a nearby soil on shale (Kämpf and 
Schwertmann, 1982). Hematite is the preferred phase where the activity of water is low, as in small pores, and is also the most stable phase thermodynamically in smaller particles (Langmuir and Whittemore, 1971). These latter authors predicted that goethite would be the stable phase in particles $>76 \mathrm{~nm}$ and hematite in smaller particles. While Al substitution for Fe is common in all Fe oxides, synthetic work has shown that goethite can accommodate more Al in its structure than hematite. Fritsch et al. (2005) explained yellowing towards the surface of a weathering profile on sediments in Brazil by upward changes in both the relative amounts of goethite and hematite and also in the extent of Al-substitution of goethite.

Hematite and Al-poor goethite that are remnants of prior weathering of the sediments in a different climate have dissolved, with Al-rich goethite forming in their place by recrystallization, according to Fritsch et al. (2005). In some tropical soils the formation of hematite is at the expense of goethite when temperatures are high, the aeration good, the $\mathrm{pH}$ near neutrality, and organic matter is rapidly transformed (Etame et al., 2009).

Poorly crystallized or nanocrystalline ferrihydrite is also widespread in soils, particularly in those formed from tephra, and also in the illuvial or placic B horizons of podzols (see Churchman, 2000, and McDaniel et al., Section 33.3). Its formation is favored by rapid oxidation of $\mathrm{Fe}$ and when silicates and organic matter, particularly, but also other ions, are present in soil solutions to inhibit crystallization of goethite and other Fe oxides, including lepidocrocite (Churchman, 2000; Bigham et al., 2002), and soil ferrihydrites can contain significant amounts of Si (Childs, 1992). Nonetheless, ferrihydrite often also occurs in association with goethite and lepidocrocite (Bigham et al., 2002). In the laboratory, it has been found that ferrihydrite is easily converted to hematite (Schwertmann and Taylor, 1989). Nonetheless, ferrihydrite and hematite are rarely found together in soils, indicating that the conversion is also rapid in nature. Even so, Adomo et al. (1997) found ferrihydrite together with both hematite and goethite in the products of weathering of a volcanic rock by lichens. They appear to occupy different microsites in the altering rock.

The formation of lepidocrocite is favored by seasonally anaerobic conditions in noncalcareous soils. It forms when there is an accumulation of $\mathrm{Fe}^{2+}$ together with a slow rate of oxidation (Alekseev et al., 2005). Lepidocrocite is found in ochreous mottles, root mats, and crusts (Cornell and Schwertmann, 1996; Churchman, 2000; Bigham et al., 2002). It is often found in association with goethite. Lepidocrocite was found in all three soils in a hydromorphic sequence in Ohio (Smeck et al., 2002), but in different amounts according to ease of drainage. These authors concluded that the formation of lepidocrocite was favored in 
horizons that were saturated for between $5 \%$ and $50 \%$ of the part of the year when the soil temperatures were $>5^{\circ} \mathrm{C}$. Alekseev et al. (2005) found that lepidocrocite was concentrated in the bottom of the "active" layer immediately above permafrost in Russia. The existence of the permafrost below concentrates solutes in this layer and the low temperature slows oxidation.

Maghemite occurs in soils in the tropics and subtropics, often in association with hematite, and most often in surface soils (Schwertmann and Taylor, 1989; Churchman, 2000; Bigham et al., 2002). A common mode of formation of maghemite appears to be through the heating of other Fe oxides in the presence of organic matter, as occurs in bush and forest fires. Schwertmann and Taylor (1989) suggested that a temperature of between $300{ }^{\circ} \mathrm{C}$ and $425^{\circ} \mathrm{C}$ is conducive to the formation of maghemite. It may also form by the oxidation of precursor magnetite in parent materials, according to the authors cited herein. However, a completely different, alternative origin for this magnetic mineral was suggested by Rivers et al. (2004) to explain its occurrence in association with hematite in soils on alluvium that has in-filled low-lying areas in Tennessee. These authors suggested that there had been reduction of $\mathrm{Fe}(\mathrm{III})$, either microbial or abiotic, to form magnetite in the hydromorphic soil. Magnetite occurs in many soils but is usually found in the sand and silt fractions rather than the clay fraction and is generally considered to have been inherited from the parent rock. Nonetheless, a partially oxidised form of magnetite was found to occur along with hematite in nodules in an Oxisol in Brazil that has developed from magnetite-free parent materials, so a pedogenic origin has been invoked for the mineral in this soil (Viana et al., 2006). These authors considered that the magnetite in this soil formed under seasonal burning and also that it is becoming converted to hematite by atmospheric oxidation in air. Some authors (Maher and Taylor, 1988; Geiss and Zanner, 2006) have considered that some magnetite in soils may have had a bacterial origin (see Section 20.2.5.3.5).

Other Fe oxides formed in soils include schwertmannite, from acid sulfate soils (see Section 20.2.5.3), and "green rusts", found in a highly hydromorphic soil by Trolard et al. (1997).

Iron oxides can be extremely labile in the soil environment. They are quickly reduced or oxidised when redox conditions change in soils, as they can do intermittently over even quite short time periods (hours to days or weeks) and also seasonally. The activity of microbes can play a central role in the formation and dissolution of iron oxides. A wide 
variety of microorganisms are involved in these processes and much remains to be understood about their operation (Fortin and Langley, 2005). Suffice it to say here that Fe oxides are often biogenic (see also Section 20.2.5.3). Furthermore, there is widespread recognition that Fe is commonly mobilized in soils by reduction occurring through the activity of microbes in anoxic conditions (Robert and Berthelin, 1986; Schwertmann and Taylor, 1989; Robert and Chenu, 1992). The ensuing reduction occurs along with the oxidation of decomposing biomass.

It is a feature of iron oxides in soils that they are most often closely associated with the other components of soils, including particularly aluminosilicate clay minerals, which as small charged particles attract Fe oxides and other reactive species to their surfaces and pores. Following the well-accepted convention that (citrate-) dithionite-extractable Fe represents free, or well-crystallized oxides, (acid ammonium) oxalate-extractable Fe represents poorly crystallized oxides, and pyrophosphate-Fe stands for the metal associated with organic matter, Table 20.5 shows the relative amounts of these forms of Fe and their distribution in relation to aluminosilicate clays in a range of soils, mainly taken from papers in the most recent literature. which have presented data for both different forms of Fe and also estimates of the relative abundance of the phyllosilicates present. The data for selected horizons within one soil of each type are given in Table 20.5. The soils in Table 20.5 represent a wide range of soil orders and lithologies, and soil horizons are also given for each soil.The table shows that there were substantial proportions of iron oxides and Fe-organic complexes in their various forms in all horizons of all the soils examined. They were associated with virtually all of the types of phyllosilicates that occur in soils.

\section{$\underline{\text { Insert Table } 20.5 \text { here }}$}

\subsubsection{Occurrence of manganese oxides in soils}

Manganese oxides are a widespread but usually minor component of soils (McKenzie, 1989; Dixon and White, 2002). Generally, they occur in soils in small particles, leading to poor peaks in XRD. They are more abundant in soils from mafic,that is, basic, rocks than from siliceous materials (Dixon and White, 2002). Because reduced Mn (Mn(II)) is very soluble as a divalent cation and is mobile in soils, they commonly form as coatings on rocks, on ped 
surfaces and on other soil particles as well as in concretions, segregations, pans, and nodules, often with Fe oxides (McKenzie, 1989; Churchman, 2000; Dixon and White, 2002). They are characteristically black in color but give a brown streak. Their distinctive appearance, especially in, for example, concretions and nodules, gives a strong indication of prior oxidation, including by seasonal drying as noted earlier in this chapter (e.g., Birkeland, 1999; Vespraskas et al., 2004). Churchman et al. (2010) used their occurrence to trace a history of dehydration, leading to the conditions for the formation of kaolinite rather than halloysite in some saprolites in Hong Kong. Manganese oxides form when conditions favor their oxidation; hence, they are often found in subsoils with a higher $\mathrm{pH}$ than the upper layers and are common in calcareous soils. Manganese also occurs as a Mn carbonate (rhodocrocite) in calcareous soils (Dixon and White, 2002).

Among the polymorphs of $\mathrm{MnO}_{2}$, birnessite, especially, and lithiophorite have most often been identified in soils. However, birnessite occurs in soils as poorly developed crystals and the crystals of birnessite produced by biological oxidation of $\mathrm{Mn}(\mathrm{II})$ in the laboratory are similarly poorly developed, as are those precipitated from solutions with a high Si content (Dixon and White, 2002), suggesting that their formation in soils occurs via microbiological oxidation or at an early stage of soil formation, or both (McKenzie, 1989; Dixon and White, 2002). Todorokite has been identified in Texas in nodules from a Vertisol and on the surface of weathered siderite boulders (Dixon and White, 2002) and appeared in large crystals in saprolite on both granite and volcanic tuff in Hong Kong (Churchman et al., 2010), as seen_in Fig. 20.11, alongside both halloysite tubes and platy kaolinite particles. 


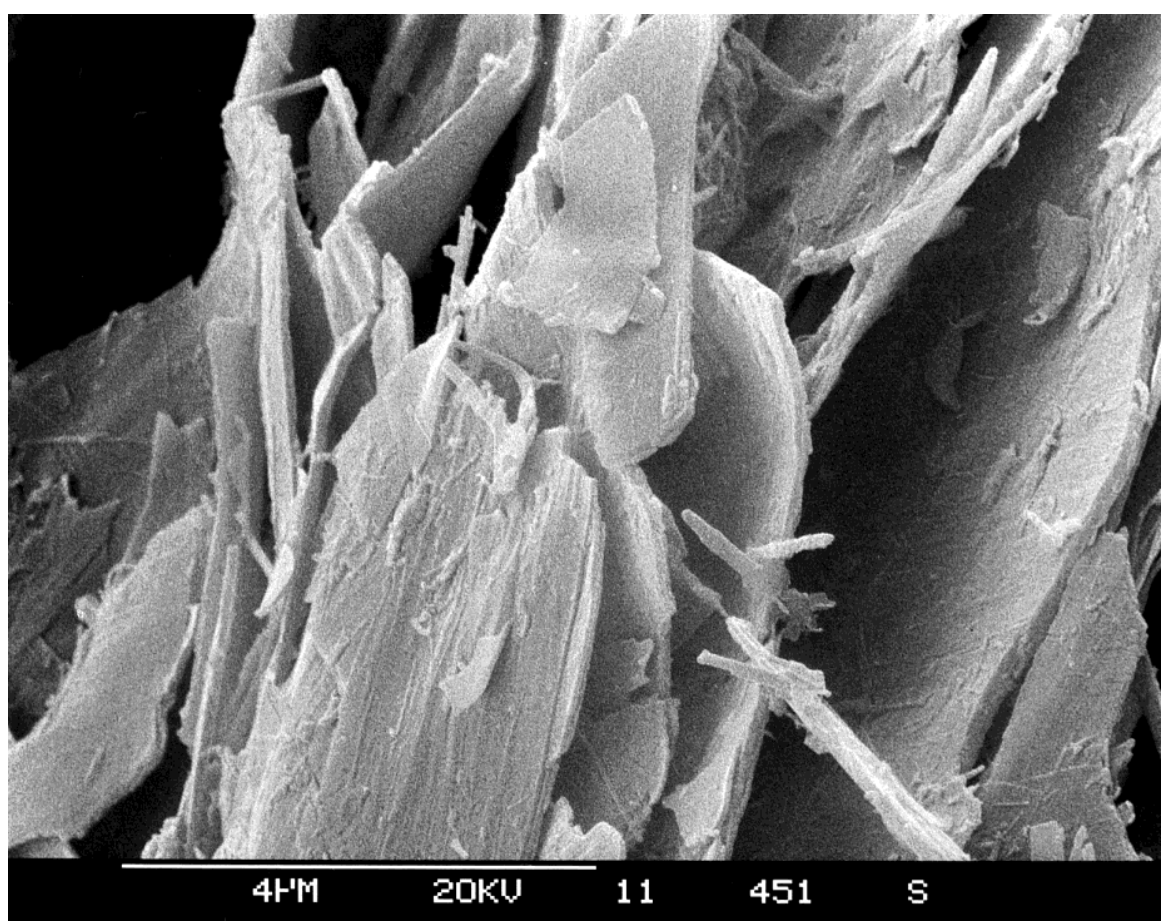

FIGURE 20.11 Scanning electron micrograph of crystals of todorokite, with some kaolin minerals, in infill formed as a result of the weathering of granitic saprolite in Hong Kong. (Photo by Stuart McClure. Reproduced with the permission of the Geotechnical Engineering Office, Civil Engineering Office, Hong Kong.)

\subsubsection{Occurrence of aluminum hydroxides, oxyhydroxides, and oxides in soils}

Gibbsite is the most common of the various hydroxides, oxyhydroxides, and oxides of aluminum in soils (e.g., see Churchman, 2000). It occurs in soils of any age whenever Si is in low supply. Hence, it occurs under strong leaching. Where there is a gradation in the extent of leaching, often because of an altitudinal change, gibbsite may occur in the most heavily leached soils whereas kaolinite occurs when there is a lesser degree of leaching. This tendency appeared to be the case for temperate mountain soils in South Carolina (Norfleet et al., 1993), as well as for soils in the humid tropics, where gibbsite was dominant in the highlands and kaolinite in the lowlands (Herbillon et al., 1981). In some Oxisols, gibbsite may be most abundant in upper horizons but decrease in concentration with depth (Huang et al., 2002). These authors also pointed out that, in the tropics, particularly, landscapes may be extremely old and the occurrence of gibbsite not necessarily related to the present soil environment. This polygenesis was illustrated in a study by Bhattacharyya et al. (2000), who found gibbsite occurring alongside mica-vermiculite phases containing hydroxy-Al interlayers in an acidic tropical soil in India. However, it has long been considered (Jackson, 
1963) that the presence of these latter aluminous interlayers preclude the formation of gibbsite by the so-called anti-gibbsite effect. Bhattacharyya et al. (2000) explained the presence of gibbsite and these interlayers together by the prior formation of gibbsite, possibly mainly from sillimanite, in an earlier neutral to alkaline $\mathrm{pH}$ environment. The aluminous interlayers, by contrast, are products of weathering in the current acidic environment. An apparent contradiction of the "anti-gibbsite" effect was also seen by Jolicoeur et al. (2000) when they observed each of hydroxyl(-Al) interlayered vermiculite (HIV), kaolinite and/or halloysite, and gibbsite occurring together as pseudomorphs after biotite in scanning electron micrographs of saprolites and soils in central Virginia. They were considered to coexist because they each occupy their own particular microsites and microenvironments of weathering, especially in the vicinity of the altering rock material (Jolicoeur et al., 2000). Gibbsite in soils may also be inherited from saprolites (e.g., Huang et al., 2002; Simas et al., 2005). In these cases, its content decreases towards the surface within the soil profile. In another situation, the co-occurrence of both gibbsite and halloysite, together with kaolinite, goethite, hematite, maghemite, quartz, and cristobalite in old soils formed on strongly weathered andesite or associated alluvium in tropical Costa Rica, was studied by Kleber et al. (2007). They attributed the clay mineral depth distribution patterns firstly to intense weathering, with gibbsite increasing with depth as the end product of prolonged tropical weathering, as noted earlier. However, the seemingly paradoxical enrichment of kaolin group minerals and quartz near the soil surface was attributed to onging dissolution of $\mathrm{Si}$ (quartz being unstable at the silica concentrations necessary for gibbsite formation, namely $<0.5$ ppm) and its vertical redistribution by a plant-based "biological resilication mechanism" (Kleber et al., 2007, and see also Section 20.2.5.3.3).

Gibbsite may also occur as coatings or infillings of voids in weathered upper soil horizons (e.g., Huang et al., 2002). Gibbsite is also favored if parent materials are rich in Al (e.g., Lowe, 1986), as illustrated by the example of sillimanite within gneiss in Bhattacharyya et al.'s (2000) study.

Among Al oxyhydroxides, boehmite has been identified, along with some other poorly ordered, nanocrystalline and/or amorphous phases in lateritic profiles, particularly at their surfaces, and also in tropical soils (e.g., Churchman, 2000; Huang et al., 2002). Some may have resulted from the dehydration of gibbsite. Other Al hydroxides, bayerite, norstrandite, and doyleite, have been identified only rarely in soils (Huang et al., 2002). The $\mathrm{Al}$ oxyhydroxide, boehmite, and the $\mathrm{Al}$ oxide, corundum, have been reported at the surfaces 
of ferralitic (lateritic) profiles, whereas corundum has often been seen in the same soils that contain maghemite, for example, in ferralitic duricrusts in Western Australia (Anand and Gilkes, 1987), and these authors proposed that it formed from gibbsite and/or boehmite by dehydration in bushfires. A bushfire origin has also been suggested for maghemite (Section 20.3.7 herein).

\subsubsection{Occurrence of phosphate, sulfide, and sulfate minerals in soils}

Phosphate minerals in soils appear to derive mainly by inheritance or by alteration through weathering of forms of apatite, namely fluorapatite and hydroxyapatite, from rocks or other geological deposits, or else from reactions between phosphorus fertilizers and soil minerals (Lindsay et al., 1989; Churchman, 2000; Harris, 2002). The products are various forms of phosphates in which the $\mathrm{Ca}$ in apatite is substituted, to a greater or lesser degree, by other cations. Hence there are forms of variscite, where the major cation is $\mathrm{Al}$, strengite $(\mathrm{Fe})$, also barrandite $(\mathrm{Al}, \mathrm{Fe})$, vivianite $(\mathrm{Fe}(\mathrm{II}))$, crandallite $(\mathrm{Ca}, \mathrm{Al})$, plumbogummite $(\mathrm{Pb}, \mathrm{Al}$, and other elements), gorceixite ( $\mathrm{Ba}, \mathrm{Al})$, leucophosphite $(\mathrm{K}, \mathrm{Fe})$, along with many other variations (Norrish, 1968; Lindsay et al., 1989; Churchman, 2000; Harris, 2002). A hydrated Al hydroxyl phosphate, wavellite, is the most common $\mathrm{Al}$ phosphate in soils derived from phosphoritic marine sediments, which are the most extensive phosphate-rich geological materials at the Earth's surface (Harris, 2002). Nevertheless, phosphates generally occur very sparsely in soils and have to be either concentrated or examined by electron optical methods to be identified (e.g., Norrish, 1968).

Sulfide minerals in soils originate ultimately from the bacterial reduction of sulfate in sea water (Doner and Lynn, 1989; Fanning et al., 2002). They occur in the unoxidized parent materials of soils and are very readily oxidized on exposure to air and drying. Pyrite is the most common sulfide mineral in the unoxidized parent materials. Sulfates, including sulfuric acid, are the products of their oxidation. The reaction of the sulfuric acid thus produced with silicates leads to hydroxyl Fe sulphate minerals, especially jarosite and schwertmannite. These, and their variants, occur typically in acid sulfate soils, with their attendant environmental problems (see also Section 20.2.5.3.4). Gypsum occurs in soils as a result of its inheritance from gypsiferous parent materials (or from agricultural application), while barite, of unknown origin, has also been found in some soils, often as a white powder (Fanning et al., 2002). 


\subsubsection{Occurrence of pyrophyllite, talc and zeolites in soils}

Both pyrophyllite and talc are rare in soils (Zelazny and White, 1989; Churchman, 2000; Zelazny et al., 2002). As minerals originating at high temperatures and pressures, they are seldom inherited in soils. Pyrophyllite, particularly, is broken down into finer fractions by physical processes (Zelazny et al., 2002). As with other types of minerals, it is the dioctahedral species, pyrophyllite, that is more stable in the soil environment than its trioctahedral counterpart, talc (Zelazny et al., 2002). Generally, talc weathers quickly to nontronite or to Fe oxides. Both pyrophyllite and talc have been protected from breakdown by their encapsulation within Fe oxides in some soils (Zelazny et al., 2002).

Occurrences of zeolites have rarely been reported in soils, but some may have been overlooked because they are generally only present in trace amounts (Boettinger and Ming, 2002). Apart from their inheritance from zeolitic parent materials, such as through hydrothermal alteration (e.g., Kirkman, 1976), some zeolites have formed pedogenically (Ming and Mumpton, 1989; Churchman, 2000; Boettinger and Ming, 2002). The most common pedogenic zeolite is analcime. Along with chabazite, mordenite, natrolite and phillipsite, analcime has been found to form in salt-affected, alkaline soils, which contain sodium carbonate and have a high pH (Churchman, 2000; Boettinger and Ming, 2002). These soils were both volcanic and non-volcanic in origin. A number of zeolites have been found in soils in Antarctica that appear to have a secondary origin. These include stilbite, from the weathering of dolerite (Claridge and Campbell, 1968), phillipsite, from tephra dissolved in lakes (Claridge and Campbell, 2008), and chabazite, which has been identified by many workers and which Claridge and Campbell (2008) suggested is quite widespread as a product of thin saline films in intergranular spaces in soils. Other zeolites that have been inhertited in soils from parent materials include clinoptilolite, heulandites, gismondine, mordenite, stilbite, and laumontite (Boettinger and Ming, 2002).

\subsubsection{Occurrence of neogenetic silica in soils}

Because leaching in soil formation results in desilication, silica is often mobilised and then (if not combined with $\mathrm{Al}$ for example to form an aluminosilicate clay), can_be re-precipitated deeper in the soil environment. Chemically precipitated overgrowths of quartz, particularly on carbonates, are relatively common in soils (Drees et al., 1989; Churchman, 2000). Quartz 
apparently formed by crystallization out of the dissolution products of microcline (EstouleChoux et al., 1995; Section 20.2.4.2). In soils across two chronosequences on fluvial deposts in arkosic sands in southern California, Kendrick and Graham (2004) found that the amount of pedogenic, opaline silica (measured by extraction with tiron) increased with duration of soil development from $1.2 \%$ to $4.6 \%$ of the soil. The loss of Si from primary minerals approximately equalled the gain of secondary (opaline) silica (Kendrick and Graham, 2004). A number of studies of fine quartz from soils and also shales found a systematic increase in oxygen isotopic ratios with decreasing size, suggesting that the smallest particles of quartz were authigenic (Sridhar et al., 1975; Churchman et al., 1976; Clayton et al., 1978). However, much neogenetic silica in soils occurs in other forms besides quartz (Monger and Kelly, 2002).

Silica cements are common in hardpans or duripans (Chadwick et al., 1987) and also fragipans (Harlan et al., 1977; Marsan and Torrent, 1989) in soils and have been seen to coat surfaces of primary minerals, for example, micas, and to fill gaps in altered minerals including feldspars and micas (Chadwick et al., 1987; Singh and Gilkes, 1993). In the extreme, silica forms massive silcretes in acidic environments (Thiry and Simon-Coinçon, 1996). Secondary silica is sometimes identified as a form of opal, either opal-CT, which is usually inherited from rocks (Munk and Southard, 1993), or opal-A, which is biogenic, and includes plant opals. These are common in some Andisols (Drees et al., 1989) and may be recycled through the death and regrowth of plants (Alexandre et al., 1997). Precipitation of secondary silica may be aided by plant-based processes related to Si uptake and recycling (Henriet et al., 2008) and by evaporation or freezing of soil water. Inorganic silica polymorphs are distinguishable from plant-derived forms of silica, phytoliths, because the latter have more complex shapes inherited from biological cells (Nanzyo, 2007). Farmer et al. (2005) concluded from their study on the concentration and flux of Si in European forest soils (both podzols and acid brown soils) that phytoliths must be the principal immediate sink of silica in soil solution (although weathering is the ultimate source). During the growing season, forest vegetation takes up most of the Si released through weathering of soil minerals and phytolith dissolution and converts it into (new) phytoliths, the latter then becoming the main source of Si leached from the soil during winter rains and spring snowmelt (Farmer et al., 2005). Opals may be transformed to quartz in duripans in soils and also by diagenesis in fossilized wood and sediments (Drees et al., 1989). 
Elsass et al. (2000) examined hard plates in laminar horizons and gray mottles at depth in indurated volcanic soils ("tepetates") in Mexico and found strong evidence for the transformation of halloysite to cristobalite via an amorphous opal-A stage. In this case, it appears that the secondary silica phase, first opal-A and then eventually cristobalite, had formed as a result of subtraction of $\mathrm{Al}$ from halloysite into solution, rather than through addition of Si from solution as in other cases of the occurrence of secondary Si in soils. Other studies, however, have demonstrated that cristobalite in soils is usually of primary volcanic origin (e.g., Mizota et al., 1987; Wallace, 1991; Mizota and Itoh, 1993). In northern New Zealand, cristobalite isolated from three weathered, halloysitic volcanic soils was identified as alpha cristobalite (opal-C) and invariably was found to be accompanied by tridymite (Wallace, 1991). SEM and oxygen isotope data, along with the highly ordered crystal structure and subhedral grain morphologies, were interpreted to indicate that the cristobalite and tridymite had formed at high temperature from primary volcanic sources (Wallace, 1991; cf. Lowe, 1986).

\subsubsection{Occurrence of titanium and zirconium minerals in soils}

Although the major forms of titanium oxide, namel, anatase and rutile, and also their polymorph,_brookite, as well as the Fe-Ti minerals, ilmenite, pseudorutile, titanomaghemite and others, can all form by neogenesis in intensely weathered soils, only anatase and pseudorutile commonly form this way (Milnes and Fitzpatrick, 1989; Churchman, 2000; Fitzpatrick and Chittleborough, 2002). Otherwise, the titanium minerals in soils are inherited from parent materials. Fitzpatrick and Chittleborough (2002) leave open the possibility that zircon, the most common $\mathrm{Zr}$-containing mineral, could also form authigenically in intensely weathered soils. Nevertheless, it is generally inherited from parent materials.

Pseudorutile, which occurs widely in soils, is primarily found there as an alteration product of ilmenite (Fitzpatrick and Chittleborough, 2002). In turn, pseudorutile can dissolve to yield either rutile (Grey and Reid, 1975) or anatase (Anand and Gilkes, 1984). The authigenic formation of titanomaghemite and also ferrian ilmenite may occur by heating $\mathrm{Fe}$ Ti oxides to high temperatures as occurs in bushfires (Fitzpatrick and Chittleborough, 2002). Some $\mathrm{Ti}^{4+}$ can become incorporated in other minerals, notably the Fe oxides goethite and hematite, by isomorphous substitution, thereby potentially leading to a reversal of the charge 
of the Fe oxides (Fitzpatrick and Chittleborough, 2002). Singer et al. (2004) have also found $\mathrm{Ti}$ as an isomorphous substitute for $\mathrm{Al}$ in halloysite (Section 20.3.2).

\subsubsection{Occurrence of highly soluble minerals in soils}

The most common minerals that are laid down following their dissolution from the preformed solid state, whether primary or secondary in origin, and then reprecipitation after evaporation, include calcium carbonate, mainly as calcite, but also as aragonite and $\mathrm{Mg}$ calcite (Doner and Grossl, 2002). Magnesite and also dolomite may be formed in that fashion and gypsum probably has a similar origin in arid and semiarid environments (Kohut et al., 1995; Churchman, 2000). Bassanite (or hemihydrite) is usually found in surface soils, indicating its likely evaporative origin (Doner and Grossl, 2002). The highly soluble salts, halides, sulphates, and some carbonates often occur in saline soils and also in arid environments such as Antarctica (Section 20.2.5.2), which is where Bockheim (1997) observed niter $\left(\mathrm{NaNO}_{3}\right)$ in soils. It is an indication of its extreme aridity that nitrate, borate, chromate, and perchlorate salts have been found in the Atacama Desert in Chile (Erickson, 1983; Doner and Grossl, 2002).

\subsubsection{Occurrence of secondary minerals in soils: summary}

The main properties of the common types of secondary minerals, and characteristics of their occurrence in soils, are summarized in Table 20.6.

Insert Table 20.6 here

\subsection{Influence of mode of formation upon predictions of properties of soils from their clay mineralogy}

\subsubsection{Introduction: the role of mineralogy in soil science}

Broadly speaking, soils are studied and interpreted either as products of the natural environment which reflect their environmental history, or else as useful materials in which to 
grow plants or for removing and cleaning wastes and pollutants or providing resources or "environmental services" such as regulating water flow. Minerals, and particularly secondary (clay) minerals, have likewise been regarded and assessed either as indicators of the origin of soils and of changes which have occurred in them through their development, or else as the most reactive inorganic components of soils. For the latter role, it has often been considered that knowledge of the properties of clay minerals would be useful in predicting the agronomic and adsorptive capacities of soils. However, several indicators have suggested that soil mineralogy has come to be regarded as less important to practitioners of the discipline of soil science in recent years than its other main sub-disciplines such as soil chemistry, soil physics, soil biology, pedology, spatial analysis, and pedometrics, let alone the major applied aspects of soil fertility and soil pollution, than once was the case. For example, an analysis of papers that were published in the first 100 volumes of Geoderma, spanning from 1967 to 2001, showed a sharp decline in those on soil mineralogy, but either a rise or no significant decline in those from the other main subdivisions of soil science (Hartemink et al., 2001). It appears that mineralogical studies have been able to make fewer worthwhile contributions in comparison to those of other aspects of soil science than in earlier times. Nonetheless, the survey of the literature for this chapter suggests that a great deal of research continues to be undertaken into the origin of secondary minerals in soils and also, to some extent, into their mode of occurrence within soils. This new work includes the recognition that the clay fractions of many soils and associated materials contain nanominerals (including allophanes and ferrihydrite as discussed earlier), which confer unique properties and reactivities (Theng and Yuan, 2008; Waychunas and Zhang, 2008). Nanoscale minerals are defined as having at least one dimension in the nanorange, that is, 1-100 $\mathrm{nm}$ (Hochella, 2008). Nanoscience is now regarded as being a critically important new offshoot of more traditional colloid or clay mineralogy, and the growth rate of articles being published on nanoparticle science (relevant to the geosciences) is around $10 \%$ per year, about triple the average growth rates of all scientific disciplines over a 5-year period (Hochella, 2008).

\subsubsection{Contributions of classical clay mineralogy towards explanations of soil properties}

Clay mineralogy is a relatively young area of study. Up until 1929, with the publication of a pioneering bulletin by Hendricks and Fry on the X-ray examination of soil clays that was quickly followed by a journal paper (Hendricks and Fry, 1930), most had regarded clays, 
which were largely indistinct in optical microscopes, as being amorphous (Cady and Flach, 1997). XRD was very successful in determining that much of the clay-sized inorganic material in soils was composed of regular crystals like those that had been identified in minerals in rocks or other geological deposits. Although many other instrumental techniques have been applied to their identification and characterization over the intervening years, the search for and refinement of crystal structures has remained a major pursuit of clay mineralogists and XRD has continued to be their major work-horse. Its use, whether for structural determination or as the major instrument for the identification of clay-sized minerals in soils, has defined classical clay mineralogy.

Among the most useful roles promised for classical clay mineralogy in soil studies has been that of explaining the abundance of certain plant nutrients by soils. Probably chief among these has been potassium, with $\mathrm{K}$-micas apparently providing a labile source of $\mathrm{K}^{+}$ (e.g., Norrish, 1973; Loveland, 1984). Loveland et al. (1999), in writing a history of clay mineralogy at the Rothamsted Experimental Station from 1934 to 1988, attempted to identify the reasons why considerable effort was put into this area of soil science at one of the world's leading centres of soil research. At its outset in 1934, clay mineralogy was supposed to provide an understanding of the physicochemical behaviour of the soil clay fraction mainly with respect to "the sorption and desorption of water and nutrients, with their practical consequence for soil workability and plant nutrient supply” (Loveland et al., 1999, p. 165). Its most important contributions are judged by these authors to have been in the identification of the phenomenon of interstratified minerals and the behaviour of soil K. Even so, in spite of a large number of British studies, at Rothamsted and elsewhere in the United Kingdom, on the influence of clay mineralogy on the potassium-supplying power of soils, Loveland (1984, p.700) stated that "none were successful in using clay mineralogy as a reasonably exact predictive tool for this property". Loveland (1984) concluded that (classical) clay mineralogy related better to geotechnical properties of soils than to their nutrient-supplying power. In apparent contrast, the K-supplying power of soils formed from quartzo-feldpathic loess or alluvium and colluvium from sedimentary rocks in New Zealand showed a close relationship to the mica contents of their clay fractions (Surapenini et al., 2002). Barré et al. (2008), studying two French soils and one from the United States, also found that micaceous minerals in soil clay-size fractions serve as reservoirs for potassium. However, they found that the ability of soils to supply $\mathrm{K}$ to plants, and also to extract $\mathrm{K}$ when it was in excess, through fertilizer additions, could only be fully understood when the micaceous minerals were 
delineated into five different types. These were a well-crystallized illite, a poorly crystallized illite, a highly smectitic interstratification of illite and smectite, and also its highly illitic counterpart, and a soil vermiculite. These could be separately determined quantitatively, relative to one another, by decomposition of the XRD peak profile, following Lanson's (1997) procedure. Barré et al. (2008) claimed that the approach could be used to predict the K release potential of soils generally and Velde and Barré (2010) provide many examples of the utility of this approach. It may offer a wider applicability than the relationships developed by Surapenini et al. (2002) for soils which have quite similar origins in just one country.

\subsubsection{Potential of classical clay mineralogy for explaining soil properties}

A different mineralogical approach, using X-ray fluorescence (XRF) analyses of whole soils and also analyses of acid digests of soils by inductively coupled plasma mass spectroscopy (ICP-MS) was used to determine the normative mineralogies of forest soils in Finland at the early stages of weathering in order to explore the availability of reserves of the nutrients $\mathrm{Ca}$ and $\mathrm{Mg}$ (Starr and Lindroos, 2006). At the earliest stages of weathering, it is the extent of alteration of primary minerals rather than the nature of any secondary products that is the mineralogical characteristic which best relates to agronomic properties. Clay mineralogy per se is of little predictive use when clays have hardly been formed. For soils in most of the world's agricultural areas, however, the overwhelming contribution to the surface area of the soils, as well as virtually all of their charge, arises from material in their clay fraction (e.g. Gilkes, 1990; Churchman, 2006). The highly reactive clay-size material includes both organic and inorganic components, and it is the task of soil clay mineralogists to understand the source of the contribution made by the inorganic components. Gilkes (1990) noted that Norrish and coworkers recognised some time ago that secondary minerals in soils could hold and, when required, supply, other important nutrients besides $\mathrm{K}$ for plants. These included manganese oxides, for cobalt (Adams et al., 1969), and iron oxides, for phosphorus (Norrish and Rosser, 1983). Classical clay mineralogy, using XRD, may be capable of detecting the presence of these oxides in soils provided that they are reasonably well crystallized, and that their XRD peaks are not masked by stronger peaks for other minerals. Even so, it is not simply their presence, but rather their detailed structural, chemical, and physical characteristics, as well as their associations with other soil entities that govern the reactivities 
- both chemical and physical - of these and other oxides, hydroxides, and oxyhydroxides, as well as of aluminosilicate phases in soils. Furthermore, much evidence points to the idea that metal oxides (used generally hereafter to include both oxydroxides and hydroxides) play a role in determining many of the useful properties of many soils that is out of proportion to their content in the soils. This status includes the indication from several earlier studies, van Raij and Peech (1972) and also Gallez et al. (1976), among them, that the surface charge-pH curves of many tropical soils show the characteristic features of metallic oxides, which have a pH-dependent variable charge. Similarly, nanocrystalline aluminosilicates such as allophane also make an extremely disproportionate contribution to both the surface area and reactivity of soils, including through a $\mathrm{pH}$-dependent variable charge, even where only small amounts are present (e.g., Lowe, 1995; McDaniel et al., Section 33.3). In an effort to try to reconcile studies which have found that $\mathrm{Fe}$ oxides play a positive role in aggregation in soils (e.g., Colombo and Torrent, 1991; Oades and Waters, 1991) with others in which Fe oxides do not appear to affect aggregate stabilities (e.g., Deshpandhe et al., 1968; Borggaard, 1983), Duiker et al. (2003) found that their effect depended upon their crystallinity. The most poorly crystalline Fe oxides played an important role along with organic matter in aggregate stabilization and, where organic matter contents were low, as in B horizons, their contributions to indices of aggregation were found to equal or exceed that of organic matter (Duiker et al., 2003), confirming similar trends seen by Churchman and Tate (1987) for the particular case of soils on volcanic ash. However, Al oxides may be more important than $\mathrm{Fe}$ oxides in governing both aggregate stability and also $\mathrm{P}$ adsorption in some soils. This relationship appeared to hold for latosols in Brazil (Schaefer et al., 2004). In one soil, at least, an amorphous Al-hydroxy phase appeared to play an important role in both aggregation and $\mathrm{P}$ adsorption.

One property of soils that particularly demands explanation and, if possible, prediction, at this time is that of the capacity of soils to adsorb and retain organic carbon. The momentum for work to be done in this area comes from growing community concerns about the increased levels of carbon dioxide in the atmosphere, its links to global warming, and the role that soils may be able to play in sequestering excess carbon and isolating it from the atmosphere (Amundson, 2001; Kahle et al., 2002a). As Kahle et al. (2002a) pointed out, many workers have discovered relationships between clay content and carbon content, although it is noteworthy that not all have found such a link, for reasons we will discuss herein. Nevertheless, it has long been known (e.g., Greenland, 1965) that clays and organic 
matter can be strongly associated in soils. Even so, it has long been appreciated (e.g., Kubota, 1975; Hamblin and Greenland, 1977) that the links between clays and organic matter can occur through Fe and Al oxides. Mikutta et al. (2005) and also Kleber et al. (2005) reported that, for acid subsoils under forest and representing a wide range of parent rock types and rainfall, poorly crystalline oxides of both $\mathrm{Fe}$ and $\mathrm{Al}$ provided the strongest binding agents for organic matter. According to Mikutta et al. (2005), poorly crystalline to nanocrystalline Fe oxides such as ferrihydrite were particularly effective for stabilising organic $\mathrm{C}$ in these soils. It is also significant that these authors found that none of the factors of clay content, namely, the specific surface area of the minerals as determined by nitrogen gas adsorption using the BET equation, total iron oxide content, or the nature of the phyllosilicate clays, was a good predictor of the ability of the soils to stabilise C. Their results confirmed those of Percival et al. (2000) who correlated the organic C contents of 167 New Zealand soils with several soil properties and found they showed significant linear relationships with oxalate-extractable $\mathrm{Si}$ and $\mathrm{Al}$, which together represent allophane content, and also with pyrophosphate-extractable $\mathrm{Al}$, which represents $\mathrm{Al}$ associated with organic matter, that is, "Al-humus complexes", but found no relationship with total clay content. Rasmussen et al. (2005), also studying forest soils, came to similar conclusions as those of Percival et al. (2000). In a different, tropical environment, but again studying forest soils on volcanic ash, Basile-Doelsch et al. (2005) found that organic $\mathrm{C}$ in buried horizons was strongly bound in abundant amounts in soils containing allophane, whereas buried horizons with large amounts of crystalline minerals, including feldspars and gibbsite, had little capacity for C storage. The studies by Mikutta et al. (2005) and also Kleber et al. (2005), which were on samples devoid of allophane, showed that it is not the particular occurrence of allophane or even of ferrihydrite that is necessary to provide strong links to organic $\mathrm{C}$. Rather it is the capacity of poorly crystalline or nanocrystalline minerals of both Fe and $\mathrm{Al}$ to provide singly coordinated hydroxyl groups that are able to participate in ligand exchange with organic functional groups, which ensures strong associations with organic $\mathrm{C}$, according to Kleber and coworkers in the two related 2005 reports. This generalisation also bears out the results of experiments by Kahle et al. (2004) in which dissolved organic carbon (DOC) was added to soil clays that had been depleted of organic $\mathrm{C}$ and also to "type" phyllosilicates from nonsoil sources. This experiment showed that soil clays adsorbed much more DOC than the type clay minerals and that the difference appeared to be due to pedogenic oxides, mainly of Fe, which provide reactive hydroxyl groups for DOC sorption. In the case of some tropical soils, Barthès et al. (2008) found that organic C content and also aggregate stability 
were promoted when sesquioxides, especially goethite and hematite, in the soils included substitutions by $\mathrm{Al}$, which increased their specific surface areas.

One of the common characteristics of Andisols is accumulation of relatively large quantities of organic matter, both in the allophanic (moderate $\mathrm{pH}$ ) and non-allophanic Andisols (low pH). Allophanic Andisols may contain $~ 10 \%$ or more C, whereas nonallophanic Andisols (dominated by Al- and/or Fe-humus complexes) may contain as much as $\sim 30 \%$ of $\mathrm{C}$. However, the residence time of $\mathrm{C}$ in soils containing allophane, as measured by ${ }^{14} \mathrm{C}$, is much greater than that of other soils (Fig. 20.12; also see Parfitt, 2009).

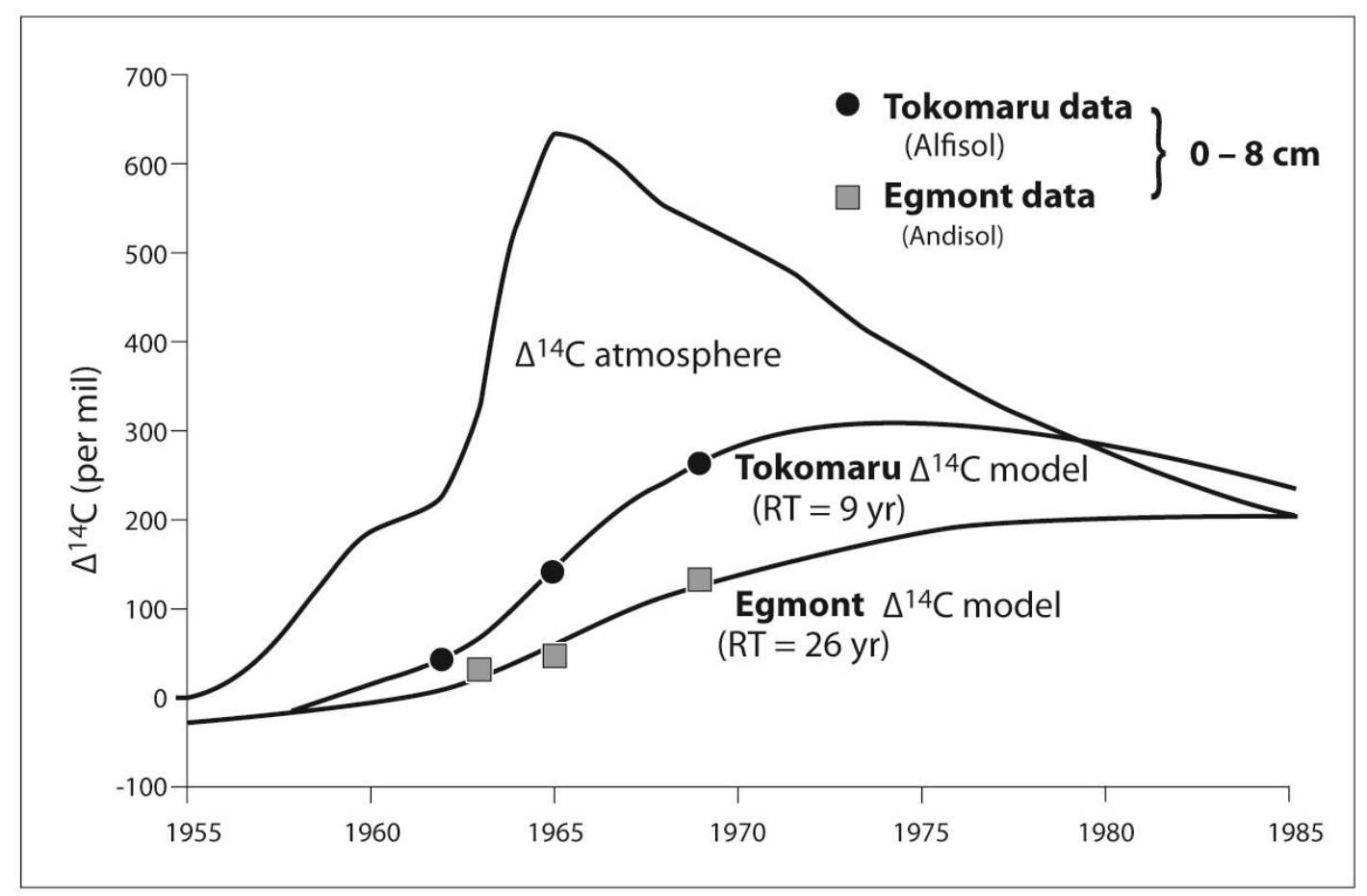

FIGURE 20.12 Model showing slower rates of incorporation and turnover of organic $\mathrm{C}$ using bombderived ${ }^{14} \mathrm{C}$ in an allophanic soil (Egmont series) compared with those of a soil without appreciable allophane (Tokomaru series) under similar climate and land use in New Zealand. (Based on Baisden, WT., R.L. Parfitt. and C. W Ross. 2010. Radiocarbon evidence for contrasting soil carbon dynamics in an Andisol and non-Andisol pasture soil comparison. J. Integr. Field Sci. 7:59- 64.) RT, residence time of carbon. (Modified diagram from Parfitt, R.L. 2009. Allophane and imogolite: Role in soil biogeochemical processes. Clay Miner. 44:135-155. With permission of The Mineralogical Society of Great Britain and Ireland.)

Albeit that the studies by Kleber and coworkers on acid subsoils showed no relationship between stabilized organic $\mathrm{C}$ and the surface area of minerals in the soils, extent of surface intuitively appears likely to be able to explain the capacity of soils for organic $\mathrm{C}$, and several workers have proposed such a relationship (e.g., Saggar et al., 1996; Kaiser and 
Guggenberger, 2000; Esterhues et al., 2005). Indeed, to illustrate the point that different soils lead to different generalizations about the relationship between $\mathrm{C}$ content and surface area, and, incidentally, forms of Fe in soils, Kahle et al. (2002b) found that a combination of specific surface area and total (i.e., dithionite-extractable) Fe oxide content predicted C content almost completely, with an $\mathrm{R}^{2}$ of 0.96 , in the topsoils of a set of illitic soils with more or less neutral pHs that had been farmed since Medieval times. The surface areas were determined using the sorption of nonreactive nitrogen gas and hence gave a good measure of external surface (e.g., Churchman and Burke, 1991). Using isotopically labelled plant material, Saggar et al. (1996) found that its residence time during its initial decomposition in soils correlated well with the surface area of the soil as measured by the adsorption of $p$ nitrophenol. It is noteworthy that it was this particular ( $p$-nitrophenol adsorption) method that showed a good relationship with organic $\mathrm{C}$ retained in this case. Like Churchman and Burke (1991), these authors also tried to explain soil properties (organic $\mathrm{C}$ uptake in this instance) by the sum of the surface areas from the literature for the mineral components of the soils and also largely failed. By contrast, consideration of the specific surface areas (SSAs) from $\mathrm{N}_{2}$ sorption of different soil types in relation to those calculated for their constituent $\mathrm{Fe}$ oxides and allophane led Eusterhues et al. (2005) to conclude that almost all mineralassociated organic matter in soils is bound to Fe oxides. Churchman and Burke (1991) generally found that the strength of the relationship between a soil property and surface area depended upon the technique chosen to measure surface area (they compared $\mathrm{N}_{2}$ gas sorption, sorption of a polar liquid ethylene glycol monoethyl ether (EGME) and water) and the relevance of the adsorbate to the soil property of interest. A good relationship between a particular soil property and surface area deduced from the sorption of a particular adsorbate shows that the property and the capacity of the surface for the adsorbate have similar causes but does not show that the property relates to a generic measure of surface area, which most probably does not exist.

To further complicate the nature of the relationship between minerals and organic $\mathrm{C}$ in soils, it is noted that a study of the energetics of organic C sorption by Mayer and Xing (2001) revealed that minerals appeared to be occluded by OM, rather than the OM being adsorbed by minerals and that micropores were likely to be responsible for some of the associations. Kaiser and Guggenberger (2003) suggested that organic matter was preferentially adsorbed within, or at the mouths of, micropores $<2 \mathrm{~nm}$ in diameter in iron oxides in soils. The results of density fractionations combined with TEM led Chenu and 
Plante (2006) to conclude that most OM was stabilized in soils by close associations with clays in very small microaggregates, either through adsorption or by entrapment. Wan et al. (2007) mapped organic carbon along with other elements in different soils using scanning transmission X-ray microscopy (STXM) and found that OM exists as distinct particles within microaggregates more often than as coatings on minerals. Using small angle X-ray scattering to directly observe pores and their constituents, McCarthy et al. (2008) found that most OM was held within pores, although not necessarily very small pores, in formely cultivated soils that had been restored to tallgrass prairie. Their main conclusion was that OM was encapsulated, rather than adsorbed, by minerals. According to Richards et al. (2009), it is the occurrence of aggregates, rather than the abundance of oxides of $\mathrm{Fe}$ and $\mathrm{Al}$, that enabled the stabilization of $\mathrm{OM}$ in oxide-rich soils in the Australian subtropics. As a result, more organic $\mathrm{C}$ was held in soils under rainforest and pastures than in those under pine plantations. Furthermore, Spielvogel et al. (2008), like many others (e.g., Kleber et al., 2005; Mikutta et al., 2005; Rasmussen et al., 2005), examined the causes of OM stabilization in acidic forest soils, but arrived at the conclusion that, while Fe and Al oxides, and, particularly, their poorly crystalline to nanocrystalline varieties, were responsible for stabilization, they are bound to, and stabilize, only a specific fraction of the OM. This fraction was concentrated in $\mathrm{O} / \mathrm{N}$-alkyl $\mathrm{C}$ and microbially-derived sugars compared with the nonstabilized remainder (Spielvogel et al., 2008).

It, therefore, appears likely that the properties of the mineral fraction, which control the uptake and retention of organic $\mathrm{C}$ by soils, vary greatly between soils. Any generalisation is likely to founder when applied to a particular case. Indeed, following Kaiser and Guggenberger (2003), Chenu and Plante (2006), Wan et al. (2007), McCarthy et al. (2008), and Richards et al. (2009), we suggest that it may be that the properties of minerals which are most important are those which enable them to form pores or aggregates for encapsulating OM, and their identification probably defies a simple summary. At the most, it can probably be concluded only that a number of possible characteristics of the mineral phases are likely to influence the capacity of soils to stabilise $\mathrm{C}$ and it remains for practice to show which are more important than the others in each instance. A possible list of such characteristics is given in Table 20.7. A number of studies have attempted, like Churchman and Burke (1991) and Saggar et al. (1996) with specific surface area, to explain soil properties by the sum of the contributions from their different mineral (and also, sometimes, organic) components. Properties that were proposed for explanation in this way have included CEC (Seybold et al., 
2005). CECs could be largely explained within mineralogical groupings from Soil Taxonomy when organic C was included. Churchman and Burke (1991) also found good relationships between CECs and a measure of water retention within mineralogical groupings of soils with low carbon contents.

\section{$\underline{\text { (Insert Table } 20.7 \text { here) }}$}

Together, these results suggested that the use of classical clay mineralogy to group mineralogically similar soils may be reasonably successful for predicting CECs. In addition, close comparisons of experimental and theoretical titration curves indicated that surface charge densities of some soils from Argentina were apparently successfully modeled by the sum of those of their constituent mineral phases when the mineralogical compositions of the soils were determined by a Rietveld approach (Taubaso et al., 2004). This result suggests further that the charges on soils may be largely additive of those on their constituent clay-size minerals. Nonetheless, this and earlier work by a group from the same laboratory (Torres Sanchez et al., 2001), showed that there was a mis-match between the point of zero net charge (PZNC) and the isoelectric point for those soils in which Fe oxides were adsorbed on to phyllosilicate clays. Hence, the diffusion behaviour of these soils, which relates to their isoelectric points (IEPs), cannot be simply regarded as additive of their component colloidal minerals but must account also for their associations with one another.

While there has been some success with the modeling of charge characteristics, both permanent (Seybold et al., 2005) and variable (Taubaso et al., 2004) from the mineral composition of soils, mineral composition patently could not describe organic matter stabilization by minerals in soils. However, in some cases, at least (Kahle et al., 2004; Kleber et al., 2005; Mikutta et al., 2005; see also Table 20.7), it appears that some functional groups, singly coordinated hydroxyl groups in particular, play a crucial role in binding natural organic compounds - albeit perhaps only a fraction of the total soil organic matter, following Spielvogel et al. (2008). Therefore the question arises as to whether more accurate descriptions of mineral-organic associations, and of reactions of other species, for example, anions such as phosphates and arsenates with mineral surfaces, might be better made on the basis of the amount of the important functional groups present, by an approach that is analogous to that taken by modern soil organic matter studies using, for example, ${ }^{13} \mathrm{C}-\mathrm{NMR}$ and FTIR spectral analyses (e.g., Baldock and Nelson, 2000). 
Gustafsson (2001) used a "component additivity" approach in an attempt to predict, or model the adsorption of arsenate in competition with sulfate, silicic acid, and phosphate on allophane and also ferrihydrite and tested the results against experimental data for the adsorption on the spodic horizon of a Swedish soil that contained both ferrihydrite and allophane but little organic matter. Although this approach led to results that were qualitatively realistic, Gustafsson (2001) nevertheless concluded that the approach is probably impractical, partly, at least, because it relies on the assumption that the properties of allophane and ferrihydrite in real soils can be approximated by those of gibbsite and ferrihydrite synthesised in the laboratory. Among many others, Gérard et al. (2007) have shown that this assumption is simplistic and unrealistic. In the particular case that these last authors studied, allophane formed on basalt in the Azores was found to have an especially complex genesis, leading to allophanic products with a large range of compositions. Gérard et al. (2007) claimed that not all of the allophane formed was the product of recrystallization from solution, describing some of it as "alteromorphs after lapilli or pumice", which result from the leaching of $\mathrm{Si}$ and cations from these materials. The products encompassed a compositional range from pure aluminosilicates to $\mathrm{Fe}$ - and $\mathrm{Ti}$ - enriched aluminosilicates and included varieties of both Al-rich and Si-rich allophanes, while the soils also contained many different iron phases, ferrihydrite, hematite, and also "iddingsite" (see Section 20.2.4.1), among them.

The component additivity modeling approach adopted by Gustafsson (2001) foundered because allophanes and ferrihydrite, as they are found in soils, differ in many important respects from either natural minerals from nonsoil environments such as the "stream deposit allophane" (Childs et al., 1990; Parfitt, 1990) or synthetic minerals of the same name, in the case of ferrihydrite. They are unique to soils, and they also show variations within their type. A number of other minerals are unique, or almost unique, to soil environments and the properties and reactivities of these, also, cannot be modeled upon those of minerals found in nonsoil environments. These include fully or partially-expanded 2:1 Si:Al aluminosilicates with hydroxyl-Al interlayers (see Section 20.2.4.3), which may show even seasonal changes in the soil biological system (see Section 20.2.5.3). They also include interstratified phases in their various manifestations. Velde and Meunier (2008) have characterized those of illite and smectite as being "peculiar to the soil environment" (Section 20.2.5.3), as well as being "the most widespread and representative soils clays". By the same token, smectites found in soils have been characterized as being commonly ferribeidellitic in composition and therefore are 
quite different from the bentonites from which typical nonsoil montmorillonites have usually been extracted to serve as models for smectites in soils (Section 20.3.5).

However, it is not just the particular composition, structure, and arrangement of layers of the minerals in soils that often make them different from so-called typical minerals taken from nonsoil sources. They differ from the latter partly because important physical properties of secondary minerals in soils are generally different from those of nonsoil minerals. Studies of soil kaolinites from soils on three continents by Singh, Gilkes and coworkers (Section 20.3.1), a number of studies of soil halloysites (Section 20.3.2), and a study of iron oxides by Trakoonyingcharoen et al. (2006) (Section 20.3.7), have focussed specifically on the sizes and sometimes also surface areas of the particles. The studies generally concluded that those of the soil particles are almost invariably much smaller than those of their "reference" nonsoil counterparts with the same mineral names.

Soil clay minerals also differ from most, at least, of their nonsoil counterparts because of their associations with other species in soils. Apart from their ready association with organic matter that has already been discussed in this section, they are very commonly associated also with other minerals. Almost universally, they are associated with iron oxides (see Table 20.5 and Section 20.3.7), and, often, also with aluminum oxides. While the content of $\mathrm{Fe}$ in its various forms varies widely (Table 20.5), it is probably only in very young soils that it is nearly negligible in affecting soil properties. The youngest soil in a chronosequence on andesitic lave studied by Niewenhuyse et al. (2000) contained only $0.4 \%$ total Fe in its lowest, $\mathrm{CB}$ horizon. This horizon also contained $2.2 \%$ oxalate-extractable $\mathrm{Al}$, and, hence, $\sim 8 \%$ allophane, but no phyllosilicate minerals (Niewenhuyse et al., 2000). Table 20.5 also shows that soils are almost certainly never mono-mineralic in their secondary minerals. Only one of the soils shown there (an Orthoxic Tropohumult) is apparently monomineralic in phyllosilicates (kaolinite, in this case), but clearly also contains goethite, at least, in addition.

\subsubsection{Nature of soil minerals and relationship to their mode of formation}

Clearly, properties of soils relate to properties of clays besides those arising from their particular mineralogical characterization. Properties such as particle size and associations that minerals form with other minerals derive from their mode of formation. In general 
terms, minerals with a neogenetic origin from solutions in the soil occur in smaller particles than those formed by either transformation in the solid phase from primary minerals or even those that may be inherited from a source of minerals of authigenic origin from beyond the soil environment, for example, hydrothermally formed kaolinite and halloysite, or smectite in bentonite deposits of marine or lacustrine origins. A dramatic illustration of the differences that are wrought by pedogenesis in comparison with a nonsoil genesis (in this case, saprolitic) is given by the observation that the area of the 001 faces of kaolinite crystals that formed in the saprolite below $58 \mathrm{~m}$ depth in Brazil were more than five times larger than those that formed in the soil above it (Varajão et al., 2001). It is recalled that Kahle et al. (2002b) found that a combination of specific surface area and total (i.e., dithionite-extractable) Fe oxide content predicted $\mathrm{C}$ content almost completely in a set of illitic soils whereas explanations of C contents of other soils from mineral properties were more complex and usually involved poorly crystalline or nanocrystalline phases (see also Section 20.4.3). Even though the landuse history of the illitic soils and their $\mathrm{pH}$ may have played a role in simplifying the relationships between the inorganic (mineral) and organic components of the illitic soils (and, incidentally, in altering the course of mineral genesis), it is also most likely that the probable formation of the illite in the soils by transformation rather than neogenesis has led to mineralorganic relationships that are different from those in soils with higher proportions, at least of neogenetic minerals, including poorly crystalline/nanocrystalline metal oxides (e.g., Kleber et al., 2005; Mikutta et al., 2005). Furthermore, it has been found that the nature of aggregation within soils dominated by kaolinites in close associations with $\mathrm{Fe}$ and $\mathrm{Al}$ oxides differs from that in soils that are more illitic. Both in a study in which aggregates were broken down mechanically (Oades and Waters, 1991) and another in which they were given the opportunity to build up through plant growth and inputs of plant residues (Denef and Six, 2005), aggregates in the kaolinitic soils were shown to comprise largely self-associations of minerals, while those in the illitic soils included close associations of minerals with organic matter.

The application of analytical techniques with higher resolution than XRD, and particularly electron microscopy, has shown that (1) "many clay particles in soils consist of complex intergrowths of different structural types rather than being the ideal monomineralic species described in textbooks" (Gilkes, 1990, p. 72); and (2) the extent and nature (e.g., charge) of two types of kaolinites (in different Australian soils) were quite different (op. cit., p. 67). Soils are highly heterogeneous in composition and are not simply mixtures of 
nonassociated entities. In particular, clay minerals are commonly coated by other minerals or organic matter, or both, so that the properties of their reactive surfaces reflect the characteristics of the coating material rather than the mineral substrate. For instance it was found that, "without exception, the suspended particles in rivers and gesturing waters were negatively and quite uniformly charged" (R.J. Hunter, 1981 in Mills, 2003, p. 11). It is almost certain that these particles had a soil source. Furthermore, "Since the particles themselves varied widely as to composition, Hunter concluded that this was likely due to a coating of organic matter or metal (iron, aluminum and/or manganese) oxide" (Mills, 2003, p. $11)$.

These observations all suggest that the colloidal "particles" controlling soil properties are generally heterogeneous mixtures of various types of materials, both inorganic and organic. Predictions of their properties from those of well-crystallized minerals are likely to fall short of the mark. Grouping of soils by their dominant idealized mineral types can generally give only poor, or, at best, only qualitative, predictions of their properties. A structural alternative of grouping soils by the nature of their associations of, efor example, particular aluminosilicate minerals, metal oxides, and organic matter together would provide the hopeless case of too many categories; indeed, each association would be very likely unique. A better alternative is suggested by the example of research into the nature of purely organic colloids in soils.

Organic colloids in soils are alternatively known as "humic macromolecules". Hayes et al. (1989, p. 16) have concluded, on theoretical grounds, that "it is highly unlikely that there are two humic macromolecules on earth... which are exactly the same". Even so, the field of the chemical and analytical study of organic colloids in soils is a very active one. It has had continuing success because, instead of seeking definitive general structures of inevitably heterogeneous molecules, it has sought instead to characterize organic colloids by their "functional groups" (e.g., aromatic, carbohydrate, alkyl, carboxyl) - in other words, by their capacities to participate in reactions with other entities in soils.

Since a structural characterization of the "ultimate" particles or groupings of minerals would be similarly fraught with difficulties as that of organic colloids per se, it may be useful to classify soil minerals as contributors to soil properties (mostly via complex heterogeneous mixtures) through their characterization and appropriate grouping according to their most relevant capacities. These might include (on a weight basis) their surface area - as measured 
by various techniques - their charge and its variability with $\mathrm{pH}$, their content of plantavailable potassium, their shrink-swell capabilities, and their concentrations of reactive hydroxyl groups. Together, these properties reflect many of the most important for soil applications and may be correlated with other properties, for example, their affinity with organic matter and their capacity to adsorb phosphates or chlorides and other anions.

Nevertheless, selection of a set of useful properties by which to characterize mineral properties does not provide advances in understanding the origin of these properties. As has always been the case in mineralogical studies, this uncertainty will be reduced by advances in new instrumental techniques and in their application to soils. Undoubtedly, electron microscopy at higher resolutions, both for viewing and also for quantitative analyses, will be among these. Such techniques of surface analysis as XPS might also help. For example, Gerin et al. (2003) were able to analyse the nature of soil surface coatings, both of organic matter and also Fe and Al species, in order to better understand mineral-organic associations, and they projected more similar work with XPS. With the advent of synchrotron radiation, X-ray spectroscopic techniques, which include and enhance XPS and also XRD and XRF, but also encompass extended X-ray absorption fine structure (EXAFS), X-ray absorption nearedge structure (XANES), and other related methods have become available to determine the sites on mineral surfaces that are involved in interactions with other species (Gates, 2006).

Continuing developments in instrumental techniques undoubtedly enable better descriptions of processes involving minerals in soils, but the foregoing discussion nonetheless leads us to conclude that in order to be able to provide the best predictions or explanations of soil behaviour from its clay mineralogy, the origins of the clays have themselves to be thoroughly understood. The earlier parts of this chapter on the alteration, formation, and occurrence of minerals in soils thereby gains relevance to the understanding of soils both as useful materials and providers of essential ecological and human services.

\section{Acknowledgments}

We thank Max Oulton (University of Waikato) for preparing the diagrams, Stuart McClure (formerly of CSIRO Land and Water) for the scanning electron micrographs, Balwant Singh (Sydney University) for the prints of the transmission electron micrographs, Greg Rinder (Adelaide) for their preparation, and Bruce Velde (Ecole Normale Supérieure, France) for 
providing us with galley proofs of parts of his recent book (with A. Meunier) prior to its publication. We appreciated very much the comments, encouragement, and patience of section editor Joseph W. Stucki, and very useful comments from Aaron Thompson (University of Georgia) as a reviewer. Graham Shepherd, Brent Green, Hiroshi Takesako, Rob Fitzpatrick, and M.S. Skwarnecki, are especially thanked for allowing us to cite unpublished data. 


\section{References}

Adamo, P., C. Colombo and P. Violante. 1997. Iron oxides and hydroxides in the weathering interface between Stereocaulon vesuvianum and volcanic rock. Clay Minerals 32: 453461.

Adamo, P. and P. Violante. 2000. Weathering of rocks and neogenesis of minerals associated with lichen activity. Applied Clay Science 16: 229-256.

Adamo, P., P. Violante and M.J. Wilson. 2001. Tubular and spheriodal halloysite in pyroclastic deposits of the Roccamonfina volcano (Southern Italy). Geoderma 99: 295316.

Adams, S.N., J.L. Honeysett, K.G. Tiller and K. Norrish. 1969. Factors controlling the increase of cobalt in plants following the addition of a cobalt fertilizer. Australian Journal of Soil Research 7: 29-42 .

Ahn, J.-H. and D.R. Peacor. 1987. Kaolinization of biotite - TEM data and implications for an alteration mechanism. American Mineralogist 72: 353-356.

Aldridge, L.P. and G.J. Churchman. 1991. The role of iron in the weathering of a climosequence of soils derived from schist. Australian Journal of Soil Research 29: 387398.

Alekseev, A., T. Alekseeva, V. Ostroumov, C. Siegert and B. Gradusov. 2005. Mineral transformations in parmaforst-affected soils, North Kolyma lowland, Russia. Soil Science Society of America Journal 67: 596-605.

Alexandre, A., J.-D. Meunier, F. Colin and J.-M. Koud. 1997. Plant impact on the biogeochemical cycle of silicon and related weathering processes. Geochimica et Cosmochimica Acta 61: 677-682.

Alimova, A., Katz, A., Steiner, N., Rudolph, E., Wei, H., Steiner, J.C. and P. Gottleib, 2009. Bacteria-clay interaction: structural changes in smectite induced during biofilm formation. Clays and Clay Minerals 57: 205-212.

Allen, B.L. and B.F. Hajek. 1989. Mineral occurrence in soil environments. Pp. 199-278. In J.B. Dixon and S.B. Weed (editors.) Minerals in Soil Environments. 2nd edition, Soil Science Society of America, Madison, Wisconsin.

Alloway, B.V., M.S. McGlone, V.E. Neall and C.G. Vucetich. 1992. The role of Egmontsourced tephra in evaluating the paleoclimatic correspondence between the bio- and soilstratigraphic records of central Taranaki, New Zealand. Quaternary International 13-14: 187-194. 
Altschuler, Z.S., E.J. Dwornik and H. Kramer. 1963. Transformation of montmorillonite to kaolinite during weathering. Science 141: 148-152.

Amrhein, C. and D.L. Suarez. 1988. The use of a surface complexation model to describe the kinetics of ligand-promotion dissolution of anorthite. Geochimica et Cosmochimica Acta 52: $2785-2793$.

Amundson, R. 2001. The carbon budget in soils. Annual Review of Earth and Planetary Sciences 29: 535-562.

Anand, R.R. and R.J. Gilkes. 1984. Weathering of ilmenite in a lateritic pallid zone. Clays and Clay Minerals 32: 363-374.

Anand, R.R. and R.J. Gilkes. 1987. The association of maghemite and corundum in Darling Range Laterites, Western Australia. Australian Journal of Soil Research 25: 303-311

Anand, R.R., R.J. Gilkes, T.M. Armitage and J.W. Hillyer. 1985. Feldspar weathering in lateritic saprolite. Clays and Clay Minerals 33: 31-43.

Aomine, S. and C. Mizota. 1973. Distribution and genesis of imogolite in volcanic ash soils of northern Kanto, Japan. Pp. 207-213. In J.M. Serratosa (editor). Proc. Int. Clay Conf. (Madrid, Spain) 1972.

Aomine, S. and K. Wada. 1962. Differential weathering of volcanic ash and pumice resulting in formation of hydrated halloysite. American Mineralogist 47: 1024-1048.

Aoudjit, H., F. Elsass, D. Righi and M. Robert. 1996. Mica weathering in acidic soils by analytical electron microscopy. Clay Minerals 31: 319-332.

April, R. and D. Keller. 1990. Mineralogy of the rhizosphere in forest soils of the eastern United States. Biogeochemistry 9: 1-18.

April, R.H., D. Keller, and C.T. Driscoll. 2004. Smectite in Spodosols from the Adirondack Mountains of New York. Clay Minerals 39: 99-113.

Aragoneses, F.J. and M.T. García-González. 1991. High-charge smectite in Spanish "Raña" soils. Clays and Clay Minerals 39: 211-218.

Ashman, M.R. and G. Puri. 2002. Essential soil science. Blackwell, Oxford. 198pp.

Aspandiar, M.F. and R.A. Eggleton. 2002a. Weathering of chlorite I: Reactions and products in microsystems controlled by primary minerals. Clays and Clay Minerals 50: 685-698.

Aspandiar, M.F. and R.A. Eggleton. 2002b. Weathering of chlorite II: Reactions and products in microsystems controlled by solution avenues. Clays and Clay Minerals 50: 699-709.

Bailey, S.W. 1990. Halloysite - a critical assessment. In V.C. Farmer and Y. Tardy (eds.) Proceedings of the $9^{\text {th }}$ International Clay Conference, Strasbourg, Volume II: Science Géologiques 86: 89-98. 
Bain, D.C. 1977. The weathering of ferruginous chlorite in a podzol from Argyllshire, Scotland. Geoderma 17: 193-208.

Bain, D.C. and J.D. Russell. 1981. Swelling minerals in a basalt and its weathering products from Morven, Scotland: II Swelling chlorite. Clay Minerals 16: 203-212.

Baisden, W.T., R.L. Parfitt, and C.W. Ross. 2010. Radiocarbon evidence for contrasting soil carbon dynamics in an Andisol and non-Andisol pasture soil comparison. J. Integr. Field Sci. 7:59- 64 .

Bakker, L., D.J. Lowe and A.G. Jongmans. 1996. A micromorphological study of pedogenic processes in an evolutionary soil sequence formed on Late Quaternary rhyolitic tephra deposits, North Island, New Zealand. Quaternary International 34-36: 249-261.

Baldock, J.A. and P.N. Nelson, 2000. Soil organic matter, pp. B25-B84 In M.E. Sumner (ed.) Handbook of Soil Science. CRC Press, Boca Raton, Florida.

Banfield, J.F. and W.W. Barker. 1994. Direct observation of reactant-product interfacse formed in natural weathering of exsolved, defective amphibole to smectite: Evidence of episodic, isovolumetric reactions involving structural inheritance. Geochimica et Cosmochimica Acta 58: 1419-1429.

Banfield, J.F., G.G. Ferruzzi, W.H. Casey and H.R. Westrich. 1995. HRTEM study comparing naturally and experimentally weathered pyroxenoids. Geochimica et Cosmochimica Acta 59: 19-31.

Banfield, J.F. and R.A. Eggleton. 1988. A transmission electron microscope study of biotite weathering. Clays and Clay Minerals 36: 46-70.

Banfield, J.F. and R.A. Eggleton. 1989. Apatite replacement and rare earth mobilization, fractionation and fixation during weathering. Clays and Clay Minerals 37: 113-127.

Banfield, J.F. and T. Murakami. 1998. Atomic-resolution transmission electron microscope evidence for the mechanism by which chlorite weathers to 1:1 semi-regular chloritevermiculite. American Mineralogist 83: 348-357.

Banfield, J.F., B.J. Jones and D.R. Veblen. 1991. An AEM-TEM study of weathering and diagenesis, Albert Lake, Oregon. Parts I and II. Geochimica et Cosmochimica Acta 55: 2781-2810.

Barker, W.W., S.A. Welch and J.F. Banfield. 1997. Biogeochemical weathering of silicate minerals. Pp. 391-428 In J.F. Banfield and K.H. Nealson (eds.) Geomicrobiology: Interactions between Microbes and Minerals. Reviews in Mineralogy Vol. 35. Mineralogical Society of America, Washington, D.C. 
Barnhisel, R.I. and P.M. Bertsch. 1989. Chlorites and hydroxy-interlayered vermiculite and smectite. p. 729-788. In J.B. Dixon and S.B. Weed.(eds.) Minerals in Soil Environments. 2nd edition, Soil Science Society of America, Madison, Wisconsin.

Barré, P., B. Velde, C. Fontaine, N. Catel and L. Abbadie. 2008. Which 2:1 clay minerals are involved in the soil potassium reservoir? Insights from potassium addition or removal experiments on three temperate grassland soil clay assemblages. Geoderma 146: 216223.

Barré, P., G. Berger and B. Velde. 2009. How element translocation by plants may stabilize illitic clays in the surface of temperate soils. Geoderma 151: 22-30.

Barthès, B.G., E. Kouakoua, M.-C. Larré-Larrouy, T.M. Razafimbelo, E.F. de Luca, A. Azontonde, C.S.V.J. Neves, P.L. de Freitas and C.L. Feller. 2008. Texture and sesquioxide effects on water-stable aggregates and organic matter in some tropical soils. Geoderma 143: 14-25.

Barshad, I. and F.M. Kishk. 1969. Chemical composition of soil vermiculite clays as related to their genesis. Contributions to Mineralogy and Petrology 24: 136-155.

Basile-Doelsch, I., R. Amundson, W.E.E. Stone, C.A. Masiello, J.Y. Bottero, F. Colin, D. Borschneck and J.D. Meunier. 2005. Mineralogical control of organic carbon dynamics in a volcanic ash soil on La Réunion. European Journal of Soil Science 56: 689-703.

Bassett, W.A. 1959. The origin of the vermiculite deposit at Libby, Montana. American Mineralogist 44: 282-299.

Batchelder, M., J.D. Mather and J.B. Joseph. 1998. The stability of the Oxford clay as a mineral liner for landfill. Water and Environment Journal 12: 92-97.

Bates, T. E. 1962. Halloysite and gibbsite formation in Hawaii. Clays and Clay Minerals 9: 315-328.

Bennett, P.C., J.R. Rogers, W.J. Choi and F.K. Hiebert. 2001. Silicates, silicate weathering, and microbial ecology. Geomicrobiology Journal 18: 3-19.

Berg, A. and S. Banwart. 2000. Carbon dioxide mediated dissolution of Ca-feldspar: implications for silicate weathering. Chemical Geology 163: 25-52.

Bergaya, F., B.K.G. Theng and G. Lagaly (editors). 2006. Handbook of Clay Science.

Developments in Clay Science 1, Elsevier, Amsterdam.

Berkgaut, V., A. Singer and K. Stahr. 1994. Palagonite reconsidered: Paracrystalline illitesmectites from regoliths on basic pyroclastics. Clays and Clay Minerals 42: 582-592. 
Berner, R.A. and G.R. Holdren, Jr. 1979. Mechanism of feldspar weathering. II Observations of feldspars from soils. Geochimica et Cosmochimica Acta 43: 1173-1186.

Bétard, F., L. Caner and Y. Gunnell. (2009). Illite neoformation in plagioclase during weathering: Evidence from semi-arid Northeast Brazil. Geoderma 152: 53-62.

Bhattacharyya, T., D.K. Pal and P. Srivastava. 2000. Formation of gibbsite in the presence of 2:1 minerals: an example from Ultisols of northeast India. Clay Minerals 35: 827-840.

Bigham, J.M., R.W. Fitzpatrick and D.G. Schulze. 2002. Iron oxides. Pp. 323-366 In: Dixon, J.B. and D.G. Schulze (eds), Soil Mineralogy with Environmental Applications. Soil Science Society of America Book Series No. 7, Madison, Wisconsin,

Birkeland, P.W. 1999. Soils and Geomorphology $3^{\text {rd }}$ ed. Oxford Univ. Press, New York. 429 pp.

Bishop, J. L., Noe Dobrea, E. Z., McKeown, N. K., Parente, M., Ehlmann, B. L., Michalski, J. R.,Milliken, R. E., Poulet, F., Swayze, G. A., Mustard, J. F., Murchie, S. L. and J.-P. Bibring, (2008) Phyllosilicate diversity and past aqueous activity revealed at Mawrth Vallis,Mars. Science, 321: 830-833.Bleeker, P. and R.L. Parfitt. 1974. Volcanic ash and its clay mineralogy at Cape Hoskins, New Britain, Paua New Guinea. Geoderma 11: 123-135.

Bleeker, P. and R.L. Parfitt. 1974. Volcanic ash and its clay mineralogy at Cape Hoskins, New Britain, Papua New Guinea. Geoderma 11: 123-135.

Blum, A.E. and L.L. Stillings. 1995. Feldspar dissolution kinetics. Pp.291-351 In A.F. Whiteand S.L. Brantley.(eds.). Chemical Weathering Rates of Silicate Minerals. Reviews in Mineralogy Vol. 31. Mineralogical Society of America, Washington, D.C.

Blum, W.E.H., Warkentin, B.R. and Frossard, E.E. 2006. Soil, human society and the environment. Geological Society, London, Special Publications 266: 1-8.

Bockheim, J.G. 1997. Properties and classification of cold desert soils from Antarctica. Soil Science Society of America Journal 61:224-231.

Boettinger, J.L. and R.J. Southard 1995. Phyllosilicate distribution and origin in Aridosols on a granitic pediment, Western Mojave Desert. Soil Science Society of America Journal 59: 1189-1198.

Boettinger, J.L., and D.W. Ming. 2002. Zeolites. p.585-610. In J.B. Dixon and D.G. Schulze (eds.) Soil Mineralogy with Environmental Applications. Soil Science Society of America, Inc. Madison, Wisconsin, USA.

Bonifacio, E., E. Zanini, V. Boero and M. Franchini-Angela. 1997. Pedogenesis in a soil catena on serpentinite in north-western Italy. Geoderma 75: 33-51. 
Borchardt, G. 1989. Smectites. p. 675-727. In J.B. Dixon and S.B. Weed (eds.) Minerals in Soil Environments. 2nd edition, Soil Science Society of America, Madison, Wisconsin. Borggaard, O.K. 1983. Iron oxides in relation to aggregation of soil particles. Acta. Agric. Scand. 33: 257-260.

Bouza, P.J., M. Simón, J. Aguilar, K. Del Valle and M. Rostagno. 2007. Fibrous-clay mineral formation and soil evolution in Aridosols of northeastern Patagonia, Argentina. Geoderma 139: 38-50.

Bowen, N.L. 1922. The reaction principle in petrogenesis. Journal of Geology 30: 177-198. Boyer, S.J. 1975. Chemical weathering of rocks on the Lassiter Coast, Antarctic Peninsula, Antarctica. New Zealand Journal of Geology and Geophysics 18: 623-628.

Brinkman, R. 1970. Ferrolysis, a hydromorphic soil forming process. Geoderma 3: 199-206.

Bühmann, C. and P.L.C. Grubb. 1991. A kaolin-smectite interstratification sequence from a red and black complex. Clay Minerals 26: 343-358.

Buol, S. W. 1965. Present soil-forming factors and processes in arid and semiarid regions. Soil Science 99: 45-49.

Buol, S.W., R.J. Southard, R.C. Graham and P.A. McDaniel. 2003. Soil Genesis and Classification $5^{\text {th }}$ edition. Iowa State Press, Ames, IA, USA. 512 p.

Burton, E.D., R.T. Bush and L.A. Sullivan. 2006. Sedimentary iron geochemistry in acidic waterways associated with coastal lowland acid sulfate soils. Geochimica et Cosmochimica Acta 70: 5455-5468.

Burton, E.D., R.T. Bush, L.A. Sullivan and D.R.G. Mitchell. 2008. Schwertmannite transformation to goethite via the $\mathrm{Fe}(\mathrm{II})$ pathway: Reaction rates and implications for iron-sulfide formation. Geochimica et Cosmochimica Acta 72: 4551-4564.

Burton, E.D., R.T. Bush, L.A. Sullivan, R.K. Hocking, D.R.G. Mitchell, S.G. Johnston, R.W. Fitzpatrick, M. Raven, S. McClure and L.Y. Yang. 2009. Iron-monosulfide oxidation in natural sediments: Resolving microbially mediated S transformations using XANES, electron microscopy, and selective extractions. Environmental Science and Technology 43: 3128-3134.

Buurman, P. and A.G. Jongmans. 2005. Podzolisation and soil organic matter dynamics. Geoderma 125: 71-83.

Cady, J.G. and K.W. Flach. 1997. History of soil mineralogy in the United States Department of Agriculture. Advances in GeoEcology 29: 211-240.

Caillaud, J., D. Proust, D. Righi and F. Martin. 2004. Fe-rich clays in a weathering profile developed from serpentinite. Clays and Clay Minerals 52: 779-791. 
Calvaruso, C., L. Mareschal, M.-P. Turpault and E. Leclerc. 2009. Rapid clay weathering in the rhizosphere of Norway spruce and oak in an acid forest ecosystem. Soil Sci. Soc. Am. J. 73: 331-338.

Calvert, C.S., S.W. Buol and S.B. Weed. 1980. Mineralogical transformations of a vertical rock-saprolite-soil sequence in the North Carolina Piedmont. Soil Science Society of America Journal 44: 1096-1112.

Carnicelli, S., A. Mirabella, G. Cecchini and G. Sanesi. 1997. Weathering of chlorite to a low-charge expandable mineral in a Spodosol on the Apennine Mountains, Italy. Clays and Clay Minerals 45: 28-41.

Carroll, D. 1970. Rock Weathering. Monographs in Geoscience. Plenum Press, New York

Carson, C.D. and G.W. Kunze. 1970. New occurrence of tabular halloysite. Soil Science Society of America Proceedings 34: 538-540.

Carson, J.K., Campbell, L., Rooney, D., Clipson, N. and D.B. Gleeson, 2009. Minerals in soil select distinct bacterial communities in their microhabitats. FEMS Microbiol Ecol. 67: 381-388.

Cas, R.A.F. and J.V. Wright. 1987. Volcanic Successions - Modern andAncient. Allen and Unwin, London, 528pp.

Casey, W.H. 1995. Surface chemistry during the dissolution of oxides and silicate minerals. Pp. 185-217 In D.J. Vaughan and R.A.D. Pattrick (eds.) Mineral Surfaces. Chapman and Hall, London.

Casey, W.H., M.F. Hochella and H.R. Westrich. 1993. The surface chemistry of manganiferous silicate minerals as inferred from experiments on tephroite $\left(\mathrm{Mn}_{2} \mathrm{SiO}_{4}\right)$. Geochimica et Cosmochimica Acta 57: 785-793.

Casey, W.H., H.R. Westrich and G. W. Arnold. 1988. Surface chemisty of labradorite feldspar reacted with aqueous solutions at $\mathrm{pH}=2,3$ and 12 . Geochimica et Cosmochimica Acta 52: 821-832.

Casey, W.H., H.R. Westrich, G. W. Arnold and J.F. Banfield. 1989. The surface chemistry of dissolving labradorite feldspar. Geochimica et Cosmochimica Acta 53: 2795-2807.

Certini, G. and R. Scalenghe. 2006. Soil formation on Earth and beyond: the role of additional soil-forming factors. p. 193-210 In G. Certini and R. Scalenghe (eds.) Soils: basic concepts and future challenges. Cambridge University Press, Cambridge.

Certini, G., S. Hillier, E. McMurray and A.C. Edwards. 2003. Weathering of sandstone clasts in a forest soil in Tuscany (Italy). Geoderma 116: 357-372. 
Certini, G., M.J. Wilson, S.J. Hillier, A.R. Fraser and E. Delbos. 2006. Mineral weathering in trachydacitic-derived soils and saprolites involving formation of embryonic halloysite and gibbsite at Mt. Amiata, Central Italy. Geoderma 133: 173-190.

Chadwick, O.A. and J. Chorover. 2001. The chemistry of pedogenic thresholds. Geoderma 100: 321-353.

Chadwick, O.A., D.M. Hendricks and W.D. Nettleton. 1987. Silica in duric soils: I. A depositional model. Soil Science Society of America Journal 51: 975-982.

Chadwick, O.A., R.T. Gavenda, E.F. Kelly, K. Ziegler, C.G. Olson, W.C. Elliott and D.M. Hendricks. 2003. The impact of climate on the biogeochemical functioning of volcanic soils. Chemical Geology 202: 195- 223.

Chamley, H. 1989. Clay Sedimentology. Springer-Verlag, Berlin.

Chan, C.S., S.C. Fakra, D.C. Edwards, D. Emerson and J.F. Banfield. 2009. Iron oxyhydroxide mineralization on microbial extracellular polysaccharides. Geochimica et Cosmochimica Acta 73: 3807-3818.

Chen, J., Blume, H.-P. and L. Beyer. 2000. Weathering of rocks induced by lichen colonization - a review. Catena 39: 121-146.

Chenu, C. and A.F. Plante, 2006. Clay-sizeed organo-mineral complexes in a cultivation chronosequesnce: revisiting the concept of the 'primary organo-mineral complex'. European Journal of Soil Science 57: 596-607.

Childs, C.W. 1992. Ferrihydrite: A review of structure, properties and occurrence in relation to soils. Zeitschrift für Pflanzenernährung und Bodenkunde 155: 41-448.

Childs, C.W., R.L. Parfitt, and R.H. Newman. 1990. Structural studies of Silica Springs allophane. Clay Minerals 25, 329-341.

Cho, Hi Doo and A.R. Mermut. 1992. Evidence for halloysite formation from weathering of ferruginous chlorite. Clays and Clay Minerals 40: 608-619.

Churchman, G.J. 1978. Studies on a climosequence of soils in tussock grasslands. 21. Mineralogy. New Zealand Journal of Science 21: 467-480.

Churchman, G.J. 1980. Clay minerals formed from micas and chlorites in some New Zealand soils. Clay Minerals 15: 59-76.

Churchman, G.J. 1990. Relevance of different intercalation tests for distinguishing halloysite from kaolinite in soils. Clays and Clay Minerals 38: 591-599.

Churchman, G.J. 2000. The alteration and formation of soil minerals by weathering. Pp. F3F76 In M.E. Sumner (ed.) Handbook of Soil Science. CRC Press, Boca Raton, Florida. 
Churchman, G.J. 2006. Soil phases: the inorganic solid phase. Pp. 23-44. In G. Certini and R. Scalenghe (eds.) Soils: basic concepts and future challenges. Cambridge University Press, Cambridge.

Churchman, G.J. 2010. Is the geological concept of clay minerals appropriate for soil science? Journal of Physics and Chemistry of the Earth 35: 922-940.

Churchman, G.J. and J.G. Bruce. 1988. Relationships between loess deposition and mineral weathering in some soils in Southland, New Zealand. Pp. 11-31. In D.N. Eden and R.J. Furkert (eds.) Loess: Its distribution, geology and soils. A.A. Balkema, Rotterdam

Churchman, G.J. and C.M. Burke. 1991. Properties of subsoils in relation to various measures of surface area and moisture contents. Journal of Soil Science 42: 463-478.

Churchman, G.J. and R.M. Carr, 1975. The definition and nomenclature of halloysites. Clays and Clay Minerals 23: 382-388.

Churchman, G.J. and R.J. Gilkes. 1989. Recognition of intermediates in the possible transformation of halloysite to kaolinite. Clay Minerals 24: 579-590.

Churchman, G.J. and K.R. Tate 1987. Stability of aggregates of different size grades in allophanic soils from volcanic ash in New Zealand. Journal of Soil Science 38: 19-27.

Churchman, G.J. and B.K.G. Theng. 1984. Interactions of halloysites with amides: Mineralogical factors affecting complex formation. Clay Minerals 19: 161-175.

Churchman, G.J., R.N. Clayton, K. Sridhar and M.L. Jackson. 1976. Oxygen isotopic composition of aerosol-sized quartz in shales. Journal of Geophysical Research 81: 381386.

Churchman, G.J., P.G. Slade, P.G. Self and L.J. Janik. 1994. Nature of interstratified kaolinsmectites in some Australian soils. Australian Journal of Soil Research 32: 805-822.

Churchman, G.J., I.R. Pontifex and S.G. McClure . 2010.. Factors influencing the formation and characteristics of halloysites or kaolinites in granitic and tuffaceous saprolites in Hong Kong. Clays and Clay Minerals 58: 122-139.

Claridge, G.G.C. 1965. The clay mineralogy and chemistry of some soils from Ross Dependency, Antarctica. New Zealand Journal of Science 8: 186-220.

Claridge, G.G.C. and I.B. Campbell, 1968. Soils of the Shackleton Glacier, Queen Maud Range, Antarctica. New Zealand Journal of Science 11: 171-218.

Claridge, G.G.C. and I.B. Campbell, 2008. Zeolites in Antarctic soils: Examples from Coombs Hills and Marble Point. Geoderma 144: 66-72. 
Clayton, R. N., M.L. Jackson and K. Sridhar. 1978. Resistance of quartz silt to isotopic exchange under burial and intense weathering conditions. Geochimica et Cosmochimica Acta 42: 1517-1522.

Coleman, D.C. and D.A. Crossley Jr. 2003. Fundamental of Soil Ecology. Academic Press, Amsterdam.

Colombo, C. and J. Torrent. 1991. Relationships between aggregation and iron oxides in Terra Rossa soils from southern Italy. Catena 18: 51- 59.

Cornell, R.M. and U. Schwertmann. 1996. The Iron Oxides. VCH, Weinheim.

Courchesne, F. 2006. Factors of soil formation: biota. As exemplified by case studies on the direct imprint of trees on trace metal concentrations. p. 165-179. In G. Certini and R. Scalenghe (eds.) Soils: basic concepts and future challenges. Cambridge University Press, Cambridge.

Cradwick, P.D.G., V.C. Farmer, J.D. Russell, C.R. Masson, K. Wada and N. Yoshinaga. 1972. Imogolite, a hydrated aluminium silicate of tubular structure. Nature Physical Science 240: 187-189.

Craig, D.C. and F.C. Loughnan. 1964. Chemical and mineralogical transformations accompanying the weathering of basic volcanic rocks from New South Wales. Australian Journal of Soil Research 2: 218-234.

Cronin, S.J., V.E. Neall and A.S. Palmer. 1996. Investigation of an aggrading paleosol developed into andesitic ring-plain deposits, Ruapehu volcano, New Zealand. Geoderma 69: 119-135.

Cuadros, J., A. Delgado, A. Cardenete, E. Reyes and J. Linares. 1994. Kaolinite/montmorillonite resembles beidellite. Clays and Clay Minerals 42: 643-651.

Dahlgren, R.A., J.P. Dragoo and F.C. Ugolini. 1997. Weathering of Mt. St. Helens tephra under a cryic-udic climatic regime. Soil Science Society of America Journal 61: 15191525 .

Dahlgren, R.A., M. Saigusa and F.C. Ugolini. 2004. The nature, properties, and management of volcanic soils. Advances in Agronomy 82: 113-182.

Daux, V., J.L. Crovisier, C. Hemond and J.C. Petit. 1994. Geochemical evolution of basaltic rocks subjected to weathering: fate of the major elements, rare earth elements, and thorium. Geochimica et Cosmochimica Acta 58: 4941-4954.

Delmonte, B., I. Basile-Doelsch, J.-R. Petit, V. Maggi, M. Revel-Rolland, A. Michard, E. Jagoutz and F. Grousset. 2004. Comparing the Epica and Vostok dust records during the last 220,000 years: stratigraphical correlation and provenance in glacial periods. Earth- 
Science Reviews 66, 63-87.

Delvaux, B. and A.J. Herbillon, 1995. Pathways of mixed-layer kaolin-smectite formation in soils. Pp. 457-461 In Churchman, G.J., R.W. Fitzpatrick, and R.A. Eggleton (eds) Clays: controlling the environment. Proceedings of the $10^{\text {th }}$ International Clay Conference, 1823 July 1993, Adelaide, Australia. CSIRO Publishing, Melbourne.

Delvigne, J. 1998. Atlas of micromorphology of mineral alteration and weathering. Mineralogical Association of Canada (Canadian Mineralogist, Special Publication 3, 494 pp.

Denef, K. and J. Six. 2005. Clay mineralogy determines the importance of biological versus abiotic processes for macroaggregate formation and stabilization. European Journal of Soil Science 56: 469-479.

Dent, D.L. and L.J. Pons. 1995. A world perspective on acid sulphate soils. Geoderma 67: 263-276.

Derry, L.A., Kurtz, A.C., Ziegler, K. and O.A. Chadwick,, 2005. Biological Control of Terrestrial Silica Cycling and Export Fluxes to Watersheds. Nature, 433: 728-731.

Deshpande, T.L., D.J. Greenland and J.P. Quirk. 1968. Changes in soil properties associated with the removal of iron and aluminium oxides. Journal of Soil Science 19: 108-122.

De Vleeschouwer, F., B. Van Vliët Lanoé and N. Fagel. 2008. Long term mobilisation of chemical elements in tephra-rich peat (NE Iceland). Applied Geochemistry 23: 38193839 .

Dias, I., I. Gonzalez, S. Prates and E. Galán. 1997. Palygorskite occurrences in thye Portuguese sector of the Tagus basin: a preliminary report. Clay Minerals 32: 323-328.

Dixon, J.B. and T.R. McKee. 1974. Internal and external morphology of tubular and spheroidal halloysite particles. Clays and Clay Minerals 22: 127-137.

Dixon, J.B., and G.N. White. 2002. Manganese oxides. Pp. 367-388. In J.B. Dixon and D.G. Schulze (eds.) Soil Mineralogy with Environmental Applications. Soil Science Society of America, Inc. Madison, Wisconsin, USA.

Do Nascimento, N.R., G.T. Bueno, E. Fritsch, A.J. Herbillon, Th. Allard, A.J. Melft, R. Astolfo and Y. Li. 2004. Podzolization as a deferralization process: a study of an Acrisol-Podzol sequence derived from Palaeozoic sandstones in the northern Amazon Basin. European Journal of Soil Science 55: 523-538.

Doner, H.E. and P.R. Grossl. 2002. Carbonates and evaporates. Pp. 199-228. In J.B. Dixon and D.G. Schulze (eds.) Soil Mineralogy with Environmental Applications. Soil Science Society of America, Inc. Madison, Wisconsin, USA. 
Doner, H.E. and W.C. Lynn. 1989. Carbonate, halide, sulfate, and sulfide minerals. Pp. 279330. In J.B. Dixon and S.B. Weed (eds.) Minerals in Soil Environments. 2nd edition, Soil Science Society of America, Madison, Wisconsin.

Dong, H., D.P. Jaisi, J. Kim and G. Zhang. 2009. Microbe-clay mineral interactions. American Mineralogist 94: 1505-1519.

Douglas, L.A. 1989. Vermiculites. Pp. 635-674. In J.B. Dixon and S.B. Weed (eds.) Minerals in Soil Environments. 2nd edition, Soil Science Society of America, Madison, Wisconsin.

Drees, L.R., L.P. Wilding, N.E. Smeck and A.L. Senkayi. 1989. Silica in soils: quartz and disordered silica polymorphs. Pp. 913-974 In Dixon, J.B. and S.B. Weed (editors), Minerals in soil environments, $2^{\text {nd }}$ edition. Soil Sci. Soc. Am. Book Series no. 1, Madison, WI.

Drief, A. and P. Schiffman. 2004. Very low-temperature alteration of sideromelane in hyaloclastites and hyalotuffs from Kilauea and Mauna Kea volcanoes: implications for the mechanism of palagonite formation. Clays and Clay Minerals 52: 622-634.

Ducloux, J., Y. Guero, P. Sardini and A. Decarreau. 2002. Xerolysis: a hypothetical process of clay particles weathering under Sahelian climate. Geoderma 105: 83-110.

Ducloux., J., A. Meunier and B. Velde. 1976. Smectite, chlorite and a regular interlayered chlorite-vermiculite in soils developed on a small serpentinite body, Massif Central, France. Clay Minerals 11: 121-135.

Dudas, M.J. and M.E. Harward. 1975. Weathering and authigenic halloysite in soil developed in Mazama ash. Soil Science Society of America Proceedings 39: 561-566.

Duiker, S.W., F.E. Rhoton, J. Torrent, N.E. Smeck and R. Lal. 2003. Iron (hydr)oxide crystallinity effects on soil aggregation. Soil Sci. Soc. Am. J. 67: 606-611.

Egashira, K. and S. Tsuda, 1983. High-charge smectite found in weathered granitic rocks of Kyushu. Clay Science 6: 67-81.

Eger, A. and A.E. Hewitt. 2008. Soils and their relationship to aspect and vegetation history in the eastern Southern Alps, Canterbury High Country, New Zealand. Catena 75: 297307.

Eggleton, R.A. 1984. Formation of iddingsite rims on olivine: a transmission electron microscopy study. Clays and Clay Minerals 32: 1-11.

Eggleton, R.A. and J.N. Boland. 1982. Weathering of enstatite to talc through a sequence of transitional phases. Clays and Clay Minerals 30: 11-20. 
Eggleton, R.A. and P.R. Buseck. 1980. High resolution electron microscopy of feldspar weathering. Clays and Clay Minerals 28: 173-178.

Egli, M., A. Mirabella, A. Mancabelli and G. Sartori. 2004. Weathering of soils in alpine areas as influenced by climate and parent material.

Egli, M., M. Nater, M., A. Mirabella, S. Raimondi, M. Plötze and L. Alioth. 2008. Clay minerals, oxydydroxide formation, element leaching and humus development in volcanic soils. Geoderma 143: 101-114.

Ehlmann, B. L., J.F. Mustard, G.A. Swayze, R.N. Clark, J.L. Bishop, F. Poulet, D.J.D.

Marais, L.H. Roach, R.E. Milliken, J.J. Wray, O. Barnouin-Jha and S.L. Murchie. 2009.

Identification of hydrated silicate minerals on Mars using MRO-CRISM: Geologic

context near Nili Fossae and implications for aqueous alteration. Journal of Geophysical

Research 114, E00D08, doi:10.1029/2009JE003339

Elsass, F., D. Dubreoucq and M. Thiry. 2000. Diagenesis of silica minerals from clay minerals in volcanic soils of Mexico. Clay Minerals 35: 477-489.

Erickson, G.E. 1983. The Chilean nitrate deposit. Am. Sci. 71: 366-374.

Estoule-Choux., J., J. Estoule and D. Hallalouche. 1995. Congruent dissolution of microcline and epitaxial growth of 'skeletal' quartz during weathering of a granite frm the central Hoggar (Algeria). Pp.373-377 In G.J. Churchman, R.W Fitzpatrick and R.A. Eggleton. (eds.) Clays Controlling the Environment. Proceedings of the $10^{\text {th }}$ International Clay Conference. CSIRO Publishing, Melbourne.

Eswaran, H. and Wong Chaw Bin. 1978. A study of a deep weathering profile on granite in Peninsular Malaysia. Parts I, II, and III. Soil Science Society of America Journal 42: 144-158.

Eswaran, H. and Yeow Yew Hong. 1976. The weathering of biotite in a profile on gneiss in Malaysia. Geoderma 16: 9-20.

Etame, J., Gerard, M., Suh, C.E. and Bilong, P. 2009. Halloysite neoformation during the weathering of nephelinitic rocks under humid tropical conditions at Mt Etinde, Cameroon. Geoderma 154: 59-68.

Eusterhues, K., C. Rumpel and I. Kögel-Knabner. 2005. Organo-mineral associations in sandy acid forest soils: importance of specific surface area, iron oxides and micropores. European Journal of Soil Science 56: 753-763.

Fairbridge, R.W. and J. Bourgeois. 1978. The Encylopedia of Sedimentology. Dowden, Hutcinson and Ross, Inc., Stroudsberg. 
Fanning, D.S., M.C. Rabenhorst, S.N. Burch, K.R. Islam and S.A. Tangren. 2002. Sulfides and Sulfates. Pp. 229-260. In J.B. Dixon and D.G. Schulze (eds.) Soil Mineralogy with Environmental Applications. Soil Science Society of America, Inc. Madison, Wisconsin, USA.

Fanning, D.S., V.Z. Keramidas and M.A. El-Desoky. 1989. Micas. Pp. 551-634. In J.B. Dixon and S.B. Weed (eds.) Minerals in Soil Environments. 2nd edition, Soil Science Society of America, Madison, Wisconsin.

Farmer, V.C. 1982. Significance of the presence of allophane and imogolite in podzol Bs horizons for pozolization mechanisms: a review. Soil Science and Plant Nutrition 28: 571-578.

Farmer, V.C. 1997. Conversion of ferruginous allophanes to ferruginous beidellites at $95^{\circ} \mathrm{C}$ inder alkaline conditions with alternating oxidation and reduction. Clays and Clay Minerals 45: 591-597.

Farmer, V.C. 2005. Forest vegetation does recycle substantial amounts of silicon from and back to the soil solution with phytoliths as an intermediate phase, contrary to recent reports. European Journal of Soil Science 56: 271-272.

Farmer, V.C. and A.R. Fraser. 1982. Chemical and colloidal stability of sols in the $\mathrm{Al}_{2} \mathrm{O}_{3}-$ $\mathrm{Fe}_{2} \mathrm{O}_{3}-\mathrm{SiO}_{2}-\mathrm{H}_{2} \mathrm{O}$ system: their role in podzolization. Journal of Soil Science 33: 737742.

Farmer, V.C. and D.G. Lumsdon. 2001. Interactions of fulvic acid with aluminium and a proto-imogolite sol: the contribution of E-horizon eluates to podzolization. European Jurnal of Soil Science 52: 177-188.

Farmer, V.C., J.D. Russell, W.J. McHardy, A.C.D. Newman, J.L. Ahlrichs and J.Y.H. Rimsaite. 1971. Evidence for loss of protons and octahedral iron from oxidised biotites and vermiculites. Mineralogical Magazine 38: 121-137.

Farmer, V.C., J.D. Russell and M.L. Berrow. 1980. Imogolite and proto-imogolite allophane in spodic horizons: evidence for a mobile aluminium silicate complex in podzol formation. Journal of Soil Science 31: 673-684.

Farmer, V.C., J.D. Russell and B.F.L. Smith. 1983. Extraction of inorganic forms of translocated Al, Fe and Si from a podzol Bs horizon. Journal of Soil Science 34: 571576. 
Farmer, V.C., W.J. McHardy, L. Robertson, A. Walker and M.J. Wilson. 1985. Micromorphology and sub-microscopy of allophone and imogolite in a podzol Bs horizon: evidence for translocaton and origin. Journal of Soil Science 36: 87-95.

Farmer, V.C., E. Delbos and J.D. Miller. 2005. The role of phytolith formation and dissolution in controlling concentrations of silica in soil solutions and streams. Geoderma 127: 71-79.

Ferris, F.G. 1997. Formation of authigenic minerals by bacteria. Pp. 187-208 In J.M. McIntosh and L.A.Groat (eds.) Biological-Mineralogical Interactions. Mineralogical Association of Canada Short Course Volume 25. Mineralogical Association of Canada, Ottawa.

Fieldes, M. 1955. Clay mineralogy of New Zealand soils. Part II: Allophane and related mineral colloids. New Zealand Journal of Science and Technology 37: 336-350.

Fieldes 1966

Fieldes, M. 1968. Clay mineralogy. In Soils of New Zealand, Part 2. New Zealand Soil Bureau Bulletin 26(2): 22-39.

Fieldes, M. and L.D. Swindale. 1954. Chemical weathering of silicates in soil formation. New Zealand Journal of Science and Technology B36: 140-154.

Fisher, R.V. and Schminke, H.-U. 1984. Pyroclastic Rocks. Springer-Verlag, Berlin, 472pp.

Fisher, C.B. and P.C. Ryan. 2006. The smectite-to-disordered kaolinite transition in a tropical soil chronosequence, Pacific coast, Costa Rica. Clays and Clay Minerals 54: 571-586.

Fitzpatrick, R.W. and D.J. Chittleborough. 2002. Titanium and zirconium minerals. Pp. 667 690. In J.B. Dixon and D.G. Schulze (ed.) Soil Mineralogy with Environmental Applications. Soil Science Society of America, Inc. Madison, Wisconsin, USA.

Fitzpatrick, R.W., E. Fritsch and P.G. Self. 1996. Interpretation of soil features produced by ancient and modern processes in degraded landscapes. V. Development of saline sulfidic features in non-tidal seepage areas. Geoderma 69: 1-29.

Fortin, D. and S. Langley. 2005. Formation and occurrence of biogenic iron-rich minerals. Earth-Science Reviews 72: 1-19.

Franke, W.A. and R. Teschner-Steinhardt. 1994. An experimental approach to the sequence of the stability of rock-forming minerals towards chemical weathering. Catena 21:279290.

Fritsch, E., G. Morin, A. Bedidi, D. Bonnin, E. Balan, S. Caquineau and G. Calas. 2005. Tranformation of haematite and Al-poor goethite to Al-rich goethite and associated 
yellowing in a ferralitic clay soil profile of the middle Amazon Basin (Manaus, Brazil). European Journal of Soil Science 56: 575-588.

Fu, F.F., T. Akagi and S. Yabuki. 2002. Origin of silica particles found in the cortex of Matteuccia roots. Soil Sci. Soc. Am. J. 66: 1265-1271.

Furian, S., L.Barbiéro, R. Boulet, P. Curmi, M. Grimaldi and C. Grimaldi. 2002. Distribution and dynamics of gibbsite and kaolinite in an Oxisol of Serra do Mar, southeastern Brazil. Geoderma 106: 83-100.

Furquim, S.A.C., R.C. Graham, L. Barbiero, J.P.deQ. Neto and V. Valles. 2008. Mineralogy and genesis of smectites in an alkaline-saline environment of Pantanal wetland, Brazil. Clays and Clay Minerals 56: 579-595.

Gaines, R.V., H.W. Skinner, E.F. Foord, B. Mason and A. Rosenzweig. 1997. Dana's New Mineralogy. John Wiley \& sons, New York.

Galán, E. and A. Castillo. 1984. Sepiolite-palygorskite in Spanish Tertiary basins: Genetical patterns in continental environments. Pp. 87-124 In A. Singer and E Galán (eds.) Palygorskite-Sepiolite, Occurrence, Genesis and Uses. Development in Sedimentology 37. Elsevier, Amsterdam.

Galán, E., J.M. Brell, A. La Iglesia and H.S. Robertson. 1975. The Cáceras palygorskite deposit, Spain. Pp. 81-94 In S.W. Bailey (ed.) Proceedings of the International Clay Conference, Mexico. Applied Publishing, Wilmette, Illinois.

Gallez, A., A.S.R. Juo and A.J. Herbillon. 1976. Surface and charge characteristics of selected soils in the tropics. Soil Sci. Soc. Am. J. 40:601-608.

Gardam, M., A.J. Mason, A.F. Reid, G.J. Churchman and M. Raven. 2008. Arumpo bentonite deposits: distinctive indicators of past volcanic events in the Murray Basin, southeastern Australia. Australian Journal of Earth Sciences 55: 183-194.

Garrels, R.M. and F.T. Mackenzie. 1971. Evolution of Sedimentary Rocks. W.W. Norton and Co., New York.

Gates, W.P. 2006. X-ray absorption spectroscopy. Pp. 789-864. In Bergaya, F., B.K.G. Theng, and G. Lagaly (eds.) 2006. Handbook of Clay Science. Developments in Clay Science 1, Elsevier, Amsterdam.

Geiss, C.E. and C.W. Zanner. 2006. How abundant is pedogenic magnetite? Abundance and grain size estimates for loessic soils based on rock magnetic analyses. Journal of Geophysical Research 111, B12S21, doi:10.1029/2006JB004564 
Gérard, M., S. Caquineau, J. Pinheiro and G. Stoops. 2007. Weathering and allophane neoformation in soils developed on volcanic ash in the Azores. European Journal of Soil Science 58: 496-515.

Gerin, P.A., M.J. Genet, A.J. Herbillon and B. Delvaux. 2003. Surface analysis of soil material by X-ray photoelectron spectroscopy . European Journal of Soil Science 54: 589-603.

Giesler, R., H. Ilvesniemi, L. Nyberg, P. van Hees, M. Starr, K. Bishop, T. Kareinen, U. S. Lundström. 2000. Distribution and mobilization of Al, Fe and Si in three podzolic soil profiles in relation to the humus layer. Geoderma 94: 249-263.

Gilkes, R.J. 1990. Mineralogical insights into soil productivity: an anatomical perspective. Pp. 63-73. In Transactions, $14^{\text {th }}$ International Congress of Soil Science, 12-18 August 1990, Kyoto, Japan, Plenary papers, International Society of Soil Science.

Gilkes, R.J. and A. Suddhiprakarn. 1979. Biotite alteration in deeply weathered granite. I. Morphological, mineralogical, and chemical properties. Clays and Clay Minerals 27: 249-360.

Gillot, F., D. Righi and M.L. Räisänen. 2001. Layer-charge evaluation of expandable clays from a chronosequence of podzols in Finland using an alkylammonium method. Clay Minerals 36: 571-584.

Gislason, S.R. and E.H. Oelkers. 2003. Mechanism, rates, and consequences of basaltic glass dissolution: II. An experimental study of the dissolution rates of basaltic glass as a function of $\mathrm{pH}$ and temperature. Geochimica et Cosmochimica Acta 67: 3817-3832.

Gjems, O. 1970. Mineralogical composition and pedogenic weathering of the clay fraction in podzol weathering profiles in Zalesine, Yugoslavia. Soil Science 110: 237-243.

Glassmann, J.R. and G.M. Simonson. 1985. Alteration of basalt in soils of western Oregon. Soil Science Society of America Journal 49: 262-273.

Goldich, S.S. 1938. A study in rock weathering. Journal of Geology 46: 17-58.

Goodman, B.A., J.D. Russell, B. Montez, E. Oldfield and R.J. Kirkpatrick. 1985. Structural studies of imogolite and allophanes by aluminum-27 and silicon-29 nuclear magnetic resonance spectroscopy. Physics and Chemistry of Minerals 12: 342-346.

Green, B.E. 1987. Weathering of buried paleosols on late Quaternary rhyolitic tephras, Rotorua region, New Zealand. Unpublished MSc thesis, University of Waikato, Hamilton. 
Greenland, D.J. 1965. Interactions between clays and organic compounds in soils. Part 1. Mechanisms of interaction between clays and defined organic compounds. Soils and Fertilisers 28: 415-425.

Grey, I.E. and A.F. Reid. 1975. The structure of pseudorutile and its role in the natural alteration of ilmenite. American Mineralogist 60: 898-906.

Grim, R.E. 1968. Clay Mineralogy. McGraw-Hill, New York.

Grim, R.E., R.H. Bray and W.F. Bradley. 1937. The mica in argillaceous sediments. American Mineralogist 22: 813-829.

Gustafsson, J.P. 2001. Modelling competitive anion adsorption on oxide minerals and an allophane-containing soil. European Journal of Soil Science 52: 639-653.

Hall, P.L., G.J. Churchman and B.K.G. Theng. 1985. Size distribution of allophane unit particles in aqueous suspensions. Clay and Clay Minerals 33: 345-349.

Hamblin, A.P. and D.J. Greenland. 1977. Effect of organic constituents and complexed metal ions on aggregate stability of some East Anglian soils. Journal of Soil Science 28: 410416.

Hamilton, V.E., Christensen, P.R. and J.L. Bandfield. 2003. Volcanism or aqueous alteration on Mars? Nature 421: 711-712.

Harlan, P.W., D.P. Franzmeier and C.B. Roth. 1977. Soil formation on loess in southwestern Indiana. II. Distribution of clay and free iron oxides and fragipan formation. Soil Science Society of America Journal 42: 99-103.

Harder, H. 1972. The role of magnesium in the formation of smectite minerals. Chemical Geology 10: 31-39.

Harder, H. 1977. Clay mineral formation under lateritic weathering conditions. Clay Minerals 12: 281-288.

Harris, W.G. 2002. Phosphate Minerals. Pp. 637 - 665. In J.B. Dixon and D.G. Schulze (eds.) Soil Mineralogy with Environmental Applications. Soil Science Society of America, Inc. Madison, Wisconsin, USA.

Hart R.D., W. Wiriyakitnateekul and R.J. Gilkes. 2003. Properties of soil kaolins from Thailand. Clay Minerals 38: 71-94.

Hart, R.D., R.J. Gilkes, S. Siradz and B. Singh. 2002. The nature of soil kaolins from Indonesia and Western Australia. Clays Clay Miner. 50: 198-207.

Hartemink, A.E., A.B. McBratney and J.A. Cattle, J.A. 2001. Developments and trends in soil science: 100 volumes of Geoderma (1967-2001). Geoderma 100: 217-268. 
Hay, R.L. 1960. Rate of clay formation and mineral alteration in a 4000-year-old volcanic ash soil on St. Vincent, B.W.I. American Journal of Science 258: 354-368.

Hayes, M.H.B., P.MacCarthy, R.L. Malcolm and R.S. Swift 1989. The search for structure: setting the scene. Pp.3-31 In M.H.B.Hayes, P.MacCarthy, R.L. Malcolm and R.S.Swift (eds.) Humic Substances II. John Wiley \& Sons, Chichester.

He, Y., D.C. Li, B. Velde, Y.F. Yang, C.M. Huang, Z.T. Gong and G.I. Zhang. 2008. Clay minerals in a soil chronosequence derived from basalt on Hainan Island, China and its implication for pedogenesis. Geoderma 148: 206-212.

Hellmann, R., C.H. Egglestone, H.F. Hochelle Jr. and D.A Crerar. 1990. The formation of leached layers on albite surfaces during dissolution under hydrothermal conditions. Geochimica et Cosmochimica Acta 54: 1267-1282.

Hemley, J.J. 1959. Some mineralogical equilibria in the system $\mathrm{K}_{2} \mathrm{O}-\mathrm{Al}_{2} \mathrm{O}_{3}-\mathrm{SiO}_{2}-\mathrm{H}_{2} \mathrm{O}$. American Journal of Science 257: 241-270.

Hendricks, S.B. and W.H. Fry. 1930. The results of X-ray and microscopical examinations of soil colloids. Soil Science 29: 457-479.

Henriet, C., N. De Jaeger, M. Dore, S. Opfergelt and B. Delvaux. 2008. The reserve of weatherable primary silicates impacts the accumulation of biogenic silicon in volcanic ash soils. Biogeochemistry 90: 209-223.

Herbillon, A.J., R. Frankart and L. Vielvoye. 1981. An occurrence of interstratified kaolinite-smectite minerals in a red-black soil toposequence. Clay Minerals 16: 195-201.

Herbillon, A.J. and M.N. Makumbi 1975. Weathering of chlorite in a soil derived from a chlorito-schist under humid tropical conditions. Geoderma 13: 89-104.

Herbillon, A. J., M. M. Mestdagh, L. Vielvoye and E. Derouane. 1976. Iron in kaolinite with special reference to kaolinite from tropical soils Clay Minerals 11: 201-220.

Hillier, S. and A.L. Pharande, 2008. Contemporary pedogenic formation of palygorskite in irrigation-induced saline-sodic, shrink-swell soils of Maharashta, India. Clay and Clay Minerals 56: 531-548.

Hinsinger, P. and B. Jaillard. 1993. Root-induced release of interlayer potassium and vermiculitization of phlogopite as related to potassium depletion in the rhizosphere of ryegrass. Journal of Soil Science 44: 525-534.

Hinsinger, P., B. Jaillard and J.E Dufey. 1992. Rapid weathering of a trioctahedral mica by the roots of ryegrass. Soil Science Society of America Journal 56: 977-982.. 
Hinsinger, P., F. Elsass, B. Jaillard and M. Robert. 1993. Root-induced irreversible transformation of a trioctahedral mica in the rhizosphere of rape. Journal of Soil Science 44: 535-545.

Hinsinger, P., O.N.F. Barros, M.F. Benedetti, Y. Noack and G. Callot. 2001. Plant-induced weathering of a basaltic rock. Geochim. Cosmochim. Acta 65: 137-152.

Hiradate, S. and S.-I. Wada. 2005. Weathering processes of volcanic glass to allophane determined by ${ }^{27} \mathrm{Al}$ and ${ }^{29} \mathrm{Si}$ solid-state NMR. Clays and Clay Minerals 53: 401-408.

Hiradate, S., T. Nakadai, H. Shindo and T. Yoneyama. 2004. Carbon source of humic substances in some Japanese volcanic ash soils determined by carbon stable isotopic ratio, $\delta^{13}$ C. Geoderma 119: 133-141.

Hiradate, S., H. Hirai and H. Hashimoto. 2006. Characterisation of allophanic Andisols by solid-state ${ }^{13} \mathrm{C},{ }^{27} \mathrm{Al}$, and ${ }^{29} \mathrm{Si}$ NMR and by $\mathrm{C}$ stable isotopic ratio, $\delta^{13} \mathrm{C}$. Geoderma 136 : 696-707.

Hochella, M.F., Jr. 2008. Nanogeoscience: from origins to cutting-edge applications. Elements 4: 373-379.

Hochella, M.F., Jr. and J.F. Banfield. 1995. Chemical weathering of silicates in nature: a microscopic perspective with theoretical considerations. Pp. 353-406 In A.F. Whiteand S.L. Brantley (eds.). Chemical Weathering Rates of Silicate Minerals. Reviews in Mineralogy Vol. 31. Mineralogical Society of America, Washington, D.C.

Hodder, A.P.W., B.E. Green and D.J. Lowe. 1990. A two-stage model for the formation of clay minerals from tephra-derived volcanic glass. Clay Minerals 25: 313-327.

Hodder, A.P.W., P.J.de Lange and D.J. Lowe. 1991. Dissolution and depletion of ferromagnesian minerals from Holocene tephras in an acid bog, New Zealand, and implications for tephra correlation. Journal of Quaternary Science 6: 195-208.

Hodder, A.P.W. T.R. Naish and C.S. Nelson. 1993. A two-stage model for the formation of smectite from detrital volcanic glass under shallow-marine conditions. Marine Geology 109: 279-285.

Hodder, A.P.W., T.R. Naish and D.J. Lowe. 1996. Towards an understanding of thermodynamic and kinetic controls on the formation of clay minerals from volcanic glass under various environmental conditions. Pp. 1-11 In S.G Pandalai (ed.) Recent Research Developments in Chemical Geology. Research Signpost, Trivandrum, India. Hogg, A.G., T.F.G. Higham, D.J. Lowe, J. G. Palmer, P. Reimer and R.M. Newnham. 2003. A wiggle-match date for Polynesian settlement of New Zealand. Antiquity 77: 116-125. 
Hogg, A.G., D.J. Lowe, J.G. Palmer, G. Boswijk, and C.J. Bronk Ramsey. 2012. Revised calendar date for the Taupo eruption derived by ${ }^{14} \mathrm{C}$ wiggle-matching using a New Zealand kauri ${ }^{14} \mathrm{C}$ calibration data set. The Holocene 22: 439-449.

Holdren, G.R. Jr. and P.M. Speyer. 1987. Reaction rate-surface area relationships during the early stages of weathering: II Data on eight additional feldspars. Geochimica et Cosmochimica Acta 51:2311-2318.

Hong, H.-L. and J.-X. Mi. 2006. Characteristics of halloysite associated with rectorite from Hubei, China. Mineralogical Magazine 70: 257-264.

Hseu, Z.Y., H. Tsai, H.C. Hsi and Y.C. Chen. 2007. Weathering sequences of clay minerals in soils along a serpentinitic toposequence. Clays and Clay Minerals 55: 389-401.

Huang, P.M. 1989. Feldspars, olivines, pyroxenes, and amphiboles. Pp. 975-1050. In J.B.

Dixon and S.B. Weed (eds.) Minerals in Soil Environments. 2nd edition, Soil Science Society of America, Madison, Wisconsin.

Huang, P.M. and M. Schnitzer (eds.) 1986. Interactions of Soil Minerals with Natural Organics and Microbes. Soil Science Society of America Special Publication No. 17. Huang , P.M., M.K. Wang, N. Kämpf and D.G. Schulze. 2002. Aluminum hydroxides. Pp. 261-290. In J.B. Dixon and D.G. Schulze (eds.) Soil Mineralogy with Environmental Applications. Soil Science Society of America, Inc. Madison, Wisconsin, USA.

Hue, N.V., G.R. Craddock and F. Adams. 1986. Effect of organic acids on aluminum toxicity in subsoils. Soil Science Society of America Journal 50: 28-34.

Hughes, J.C. and G. Brown. 1979. A crystallinity index for soil kaolins and its relation to parent rock, climate and soil maturity. Journal of Soil Science 30: 557-563.

Hunter, R.]. 1981. The zeta potential in colloid science. Academic Press, London, U.K. Hurowitz, J.A. and S.M. McLennan, 2007. A 3.5 Ga record of water-limited, acidic weathering conditions on Mars. Earth and Planetary Science Letters 260: 432-443.

Ildefonse, P., E. Copin and B. Velde. 1979. A soil vermiculite formed from a meta-gabbro, Liore-Atlantique, France. Clay Min. 14: 201-210.

Inoue, K. and T. Sase. 1996. Paleoenvironmental history of post-Toya Ash tephric deposits and paleosols at Iwate Volcano, Japan, using aeolian dust content and phytolith composition. Quaternary International 34-36: 127-137.

Inskeep, W.P., J.L. Clayton and D.W. Mogk. 1993. Naturally weathered plagioclase grains from the Idaho Batholith: Observations using scanning electron microscopy. Soil Science Society of America Journal 57: 851-860. 
Jackson, M.L. 1959. Frequency distribution of clay minerals in major great soil groups as related to the factors of soil formation. Clays and Clay Minerals 6: 133-143.

Jackson, M.L. 1963. Aluminum bonding in soils: A unifying principle in soil science. Soil Science Society of America Proceedings 27: 1-10.

Jackson, M.L. 1964. Chemical composition of soils. Pp. 71-141. In F.E. Bear (ed.)

Chemistry of the Soil. Reinhold Publishing Corp., New York.

Jackson, M.L., S.A. Tyler, A.L. Willis, G.A. Bourbeau and R.P. Pennington. 1948.

Weathering sequence of clay-size minerals in soils and sediments. I: Fundamental generalizations. Journal of Physical and Colloid Chemistry 52: 1237-1260.

Jackson, M.L., Y. Hseung, R.B. Corey, E.J. Evans, and R.C. Van den Heuval. 1952.

Weathering of clay-size minerals in soils and sediments II. Chemical weathering of layer silicates. Soil Science Society of America Proceedings 16: 3-6.

Janik, L.J. and J.L.Keeling 1993. FT-IR partial least-squares analysis of tubular halloysite in kaolin samples from the Mount Hope kaolin deposit. Clay Minerals 28: 265-378.

Jansen, B., G.J. Nierop and J.M. Verstraten. 2005. Mechanisms controlling the mobility of dissolved organic matter, aluminium and iron in podzol B horizons. European Journal of Soil Science 56: 537-550.

Jaynes, W.F., J.M. Bigham, N.E. Smeck and M.J. Shipitalo. 1989. Interstratified 1:1-2:1 mineral formation in a polgenetic soil from southern Ohio. Soil Science Society of America Journal 53: 1888-1894.

Johnson, D.L. 2002. Darwin would be proud: bioturbation, dynamic denudation, and the power of theory in science. Geoarchaeology 17: 7-40.

Johnson, L.J. 1964. Occurrence of regularly interstratified chlorite-vermiculite as a weathering product of chlorite in a soil. American Mineralogist 49: 556-572.

Johnson, S.L., S. Guggenheim and A.F. Koster van Groos. 1990. Thermal stability of halloysite by high pressure differential thermal analysis. Clays and Clay Minerals 38: 477-484.

Johnson-Maynard, J.L., P.A. McDaniel, D.E. Ferguson and A.L. Falen. 1997. Chemical and mineralogical conversion of Andisols following invasion by bracken fern. Soil Science Society of America Journal 61: 549-555.

Jolicoeur, S., P. Ildefonse and M. Bouchard. 2000. Kaolinite and gibbsite weathering of biotite within saprolites and soils of central Virginia. Soil Science Society of America Journal 64: 1118-1119. 
Jongkind, A.G. and P. Buurman. 2006. The effect of kauri (Agathis australis) on grain size distribution and clay mineralogy of andesitic soils in the Waitakere Ranges, New Zealand. Geoderma 134, 171-186.

Jongmans, A.G., F. Van Oort, P. Buurman, A.M. Jaunet and J.D.J. van Doesburg. 1994. Morphology, chemistry and mineralogy of isotropic aluminosilicate coatings in a Guadaloupe Andisol. Soil Science Society of America Journal 58: 501-507.

Jongmans, A.G., N. Van Breeman, U. Lundström, P.A.W. van Hees, R.D. Finlay, M. Srinivasan, T. Unestam, R. Giesler, P.-A. Melkerud and M. Olsson. 1997. Rock-eating fungi. Nature 389: 682-683.

Jouquet, P., L. Mamou, M. Lepage and B. Velde. 2002. Effect of termites on clay minerals in tropical soils: fungus-growing termites as weathering agents. European Journal of Soil Science 53: 521-528.

Joussein, E., Petit, S., Churchman, G.J., Theng, B., Righi, D., Delvaux, B. 2005. Halloysite clay minerals - a review. Clay Minerals 40: 383-426.

Kadir, S., and M. Eren. 2008. The occurrence and genesis of clay minerals associated with Quaternary caliches in the Mersin area, southern Turkey. Clays and Clay Minerals 56: 244-258.

Kahle, M., M. Kleber and R. Jahn. 2002a. Review of XRD-based quantitative analyses of clay minerals in soils: the suitability of mineral intensity factors. Geoderma 109: 191205.

Kahle, M., M. Kleber and R. Jahn. 2002b. Predicting carbon content in illitic clay fractions from surface area, cation exchange capacity and dithionite-extractable iron. European Journal of Soil Science 53: 639-644.

Kahle, M., M. Kleber and R. Jahn. 2004. Predicting carbon content in illitic clay fractions from surface area, cation exchange capacity and dithionite-extractable iron. European Journal of Soil Science 53: 639-644.

Kaiser, K. and G. Guggenberger. 2000. The role of DOM sorption to mineral surfaces in the preservation of organic matter in soils. Organic Geochemistry 31: 711-724.

Kaiser, K. and G. Guggenberger. 2003. Mineral surfaces and organic matter. European Journal of Soil Science 54: 219-236.

Kämpf, N. and U. Schwertmann. 1982. Goethite and hematite in a climosequence in southern Brazil and their application in classification of kaolinitic soils. Geoderma 29: 27-39. 
Kanket, W., A. Suddhiprakern, I. Kheoruenromne and R.J. Gilkes. 2005. Chemical and crystallographic properties of kaolin from Ultisols in Thailand. Clays Clay Miner. 53: 478-489.

Kapoor, B.S. 1973. The formation of 2:1-2:2 intergrade clays in some Norwegian podzols. Clay Minerals 10: 79-86.

Kautz, C.Q. and P.C. Ryan. 2003. The $10 \AA$ to $7 \AA$ halloysite transition in a tropical soil sequesnce, Costa Rica. Clays and Clay Minerals 51: 252-263.

Kawano, M. and K. Tomita. 1994. Growth of smectite from leached layer during experimental alteration of albite. Clays and Clay Minerals 42: 7-17.

Kawano, M. and K. Tomita. 2001. Microbial biomineralization in weathered volcanic ash deposit and formation of biogenic minerals by experimental incubation. American Mineralogist 86: 400-410.

Kawano, M. and K. Tomita. 2002. Microbial formation of silicate minerals in the weathering environment of a pyroclastic deposit. Clays and Clay Minerals 50: 99-110.

Kendrick, K.J. and R.C. Graham. 2004. Pedogenic silica accumulation in chronosequence soils, southern California. Soil Sci. Soc. Am. J. 68: 1295-1303.

Khademi, H. and J.M. Arocena. 2008. Kaolinite formation from palygorskite and sepiolite in rhizosphere soils. Clays and Clay Minerals 56: 429-436.

Khormali, F. and A. Abtahi. 2003. Origin and distribution of clay minerals in calcareous arid and semi-arid soils of Fars province, southern Iran. Clay Minerals 38: 511-527.

Kirkman, J.H. 1976. Clay mineralogy of Rotomahana sandy loam soil, North Island, New Zealand. New Zealand Journal of Geology and Geophysics 19: 35-41.

Kirkman, J.H. 1981. Morphology and structure of halloysite in New Zealand tephras. Clays and Clay Minerals 29: 1-9.

Kirkman, J.H. and W.J. McHardy. 1980. A comparative study of the morphology, chemical composition and weathering of rhyolitic and andesitic glass. Clay Minerals 15: 165-173.

Kittrick, J.A. 1967. Gibbsite-kaolinite equilibria. Soil Science Society of America Proceedings 31: 314-316.

Kittrick, J.A. 1973. Mica-derived vermiculites as unstable intermediates. Clays and Clay Minerals 21: 479-488.

Kleber, M., L. Schwendenmann, E. Veldkamp, J. Rößner and R. Jahn. 2007. Halloysite versus gibbsite: Silicon cycling as a pedogenetic process in two lowland rain forest soils of La Selva, Coast Rica. Geoderma 138: 1-11. 
Kleber, M., R. Mikutta, M.S. Torn and R. Jahn. 2005. Poorly crystalline mineral phases protect organic matter in acid subsoil horizons. European Journal of Soil Science 56: 717-725.

Kohut, C., K. Muehlenbachs and M.J. Dudas. 1995. Authigenic dolomite in a saline soil in Alberta, Canada. Soil Science Society of America Journal 59: 1499-1504.

Kondo, R., C.W. Childs and I. Atkinson. 1994. Opal Phytoliths in New Zealand. Manaaki Whenua Press, Lincoln. 85 pp.

Kubota, T. 1975. Aggregate stabilisation by hydroxyaluminium ions. Soil Science and Plant Nutrition 21: 1-12.

Laird, D.A. and E.A. Nater. 1993. Nature of the illiticphase associated with randomly interstratified smectite/illite in soils. Clays Clay Miner. 41: 280-287.

Laird, D.A., P. Barak, E.A. Nater and R.H. Dowdy. 1991. Chemistry of smectitic and illitic phases in interstratified soil smectite. Soil Sci. Soc. Am. J. 55: 1499-1504.

Langmuir, D. and D.O. Whittemore. 1971. Variations in the stability of precipitated ferric oxyhydroxides. Pp. 209-234. In R.F. Gould (ed.) Nonequilibrium Systems in Natural Water Chemistry. Advances in Chemistry Series No. 106.

Lanson, B. 1997. Decomposition of experimental X-ray diffraction patterns (profile fitting): a convenient way to study clays. Clays and Clay Minerals 45: 132-146.

Lapidus, D.F. 1987. Collins Dictionary of Geology. Collins, London.

Lee, B.D., S.K. Sears, R.C. Graham, C. Amrhein and H. Vali. 2003. Secondary mineral genesis from chlorite and serpentine in an ultramafic soil toposequence. Soil Science Society of America Journal 65: 1183-1196.

Leifeld, J. 2006. Soils as sources and sinks of greenhouse gases. Geological Society, London, Special Publications 266: 23-44.

Leonard, R.A. and S.B. Weed, 1967. Influence of exchange ions on the b-dimension of dioctahedral vermiculite. Clays and Clay Minerals 15: 149-161.

Li, Zhongpei, B. Velde and Decheng Li. 2003. Loss of K-bearing clay minerals in floodirrigated, rice-growing soils in Jiangxi province, China. Clays Clay Miner. 51: 75-82.

Lilienfein, J., R.G. Qualls, S.M. Uselman and S.D. Bridgham. 2003. Soil formation and organic matter accretion in a young andesitic chronosequence at Mt. Shasta, California. Geoderma 116: 249-264.

Lim, C.H., M.L. Jackson, R.D. Koons and P.A. Helmke. 1980. Kaolins: Sources of differences in cation-exchange capacities and cesium retention. Clays and Clay Minerals 28: 223-229. 
Lin, C.-W., Z.-Y. Hseu and Z.-S. Chen. 2002. Clay mineralogy of Spodosols with high clay contents in the subalpine forests of Taiwan. Clays and Clay Minerals 50: 726-735.

Lindsay, W.L., P.L.G. Vlek and S.H. Chien. 1989. Phosphate minerals. Pp. 1089-1130. In

J.B. Dixon and S.B. Weed (eds.) Minerals in Soil Environments. 2nd edition, Soil Science Society of America, Madison, Wisconsin.

Loughnan, F.C.1969. Chemical Weathering of the Silicate Minerals. Elsevier, New York.

Loveland, P.J. 1984. The soil clays of Great Britain: 1. England and Wales. Clay Minerals 19: 681-707.

Loveland, P.J., I.G. Wood and A.H. Weir. 1999. Clay mineralogy at Rothamsted: 1934-1988. Clay Minerals 34: 165-183.

Loveland, P.J. and P. Bullock. 1975. Crystalline and amorphous components of the clay fractions in brown podzolic soils. Clay Minerals 10: 451-469.

Lowe, D.J. 1986. Controls on the rates of weathering and clay mineral genesis in airfall tephras: a review and New Zealand case study. Pp. 265-330 In S.M. Colman and D.P. Dethier (eds.) Rates of chemical weathering of rocks and minerals. Academic Press, Orlando, FL.

Lowe, D.J. 1995. Teaching clays: from ashes to allophane. Pp. 19-23 In Churchman, G.J., R.W. Fitzpatrick, and R.A. Eggleton (eds) Clays: controlling the environment. Proceedings of the $10^{\text {th }}$ International Clay Conference, 18-23 July 1993, Adelaide, Australia. CSIRO Publishing, Melbourne.

Lowe, D.J. (ed.) 2008. Guidebook for Pre-conference North Island Field Trip A1 'Ashes and Issues'. Australian and New Zealand $4^{\text {th }}$ Joint Soils Conference, Massey University, Palmerston North. New Zealand Society of Soil Science, 1-194. [ISBN 978-0-47314476-0]

Lowe, D.J., and D.J. Palmer. 2005. Andisols of New Zealand and Australia. Journal of Integrated Field Science 2: 39-65.

Lowe, D.J. and Percival, H.J. 1993. Clay mineralogy of tephras and associated paleosols and soils, and hydrothermal deposits, North Island. Guidebook for New Zealand Preconference field trip F1. $10^{\text {th }}$ International Clay Conference 18-23 July 1993, Adelaide, Australia: 1-110.

Lowe, D.J., G.J. Churchman, R.H. Merry, R.W. Fitzpatrick, M.J. Sheard and W.H Hudnall. 1996. Holocene basaltic volcanogenic soils of the Mt Gambier area, South Australia, are unusual globally: what do they tell us? Australian and New Zealand National Soils 
Conference 1996. Vol. 2, Oral Papers, 153-154. Australian Society of Soil Science, Univ. of Melbourne, Australia.

Lowe, D.J., J.M. Tippett, P.J.J.Kamp, I.J.Liddell, R.M. Briggs and J.L. Horrocks. 2001. Ages on weathered Plio-Pleistocene tephra sequences, western North Island, New Zealand. Les Dossiers de 1'Archeo-Logis 1: 45-60.

Lowe, D.J., P.A.R. Shane, B.V. Alloway and R.M. Newnham. 2008. Fingerprints and age models for widespread New Zealand tephra marker beds erupted since 30,000 years ago: a framework for NZ-INTIMATE. Quaternary Science Reviews 27: 95-126.

Lucas, Y. 2001. The role of plant in controlling rates and products of weathering: importance of biological pumping. Annual Review of Earth and Planetary Sciences 29:135-163.

Lucas, Y., F.J. Luizao, A. Chauvel, J. Rouiller and D. Nahon. 1993. The relation between biological activity of the rain forest and mineral composition of soils. Science 260: 521523.

Lundström, U.S., N. Van Breeman and D. Bain. 2000. The podzolisation process. A review. Geoderma 94: 91-107.

Ma, C and R.A. Eggleton. 1999. Surface layer types of kaolinite; a high-resolution transmission electron microscope study. Clays and Clay Minerals 47: 181-191.

Madden, M.E.M., Bodnar, R.J. and J.D. Rimstidt, 2004. Jarosite as an indicator of waterlimited chemical weathering on Mars. Nature 431: 821-823.

Maher, B. A. and R. M. Taylor. 1988. Formation of ultrafine-grained magnetite in soils, Nature, 336, 368- 370.

Maher, K., Steefel, C.I., White, A.F. and D.A. Stonestrom, 2009. The role of reaction affinity and secondary minerals in regulating chemical weathering rates at the Santa Cruz Soil Chronosequence, California. Geochimica et Cosmochimica Acta 73: 2804-2831.

Mahjoory, R.A. 1975. Clay mineralogy, physical, and chemical properties of some soils in arid regions of Iran. Soil Science Society of America Proceedings 39: 1157-1164.

Marsan, F.A. and J. Torrent. 1989. Fragipan bonding by silica and iron oxides in a soil from nothwestern Italy. Soil Science Society of America Journal 53: 1140-1145.

Marx, S.K., H.A. McGowan, and B.S. Kamber. 2009. Long-range dust transport from eastern Australia: a proxy for Holocene aridity and ENSO-type climate variability. Earth and Planetary Science Letters 282: 167-177.

Mayer, L.M. and B. Xing. 2001. Organic matter-surface area relationships in acid soils. Soil Sci. Soc. Am. J. 65: 250-258. 
McCarthy, J.F., J. Ilavsky, J.D. Jastrow, L.M. Mayer, E. Perfect and J. Zhuang. 2008.

Protection of organic matter in soil microaggregates via restructuring of aggregate porosity and filling of pores with accumulating organic matter. Geochimica et Cosmochimica Acta 72: 4725-4744.

McDaniel, P.A., D.J. Lowe, O. Arnalds, and C.-L. Ping. 2012. Andisols. In: Huang, P.M., Li, Y., Sumner, M.E. (ed.) Handbook of Soil Science, $2^{\text {nd }}$ edition. CRC Press (Taylor and Francis), London, pp.33.29-33.48.

McGahan, D.G., R.J. Southard and R.J. Zasoki. 2003. Mineralogical comparison of agriculturally acidified and naturally acidic soils. Geoderma 114: 355-368.

McIntosh, P.D. 1979. Halloysite in a New Zealand tephra and paleosol less than 2500 years old. New Zealand Journal of Science 22, 49-54.

McIntosh, P.D. 1980. Weathering products in Vitrandept profiles under pine and manuka, New Zealand. Geoderma 24, 225-239.

McKeague, J.A. and J.E. Brydon. 1970. Mineralogical properties of ten reddish brown soils from the Atlantic provinces in relation to parent materials and pedogenesis. Canadian Journal of Soil Science 50: 47-55.

McKenzie, R.M. 1989. Manganese Oxides and Hydroxides. Pp. 439-465. In J.B. Dixon and S.B. Weed (eds.) Minerals in Soil Environments. 2nd edition, Soil Science Society of America, Madison, Wisconsin.

Mehra, O.P. and M.L. Jackson. 1960. Iron oxide removal from soils and clays by a dithionite-citrate system buffered with sodium bicarbonate. Clays and Clay Minerals 7: 317-327.

Mejia, G., H. Kohnke and J.L. White. 1968. Clay mineralogy of certain soils of Columbia. Soil Science Society of America Proceedings 32: 665-670.

Melkerud, P.-A., D.C. Bain, A.G. Jongmans and T. Tarvainen, 2000. Chemical, mineralogical and morphological characterization of three podzols developed on glacial deposits in northern Europe. Geoderma 94: 125-148.

Melo, V.F., B. Singh, C.E.G.R. Schaefer, R.F. Novais and M.P.F. Fontes. 2001. Chemical and mineralogical properties of kaolinite-rich Brazilian soils. Soil Sci. Soc. Am. J. 65: 1324-1333.

Mestdagh, M. M., L. Vielvoye and A. J. Herbillon. 1980. Iron in kaolinite: II. The relationship between kaolinite crystallinity and iron content. Clay Minerals 15: 1-13.

Meunier, A. and B. Velde. 1976. Mineral reactions at grain contacts in early stages of granite weathering. Clay Minerals 11: 235-240. 
Meunier, A.and B. Velde. 1979. Weathering mineral facies in altered granites: the importance of local small-scale equilibria. Mineralogical. Magazine 43: 261-268.

Meysman, F.J.R., J.J. Middelburg and C.H.R. Heip. 2006. Bioturbation: a fresh look at Darwin's last idea. Trends in Ecology and Evolution 21: 688-695.

Mikutta, R., M. Kleber,and R. Jahn. 2005. Poorly crystalline minerals protect organic carbon in clay subfractions from acid subsoil horizons. Geoderma 128: 106-115.

Millot, G. 1970. Geology of Clays. Springer-Verlag, New York.

Mills, A.L. 2003. Keeping in touch: microbial life on soil particle surfaces. Advances in Agronomy 78, 1-43.

Milnes, A.R. and R.W. Fitzpatrick. 1989. Titanium and zirconium minerals. Pp. 1131-1205 In J.B. Dixon and S.B. Weed (eds.) Minerals in Soil Environments. 2nd edition, Soil Science Society of America, Madison, Wisconsin.

Ming, D.W. and F.A. Mumpton. 1989. Zeolites in soils. Pp. 873-911 In J.B. Dixon and S.B. Weed (eds.) Minerals in Soil Environments. 2nd edition, Soil Science Society of America, Madison, Wisconsin.

Mirabella, A. and M. Egli. 2003. Structural transformations of clay minerals in soils of a climosequence in an Italian alpine environment. Clays and Clay Minerals 51: 264-278.

Mirabella, A., M. Egli, S. Raimondi and D. Giaccai. 2005. Origin of clay minerals in soils on pyroclastic deposits in the island of Lipari (Italy). Clays and Clay Minerals 53: 409-421.

Mizota, C. and M. Itoh. 1993. Volcanic origin of a cristobalite in the Te Ngae tephric loess from North Island, New Zealand. Clays and Clay Minerals 41: 755-756.

Mizota, C. and Y.Takahashi. 1982. Eolian origin of quartz and mica in soils developed on basalts in northwestern Kyushu and Sanoin, Japan. Soil Science and Plant Nutrition (Tokyo) 28: 369-378.

Mizota, C., N. Toh, and Y. Matsuhisa. 1987. Origin of cristobalite in soils derived from volcanic ash in temperate and tropical regions. Geoderma 39: 323-330.

Mogk , D.W. and W.W. Locke, III. 1988. Application of Auger electron spectroscopy (AES) to naturally weathered hornblende. Geochemica et Cosmochimica Acta 52: 2537-2542.

Mokma, D.L., M. Yli-Halla and K. Lindqvist. 2004. Podzol formation in sandy soils of Finland. Geoderma 120: 259-272.

Monger, H.C. and E.F. Kelly. 2002. Silica minerals. Pp. 611-636 In J.B. Dixon and D.G. Schulze (eds.) Soil Mineralogy with Environmental Applications. Soil Science Society of America, Inc. Madison, Wisconsin, USA. 
Morgan, C.P. and M. H. Stolt. 2006. Soil morphology-water table cumulative duration relationships in southern New England. Soil Science Society of America Journal 70: 816-824.

Mortland, M.M. 1958. Kinetics of potassium release from biotite. Soil Science Society of America Proceedings 22: 503-508.

Mortland, M.M., K. Lawton and G. Uehara. 1956. Alteration of biotite to vermiculite by plant growth. Soil Science 82: 477-481.

Mossin, L., M. Mortensen and P. Nørnberg. 2002. Imogolite related to podzolization processes in Danish podzols. Geoderma 109: 103-116.

Müller, B. 2009. Impact of the bacterium Pseudomonas fluorescens and its genetic derivatives on vermiculite: Effects on trace metals contents and clay mineralogical properties. Geoderma 153: 94-103.

Muir, I.J. and H.W. Nesbitt. 1997. Reactions of aqueous anions and cations at the labradorite-water interface: Coupled effects of surface processes and diffusion. Geochimica et Cosmochimica Acta 61: 265-274.

Muir, I.J., G.M. Bancroft and H.W. Nesbitt. 1989 Characteristics of altered labradorite surfaces by SIMS and XPS. Geochemica et Cosmochimica Acta 53: 1235-1241.

Muir, I.J., G.M. Bancroft, W. Shotyk and H.W. Nesbitt. 1990. A SIMS and XPS study of dissolving plagioclase. Geochimica et Cosmochimica Acta 54: 2247-2256.

Munk, L.P. and R.J. Southard. 1993. Pedogenic implications of opaline pendants in some California Late-Pleistocene Palexeralfs. Soil Science Society of America Journal 57: 149-154.

Murakami., T., H. Isobe, T. Sato and T. Ohnuki. 1996. Weathering of chlorite in a quartzchlorite scgist: I. Mineralogical and chemical changes. Clays and Clay Minerals 44: 244256.

Mustard, J. F., Murchie, S. L., Pelkey, S. M., Ehlmann, B. L., Milliken, R. E., Grant, J. A., Bibring, J.-P., Poulet, F., Bishop, J. L., Noe Dobrea, E. Z., Roach, L. A., Seelos, F., Arvidson, R. E.,Wiseman, S., Green, R., Hash, C., Humm, D., Malaret, E., McGovern, J. A., Seelos, K., Clancy, R. T., Clark, R. N., Des Marais, D., Izenberg, N., Knudson, A. T., Langevin, Y., Martin, T., McGuire, P., Morris, R. V., Robinson, M., Roush, T., Smith, M., Swayze, G. A., Taylor, H., Titus, T. N. and M. Wolff, (2008) Hydrated silicate minerals on Mars observed by the Mars Reconnaissance Orbiter CRISM instrument. Nature, 454:305-309. 
Nadeau, P. H., M. J. Wilson, W. J. McHardy and J. M. Tait. 1984. Interparticle diffraction: A new concept for interstratification of clay minerals. Clay Minerals 19: 757-769.

Nagashima, K., R. Tada, A. Tani, S. Toyoda, Y. Sun and Y. Isozaki. 2007. Contribution of aeolian dust in Japan Sea sediments estimated from ESR signal intensity and crystallinity of quartz. Geochemistry, Geophysics, Geosystems 8, Q02Q04, doi:10.1029/2006GC001364.

Nahon, D. and F. Colin. 1982. Chemical weathering of orthopyroxenes under lateritic conditions. American Journal of Science 282: 1232-1243.

Nahon, D., F. Colin and Y. Tardy. 1982. Formation and distribution of Mg, Fe, Mn-smectites in the first stages of the lateritic weathering of forsterite and tephroite. Clay Minerals 17: 339-348.

Naish, T.R., C.S. Nelson and A.P.W. Hodder. 1993. Evolution of Holocene sedimentary bentonite in a shallow-marine embayment, Firth of Thames, New Zealand. Marine Geology 109: 267-278.

Nakao, A., S. Funakawa, T. Watanebe and T. Kosaki. 2009. Pedogenic alterations of illitic minerals represented by Radiocaesium Interception Potential in soils with different soil moisture regimes in humid Asia. Euro. J. Soil Sci. 60: 139-152.

Nanzyo, M. 2007. Introduction to studies on volcanic ash soils in Japan and international collaboration. Journal of Integrated Field Science 4: 71-77.

Ndayiragije, S. and B. Delvaux. 2003. Coexistence of allophane, gibbsite, kaolinite and hydroxyl-Al-interlayered 2:1 clay minerals in a perudic Andosol. Geoderma 117: 203214.

Neall, V.E. 1977. Genesis and weathering of Andosols in Taranaki, New Zealand. Soil Science 123: 400-408.

Nesbitt, H.W. 1997. Bacterial and inorganic weathering processes and weathering of crystalline rocks. Pp. 113-142 In J.M. McIntosh and L.A.Groat (eds.) BiologicalMineralogical Interactions. Mineralogical Association of Canada Short Course Volume 25. Minearlogical Association of Canada, Ottawa.

Nettleton, W.D., K.W. Flach and R.E. Nelson. 1970. Pedogenic weathering of tonalite in southern California. Geoderma 4: 387-402.

Newnham, R.M., D.J. Lowe and P.W. Williams. 1999. Quaternary environmental change in New Zealand: a review. Progress in Physical Geography 23: 567-610.

Newsom, H. 2005. Clays in the history of Mars. Nature 438: 570-571. 
Nieuwenhuyse, A., P.S.J. Verburg and A.G. Jongmans. 2000. Mineralogy of a soil chronosequesnce on andesitic lava in humid tropical Costa Rica. Geoderma 98: 61-82.

Nizeyimana, E., T.J. Bicki and P.A. Agbu. 1997. An assessment of colloidal constituents and clay mineralogy of soils derived from volcanic materials along a toposequence in Rwanda. Soil Science 162: 361-371.

Norfleet, M.L., A.D. Karathanasis and B.R. Smith. 1993. Soil solution composition relative to mineral distribution in Blue Ridge Mountain soils. Soil Science Society of America Journal 57: 1375-1380.

Noro, H. 1986. Hexagonal platy halloysite in an altered tuff bed, Komaki City, Aichi prefecture, Central Japan. Clay Minerals 21: 401-415.

Norrish, K. 1968. Some phosphate minerals of soils. Pp. 713-723 In Transactions, 9th International Congress of Soil Science 6-16 August 1968, Adelaide, Australia, Vol. II. International Society of Soil Science and Angus and Robertson.

Norrish, K. 1973. Factors in the weathering of mica to vermiculite. Pp. 417-432. In J.M. Serratosa (ed.) Proceedings of the 1972 International Clay Conference. Div. de Ciencas, 25-30 June 1972, Madrid, Spain.

Norrish, K. and J.G. Pickering. 1983. Clay Minerals. Pp. 281-308. In Soils: An Australian Viewpoint. CSIRO Australia; Melbourne/Academic Press, London.

Norrish, K. and H. Rosser. 1983. Mineral phosphate. Pp. 335-361. In Soils: An Australian viewpoint. CSIRO-Academic Press, Melbourne

Oades, J.M. and Waters, A.G. 1991. Aggregate hierarchy in soils. Australian Journal of Soil Research 29: 815-828.

Oelkers, E.H. and J. Schott. 1995. Experimental study of anorthite dissolution and the reklative mechanism of feldspar hydrolysis. Geochimica et Cosmochimica Acta 59: 5039-5053.

Oelkers, E.H. and S.R. Gislason. 2001. The mechanism, rates and consequences of basaltic glass dissolution: I. An experimental study of the dissolution rates of basaltic glass as a function of aqueous $\mathrm{Al}, \mathrm{Si}$ and oxalic acid concentration at $25^{\circ} \mathrm{C}$ and $\mathrm{pH}=3$ and 11 . Geochimica et Cosmochimica Acta 65: 3671-3681.

Ogura, Y., R. Tanaka and H. Takesako. 2008. Unique clay mineral formation in Andisols derived from Holocene tephras of Mt Fuji, Japan. Abstracts, Joint conference of the Australia and New Zealand Societies of Soil Science,1-5 December 2008, Palmerston North, New Zealand, p. 105. 
Ojanuga, A.G. 1973. Weathering of biotite in soils of a humid tropical climate. Soil Science Society of America Proceedings 37: 644-646.

Owliaie, H.R., A. Abtahi and R.J. Heck. 2006. Pedogenesis and clay mineralogical investigation of soils formed on gypsiferous and calcareous materials, on a transect, southwestern Iran. Geoderma 134: 62-81.

Pai, C.W., M.K. Wang and C.Y. Chiu. 2007. Clay mineralogical characterization of a toposequence of perhumid subalpine forest soils in northeastern Taiwan. Geoderma 138: 177-184.

Pai, C.W., M.K. Wang, H.B. King, C.Y. Chiu and J.-L. Hwong. 2004. Hydroxy-interlayered mineral of forest soils. Geoderma 123: 245-255.

Papoulis, D., P. Tsolis-Katagas and C. Katagas. 2004. Progressive stages in the formation of kaolin minerals of different morphologies in the weathering of plagioclase. Clays and Clay Minerals 52: 275-286.

Paquet, H. and G. Millot. 1972. Geochemical evolution of clay minerals in the weathered products in soils of Mediterranean climate. Pp. 199-206. In J.M. Serratosa (ed.) Proceedings of the International Clay Conference 25-30 June 1972, Madrid, Spain.

Parfitt, R.L. 1990. Allophane in New Zealand - a review. Australian Journal of Soil Research 28: 343-360.

Parfitt, R.L. 2009. Allophane and imogolite: role in soil biogeochemical processes. Clay Minerals 44: 135-155.

Parfitt, R.L. and G.J. Churchman. 1988. Clay minerals and humus complexes in five Kenyan soils derived from volcanic ash - a discussion. Geoderma 42: 365-367.

Parfitt, R.L. and T. Henmi. 1980. Structure of some allophanes from New Zealand. Clays and Clay Minerals 28: 285-294.

Parfitt, R.L. and Wilson, A.D. 1985. Estimation of allophane and halloysite in three sequences of volcanic soils, New Zealand. Catena Supplement 7: 1-8.

Parfitt, R.L., M. Russell and G.E. Orbell. 1983. Weathering sequence of soils from volcanic ash involving allophane and halloysite, New Zealand. Geoderma 29: 41-57.

Parfitt, R.L., M. Saigusa and J.D. Cowie. 1984. Allophane and halloysite formation in a volcanic ash bed under differing moisture conditions. Soil Science 138: 360-364.

Paton, T.R., G.S. Humphreys and P.B. Mitchell. 1995. Soils: a new global view. UCL Press, London, 213pp.

Pauling, L. 1929 The principles determining the structure of complex ionic crystals. J. Am. Chem. Soc. 51: 1010-1026. 
Percival, H.J. 1985. Soil solutions, minerals, and equilibria. New Zealand Soil Bureau Scientific Report 69.21pp.

Percival, H.J., R.L. Parfitt and N.A. Scott. 2000. Factors controlling soil carbon levels in New Zealand grasslands: Is clay content important? Soil Science Society of America Journal 64: 1623-1630.

Petit, S., T. Prot, A. Decarreau, C. Mosser and M.C. Toledo-Groke. 1992. Crystallochemical study of a population of particles in smectites from a lateritic weathering profile. Clays and Clay Minerals 40: 436-445.

Pernes-Debuyser, A., M. Pernes, B. Velde and D. Tessier. 2003. Soil mineralogy evolution in the INRA 42 plots experiment. Clays and Clay Miner. 51, 577-584.

Pochet, G., M. Van der Velde, M. Vanclooster and B. Delvaux. 2007. Hydric properties of high charge, halloysite clay soils from the tropical South Pacific region. Geoderma 138: 96-109.

Poncelot, G.M. and G.W. Brindley. 1967. Experimental formation of kaolinite from montmorillonite at low temperatures. American Mineralogist 52: 1161-1173.

Poulenard, J., P. Podwojewski and A.J. Herbillon. 2003. Characteristics of non-allophanic Andisols with hydric properties from the Ecuadorian páramos. Geoderma 117: 267-281.

Poulet, F., Bibring, J.-., P., Mustard, J. F., Gendrin, A., Mangold, N., Langevin, Y., Arvidson, R. E., Gondet, B. and C. Gomez. 2005. Phyllosilicates on Mars and implications for the early Mars history. Nature 438: 632-627.

Proust, D., J. Caillaud and C. Fontaine. 2006. Clay minerals in early amphibole weathering: Tri- to dioctahedral sequence as a fundtion of crystallization sites in the amphibole. Clays and Clay Minerals 54: 351-362.

Quantin, P., T.Becquer, J.H. Rouiller and J. Berthelin. 2001. Oxide weathering and trace metal release by bacterial reduction in a New Caledonia Ferralsol. Biogeochemistry 53: 323-340.

Quantin, P., A. J. Herbillon, C. Janot and G. Siefferman 1984. L' "halloysite" blanche riche en fer de Vate (Vanuatu); hypothese d'un edifice interstratifie halloysite-hisingerite. Clay Minerals 19: 629-643.

Raman, K.V. and M.L. Jackson. 1966. Layer charge reduction in clay minerals of micaceous soils and sediments. Clays and Clay Minerals 14: 53-68.

Rampazzo, N. and W.E.H Blum. 1992. Changes in chemistry and mineralogy of forest soils by acid rain. Water, Air and Soil Pollution 61: 209-220.

Rasmussen, C., N. Matsuyama, R.A. Dahlgren, R.J. Southard and N. Brauer. 2007. Soil 
genesis and mineral transformation across an environmental gradient on andesitic lahar. Soil Sci. Soc. Am. J. 71: 225-237.

Rasmussen, C., R.J. Southard and W.R. Horwath. 2005. Soil mineralogy affects conifer forest soil crabon source utilization and microbial priming. Soil Science Society of America Journal 71: 1141-1150.

Rebertus, R.A., S.B. Weed and S.W. Buol. 1986. Transformations of biotite to kaolinite during saprolite-soil weathering. Soil Science Society of America Journal 50: 810-819.

Reid, D.A., R.C. Graham, L.A. Douglas and C. Amrhein. 1996. Smectite mineralogy and charge characteristics along an arid geomorphic transect. Soil Science Society of America Journal 60: 1602-1611.

Rex, R.W., J.K. Syers, M.L. Jackson, and R.N. Clayton. 1969. Eolian origin of quartz in soils of Hawaiian Islands and in Pacific pelagic sediments. Science 163: 277-279.

Rice, C.M. and J.M. Williams. 1969. A Mössbauer study of biotite weathering. Mineralogical Magazine 37: 210-215.

Rich, C.I. 1968. Hydroxy interlayers in expansible layer silicates. Clays and Clay Minerals 16: $15-30$.

Richards, A.E., R.C. Dalal and S. Schmidt. 2009. Carbon storage in a Ferrasol under subtropical rainforest, tea plantations, and pasture is linked to soil aggregation. Australian Journal of Soil Research 47: 341-350.

Righi, D., F. Terribile and S. Petit. 1995. Low-charge to high-charge beidellite conversion in a Vertisol from south Italy. Clays and Clay Minerals 43: 495-502.

Righi, D., S. Petit and A. Bouchet. 1993. Characterization of hydroxy-interlayered vermiculite and illite/smectite interstratified minerals from the weathering of a chlorite in a Cryorthod. Clays and Clay Minerals 41: 484-495.

Righi, D., K. Huber, and C. Keller 1999. Clay formation and podzol development from postglacial moraines in Switzerland. Clay Minerals 34: 319-332.

Ritsema, C.J., M.E.F. van Mensvoort, D.L. Dent, Y. Tan, H.van den Bosch and A.L.M. van Wijk. 2000. Acid sulfate soils. Pp. G. 121-G 154. In M.E. Sumner (ed.) Handbook of Soil Science. CRC Press, Boca Raton, Florida.

Rivers, J.M., J.E. Nyquist, Y. Roh, D.O. Terry, Jr. and W.E. Doll. 2004. Investigation into the origin of magnetic soils on the Oak Ridge reservation, Tennessee. Soil Sci. Soc. Am. J. 68: 1772-1779.

Robert, M. and J. Berthelin. 1986. Role of biological and biochemical factors in soil mineral weathering. Pp. 453-495 In Huang, P.M. and M. Schnitzer (eds.). Interactions of Soil 
Minerals with Natural Organics and Microbes. Soil Science Society of America Special Publication No. 17.

Robert, M. and C. Chenu. 1992. Interactions between soil minerals and microorganisms. Pp. 307-404 In G. Stotsky and J.-M. Bollag (eds.) Soil Biochemistry. Marcel Dekker, New York.

Robert, M., M. Hardy and F. Elsass. 1991. Crystallochemistry, properties and organization of soil clays derived from major sedimentary rocks in France. Clay Minerals 26: 409-420.

Robertson, I.D.M. and R.A. Eggleton. 1991. Weathering of granitic muscovite to kaolinite and halloysite and of plagioclase-derived kaolinite to halloysite. Clays and Clay Minerals 39: 113-126.

Robinson, D.A., I. Lebro and H.Vereecken. 2009. On the definition of the natural capital of soils: a framework for description, evaluation, and monitoring. Soil Science Society of America Journal 73: 1904-1911.

Ross, G.J., C. Wang, A.I. Ozkan and H.W. Rees. 1982. Weathering of chlorite and mica in New Brunswick podzol developed on till derived from chlorite-mica schist. Geoderma 27: 255-267.

Ross, G.J. and M.M. Mortland. 1966. A soil beidellite. Soil Science Society of America Proceedings 39: 337-343.

Russell, E. W. 1973. Soil Conditions and Plant Growth, $10^{\text {th }}$ edition. Longman, London.

Ruxton, B.P. 1988. Towards a weathering model of Mount Lamington Ash, New Guinea. Earth-Science Reviews 25: 387-397.

Ryan, P.C., and F.J. Huertas. 2009. The temporal evolution of pedogenic Fe-smectite to Fekaolin via interstratified kaolin-smectite in a moist tropical soil chronosequence. Geoderma 151: 1-15.

Saggar, S., A. Parshotam, G.P. Sparling, C.W. Feltham and P.B.S. Hart. 1996. ${ }^{14}$ C-labelled ryegrass turnover and residence times in soils varying in clay content and mineralogy. Soil Biology and Biochemistry 28: 1677-1686.

Sakharov, B.A. and V. Drits. 1973. Mixed-layer kaolinite-montmorillonite: a comparison of observed and calculated diffraction patterns. Clays and Clay Minerals 21: 15-17.

Saigusa, M., S. Shoji and T. Kato. 1978. Origin and nature of halloysite in Ando soils from Towada tephra. Geoderma 20: 115-129. 
Sase, T., M. Hosono, T. Utsugawa and K. Aoki. 1988. Opal phytolith analysis of present and buried volcanic ash soils at Te Ngae Road tephra section, Rotorua Basin, North Island, New Zealand. The Quaternary Research (Japan) 27: 153-163.

Sawhney, B.L. 1972. Selective sorption and fixation of cations by clay minerals: a review. Clays Clay Miner. 20:93-100.

Sawhney, B.L. and M.L. Jackson 1958. Soil montmorillonite formulas. Soil Science Society of America Proceedings 22: 115-118.

Scalenghe, R., E. Bonifacio, L. Celi, F.C. Ugolini and E. Zanini. 2002. Pedogenesis in disturbed alpine soils (NW Italy). Geoderma 109: 207-224.

Schaefer, C.E.G.R., R.J. Gilkes and R.B.A. Fernandes. 2004. EDS/SEM study on microaggregates of Brazilain Latosols, in relation to $\mathrm{P}$ adsorption and clay fraction attributes. Geoderma 123: 69-81.

Schaetzl, R. and Anderson, 2005. Soils - Genesis and Geomorphology. Cambridge UP., $817 \mathrm{pp}$.

Schott, J. and R.A. Berner. 1985. Dissolution mechanisms of pyroxenes and olivines during weathering. Pp. 35-53 In J.I. Drever (ed.) The Chemistry of Weathering. Reidel, New York.

Schwertmann, U. and R.M. Taylor. 1989. Iron oxides. Pp. 379-438. In J.B. Dixon and S.B. Weed (eds.) Minerals in Soil Environments. 2nd edition, Soil Science Society of America, Madison, Wisconsin.

Schwertmann, U. 2008. Iron oxides. Pp. 363-369 In Chesworth, W. (editor), Encyclopaedia of soil science, Springer, Dordrecht.

Sedov, S., E.Solleiro-Rebolledo, P. Morales-Puente, A. Arias-Herrìe, E. Vallejo-Gòmez and C. Jasso-Castañeda, 2003. Mineral and organic components of the buried paleosols of the Nevado de Toluca, central Mexico as indicators of paleoenvironments and soil evolution. Quaternary International 106-107: 169-184.

Senkayi, A.L., J.B. Dixon, L.R. Hossner and B.E. Viani, 1983. Mineralogical transformations during weathering of lignite overburden in east Texas. Clays and Clay Minerals 31: 4956.

Seyama, H., M. Soma and A. Tanaka. 1996. Surface characterization of acid-leached olivines by X-ray photoelectron spectroscopy. Chemical Geology 129: 209-216.

Seybold, C.A., R.B. Grossman and T.G. Reinsch. 2005. Predicting cation exchange capacity for soil survey using linear methods. Soil Science Society of America Proceedings 69: 856-863. 
Shepherd, T.G. 1984. A pedological study of the Hamilton Ash Group at Welches Road, Mangawara, north Waikato. Unpublished MSc thesis, University of Waikato, Hamilton. Shikazono, N., A. Takino and H. Ohtani. 2005. An estimate of dissolution rate constant of volcanic glass in volcanic ash soil from the Mt. Fuji area, central Japan. Geochemical Journal 39: 185-196

Shoji, S., M. Nanzyo, Y. Shirato and T. Ito. 1993a. Chemical kinetics of weathering in young Andisols from northeastern Japan using $10^{\circ}$ C-normalized soil age. Soil Science 155: 53 60.

Shoji, S., M. Nanzyo, and R.A. Dahigren. 1993b. Volcanic ash soils: Genesis, properties and utilization. Developments in soil science 21: 1-288. Elsevier, Amsterdam, The Netherlands.

Shoji, S., M. Nanzyo, and T. Takahashi. 2006. Factors of soil formation: climate. As exemplified by volcanic ash soils. Pp. 131-149 In Certini, G., and R. Scalenghe (editors) Soils: Basic concepts and future challenges. Cambridge University Press, Cambridge, UK.

Siffert, B. 1978. Genesis and synthesis of clays and clay minerals: recent developments and future prospects. Pp. 337-347. In M.M. Mortland and V.C. Farmer (eds.). International Clay Conference 1978. Developments in Sedimentology 27. Elsevier, Amsterdam.

Sigfusson, B., S.R. Gislason and G.I. Paton. 2008. Pedogenesis and weathering rates of a Histic Andosol in Iceland: field and experimental soil solution study. Geoderma 144: $572-592$.

Simas, F.N.B., C.E.G.R. Schaefer, E.I.F. Filho, A.C. Chagas and P.C. Brandão. 2005. Chemistry, mineralogy and micropedology of highland soils on crystalline rocks of Serra da Mantiqueira, southeastern Brazil. Geoderma 125: 187-201.

Simas, F.N.B., C.E.G.R. Schaefer, V.F. Melo, M.B.B. Guerra, M. Saunders and R.J. Gilkes. 2006. Clay-sized minerals in permafrost-affected soils (Cryosols) from King George Island, Antactica. Clays Clay Miner. 54: 721-736.

Simonsson, M., S. Hillier and I. Öborn. 2009. Changes in clay minerals and potassium fixation capacity as a result of release and fixation of potassium in long-term field experiments. Geoderma 151: 109-120.

Singer, A. 1989. Palygorskite and sepiolite group minerals. Pp.829-872. In J.B. Dixon and S.B. Weed (eds.) Minerals in Soil Environments. 2nd edition, Soil Science Society of America, Madison, Wisconsin. 
Singer, A. 2002. Palygorskite and sepiolite. Pp. 555-584. In_J.B. Dixon and D.G. Schulze (eds.) Soil Mineralogy with Environmental Applications. Soil Science Society of America, Inc. Madison, Wisconsin, USA.

Singer, A. and A. Banin. 1990. Characteristics and mode of formation of palagonite; a review. Pp 173-181 In Farmer, V.C. and Y. Tardy (eds), Proceedings of the 9th International Clay Conference 28 August-2 September 1989, Strasbourg, France.

Singer, A. and K. Norrish. 1974. Pedogenic palygorskite occurrences in Australia. American Mineralogist 59: 508-517.

Singer, A., M. Zarei, F.M. Lange and K. Stahr. 2004. Halloysite characteristics and formation in the northern Golan Heights. Geoderma 123: 279-295.

Singh, Balwant and R.J. Gilkes. 1992a. Properties of soil kaolinites from south-western Australia. Journal of Soil Science 43: 645-667.

Singh, Balbir and R.J. Gilkes. 1992b. The electron-optical investigation of the alteration of kaolinite to halloysite. Clays and Clay Minerals 40: 212-229.

Singh, Balbir and R.J. Gilkes. 1993. The recognition of amorphous silica in indurated soil profiles. Clay Minerals 28: 461-474.

Singh, Balwant and R.J. Gilkes 1991. A potassium-rich beidellite from a lateritic pallid zone in Western Australia. Clay Minerals 26: 233-244.

Singleton, P.L., M. Mcleod and H.J. Percival. 1989. Allophane and halloysite content and soil solution silicon in soils from rhyolitic volcanic material, New Zealand. Australian Journal of Soil Research. 27: 67-77. Skiba, M. 2007. Clay mineral formation during podzolization in an alpine environment of the Tatra Mountains, Poland. Clays and Clay Minerals 55: 618-637.

Smeck, N.E., J.M. Bigham, W.F. Guertal and G.F. Hall. 2002. Spatial distribution of lepidocrocite in a soil hydrosequence. Clay Minerals 37: 687-697.

Smith, K.L., A.R. Milnes and R.A. Eggleton. 1987. Weathering of basalt: formation of iddingsite. Clays and Clay Minerals 35: 418-428.

Smith, W.W. 1962. Weathering of some Scottish basic igneous rocks with reference to soil formation. Journal of Soil Science 13: 202-215.

Smits, M.M., E. Hoffland, A.G. Jongmans and N. Van Breeman. 2005. Contribution of mineral tunnelling to total feldspar weathering. Geoderma 125: 59-69.

Soma, M., Churchman, G.J. and B.K.G. Theng. 1992. X-ray photoelectron spectroscopic analysis of halloysites with different composition and particle morphology. Clay Minerals 27: 413-421. 
Sousa, E.C. and H. Eswaran. 1975. Alteration of micas in the saprolite of a profile from Angola. A morphological study. Pedologie 25: 71-79.

Sparling, G.P., D. Wheeler, E.-T. Vesely and L.A. Schipper. 2006. What is soil organic matter worth? Journal of Environmental Quality 35: 548-557.

Spielvogel, S., J. Preitzel and I. Kogel-Knabner. 2008. Soil organic matter stabilization in acidic forest soils is preferential and soil type-specific. Euro. J. Soil Sci. 59: 674-692.

Sposito, G. 1989. The Chemistry of Soils. Oxford University Press, New York

Sridhar, K. and M.L. Jackson. 1974. Layer charge decrease by tetrahedral cation removal and silicon incorporation during natural weathering of phlogopite to saponite. Soil Science Society of America Proceedings 38: 847-851.

Sridhar, K., M.L. Jackson and R.N. Clayton. 1975. Quartz oxygen isotopic stability in relation to isolation from sediments and diversity of source. Soil Science Society of America Proceedings 42: 1209-1213.

Starr, M. and A.-J. Lindroos. 2006. Changes in the rate of release of $\mathrm{Ca}$ and $\mathrm{Mg}$ and normative mineralogy due to weathering along a 5300-year chronosequence of boreal forest soils. Geoderma 133: 269-280.

Stephen, I. and D.M.C. MacEwan. 1951. Some chlorite minerals of unusual type. Clay Minerals Bulletin 1: 157-161.

Stevens, K.F. and C.G. Vucetich. 1985. Weathering of Upper Quaternary tephras in New Zealand, 2. Clay minerals and their climatic interpretation. Chemical Geology 53: 237247.

Stewart, R.B., V.E. Neall and J.K. Syers. 1984. Occurrence and source of quartz in six basaltic soils from Northland, New Zealand. Australian Journal of Soil Research 22: 365377.

Stoch, L. and W. Sikora. 1976. Transformation of micas in the process of kaolinitization of granites and gneisses. Clays and Clay Minerals 24: 156-162.

Stroncik, N. A. and H.-U. Schmincke. 2001. Evolution of palagonite: crystallization, chemical changes, and element budget. Geochemistry, Geophysics, Geosystems 2(7), 1017, doi:10.1029/2000GC000102

Stroncik, N. A. and H.-U. Schmincke. 2002. Palagonite - a review. International Journal of Earth Sciences 91: 680-697.

Stucki, J.W. and C.B. Roth. 1977. Oxidation reduction mechanism for structural iron in nontronite. Soil Science Society of America Journal 41: 808-814. 
Sudo, T. and H. Yatsumoto. 1977. The formation of halloysite tubes from spherulitic halloysite. Clays and Clay Minerals 25: 155-159.

Surapaneni, A., A.S. Palmer, R.W. Tillman, J.H. Kirkman and P.E.H. Gregg. 2002. The mineralogy and potassium supplying power of some loessial and related soils of New Zealand. Geoderma 110: 191-204.

Swindale, L.D. and G. Uehara. 1966. Ionic relationships in the pedogenesis of Hawaiian soils. Soil Science Society of America Proceedings 30: 726-730.

Syers, J.K., V.E. Berkheiser, M.L. Jackson, R.N. Clayton and R.W. Rex 1969. Eolian sediment influence on pedogenesis during the Quaternary. Soil Science 107: 421-427.

Takahashi, T., R. Dahlgren and P. van Susteren. 1993. Clay mineralogy and chemistry of soils formed in volcanic materials in the xeric moisture regime of northern California. Geoderma 59: 131-150.

Takahashi, T., R.A. Dahlgren, B.K.G. Theng, J.S. Whitton and M. Soma. 2001. Potassiumselective, halloysite-rich soils formed in volcanic materials from northern California. Soil Sci. Soc. Am. J. 65: 516-526.

Takesako, H., D.J. Lowe, G.J. Churchman, and D.J. Chittleborough. 2010. Holocene volcanic soils in the Mt Gambier region, South Australia, p. 47-50. Proceedings published on DVD and at http://www.iuss.org, IUSS 19th World Soil Cong., Brisbane (August 1-6, 2010), Symposium 1.3.1 Pedogenesis: Ratio and range of influence.

Tamm, O. 1922. Eine methode Zur Bestimmung de anorganischen Komponente des Gelcomplexes im Boden. Meddelanden fran Statens skogsforsokanstalt Stockholm 19: 387-404.

Taubaso, C., M. Dos Santos Afonso,and R.M. Torres Sánchez. 2004. Modelling soil surface charge demsity using mineral composition. Geoderma 121: 123-133.

Taylor, R.M. 1988. Proposed mechanism for the formation of soluble $\mathrm{Si}-\mathrm{Al}$ and $\mathrm{Fe}(\mathrm{III})-\mathrm{Al}$ hydroxyl complexes in soils. Geoderma 42: 65-77.

Tazaki. K. 1979. Micromorphology of halloysite produced by weathering of plagioclase in volcanic ash. Developments in Sedimentology 27: 415-422.

Tazaki, K. 1997. Biomineralization of layer silicates and hydrated Fe/Mn oxides in microbial mats: an electron microscopical study. Clays and Clay Minerals 45: 203-212.

Tazaki, K. 2005. Microbial formation of a halloysite-like mineral. Clays Clay Miner. 53: 224233.

Theng, B.K.G., M. Russell, G.J. Churchman and R.L. Parfitt. 1982. Surface properties of allophane, halloysite, and imogolite. Clays and Clay Minerals 30: 143-149. 
Theng, B.K.G. 1995. On measuring the specific surface area of clays and soils by adsorption of para-nitrophenol: use and limitations. Pp. 304-310 In Churchman, G.J., R.W. Fitzpatrick, and R.A. Eggleton (eds) Clays: controlling the environment. Proceedings of the $10^{\text {th }}$ International Clay Conference, Adelaide, Australia (1993). CSIRO Publishing, Melbourne.

Theng, B.K.G. and G. Yuan. 2008. Nanoparticles in the soil environment. Elements 4: 395399.

Thiry, M. and R. Simon-Coinçon. 1996. Tertiary paleoweatherings and silcretes in the southern Paris Basin. Catena 26: 1-26.

Thompson, A., Chadwick, O.A., Rancourt, D.G. and J. Chorover, 2006. Iron-oxide crystallinity increases during soil redox oscillations. Geochimica et Cosmochimica Acta 70: 1710-1727.

Thompson, M.L. and L. Ukrainczyk. 2002. Micas. Pp. 431-466 In J.B. Dixon and D.G. Schulze (eds.) Soil Mineralogy with Environmental Applications. Soil Science Society of America, Inc. Madison, Wisconsin, USA.

Thorseth, I.H., H. Furnes and O. Tumyr. 1995. Textural and chemical effects of bacterialactivity on basaltic glass - an experimental approach. Chemical Geology 119: 139-160.

Tonkin, P.J. 1970. Contorted stratification with clay lobes in volcanic ash beds, RaglanHamilton region, New Zealand. Earth Science Journal 4: 129-140.

Torres Sanchez, R.M., M. Okamura and R.C. Mercader. 2001. Charge properties of red Argentine soils as an indicator of iron oxide/clay associations. Australian Journal of Soil Research 39: 423-434.

Trakoonyingcharoen, P., I. Kheoruenromne, A. Suddhiprakarn and R.J. Gilkes. 2006.

Properties of iron oxides in red Ultisols as affected by rainfall and soil parent material. Australian Journal of Soil Research 44: 63-70.

Trolard, F., J.-M. Génin, M. Abdelmoula, G. Bourrié, B. Humbert and A. Herbillon. 1997. Identification of a green rust mineral in a reductomorphic soil by Mössbauer and Raman spectroscopies. Geochimica et Cosmochimica Acta 61: 1107-1111.

Turpault, M.-P., D. Righi and C Utérano. 2008. Clay minerals: precose markers of the spatial and temporal variability of the biogeochemical soil environment. Geoderma 147: 108115 .

Tye, A.M., S.J. Kemp and P.R. Poulton. 2009. Responses of soil clay mineralogy in the Rothamsted Classical Experiments to management practice and changing land use. Geoderma 153: 136-146. 
Ueshima, M. and Tazaki, K. 2001. Possible role of microbial polysaccharides in nontronite formation. Clays Clay Miner. 49: 292-299.

Ugolini, F.C. and R.S. Sletten. 1991. The role of proton donors in pedogenesis as revealed by soil solution studies. Soil Science 151: 59-75.

Ugolini, F.C., R. Dahlgren, J. LaManna, W. Nuhn and J. Zachara. 1991. Mineralogy and weathering processes in Recent and Holocene tephra deposits of the Pacific Northwest, USA. Geoderma 51: 277-299.

Urrutia, M.M. and T.J. Beveridge. 1994. Formation of fine-grained silicate minerals and metal precipitates by a bacterial surface (Bacillus subtilis). Chemical Geology 116: 261280.

Vacca, A., P. Adamo, M. Pigna and P. Violante. 2003. Genesis of tephra-derived soils from the Roccamonfina volcano, south central Italy. Soil Science Society of America Journal 67: 198-207.

van Breeman, N., 1992. Soil: Biotic construction in a Gaian sense. Pp. 189-207 In Teller, A., P. Muthy and J.N.R. Jeffers (eds.), Responses of Forest Ecosystems to Environmental Change, Elsevier, Amsterdam.

van Breemen, N. and Finzi, A.C. 1998. Plant-soil interactions: ecological aspects and evolutionary implications. Biogeochemistry 42: 1-19.

van Breemen, N., Lundström, U.S. and Jongmans, A.G. 2000a. Do plants drive podzolisation via rock-eating mycorrhizal fungi? Geoderma 94: 163-171.

van Breemen, N., Findlay, R.D., Lundström, U.S., Jongmans, A.G., Giesler, R. and Olsson, M. 2000b. Mychorrhizal weathering: a true case of mineral nutrition? Biogeochemistry 49: 53-67.

van Raij, B. and M. Peech. 1972. Electrochemical properties of some Oxisols and Alfisols of the tropics. Proceedings of the Soil Science Society of America 36: 587-593.

Van Ranst, E. and F. De Coninck. 2002. Evaluation of ferrolysis in soil formation. European Journal of Soil Science 53: 513-519.

van Wesemael, B., J.M. Verstraten and J. Sevink. 1995. Pedogenesis by clay dissolution on acid, low-grade metamorphic rocks under mediterranean forests in southern Tuscany (Italy). Catena 24: 105-125.

Varajão, A.F.D.C., R.J. Gilkes and R.D. Hart. 2001. The relationships between kaolinite crystal properties and the origin of materials for a Brazilian kaolin deposit. Clays and Clay Minerals 49: 44-59. 
Velbel, M.A. 1985. Geochemical mass balances and weathering rates in forested watersheds of the southern Blue Ridge. American Journal of Science 285: 904-930.

Velbel, M.A. and W.W. Barker. 2008. Pyroxene weathering to smectite: Conventional and cryo-field emission scanning microscopy, Koua Bocca ultramafic complex, Ivory Coast. Clays and Clay Minerals 56: 112-127.

Velde, B. (ed.) 1995. Origin and Mineralogy of Clays. Springer-Verlag, New York, 334pp.

Velde, B. and P. Barré, 2010. Soils, Plants and Clay Minerals: Mineral and Biologic Interactions. Springer-Verlag, Berlin, 349 pp.

Velde, B. and A. Meunier. 2008. The origin of clay minerals in soils and weathered rocks. Springer-Verlag, Berlin, 406 pp.

Velde, B., and T. Peck. 2002. Clay mineral changes in the Morrow experimental plots, University of Illinois. Clays Clay Miner. 50: 364-370.

Velde, B., B. Goffé and A. Hoellard. 2003. Evolution of clay minerals in a chronosequence of poldered sediments under the influence of a natural pasture development. Clays Clay Miner. 51, 205-217.

Verrecchia, E.P. and M-N. Le Coustumer 1996. Occurrence and genesis of palygorskite and associated clay minerals in a Pleistocene calcrete complex, Sde Boqer, Negev Desert, Israel. Clay Minerals 31: 183-202.

Vepraskas, M.J. 1992. Redoximorphic features for identifying aquic conditions. North Carolina Agricultural Research Service Technical Bulletin 301. North Carolina State University. Raleigh, NC.

Vepraskas, M.J., X. He, D.L. Lindbo and R.W. Skaggs. 2004. Calibrating hydric soil field indicators to long-term wetland hydrology. Soil Science Society of America Journal 68: 146-1469.

Viana, J.H.M., P.R.C. Couceiro, M.C. Pereira, J.D. Fabris, E.I. Fernandes Filho, C.E.G.R. Schaefer, H.R. Rechenberg, W.A.P. Abrahão and E.C. Mantovani. 2006. Occurrence of magnetite in the sand fraction of an Oxisol in the Brazilian savanna ecosystem, developed from a magnetite-free lithology. Australian Journal of Soil Research 44: 7183.

Vicente, M.A., M. Razzaghe and M. Robert. 1977. Formation of aluminium hydroxy vermiculite (intergrade) and smectite from mica under acidic conditions. Clay Minerals 12: $101-112$. 
Vingiani, S., D. Righi, S. Petit and F. Terribile. 2004. Mixed-layer kaolinite-smectite minerals in a red-black soil sequence from basalt in Sardinia (Italy). Clays Clay Miner. 52: 473-483.

Wada, K. and Y. Kakuto. 1983. Intergradient vermiculite-kaolin mineral in a Korean Ultisol. Clays and Clay Minerals 31: 183-190.

Wada, K. and Y. Kakuto. 1989. "Chloritized” vermiculite in a Korean Ultisol studied by ultramicrotomy and transmission electron microscopy. Clays and Clay Minerals 37: 263268.

Wada, K. 1987. Minerals formed and mineral formation from volcanic ash by weathering. Chemical Geology 60: 17-28.

Wada, K. 1989. Allophane and imogolite. Pp. 1051-1087 In Dixon, J.B. and Weed, S.B. (editors), Minerals in soil environments, $2^{\text {nd }}$ edition. Soil Sci. Soc. Am. Book Series no. 1, Madison, WI.

Wada, K. and N. Yoshinaga. 1969. The structure of imogolite. American Mineralogist 54: 50-71.

Wada, K., Y. Kakuto and F.N. Muchena. 1987. Clay Minerals and humus complexes in five Kenyan soils derived from volcanic ash. Geoderma 39: 307-321.

Wallace, R.C. 1991. New Zealand theses in Earth sciences. The mineralogy of the Tokomaru silt loam and the occurrence of cristobalite and tridymite in selected North Island soils. New Zealand Journal of Geology and Geophysics 34: 113.

Wan, J., Tyliszczak, T. And T.K. Tokunga, 2007. Organic carbon distribution, speciation, and elemental correlations within soil microaggregates: Applications of STXM and NEXAFS spectroscopy. Geochimica et Cosmochimica Acta 71: 5439-5449.

Wang, C., McKeague, J.A. and Kodama, H. 1986. Pedogenic imogolite and soil environments: case study of Spodosols in Quebec, Canada. Soil Science Society of America Journal 50: 711-718.

Ward, W.T. 1967. Volcanic ash beds of the Lower Waikato Basin, North Island, New Zealand. New Zealand Journal of Geology and Geophysics 10: 1109-1135.

Watanebe, T., Y. Sawada, J.D. Russell, W.J. McHardy and M.J. Wilson. 1992. The conversion of montmorillonite to interstratified halloysite-smectite by weathering in the Omi acid clay deposit. Clay Minerals 27: 159-173.

Waychunas, G.A. and H. Zhang. 2008. Structure, chemistry, and properties of mineral nanoparticles. Elements 4: 381-387. 
Weaver, C.E. 1989. Clays, Muds and Shales. Developments in Sedimentology 44. Elsevier, Amsterdam.

Welch, S.A. and J.F. Banfield. 2002. Modification of olivine surface morphology and reactivity by microbial activity during chemical weathering. Geochimica et Cosmochimica Acta 66: 213-221.

Wentworth, S.A. 1970. Illite. Clay Science 3: 140-155.

Wentworth, S.J., E.K. Gibson, M.A. Velbel and D.S. McKay. 2005. Antarctic Dry Valleys and indigenous weathering in Mars meteorites: Implications for water and life on Mars. Icarus 174: 383-395.

White, A.F., Blum, A.E., Schulz, M.S., Bullen, T.D., Harden, J.W. and M.L. Peterson, 1996. Chemical weathering rates of a soil chronosequesnce on granitic alluvium: 1 . Quantification of mineralogical and surface area changes and calculation of primary silicate reaction rates. Geochimica et Cosmochimica Acta 60:2553-2550.

White, A.F. and S.L. Brantley, 2003. The effect of time on the weathering of silicate minerals: why do weathering rates differ in the laboratory and field? Chemical Geology 202: 479-506.

White, A.F., Schulz, M.S., Vivit, D.V., Blum, A.E., Stonestrom, D.A. and J.W. Harden, 2005. Chemical weathering rates of a soil chronosequesnce on granitic alluvium: III. Hydrochemical evolution and contemporary solute fluxes and rates, Geochimica et Cosmochimica Acta 69: 1975-1996.

White, G.N. and J.B. Dixon. 2002. Kaolin-serpentine minerals. Pp. 389-414 In J.B. Dixon and D.G. Schulze (eds.), Soil mineralogy with environmental applications, Soil Sci. Soc. Am. Book Series no. 7, Madison, WI.

Wildman, W.E., M.L. Jackson and L.D. Whittig. 1968. Serpentinite rock dissolution as a function of carbon dioxide pressure in aqueous solution. American Mineralogist 53: 1252-1263.

Wilson, M.J. 1970. A study of weathering in a soil derived from a biotite-hornblende rock. I. Weathering of biotite. Clay Minerals 8: 291-303.

Wilson, M.J. 1987. Soil smectites and related interstratified minerals: recent developments. Pp. 167-173. In L.G. Schultz, H.van Olphen and F.A. Mumpton (eds.) Proceedings of The International Clay Conference, Denver, 1995. The Clay Minerals Society, Bloomington, Indiana.

Wilson, M.J. 1999. The origin and formation of clay minerals in soils: past, present and future perspectives. Clay Minerals 34: 7-25. 
Wilson, M.J. 2004. Weathering of the primary rock-forming minerals: processes, products and rates. Clay Minerals 39: 233-266.

Wilson, M.J. 2006. Factors of soil formation: parent material. As exemplified by a comparison of granitic and basaltic soils. Pp. 113-129 In G. Certini and R. Scalenghe (eds.) Soils: basic concepts and future challenges. Cambridge University Press, Cambridge.

Wilson, M.J. and W. J. McHardy. 1980. Experimental etching of a microcline perthite and implications regarding natural weathering. Journal of Microscopy 120: 291-302.

Wilson, M.J., D.C. Bain and D.M.L. Duthie. 1984. The soil clays of Great Britain: II. Scotland. Clay Minerals 19: 709-735.

Wilson, M.J., G. Certini, C.D. Campbell, I.C. Anderson and S. Hillier. 2008. Does the preferential microbial colonisation of ferromagnesian minerals affect mineral weathering in soil? Naturwissenschaften 95: 851-858.

Wolff-Boenisch, D., S.R. Gislason, E.H. Oelkers and C.V. Putnis. 2004. The dissolution rates of natural glasses as a function of their composition at $\mathrm{pH} 4$ and 10.6, and temperatures from 25 to $74^{\circ} \mathrm{C}$. Geochimica et Cosmochimica Acta 68: 4843-4858.

Worden, R.H., F.D.L. Walker, I. Parsons and W.L. Brown. 1990. Development of microporosity, diffusion channels and deuteric coarsening in perthitic alkali feldspars. Contributions to Mineralogy and Petrology 104: 507-515.

Wright, J.D. and Sommerdijk, N.A.J.M. 2001. Soil-gel materials, chemistry and applications. Advanced Chemistry Texts. CRC, Boca Raton, FL. 125pp.

Yagasaki Y., Mulder J. and Okazaki M. 2006. The role of soil organic matter and short-range ordered aluminosilicates in controlling the activity of aluminum in soil solutions of volcanic ash soils. Geoderma 137: 40-57.

Yaron, B., I. Dror and B. Berkowitz. 2010. Contaminant geochemistry - a new perspective. Naturwissenschaften 97: 1-17.

Yoshinaga, N. and S. Aomine. 1962. Imogolite in some Ando soils. Soil Science and Plant Nutrition 8: 22-29.

Young, I.M. and J.W. Crawford. 2004. Interactions and self-organization in the soil-microbe complex. Science 304, 1634-1637.

Zanelli, R., M. Egli, A. Mirabella, M. Abdelmoula, M. Plötze and M. Nötzli. 2006. 'Black' soils in the southern Alps: Clay mineral formation and transformation, X-ray amorphous Al phases and Fe forms. Clays Clay Miner. 54: 703-720.

Zehetner, F., W.P. Miller and L.T. West. 2003. Pedogenesis of volcanic ash soils in Andean 
Ecuador. Soil Science Society of America Journal 67: 1797-1809.

Zelazny, L.W. and F.G. Calhoun. 1977. Palygorskite (attapulgite), sepiolite, talc, Pyrophyllite and zeolites. Pp. 435-470 In J.B. Dixon and S.B. Weed (eds.) Minerals in Soil Environments. Soil Science Society of America, Madison, Wisconsin.

Zelazny, L.W. and G.N. White. 1989. The pyrophyllite-talc group. Pp. 527-550 In J.B. Dixon and S.B. Weed (eds.) Minerals in Soil Environments. 2nd edition, Soil Science Society of America, Madison, Wisconsin.

Zelazny, L.W., P.J. Thomas and C.L. Lawrence. 2002. Pyrophyllite-talc minerals. Pp. 415430 In J.B. Dixon and D.G. Schulze (eds.), Soil mineralogy with environmental applications, Soil Sci. Soc. Am. Book Series no. 7, Madison, WI.

Ziegler, K., J.C.C. Hsieh, O.A. Chadwick, E.F. Kelly, D.M. Hendricks and S.M. Savin. 2003. Halloysite as a kinetically controlled end product of arid-zone basalt weathering. Chemical Geology 202: 461-478.

Zysset, M., Blaser, P., Luster, J. and Gehring, A.U. 1999. Aluminum solubility control in different horizons of a podzol. Soil Science Society of America Journal 63: 1106-1115. 
1 Table 20.1 Definitions of terms

\begin{tabular}{|c|c|c|c|}
\hline Term & Definitions* & References & $\begin{array}{l}\text { Issues with } \\
\text { definitions }\end{array}$ \\
\hline Mineral & $\begin{array}{l}\text { An element or compound that is } \\
\text { normally crystalline and that has } \\
\text { formed as a result of geological } \\
\text { processes }\end{array}$ & $\begin{array}{l}\text { Gaines et al. } \\
\text { (1997) }\end{array}$ & $\begin{array}{l}\text { Crystallinity implies } \\
\text { a regularity of } \\
\text { structure, but this is } \\
\text { dependent on type of } \\
\text { analysis. Some } \\
\text { materials (e.g. } \\
\text { volcanic glass) lack } \\
\text { a fixed structure and } \\
\text { are referred to as } \\
\text { mineraloids; others } \\
\text { such as allophane, } \\
\text { earlier thought to be } \\
\text { amorphous and } \\
\text { technically thus not } \\
\text { minerals, are now } \\
\text { known to be } \\
\text { nanocrystalline and } \\
\text { hence do qualify as } \\
\text { minerals }\end{array}$ \\
\hline Primary minerals & $\begin{array}{l}\text { Mineral deposited or formed at } \\
\text { the same time as the rock } \\
\text { containing it }\end{array}$ & Lapidus (1987) & $\begin{array}{l}\text { Minerals in } \\
\text { sedimentary and and } \\
\text { partially } \\
\text { metamorphosed } \\
\text { rocks may contain } \\
\text { secondary minerals } \\
\text { from earlier cycles }\end{array}$ \\
\hline Secondary minerals & $\begin{array}{l}\text { Mineral formed as a result of } \\
\text { alteration of pre-existing } \\
\text { minerals }\end{array}$ & $\begin{array}{l}\text { Adapted from } \\
\text { Lapidus (1987) }\end{array}$ & $\begin{array}{l}\text { Minerals commonly } \\
\text { altered in several } \\
\text { steps; hence all } \\
\text { products of } 1^{\circ} \\
\text { mineral alteration } \\
\text { are } 2^{\circ} \text { minerals. } \\
\text { Often referred to as } \\
\text { "clay minerals" }\end{array}$ \\
\hline Weathering & $\begin{array}{l}\text { Weathering is the break-down of } \\
\text { geological deposits by physical, } \\
\text { chemical, and biochemical } \\
\text { processes } \\
\text { - Physical weathering includes } \\
\text { break-down by thermal and } \\
\text { mechanical action, } \\
\text { generating smaller particles } \\
\text { (comminution); chemical } \\
\text { weathering includes break- } \\
\text { down by hydrolysis, } \\
\text { carbonation, hydration, } \\
\text { dissolution, oxidation and } \\
\text { reduction, changing the } \\
\text { physical and chemical } \\
\text { properties of the original } \\
\text { geological deposits }\end{array}$ & $\begin{array}{l}\text { Ashman and Puri } \\
(2002) ; \\
\text { Buol et al. (2003) }\end{array}$ & $\begin{array}{l}\text { Some regard } \\
\text { weathering as } \\
\text { encompassing both } \\
\text { the break-down of } \\
\text { primary minerals } \\
\text { and the synthesis of } \\
\text { new secondary } \\
\text { minerals, but others } \\
\text { distinguish between } \\
\text { two phases, } \\
\text { decomposition and } \\
\text { argillisation, the } \\
\text { latter being the } \\
\text { synthesis of } \\
\text { of secondary } \\
\text { minerals (mainly } \\
\text { clays) }\end{array}$ \\
\hline
\end{tabular}




\author{
The natural, three-dimensional \\ body (comprising pedons), \\ typically up to $\sim 1$ to $2 \mathrm{~m}$ thick \\ (thicknesses can vary markedly), \\ of unconsolidated mineral and \\ organic material mantling the \\ land surface that can support \\ rooted land plants, and which: \\ - is characterized by one or \\ more soil horizons ("layers") \\ that have evolved through \\ additions, losses, transfers, \\ and transformations of \\ energy and matter by \\ interactions of climate, biota, \\ relief, and parent materials \\ through time, and which \\ differ from the material(s) \\ from which they derive \\ - comprises solids (inorganic \\ and organic matter), liquids, \\ and gases \\ - is essential to life through \\ recycling of nutrients, \\ carbon, and oxygen \\ - is non-renewable in human \\ time scales
}

Schaetzl and

Anderson (2005)

$$
\begin{aligned}
& \text { soil fail to } \\
& \text { encompass and } \\
& \text { recognise its } \\
& \text { complexity as the } \\
& \text { most complex }
\end{aligned}
$$$$
\text { ecosystem on Earth }
$$
and as a biological habitat and critically important repository for genes. Soil is also being considered increasingly in policy making, for example as a provider of 'ecosystem services'(e.g., Blum et al., 2006) and as 'natural capital' (the stock of biotic and abiotic mass that contains energy and organization) (see Sparling et al., 2006; Robinson et al., 2009)

* Working definition for this chapter
} 
1 TABLE 20.2 Structure, composition and soil occurrences of common primary* minerals in soils

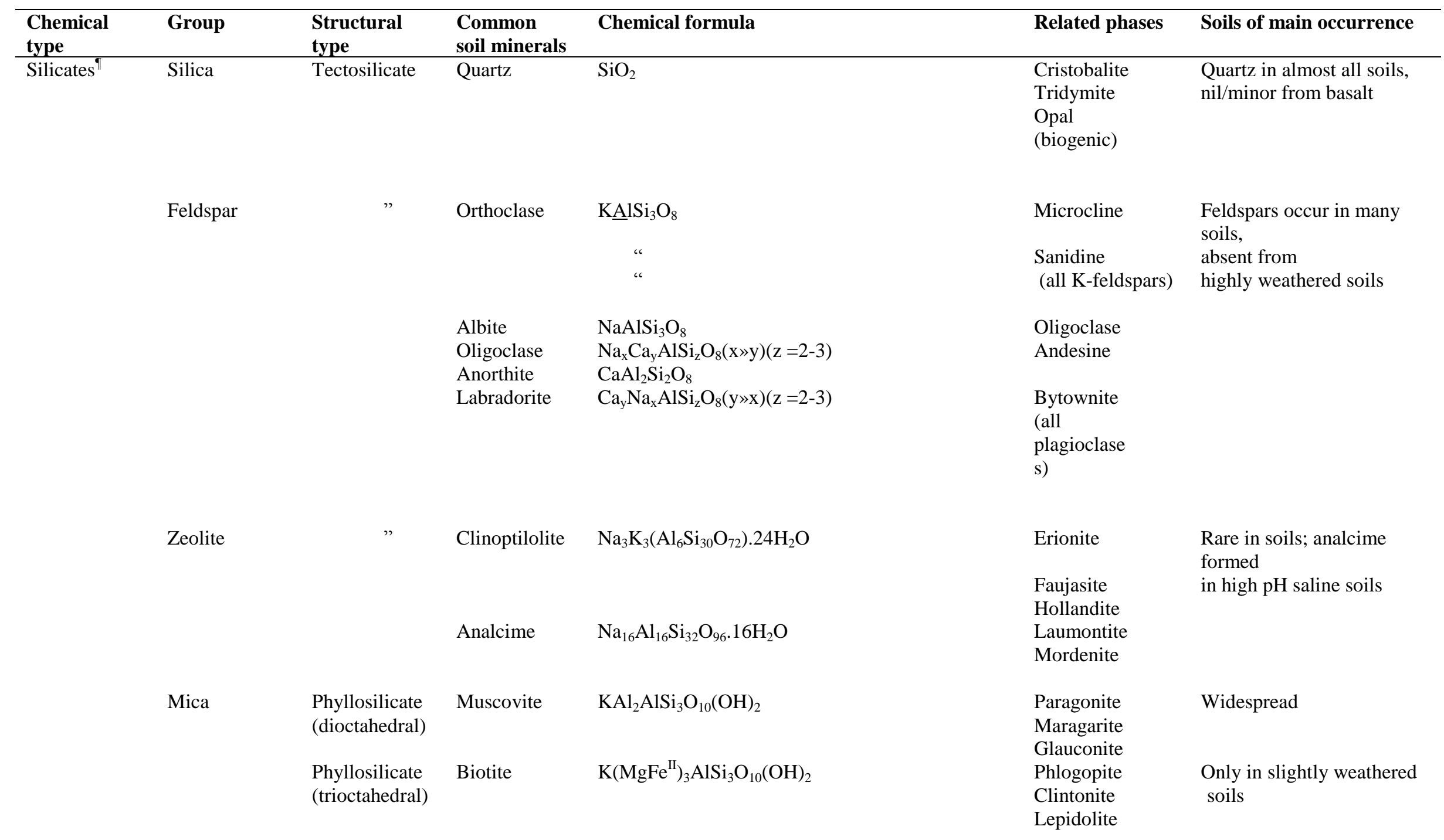




\begin{tabular}{|c|c|c|c|c|c|c|}
\hline & Chlorite & Phyllosilicate & Chlorite & $(\mathrm{Fe}, \mathrm{Mg}, \mathrm{Al})_{6}(\mathrm{Si}, \mathrm{Al})_{4} \mathrm{O}_{10}(\mathrm{OH})_{8}$ & $\begin{array}{l}\text { Cookeite } \\
\text { Sudoite } \\
\text { Bonbassite }\end{array}$ & $\begin{array}{l}\text { Only in very slightly } \\
\text { weathered ('raw') soils }\end{array}$ \\
\hline & Serpentine & $"$ & Chrysotile & $\mathrm{Mg}_{3} \mathrm{Si}_{2} \mathrm{O}_{5}(\mathrm{OH})_{4}$ & $\begin{array}{l}\text { Antigorite } \\
\text { Lizardite } \\
\text { Amesite } \\
\text { Berthierine }\end{array}$ & Rare in soils \\
\hline & Amphibole & $\begin{array}{l}\text { Inosilicate } \\
\text { (double chain) }\end{array}$ & Hornblende & $\begin{array}{l}(\mathrm{Ca}, \mathrm{Na})_{2.3}(\mathrm{Mg}, \mathrm{Fe}, \mathrm{Al})_{5}(\mathrm{Si}, \mathrm{Al})_{8} \mathrm{O}_{22} \\
(\mathrm{OH})_{2}\end{array}$ & $\begin{array}{l}\text { Tremolite } \\
\text { Actinolite } \\
\text { Cummingtonite } \\
\text { Glaucophane }\end{array}$ & $\begin{array}{l}\text { Quite widespread, but } \\
\text { absent from highly } \\
\text { weathered soils }\end{array}$ \\
\hline & Pyroxene & $\begin{array}{l}\text { Inosilicate } \\
\text { (single chain) }\end{array}$ & Augite & $(\mathrm{Ca}, \mathrm{Na})(\mathrm{Mg}, \mathrm{Al}, \mathrm{Fe})(\mathrm{Si}, \mathrm{Al})_{2} \mathrm{O}_{6}$ & $\begin{array}{l}\text { Enstatite } \\
\text { Hypersthene } \\
\text { Diopside } \\
\text { Pigeonite } \\
\text { Jadeite } \\
\text { Spodumene } \\
\text { Hedenbergerite }\end{array}$ & $\begin{array}{l}\text { Relatively rare except } \\
\text { in some volcanic soils } \\
\text { (especially } \\
\text { intermediate-basic) }\end{array}$ \\
\hline & (Cyclosilicate) & Cyclosilicate & Tourmaline & $(\mathrm{Na}, \mathrm{Ca})(\mathrm{Li}, \mathrm{Mg}, \mathrm{Al})(\mathrm{Li}, \mathrm{Fe}, \mathrm{Mn})_{6}\left(\mathrm{BO}_{3}\right)_{3} \mathrm{Si}_{6} \mathrm{O}_{18}(\mathrm{OH})_{4}$ & Beryl & Rare \\
\hline & (Sorosilicate) & Sorosilicate & Epidote & $\mathrm{Ca}_{2}(\mathrm{Al}, \mathrm{Fe}) \mathrm{Al}_{2} \mathrm{O}\left(\mathrm{Si}_{2} \mathrm{O}_{7}\right) \mathrm{SiO}_{4}(\mathrm{OH})_{4}$ & Zoisite & Uncommon \\
\hline & Olivine & Nesosilicate & Forsterite & $\mathrm{Mg}_{2} \mathrm{SiO}_{4}$ & $\begin{array}{l}\text { Fayalite } \\
\text { Tephroite } \\
\text { Monticellite }\end{array}$ & Rare \\
\hline & Garnet & 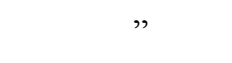 & Almandine & $\mathrm{Fe}_{3} \mathrm{Al}_{2}\left(\mathrm{SiO}_{4}\right)_{3}$ & & Rare \\
\hline & Zircon & $"$ & Zircon & $\mathrm{ZrSiO}_{4}$ & $\begin{array}{l}\text { Baddeleyite } \\
\left(\mathrm{ZrO}_{2}\right)\end{array}$ & Widespread \\
\hline Non-silicates & Phosphates & $\begin{array}{l}\text { Insular, } \\
\text { hexagonal }\end{array}$ & Apatite & $\mathrm{Ca}_{5}\left(\mathrm{PO}_{4}\right)_{3}(\mathrm{OH}, \mathrm{F}, \mathrm{Cl})$ & $\begin{array}{l}\text { Fluorapatite } \\
\text { Hydroxyapataite } \\
\text { Varsicite }\end{array}$ & Some in 'raw' soils \\
\hline
\end{tabular}




\begin{tabular}{|c|c|c|c|c|c|}
\hline & & & & $\begin{array}{l}\text { Wavellite } \\
\text { Monazite }\end{array}$ & \\
\hline $\begin{array}{l}\text { Titanium } \\
\text { oxide }\end{array}$ & Tetragonal & Rutle & $\mathrm{TiO}_{2}$ & $\begin{array}{l}\text { Brookite } \\
\text { Sphene }\left(\mathrm{CaTiSi}_{5}\right)\end{array}$ & $\begin{array}{l}\text { Widespread in small } \\
\text { amounts }\end{array}$ \\
\hline Carbonate & Rhombohedral & Calcite & $\mathrm{CaCO}_{3}$ & $\begin{array}{l}\text { Aragonite } \\
\text { Siderite }\left(\mathrm{FeCO}_{3}\right)\end{array}$ & Common in arid soils \\
\hline$"$ & $"$ & Dolomite & $\mathrm{CaMgCO}_{3}$ & $\begin{array}{l}\text { Ankerite } \\
\text { Mg-calcite }\end{array}$ & From dolomitic rocks \\
\hline Iron oxide & Cubic & Magnetite & $\mathrm{Fe}_{3} \mathrm{O}_{4}$ & Titanomagnetite & $\begin{array}{l}\text { Rare except in some } \\
\text { volcanic soils and in } \\
\text { soils derived from } \\
\text { detrital volcanic } \\
\text { deposits }\end{array}$ \\
\hline
\end{tabular}

* Some are also formed in soils, hence may also be regarded as secondary minerals

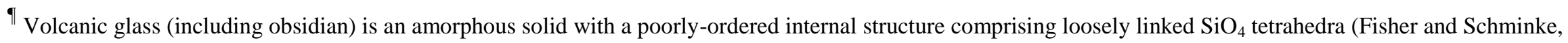
3 1984). Of widely varying composition, it is a common primary mineraloid in many volcanic soils and derivatives 
2 TABLE 20.3 The nature of bonding and the weakest bonds in different types of silicates that are common in soils (in order of decreasing 3 stability)*

\begin{tabular}{|c|c|c|c|c|c|}
\hline \multirow[t]{2}{*}{ Structural type } & \multirow[t]{2}{*}{ Group name } & \multicolumn{3}{|c|}{ Silicate unit } & \multirow[t]{2}{*}{ Examples } \\
\hline & & Formula, structure & $\begin{array}{l}\text { Shared } \\
\text { O } \\
\text { per } \mathrm{Si}\end{array}$ & Weakest bonds & \\
\hline Framework & $\begin{array}{c}\text { Tectosilicates } \\
\text { ، }\end{array}$ & $\begin{array}{l}\mathrm{SiO}_{2} \\
\mathrm{SiO}_{2} \text {, with } \mathrm{Al} \text { substitution }\end{array}$ & $\begin{array}{l}4 \\
4\end{array}$ & $\begin{array}{l}\mathrm{Si}-\mathrm{O} \\
\text { With cations }\left(\mathrm{K}^{+}, \mathrm{Na}^{+}, \mathrm{Ca}^{2+}\right)\end{array}$ & $\begin{array}{l}\text { Quartz } \\
\text { Feldspars }\end{array}$ \\
\hline Layer & Phyllosilicates & $\begin{array}{l}\mathrm{Si}_{2} \mathrm{O}_{5}{ }^{2-} \text {, with } \mathrm{Al} \text { substitution, } \\
\text { as a sheet joined to } \mathrm{Al}-, \mathrm{Mg}-\text {, } \\
\mathrm{Fe}-\mathrm{OH} \text { sheet }\end{array}$ & 3 & $\begin{array}{l}\text { With interlayer cations, usually } \\
\mathrm{K}^{+}\end{array}$ & Micas \\
\hline Single chains & Inosilicates & $\mathrm{SiO}_{3}{ }^{2-}$, with $\mathrm{Al}$ substitution & 2.5 & With divalent, and other cations & Pyroxenes \\
\hline Double chains & “ & $\mathrm{Si}_{4} \mathrm{O}_{11}{ }^{6-}$, with $\mathrm{Al}$ substitution & 2 & With divalent, and other cations & Amphiboles \\
\hline Isolated tetrahedra & Nesosilicates & $\mathrm{SiO}_{4}^{2-}$ & 0 & With divalent cations & Olivines \\
\hline
\end{tabular}


TABLE 20.4 Properties of kaolins in groups of soils (with standard deviations, where given, in brackets) and of standard kaolinites

\begin{tabular}{|c|c|c|c|c|c|c|c|}
\hline Location & $\begin{array}{c}\text { No of } \\
\text { samples }\end{array}$ & $\begin{array}{l}\mathbf{d}_{001} \\
(\AA)\end{array}$ & $\begin{array}{l}\text { CSD }^{a} \\
(\mathbf{n m})\end{array}$ & $\mathrm{HB}^{\mathrm{b}}$ index & $\begin{array}{c}\% \mathrm{Fe}_{2} \mathrm{O}_{3} \\
\left(\mathrm{~g} \mathrm{~kg}^{-1)}\right.\end{array}$ & $\begin{array}{c}\text { CEC } \\
\left(\mathrm{cmol}_{+} \mathrm{kg}^{-1}\right)\end{array}$ & $\begin{array}{c}\mathrm{SSA}^{\mathbf{c}} \\
\left(\mathrm{g} \mathrm{kg}^{-1)}\right.\end{array}$ \\
\hline \multicolumn{8}{|l|}{$\underline{\text { Soils }}$} \\
\hline Thailand (2) ${ }^{\mathrm{e}}$ & 18 & $7.19(0.03)$ & $15.4(5.5)$ & $6(1)$ & 25.3 & $15.2(4.7)$ & $44.9(12.1)$ \\
\hline Western Australia & 7 & 7.213 & 22.9 & 5.6 & 25.7 & 5.0 & 50.8 \\
\hline Nigeria & 26 & - & - & 8.0 & - & - & - \\
\hline Brazil & 21 & 7.19 & - & 12.7 & 19.6 & - & 48.5 \\
\hline \multicolumn{8}{|l|}{$\underline{\text { Standards }}$} \\
\hline Georgia \#1460 & 1 & 7.148 & 26.6 & 18.9 & 8.9 & 3.2 & 25 \\
\hline Cornwall (ECC) & 1 & 7.160 & 48.8 & 26.3 & 4.2 & 0.5 & 11 \\
\hline
\end{tabular}

Source: Data for the soil kaolins from Kanket, W. et al., Chemical and crystallographic properties of kaolin from ltisols in Thailand, Clays Clay

Miner., 53, 478, 2005, with data for the reference kaolinites from Hart, R.D. et al., The nature of soil kaolins from Indonesia and Western Australia, Clays

Clay Miner., 50, 198, 2002.

a CSD, 001 peak.

b Hughes and Brown (1979).

c Specific surface area from N2-BET.

d From Hart et al. (2003). 
e From Kanket et al. (2005);

- not determined 
2 TABLE 20.5 Occurrence of iron in oxides and oxyhydroxides and in organic complexes in a range of soils with different phyllosilicate clays

\begin{tabular}{|c|c|c|c|c|c|c|c|c|c|}
\hline \multirow[t]{2}{*}{ Soil subgroup } & \multirow[t]{2}{*}{ Main lithology } & \multirow[t]{2}{*}{ Horizon } & \multirow[t]{2}{*}{$\mathbf{p H}$} & \multicolumn{4}{|c|}{$\begin{array}{c}\mathrm{Fe}^{\mathrm{a}} \\
\left(\mathrm{g} \mathrm{kg}^{-1}\right)\end{array}$} & \multirow[t]{2}{*}{ Phyllosilicates in clay fraction $^{b}$} & \multirow[t]{2}{*}{ Reference } \\
\hline & & & & $\mathbf{F e}_{\mathrm{d}}$ & $\mathrm{Fe}_{\mathbf{o}}$ & $\mathrm{Fe}_{\mathrm{p}}$ & $\mathbf{F e}_{\mathrm{t}}$ & & \\
\hline \multirow[t]{2}{*}{ Gypsic Haplustept } & Gypsiferous & Ay & 7.6 & 7.8 & n.d. & n.d. & 16.0 & Paly $\sim$ smec $\sim$ chl $>$ ill & Owliaie et al. (2006) \\
\hline & & $2 \mathrm{By} 2$ & 7.7 & 2.1 & n.d. & n.d. & 9.9 & Paly $>$ chl ill $>$ smec & \\
\hline \multirow[t]{2}{*}{ Humic Umbrisol } & Granite, orthogneiss & Ah1 & $4.0^{\mathrm{b}}$ & 22.0 & 14.0 & 15.2 & 51.2 & Verm $\sim \mathrm{HIS} \sim \mathrm{HIV}>\mathrm{ill}=\mathrm{kaol}>\mathrm{chl}$ & Zanelli et al (2006) \\
\hline & & $\mathrm{BC}$ & 5.0 & 6.6 & 2.2 & 0.5 & 9.3 & Ill HIV (ill-HIV) allo>verm chl & \\
\hline \multirow[t]{2}{*}{ Mollic Eutrocryept } & Calcschists, serpentinites & A & 6.5 & 16.6 & 8.8 & 3.4 & 28.2 & Chl $>$ ill $>$ serp $>$ talc & Scalenghe et al. (2002) \\
\hline & & $\mathrm{C}$ & 8.1 & 12.3 & 4.5 & 0.8 & 17.8 & Chl $>$ ill $>$ serp $>$ talc & \\
\hline \multirow[t]{2}{*}{ Typic Haplorthod } & Shale, sandstone & $\mathrm{A}$ & 3.7 & 1.4 & 0.8 & 1.1 & 3.3 & Ill kaol $\sim($ ill-verm $)>$ verm & Pai et al. (2004) \\
\hline & & Bs2 & 4.8 & 48.4 & 16.9 & 10.1 & 75.4 & Ill kaol HIV $>$ ( ill-verm $)>$ verm & \\
\hline \multirow[t]{2}{*}{ Ultic Haplorthod } & Marine sediments & $\mathrm{E}$ & 3.7 & 37.6 & 8.4 & 5.5 & 51.4 & Verm (i-v) ill qtz>kaol gibb & Lin et al. (2002) \\
\hline & & Bhs & 4.2 & 59.2 & 17.7 & 19.9 & 86.8 & Verm $>$ HIV $>$ ill $\sim$ kaol $\sim$ tz $\sim$ gibb & \\
\hline \multirow[t]{2}{*}{ Typic Haploxerert } & Olivine basalt & $\mathrm{Ap}$ & 6.7 & 26 & n.d. & n.d. & 53 & $($ Kaol-smec 40:60) $>(\mathrm{k}-\mathrm{s} 95: 5)>$ ill & Vingiani et al. (2004) \\
\hline & & $\mathrm{C}$ & 8.1 & 21 & n.d. & n.d. & 96 & $(\mathrm{~K}-\mathrm{s} 40: 60)>\mathrm{kaol} \sim(\mathrm{k}-\mathrm{s}$ 95:5)>ill & \\
\hline \multirow[t]{2}{*}{ Andic Haploxeralf } & Rhyolitic ash on andesite & A1 & 6.8 & 3.2 & 0.5 & 0.1 & 3.8 & Hall $\sim \mathrm{HIV}>$ allo & Takahashi et al. (1993) \\
\hline & & $2 \mathrm{Bt} 3$ & 6.2 & 10.1 & 0.5 & 0.1 & 10.7 & Hall>gibb allo & \\
\hline \multirow[t]{2}{*}{ Acrudoxic Fulvudand } & Andesitic lava & Ah1 & 3.9 & 2.8 & 1.7 & 1.5 & 6.0 & $\mathrm{Gibb}>\mathrm{kaol}>\mathrm{goe}>$ ferr & Nieuwenhuyse et al. (2000) \\
\hline & & $\mathrm{BC}$ & 5.2 & 4.1 & 0.8 & 0.0 & 4.9 & Allo $>$ goe $>$ ferr & \\
\hline \multirow[t]{2}{*}{ Orthoxic Tropohumult } & Olivine basalt & $\mathrm{Ap}$ & 5.9 & 9.0 & n.d. & n.d. & n.d. & Kaol>goe & Gallez et al. (1976) \\
\hline & & $\mathrm{B} 21 \mathrm{t}$ & 5.8 & 10.3 & n.d. & n.d. & n.d. & Kaol>goe & \\
\hline
\end{tabular}

$3{ }^{a}$ Values of Fe extractable by ditlionite $\left(\mathrm{Fe}_{\mathrm{d}}\right) \cdot$ oxalate $\left(\mathrm{Fe}_{\mathrm{o}}\right)$, and pyrophosphate $\left(\mathrm{Fe}_{\mathrm{p}}\right)$, also total $\left(\mathrm{Fe}_{\mathrm{t}}\right)$.

$4 \quad{ }^{b}$ Minerals usually given by first three or four letters of their name, except for quartz (qtz) and HfV; interstratified minerals in brackets: their components often

5 by first letters only; relative amounts of minerals as given in the appropriate reference.

$6{ }^{\mathrm{C}}$ In $\mathrm{CaCl}_{2}$, other $\mathrm{pH}$ values in $\mathrm{H}_{2} \mathrm{O}$. 
1 TABLE 20.6 Properties of the common types of secondary minerals and characteristics of their occurrence in soils

\begin{tabular}{|c|c|c|c|c|c|c|c|}
\hline Group & $\begin{array}{l}\text { Common soil } \\
\text { mineral }\end{array}$ & Chemical formula & $\begin{array}{c}\text { Related phases and } \\
\text { names }\end{array}$ & $\begin{array}{l}\text { Specific } \\
\text { surface } \\
\left(\mathbf{m}^{2} \mathrm{~g}^{-1}\right)\end{array}$ & $\begin{array}{c}\text { CEC } \\
\left(\mathrm{cmol}_{+} \mathbf{k g}^{-1}\right)\end{array}$ & Characteristics in soils & $\begin{array}{l}\text { Soils of common } \\
\text { occurrence }\end{array}$ \\
\hline \multicolumn{8}{|l|}{$\underline{\text { Silicates }}$} \\
\hline \multirow[t]{2}{*}{ Kaolin } & Kaolinite & $\mathrm{Al}_{2} \mathrm{Si}_{2} \mathrm{O}_{5}(\mathrm{OH})_{4}$ & $\begin{array}{l}\text { Dickite, } \\
\text { nacrite }\end{array}$ & $6-40$ & $0-8$ & $\begin{array}{l}\text { Very small euhedral } \\
\text { particles, } \\
\text { associated with much Fe }\end{array}$ & $\begin{array}{l}\text { Widespread, high in well } \\
\text { weathered soils }\end{array}$ \\
\hline & Halloysite & $\mathrm{Al}_{2} \mathrm{Si}_{2} \mathrm{O}_{5}(\mathrm{OH})_{4} \cdot 2 \mathrm{H}_{2} \mathrm{O}$ & $\begin{array}{l}\text { Endellite*, } \\
\text { metahalloysite* } \\
1.0 \mathrm{~nm}(10 \AA) \\
\text { halloysite }(=\text { hydrated } \\
\text { phase }), 0.7 \mathrm{~nm}(7 \AA) \\
\text { halloysite (= } \\
\text { dehydrated phase })\end{array}$ & $20-60$ & $5-10$ & $\begin{array}{l}\text { Generally small tubular } \\
\text { or spheriodal particles, } \\
\text { associated with Fe }\end{array}$ & $\begin{array}{l}\text { Where humid, espec. from } \\
\text { tephra (incl. volcanic ash) }\end{array}$ \\
\hline $\begin{array}{l}\text { Interstratified } \\
\text { kaolin }\end{array}$ & $\begin{array}{l}\text { Kaolinite- } \\
\text { smectite }\end{array}$ & $\begin{array}{l}\text { Variable, depending } \\
\text { on proportions of } \mathrm{K}: \mathrm{S}\end{array}$ & Halloysite-smectite & unknown & $30-70$ & & Moderately drained \\
\hline Mica & Illite & $\begin{array}{l}\mathrm{K}_{0.6}(\mathrm{Ca}, \mathrm{Na})_{0.1} \mathrm{Si}_{3.4} \mathrm{Al}_{2} \\
\mathrm{Fe}^{\mathrm{III}} \mathrm{Mg}_{0.2 .} \mathrm{O}_{10}(\mathrm{OH})_{2}\end{array}$ & & $55-195$ & $10-40$ & & $\begin{array}{l}\text { Widespread, espec. weakly } \\
\text { weathered soils }\end{array}$ \\
\hline \multirow[t]{2}{*}{$\begin{array}{l}\text { Interstratified } \\
\text { mica }\end{array}$} & $\begin{array}{l}\text { Illite- } \\
\text { vermiculite }\end{array}$ & $\begin{array}{l}\text { Variable, depending } \\
\text { on proportions of I,V }\end{array}$ & Mica-vermiculite & unknown & unknown & $\begin{array}{l}\text { Usually regular, mica- } \\
\text { vermiculite }\end{array}$ & Eluvial horizons of podzols \\
\hline & Illite-smectite & $\begin{array}{l}\text { Variable, depending } \\
\text { on proportions of I,S }\end{array}$ & Mica-smectite & unknown & unknown & $\begin{array}{l}\text { Either regular, mica- } \\
\text { beidellite, or random, } \\
\text { poss. with single layers }\end{array}$ & $\begin{array}{l}\text { Regular: eluvial horizons of } \\
\text { podzols } \\
\text { Random: very widespread, } \\
\text { often in agricultural soils }\end{array}$ \\
\hline \multirow[t]{2}{*}{$\begin{array}{l}\text { Interstratified } \\
\text { chlorite }\end{array}$} & $\begin{array}{l}\text { Chlorite- } \\
\text { vermiculite }\end{array}$ & $\begin{array}{l}\text { Variable, depending } \\
\text { on proportions of } \mathrm{C} \text {, } \\
\mathrm{V}\end{array}$ & Corrensite & unknown & unknown & & $\begin{array}{l}\text { At very early stages of } \\
\text { weathering }\end{array}$ \\
\hline & Chlorite- & Variable, depending & Chlorite-swelling & unknown & unknown & & At very early stages of \\
\hline
\end{tabular}


smectite

Pedogenic chlorite, HIV, 2:1-2:2

intergrade, chloritized

vermiculite

(trioctahedral) $\quad \mathrm{M}^{\mathrm{II}}{ }_{\mathrm{x}}(\mathrm{Mg}, \mathrm{Fe})_{3}$

$\left(\mathrm{Al}_{\mathrm{x}} \mathrm{Si}_{4-\mathrm{x}}\right)$

$\mathrm{O}_{10}(\mathrm{OH})_{2} \cdot 4 \mathrm{H}_{2} \mathrm{O}$

$\begin{array}{ll}\text { Interlayered } & \begin{array}{l}\text { Pedogenic } \\ \text { chlorite }\end{array}\end{array}$

Variable, depending

on whether layers are

vermiculite or

smectite and

interlayered species

Smectite

$\begin{array}{ll}\text { Beidellite } & \mathrm{M}_{0.25}^{\mathrm{II}} \mathrm{Si}_{3.5} \mathrm{Al}_{2.5} \\ & \mathrm{O}_{10}(\mathrm{OH})_{2}\end{array}$

Montmorillonite $\quad \mathrm{M}^{\mathrm{II}}{ }_{0.25} \mathrm{Si}_{4} \mathrm{Al}_{1.5} \mathrm{Mg}_{0.5}$ $\mathrm{O}_{10}(\mathrm{OH})_{2}$

(Palagonite) Prob. variable

Hormite

$\begin{array}{ll}\text { Palygorskite } & \begin{array}{l}\mathrm{Si}_{8} \mathrm{Mg}_{5} \mathrm{O}_{20}(\mathrm{OH})_{2} \\ \left(\mathrm{OH}_{2}\right)_{4} \cdot 4 \mathrm{H}_{2} \mathrm{O}\end{array} \\ & \begin{array}{l}\mathrm{Si}_{12} \mathrm{Mg}_{8} \mathrm{O}_{30}(\mathrm{OH})_{2} \\ \left(\mathrm{OH}_{2}\right)_{4} \cdot 8 \mathrm{H}_{2} \mathrm{O}\end{array} \\ & \\ \text { Imogolite } & \begin{array}{l}\mathrm{SiO}_{2} \cdot \mathrm{Al}_{2} \mathrm{O}_{3} \cdot 2 \mathrm{H}_{2} \mathrm{O} ; \mathrm{Si} \\ \text { tetrahedra within } \mathrm{Al} \\ \text { octahedral in tube }\end{array}\end{array}$

Al:Si 2:1 - 1:1;

varable between

HIV, 2:1-2:2

intergrade, chloritized

vermiculite

HIS, chloritized

smectite

\section{Nontronite, \\ hisingerite*, \\ saponite}

Stevensite,

Hectorite

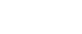

Attapulgite*

Allophanes octahedral in tube

unknown $\quad \mathrm{pH}$-variable

50-150

$100-210$

unknown unknown
3-30

Generally

260-330

1500

pH-variable

15-160 45-160

smectites)

unknown

unknown

Nanocrystalline precursors of smectites

Fibrous

Fibrous

Nanocrystalline: bundles of very thin hollow threads or tubules (nanotubes)

700-1500 pH-variable Nanocrystalline: very small spherules weathering

Leached, mildly acid soils

Early stages of weathering, espec. below soil zone

Intermediate $\mathrm{pHs}, \sim 4.6-5.8$ with wetting $\&$ drying, low organic matter

More beidellitic in acid-

leached horizons; otherwise where drainage retarded and $\mathrm{pH}$ high

Early weathering products of basaltic volcanic glass

In dry, usually calcareous regions, near textural transition in profile (both)

Limited, mainly from pumice, also podzol illuvial $B$ horizons and related soil horizons

From tephra (incl. volcanic ash) and in podzol illuvial B 
imogolite and

allophane

\section{$\underline{\text { Non-silicates }}$}

Al hydroxide,

oxyhydroxide,

Gibbsite

$\mathrm{Al}(\mathrm{OH})_{3}$

oxide

Boehmite

$\mathrm{AlOOH}$

$\mathrm{Fe}$

Goethite

oxyhydroxide,

oxide

\section{Lepidocrocite}

$\gamma \mathrm{FeOOH}$

Hematite

$\alpha \mathrm{Fe}_{2} \mathrm{O}_{3}$

Maghemite

$\gamma \mathrm{Fe}_{2} \mathrm{O}_{3}$

Ferrihydrite

$\mathrm{Fe}_{5} \mathrm{HO}_{8} .4 \mathrm{H}_{2} \mathrm{O}$

$\mathrm{Na}_{0.7} \mathrm{Ca}_{0.3} \mathrm{Mn}_{7} \mathrm{O}_{14}$ $.2 .8 \mathrm{H}_{2} \mathrm{O}$

Mn oxide
Bayerite,

norstrandite,

doylite

$\alpha$, or $\gamma$ alumina

trihydrate

Diaspore,

$\alpha$, or $\gamma$ alumina

monohydrate

Limonite*

Akagenéite

Feroxyhite
Todorokite,

hollandite,

lithiophorite,

pyrolusite (nanospheres or

nanoballs); closely

associated with o.m.

unknown, prob. high

$35-45$

unknown, prob. high

horizons, and in some other materials that are strongly

leached

Where Si low, espec. in strongly leached soils

Strongly weathered soil materials or soils, ferricrete (laterite), bauxite

Yellow to yellow-brown color

Widespread - most common iron 'oxide'

Noncalcareous soils that are seasonally anaerobic

Soils of warmer climates

Tropical and subtropical soils, from fires, poss. from bacteria

Widespread, where $\mathrm{Fe}(\mathrm{II})$ is oxidised rapidly

spherical nanoparticles, pinkish- to yellowish-red color

unknown, pH-variable (Blue-) black color

Widespread but usually minor component; in concretions, segregations, 
pans and nodules in subsoils

\begin{tabular}{|c|c|c|c|c|c|}
\hline Sulfide & Pyrite & $\mathrm{FeS}_{2}$ & $\begin{array}{l}\text { Mackinawite, } \\
\text { greigite, } \\
\text { pyrrhotite }\end{array}$ & unknown & unknown \\
\hline \multirow[t]{2}{*}{ Sulfate } & Gypsum & $\mathrm{CaSO}_{4}$ & $\begin{array}{l}\text { Bassanite, } \\
\text { anhydrite, } \\
\text { barite }\left(\mathrm{BaSO}_{4}\right)\end{array}$ & unknown & unknown \\
\hline & Jarosite & $\mathrm{KFe}_{3}(\mathrm{OH})_{6}\left(\mathrm{SO}_{4}\right)_{2}$ & $\begin{array}{l}\text { Natrojaroite, } \\
\text { schwertmannite }\end{array}$ & unknown & unknown \\
\hline Phosphate & Plumbogummite & $\begin{array}{l}\mathrm{PbAl}_{3}\left(\mathrm{PO}_{4}\right)_{2}(\mathrm{OH})_{5} \\
.2 \mathrm{H}_{2} \mathrm{O}\end{array}$ & $\begin{array}{l}\text { Variscite }(\mathrm{Al}), \\
\text { strengite }(\mathrm{Fe}), \\
\text { crandallite }(\mathrm{Ca}), \\
\text { gorceixite }(\mathrm{Ba})\end{array}$ & unknown & unknown \\
\hline Ti oxide & Anatase & $\mathrm{TiO}_{2}$ & & unknown & unknown \\
\hline Chloride & Halite & $\mathrm{NaCl}$ & & unknown & unknown \\
\hline
\end{tabular}

Coastal regions and from some sediments when unoxidized

Often in desert soils

Acid sulfate soils or strongly acid seepages

Rare, from breakdown of rock phosphate

Widespread, in small amounts

Seasonally dry saline soils 
TABLE 20.7 Characteristics of mineral phases that have helped to explain the capacity of various soils for the uptake and retention of organic carbon

\begin{tabular}{|c|c|c|}
\hline $\begin{array}{l}\text { Most relevant mineral } \\
\text { phase and/or property }\end{array}$ & Soil & References \\
\hline $\mathrm{Fe}, \mathrm{Al}$ oxides & & $\begin{array}{l}\text { Kubota (1975); Hamblin and } \\
\text { Greenland (1977) }\end{array}$ \\
\hline $\begin{array}{l}\text { Allophane + } \\
\text { pyrophosphate-Al }\end{array}$ & $\begin{array}{l}167 \text { soils (from throughout } \\
\text { New Zealand) }\end{array}$ & Percival et al. (2000) \\
\hline $\begin{array}{l}\text { Specific surface area }+ \text { total } \\
\text { Fe oxides }\end{array}$ & Neutral illitic topsoils & Kahle et al. (2002b) \\
\hline $\begin{array}{l}\text { Pedogenic oxides, mainly } \\
\text { of } \mathrm{Fe}\end{array}$ & $\begin{array}{l}\text { Range of forest and arable } \\
\text { soils with range of mineralogy }\end{array}$ & Kahle et al. (2004) \\
\hline Fe oxides & $\begin{array}{l}\text { Cambisol and podzol under } \\
\text { forest (acid) }\end{array}$ & Eusterhues et al. (2005) \\
\hline $\begin{array}{l}\text { Nanocrystalline Fe and } \mathrm{Al} \\
\text { oxides, espec. ferrihydrite }\end{array}$ & Acid subsoils under forest & $\begin{array}{l}\text { Kleber et al. (2005); Mikutta } \\
\text { et al. (2005) }\end{array}$ \\
\hline Allophane & Volcanic ash soils under forest & Basile-Doelsch et al. (2005) \\
\hline Al-substituted Fe oxides & Tropical soils & Barthès et al. (2008) \\
\hline $\mathrm{Fe}, \mathrm{Al}$ oxides & Acidic forest soils & Spielvogel et al. (2008) \\
\hline
\end{tabular}

